\title{
MODELIZACIÓN, MONITOREO Y CONTROL EN PROCESOS PARA PRODUCCIÓN DE BIOPLÁSTICOS
}

Tesis doctoral presentada por

MARTÍN JAMILIS

Presentada ante la Facultad de Ingeniería de la Universidad Nacional de La Plata como requisito para la obtención del grado académico de DOCTOR EN INGENIERÍA

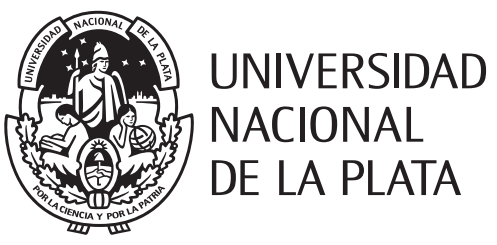

Dirección de Tesis:

Dr. Hernán De BATTISTA

Dr. Fabricio GARELLI

Jurado de Tesis:

Dr. José Luis FIgUEROA

Dr. Ernesto KofMAN

Dr. Jorge SolsonA

La Plata, 8 de septiembre de 2016 

A Tere

A mis papás 



\section{Resumen}

La presente tesis aborda problemas de estimación y control de procesos de alta densidad celular. Como caso de estudio particular se toma la producción de bioplásticos mediante $\mathrm{Cu}$ priavidus necator. Se hacen contribuciones novedosas en cuanto a modelizado de los procesos, monitorización de tasas de reacción y optimización en línea mediante control.

Con el objetivo de proveer un marco más realista y preciso, se desarrollan modelos orientados al control capaces de describir las variaciones de volumen en procesos de alta densidad celular, alimentados con medios concentrados y con acumulación de productos intracelulares. Los modelos obtenidos son prácticos en cuanto a que no dependen de parámetros difíciles de obtener y son más precisos que otros previamente reportados.

Para la monitorización de proceso, se desarrollan algoritmos de estimación de las tasas de reacción. Se diseñan observadores para cada una de las fases del proceso de producción de bioplásticos teniendo en cuenta las restricciones impuestas por las plantas experimentales y la incertidumbre de los modelos del microorganismo. Los estimadores propuestos utilizan los modelos de volumen antes desarrollados y constituyen un aporte importante a la monitorización de procesos en condiciones restrictivas como las presentes en procesos de alta densidad celular. Junto con el diseño de los estimadores se hacen aportes originales al análisis de errores, pruebas de estabilidad y condiciones sobres las ganancias de los algoritmos para satisfacer tasas de decaimiento de los errores. Además se proveen validaciones con resultados experimentales.

La optimización en línea de los procesos viene dada por la aplicación de controles para seguimiento de extremos que buscan maximizar las tasas de reacción en puntos de operación que, a priori, no son conocidos. Se propone un novedoso esquema de control no lineal, que incluye la estimación de un gradiente que permite converger al óptimo de una función objetivo (el mapa de sustrato a tasa de reacción). Se dan por primera vez pruebas de estabilidad para este controlador, incluyendo incertidumbre estructurada. Además, se derivan condiciones de diseño sobre sus ganancias. El control propuesto mejora a los reportados en la literatura en cuanto a velocidad de respuesta y suavidad de las tasas obtenidas. Además, está basado en la utilización de sensores cuya utilización es más factible en procesos de alta densidad celular. El algoritmo de control es finalmente aplicado a la producción de bioplásticos, obteniéndose resultados muy satisfactorios. 



\section{Abstract}

This thesis addresses the control and estimation problem in high cell density processes. As case of study the production of bioplastics via Cupriavidus necator is studied. Novel contributions to process modelling, monitoring and on line optimization are done.

With the objective of giving a more realistic and precise process description, control oriented models are developed for the volume variations in high cell density processes. Specially, for those which are fed with concentrated media and in which intracellular products are stored. The models obtained are practical in the sense that there is no dependence with difficult to obtain parameters and are more precise than other models previously reported.

For process monitoring, algorithms are developed to estimate the reaction rates of the process. Observers are proposed for each of the phases of the bioplastics production process. The estimation algorithms make use of the previously developed volume models and constitute an important contribution to process monitoring in restrictive conditions, such as the ones found in high cell density processes. Along with the design of the estimators, original contributions are made to error analysis, stability proofs and conditions on the algorithm gains to achieve given decay rates in the errors. Also, experimental validation of the estimators is provided.

The on line optimization of the processes is given by the use of extremum seeking controllers whose purpose is to maximize the reaction rates at, a priori, unknown operating points. A novel non linear control scheme is proposed, including a gradient estimation which allows convergence to the optimum of an objective function (the substrate to reaction rate map). For the first time, stability conditions are given for this controller, including unstructured uncertainty. Also, conditions on the design gains are obtained. The proposed control scheme improves previously reported ones in convergence speed and the smoothness of the obtained reaction rates. Moreover, it is based on the use of sensors of feasible application to high cell density processes. The control algorithm is finally applied to the bioplastics production process, obtaining satisfactory results. 



\section{Agradecimientos}

Primero, quiero agradecer a mi familia, por apoyarme siempre durante mi carrera de grado y de postgrado, y por enseñarme el valor del trabajo.

Quiero agradecer a mis directores, Fabricio y Hernán, por su dirección y por haberme dado la posibilidad de ser integrante de su grupo de investigación, en el cual me he sentido muy a gusto tanto en lo humano como en la forma de trabajar.

Una mención especial merecen el Griego, que siempre me dio una mano cuando tenía dudas, y el Seba con su paciencia infinita y colaboración constante (y que por su culpa fuimos al curso de Fermentaciones Industriales).

El agradecimiento más grande es para Tere. Un poco por ser mi consultora privada en materia de biotecnología, pero más que nada por ser mi razón de vivir y encarar nuevas cosas, mi compañera leal en todo.

No quiero dejar de agradecer también a todos mis compañeros del LEICI, en especial, a aquellos con los que hemos compartido cursos, mates, bondiolitas y cervezas: Hacha, Fede, Ramiro (mucho mate le debo), Talco, Lucho y Nico.

Finalmente, le agradezco al pincha, que es lo más grande de la Argentina. 



\section{Índice general}

1. Introducción $\quad 1$

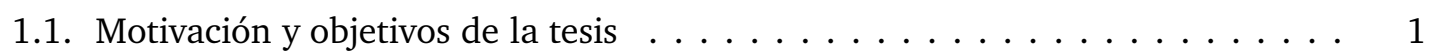

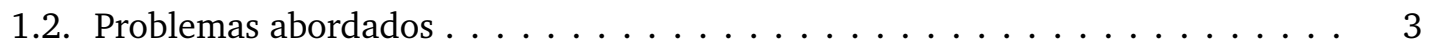

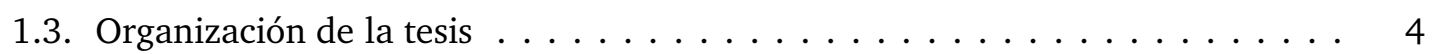

1.4. Aportes originales de la tesis $\ldots \ldots \ldots \ldots \ldots \ldots \ldots \ldots \ldots \ldots \ldots \ldots \ldots$

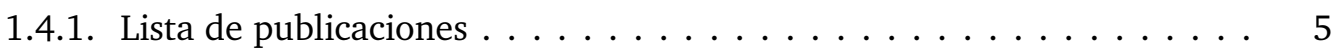

2. Introducción a los bioprocesos $\quad 7$

2.1. Definiciones y conceptos generales $\ldots \ldots \ldots \ldots \ldots \ldots \ldots$

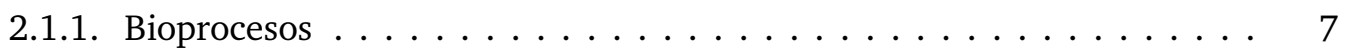

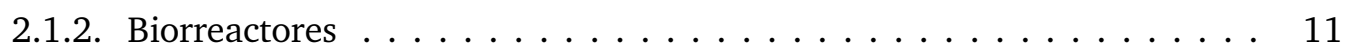

2.2. Instrumentación disponible para biorreactores $\ldots \ldots \ldots \ldots \ldots$

2.3. Control de bioprocesos . . . . . . . . . . . . . . . . . . . . . . 15

2.4. Modelos de bioprocesos . . . . . . . . . . . . . . . . . . . . 17

2.4.1. Clasificación de modelos para bioprocesos . . . . . . . . . . . 18

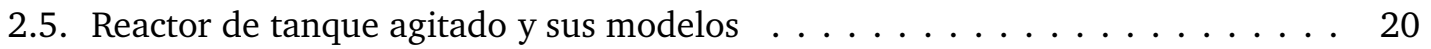

2.6. Modelos de biorreacciones . . . . . . . . . . . . . . . . . . . . . 25

2.6.1. Procesos biológicos como reacciones químicas . . . . . . . . . . . . 25

2.6.2. Estequiometría del crecimiento microbiano . . . . . . . . . . . 26

2.6.3. Cinética del crecimiento microbiano . . . . . . . . . . . . . . . . . . 29

2.6.4. Modelo final para biorreactores de tanque agitado . . . . . . . . . 33

3. Modelizado de bioprocesos de alta densidad celular y de producción de bioplásticos

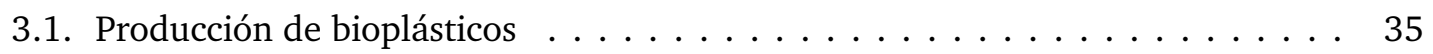

3.2. Modelo para la producción de PHB . . . . . . . . . . . . . . . . . 37

3.2.1. Modelo para la etapa de crecimiento . . . . . . . . . . . . . . . 41

3.2.2. Modelo para la etapa de producción . . . . . . . . . . . . . . . 42

3.3. Aportes a la modelización del volumen en alta densidad celular . . . . . . . . . 43

3.3.1. Insuficiencias del modelo clásico . . . . . . . . . . . . . . . . . 43

3.3.2. Modelo basado en volúmenes molares parciales . . . . . . . . . . . . . . 44

3.3.3. Propuesta de modelo práctico para la etapa de crecimiento . . . . . . . . 46

3.3.4. Propuesta de modelo práctico para la etapa de producción . . . . . . . . 49

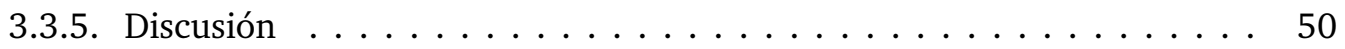


4. Observadores para etapa de crecimiento 53

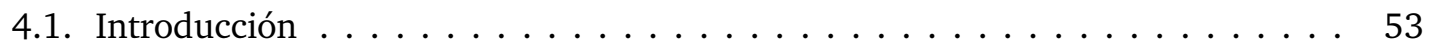

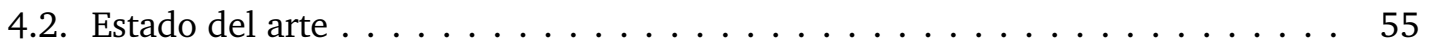

4.2.1. Observadores exponenciales y de alta ganancia . . . . . . . . . 56

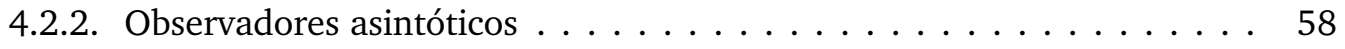

4.2.3. Observadores por modos deslizantes . . . . . . . . . . . . . . . 59

4.2.4. Antecedentes en la producción de PHB . . . . . . . . . . . . . . 60

4.3. Observador de tasa de crecimiento . . . . . . . . . . . . . . . . . . . 61

4.3.1. Observador de tasa específica de crecimiento . . . . . . . . . . 63

4.3.2. Observador asintótico propuesto . . . . . . . . . . . . 63

4.3.3. Primeras horas: Observador exponencial . . . . . . . . . . . . . 67

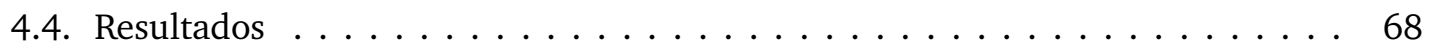

4.4.1. Resultados de simulaciones . . . . . . . . . . . . . . . . . . . . . 69

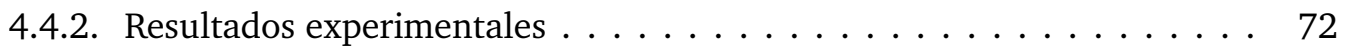

4.5. Resumen del capítulo . . . . . . . . . . . . . . . . . . . . . . . . 75

5. Observadores para etapa de producción $\quad 77$

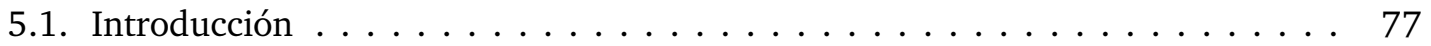

5.2. Reducción del modelo para la etapa de producción . . . . . . . . . . . . . 79

5.3. Observador de tasa específica de producción . . . . . . . . . . . . . . 80

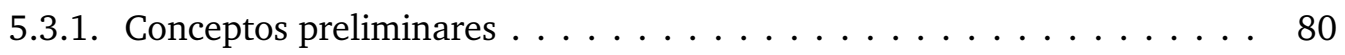

5.3.2. Observador con medición de biomasa residual . . . . . . . . . . . 81

5.3.3. Análisis de estabilidad del observador . . . . . . . . . . . . . . 81

5.3.4. Cotas para la convergencia . . . . . . . . . . . . . . . . . . 84

5.3.5. Observador con medición de volumen . . . . . . . . . . . . . 85

5.4. Resultados de la aplicación del observador a la producción de PHB . . . . . . 86

5.4.1. Resultados de simulación . . . . . . . . . . . . . . . . . 87

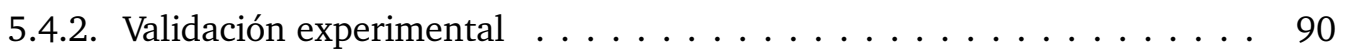

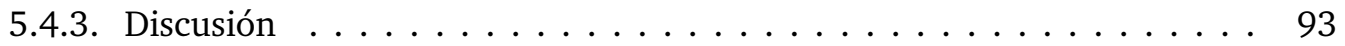

6. Control para optimización en línea del proceso 95

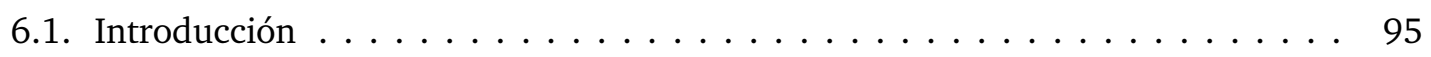

6.2. Formulación del problema . . . . . . . . . . . . . . . . . . . . . . . . . 99

6.3. Controlador para seguimiento de extremos . . . . . . . . . . . . . . 102

6.3.1. Ley de control propuesta . . . . . . . . . . . . . . . . . . . . 102

6.3.2. Estimación de gradiente . . . . . . . . . . . . . . . 103

6.3.3. Observadores auxiliares . . . . . . . . . . . . . . . . . . . . . . . . 104

6.4. Demostración de estabilidad del controlador . . . . . . . . . . . . . . . . . 105

6.4.1. Estabilidad nominal del controlador . . . . . . . . . . . . . . . 105

6.4.2. Estabilidad práctica . . . . . . . . . . . . . . . . . . . 107

6.5. Ejemplo de aplicación del controlador propuesto a un crecimiento simple . . 110 
6.6. Aplicación al proceso de producción de PHB . . . . . . . . . . . . . 116

6.6.1. Optimización de etapa de crecimiento . . . . . . . . . . . . 117

6.6.2. Optimización de etapa de producción . . . . . . . . . . . . . 120

6.7. Discusión . . . . . . . . . . . . . . . . . . . . . . . 123

7. Conclusiones

7.1. Líneas futuras de investigación . . . . . . . . . . . . . . . . . . 127

$\begin{array}{ll}\text { Bibliografía } & 129\end{array}$ 



\section{Índice de figuras}

2.1. Esquemas de distintos tipos de biorreactores. . . . . . . . . . . . . . . . . . 13

2.2. Esquema de un auxostat. Por GYassineMrabetTalk (Own work) [CC BY-SA 3.0) or GFDL ], via WikimediaCommons. . . . . . . . . . . . . . . . . . . . . . 17

2.3. Esquema de un reactor de tanque agitado . . . . . . . . . . . . . . . . 20

2.4. Esquema de modos de operación de un reactor de tanque agitado. . . . . . . . 22

2.5. Ejemplos de cinéticas de Monod, Haldane y Teissier con inhibición . . . . . . 32

3.1. Fotografía de bacterias acumulando PHA. Por Njacquel (Own work) [CC BY-SA 3.0], via

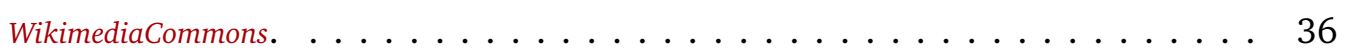

3.2. Esquema de fases del proceso de producción de PHB . . . . . . . . . . . . 37

3.3. Superficies de los modelos cinéticos. . . . . . . . . . . . . . . . . . . . 42

3.4. Esquema de masa equivalente de solución diluida. . . . . . . . . . . . . . . 47

4.1. Esquema de un observador de estados: $u$ entradas del proceso, $y$ estados medibles o salidas, $x$ estados no medibles, $\hat{y}$ estimación de estados medibles, $\hat{x}$ estimación de estados no medibles, $\tilde{y}$ error de estimación en estados medibles. 54

4.2. Resultados de simulación considerando incertidumbre en el rendimiento de nitrógeno alimentado $\eta$. Valor verdadero (trazo negro), estimación (línea continua roja), estimación con $\eta=75 \% \eta_{N}$ (trazos y puntos azul) y estimación on

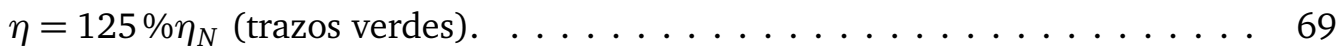

4.3. Resultados de simulación para el caso en que el rendimiento $y_{x n}$ presenta va-

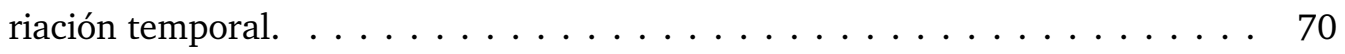

4.4. Resultados de simulación para el caso en que la concentración de nitrógeno varía. 71

4.5. Resultados experimentales: Concentraciones de metabolitos y sustratos principales en dos experimentos distintos. . . . . . . . . . . . . 72

4.6. Resultados experimentales para el observador propuesto con diferentes valores

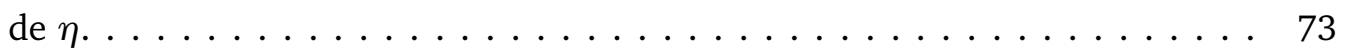

4.7. Resultados experimentales para el observador propuesto con diferentes condiciones iniciales en el observador exponencial. . . . . . . . . . . . . 74

5.1. Pares de $\alpha$ y $\beta$ para los cuales se asegura estabilidad del observador. . . . . . 84

5.2. Tasa de decaimiento para distintos pares $\alpha$ y $\beta \ldots \ldots \ldots \ldots \ldots$. . . . 85

5.3. Resultados de simulación: sistema sin perturbar y respuesta a condiciones ini-

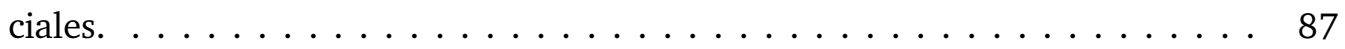

5.4. Resultados de simulación: efecto del ruido de medición. . . . . . . . . . . 88 
5.5. Resultados de simulación: respuesta del observador ante variaciones en la concentración de sustrato. . . . . . . . . . . . . . . . . . . . . . . . 90

5.6. Resultados de simulación: respuesta del observado por modos deslizantes $\mathscr{O}_{\mathscr{S} \mathscr{M}}$ ante fallas en el sensor de biomasa y comparación con observador exponencial

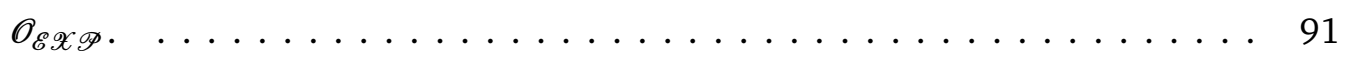

5.7. Resultados experimentales: respuesta del observador. . . . . . . . . . . . . . 92

5.8. Resultados experimentales: contenido intracelular de PHB y volumen. . . . . . 93

6.1. Esquema de control para seguimiento de extremos basado en perturbación. $\dot{x}=f(x, u)$ dinámica del proceso. $y=J(x, u)$ función objetivo a optimizar (medida). $\hat{u}^{*}$ estimación de acción de control óptima. $\hat{\omega}$ estimación del gradiente. 96

6.2. Esquema de control para seguimiento de extremos basado en modelo. . . . . . 97

6.3. Esquema de control para seguimiento de extremos basado en perturbación. . . 98

6.4. Esquema del control para seguimientos de extremos propuesto. . . . . . . . . 102

6.5. Cotas en el hessiano para asegurar estabilidad nominal. . . . . . . . . . . . 107

6.6. Modelo cinético de $\mu$ y hessiano usados en las simulaciones . . . . . . . . . . . 111

6.7. Resultados de simulación para el controlador propuesto con diferentes condiciones iniciales del sustrato. Líneas rojas: concentración de sustrato inicial menor al valor óptimo. Líneas azules: concentración inicial de sustrato mayor a la

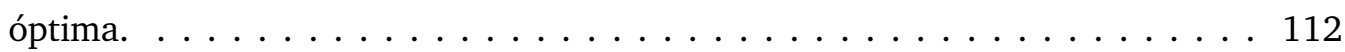

6.8. Resultados de simulación para el controlador propuesto, sintonización de las ganancias para mayor velocidad de convergencia. . . . . . . . . . . . . . 113

6.9. Resultados de simulación para el controlador propuesto cuando las condiciones iniciales de los observadores tienen errores. Líneas continuas: valores verdaderos. Líneas a trazos y puntos: valores estimados. Líneas a trazos: valores óptimos113

6.10. Resultados de simulación para el control de seguimiento de extremos propuesto para maximizar la tasa específica de producción de PHB. Líneas azules: valores verdaderos. Líneas a trazos: (a) y (c) valores óptimos, (b) gradiente estimado, (d) mapa inicial. Líneas a trazos y puntos: (d) mapa final. . . . . . . . . . . . 114

6.11. Resultados de simulación para el control de seguimiento de extremos propuesto para maximizar la tasa específica de producción de PHB con un $k_{1}$ mayor. Líneas azules: valores verdaderos. Líneas a trazos: (a) y (c) valores óptimos, (b) gradiente estimado, (d) mapa inicial. Líneas a trazos y puntos: (d) mapa

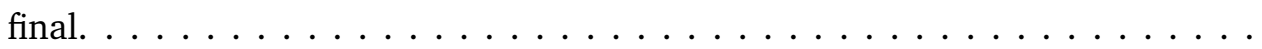

6.12. Resultados de simulación para el control propuesto bajo ruido de medición. Líneas azules: valores verdaderos. Líneas verdes: valores estimados. Líneas a

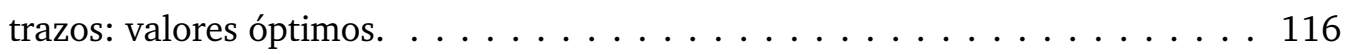

6.13. Resultados de simulación para el control de seguimiento de extremos propuesto para la maximización de la tasa específica de crecimiento en un proceso de producción de PHB. Evolución de variables respecto al tiempo. . . . . . . . . . 119 
6.14. Resultados de simulación para el control de seguimiento de extremos propuesto para la maximización de la tasa específica de crecimiento en un proceso de producción de PHB. Trayectorias en el plano $(n, x) \ldots \ldots \ldots$. . . . . . . 120

6.15. Resultados de simulación para el control de seguimiento de extremos propuesto para maximizar la tasa específica de producción de PHB. . . . . . . . . . . . 122

6.16. Resultados de simulación para el control de seguimiento de extremos propuesto para maximizar la tasa específica de producción de PHB. . . . . . . . . . . 123 



\section{Índice de tablas}

2.1. Valores en gramos de 1 c-mol de distintas fuentes de carbono . . . . . . . . . 27

2.2. Grados de reducción de compuestos orgánicos al oxidarse. . . . . . . . . . 28

2.3. Modelos cinéticos . . . . . . . . . . . . . . . . . . . . . . 31

3.1. Parámetros del modelo del proceso de producción de PHB. . . . . . . . . . . 39

3.2. Valores de los parámetros del modelo macroscópico y de los modelos cinéticos. 40

3.3. Parámetros de los modelos de volumen para procesos de alta densidad. . . . . 46

5.1. Valores de parámetros del observador y modelos utilizados en las simulaciones y validación experimental . . . . . . . . . . . . . . . . . 86

6.1. Variables y parámeteros … . . . . . . . . . . . . . . . . . . . 101

6.2. Parámetros del controlador para la etapa de crecimiento. . . . . . . . . . . 118

6.3. Parámetros del controlador para la etapa de producción. . . . . . . . . . . . . . 121 



\section{Nomenclatura}

(仓) Estimación de la variable $(\bullet)$

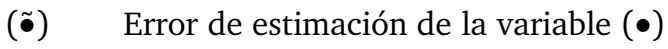

$\gamma_{i} \quad$ Ganancia $i$ del observador exponencial de $\mu$

$\kappa_{i} \quad$ Ganancia $i$ del estimador de gradiente

$\lambda_{i} \quad$ Autovalor $i$ del observador exponencial de $\mu$

$\mu \quad$ Tasa específica de crecimiento $\left[\mathrm{h}^{-1}\right]$

$\mu^{*} \quad$ Tasa específica de crecimiento óptima $\left[\mathrm{h}^{-1}\right]$

$\omega \quad$ Gradiente de $\mu(s)$ (Derivada parcial de $\mu(s)$ con respecto a $s$ )

$\rho_{n} \quad$ Densidad del medio con concentración de fuente de nitrógeno $n\left[\mathrm{gl}^{-1}\right]$

$\rho_{P} \quad$ Densidad del PHB $\left[\mathrm{gl}^{-1}\right]$

$\rho_{s} \quad$ Densidad del medio con concentración de fuente de carbono $s\left[\mathrm{gl}^{-1}\right]$

$\rho_{w} \quad$ Densidad del agua $\left[\mathrm{gl}^{-1}\right]$

$\rho_{n f} \quad$ Densidad del medio con concentración de fuente de nitrógeno $n_{f}\left[\mathrm{gl}^{-1}\right]$

$\rho_{s f} \quad$ Densidad del medio con concentración de fuente de carbono $s_{f}\left[\mathrm{gl}^{-1}\right]$

$\varpi \quad$ Estimación auxiliar de tasa específica de reacción

$\xi \quad$ Estados transformados para demostraciones de estabilidad

$F_{n} \quad$ Caudal de entrada de fuente de nitrógeno $\left[1 \mathrm{~h}^{-1}\right]$

$F_{s} \quad$ Caudal de entrada de fuente de carbono $\left[1 \mathrm{~h}^{-1}\right]$

$h \quad$ Hessiano de $\mu(s)$ (Derivada parcial segunda de $\mu(s)$ con respecto a $s$ )

$N \quad$ Masa total de fuente de nitrógeno en el bioreactor [g]

$n \quad$ Concentración de fuente de nitrógeno $\left[\mathrm{gl}^{-1}\right]$

$n^{*} \quad$ Concentración de fuente de nitrógeno óptima $\left[\mathrm{gl}^{-1}\right]$

$P \quad$ Masa total de producto en el biorreactor $[\mathrm{g}]$

p Concentración de producto $\left[\mathrm{gl}^{-1}\right]$

$q^{*} \quad$ Tasa específica de producción óptima $\left[\mathrm{h}^{-1}\right]$

$r_{n} \quad$ Velocidad volumétrica de consumo de fuente de nitrógeno[ $\left[\mathrm{gl}^{-1} \mathrm{~h}^{-1}\right]$ 


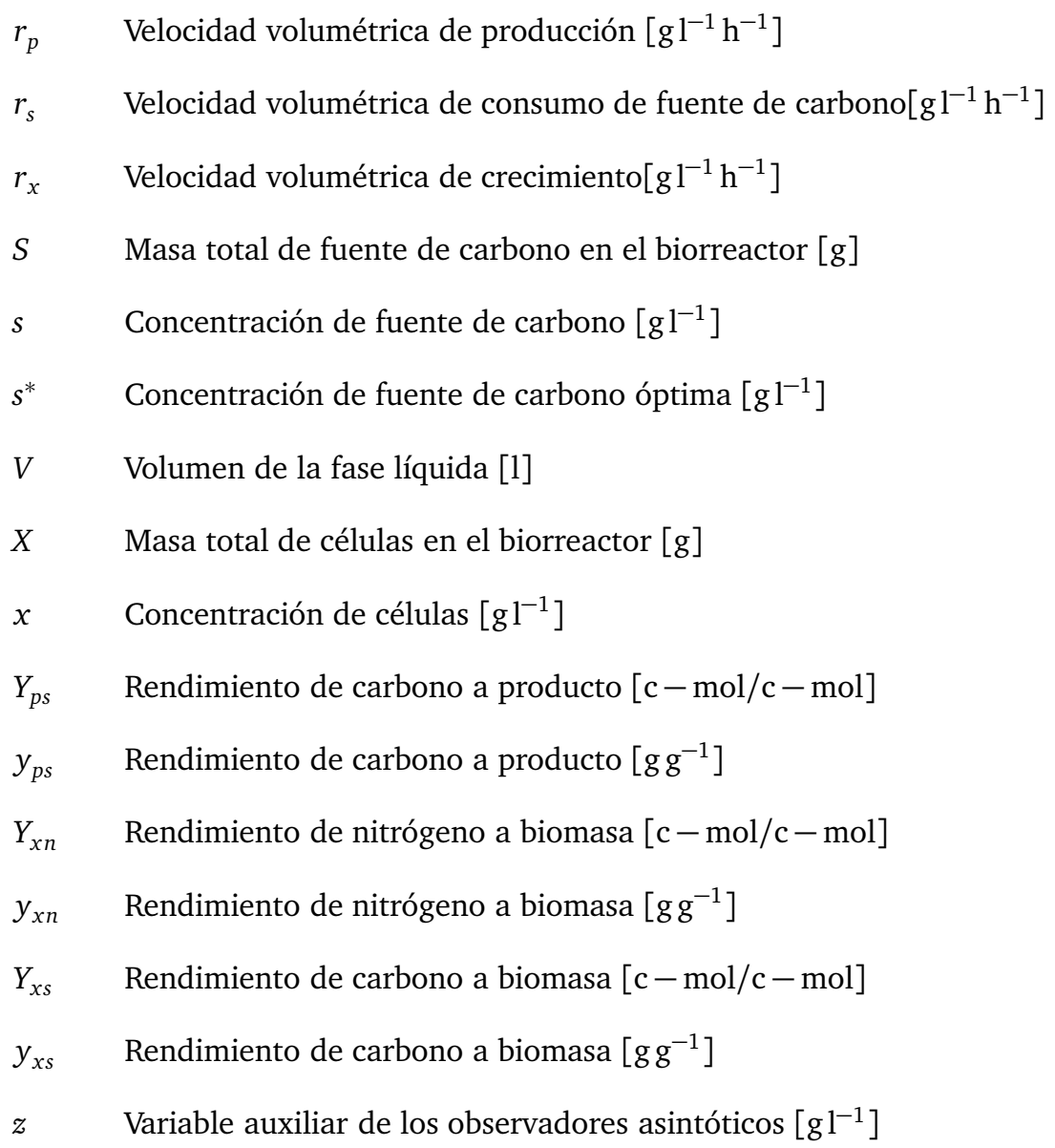




\section{Lista de acrónimos}

c-mol Carbono mol.

EKO Observador de Kalman extendido (Extended Kalman Observer).

ELO Observador de Luenberger extendido (Extended Luenberger Observer).

ESC Control por seguimiento de extremos (Extremum Seeking Control).

FCE Fuente de carbono y energía.

FN Fuente de nitrógeno.

GEVP Problema generalizado de autovalores (Generalized Eigenvalue Problem).

LDI Inclusión diferencial lineal (Linear Differential Inclusion).

MD Modos deslizantes.

MDPO Modos deslizantes de primer orden.

MDSO Modos deslizantes de segundo orden.

OD Densidad óptica (Optical Density).

ODE Ecuación diferencial ordinaria (Ordinary Differential Equation).

PDE Ecuación diferencial en derivadas parciales (Partial Differential Equation).

PHA Polyhydroxyalkanoato.

PHB Polyhydroxybutyrato.

PLDI Inclusión diferencial lineal politópica (Polytopic Linear Differential Inclusion).

STA Algoritmo Super-Twisting (Super-Twisting Algorithm).

STR Reactor de tanque agitado (Stirred Tank Reactor). 



\section{| Capítulo 1 \\ Introducción}

\subsection{Motivación y objetivos de la tesis}

El uso de microorganismos como fábricas celulares para la producción de metabolitos especializados de alto valor añadido (por ejemplo antibióticos, ácidos, biopolímeros y biogases) es de vital importancia para el presente y futuro de la industria de procesos y el desarrollo sostenible. Aún así, la marcada incertidumbre en los modelos y la falta de conocimiento profundo en tiempo real sobre el estado del proceso fuerza tanto a la industria como a la experimentación científica a operar en regímenes demasiado conservadores, no óptimos, con el fin de evitar estados fisiológicos no deseables de los microorganismos e inestabilidad de los procesos [1]. Por ejemplo, es un estándar de la industria la utilización de leyes de control a lazo abierto para alimentar a los reactores con caudales constantes o exponenciales [2]. O bien, la toma de muestras manual y análisis fuera de línea como única herramienta de monitorización.

El control automático aporta herramientas que pueden contribuir a la optimización en tiempo real de procesos biotecnológicos, en su modelizado y análisis, estimación de variables para su monitorización continua y desarrollo de leyes de control para la operación en regiones de operación deseadas. El aporte además se extiende a la mejora de la calidad y reproducibilidad de los procesos. En 2004 se publicó la iniciativa PAT (Process Analytical Technology) por la Food and Drugs Administration (FDA) de los EE.UU. [3]. Uno de sus puntos centrales apunta a mejorar la calidad de los productos y la seguridad y eficiencia de los procesos. Entre las recomendaciones dadas está la incorporación de sistemas que permitan un seguimiento en tiempo real de atributos críticos y diseño de sistemas de control que permitan ajustarlos. Estas recomendaciones no se restringen solamente a la industria farmacéutica, si no que se extienden al resto de la industria de bioprocesos.

Recientemente ha resurgido el interés en el desarrollo de procesos que permitan obtener productos de valor añadido a partir de deshechos industriales o agrícolas. Estos procesos surgen como alternativas a otros ya existentes en la industria con mayor impacto ambiental o menor biocompatibilidad. Uno de los casos de estudio más interesante y representativo es el de la producción de bioplásticos $[4,5,6]$, donde se utilizan bacterias para producir de manera 
intensiva biopolímeros que se almacenan intracelularmente ${ }^{1}$. Estos bioplásticos son alternativas biodegradables a los plásticos convencionales y su producción es más limpia (no derivada del petróleo). Otro caso representativo es la producción de lípidos mediante levaduras para la posterior producción de biodiesel como alternativa al obtenido a partir de aceites de origen vegetal provenientes de la agricultura [7, 8]. O bien, la producción de aceites a partir de glicerol residual de la industria del biodiesel [9]. La necesidad de obtener procesos competitivos a nivel económico y productivo lleva usualmente a utilizar sustratos baratos, provenientes del descarte de otras industrias. También lleva a operar en regímenes de alta densidad celular, es decir, con concentraciones de microorganismos muy elevadas. Este tipo de operación presenta complicaciones adicionales: acumulación de productos y residuos que pueden inhibir la producción, elevadas demandas de oxígeno y sustratos, aumentos en la densidad y viscosidad del medio por la utilización de medios altamente concentrados [10]. Además, cuando provienen de residuos, los sustratos pueden ser impuros y poco caracterizados.

Durante los últimos 30 años se han desarrollado numerosos algoritmos de estimación y control para bioprocesos, siendo una referencia los aportes realizados por Georges Bastin y Dennis Dochain [11]. Sin embargo, el desarrollo de algoritmos específicos para procesos de alta densidad, con las restricciones que estos implican, es aún poco explorado. Por ejemplo, es usual que muchos algoritmos dependan de la medición de sustratos. En procesos de alta densidad celular como los antes mencionados esto no sería conveniente o posible si se utilizan sustratos impuros provenientes de residuos. O bien, que los modelos hayan sido desarrollados considerando bajas concentraciones de microorganismos y sustratos. De manera general se puede decir que es necesario el desarrollo de algoritmos de estimación y control específicos para procesos de alta densidad celular. Estos deben depender menos de la información de los sustratos y deben ser implementables con equipos y sensores disponibles en un laboratorio estándar o en la industria. Adicionalmente, se deben adaptar los modelos clásicos para incluir los efectos causados por la alta densidad celular y sus implicaciones.

Durante el desarrollo de la presente tesis surgió una colaboración con el laboratorio de Control de Biosistemas de la Universidad de Gante para trabajar sobre un proceso de producción de bioplásticos. Como ya se mencionó, este es un proceso representativo de los que se pretende estudiar, en cuanto a la elevada densidad celular, utilización de medios concentrados provenientes de residuos y almacenamiento de productos intracelulares. Las particularidades del proceso se desarrollan en los próximos capítulos, pero de manera resumida se puede decir que se utiliza la bacteria Cupriavidus necator que tiene la capacidad de almacenar el biopolímero polyhydroxybutyrato intracelularmente hasta varias veces su peso. El proceso se realiza en dos etapas, una de acumulación de microorganismos y otra para la producción del biopolímero. La diferencia principal entre una etapa y otra es la presencia o no de uno de los sustratos (fuente de nitrógeno) para fomentar el crecimiento o la producción. Modos de operación similares se utilizan en $[7,8]$ para la producción de lípidos mediante Rhodosporidium toruloides y en [9] para la producción de aceites mediante Rhodotorula glutinis. Por lo antes mencionado

\footnotetext{
${ }^{1}$ Dentro de la célula, por lo general en el citoplasma.
} 
se tomó a este proceso como caso de estudio de la tesis, sin perder de vista a los procesos de alta densidad celular en general. Cabe mencionar que al inicio de la colaboración el proceso contaba solamente con una lazo de control de $\mathrm{pH}$ y algunas alimentaciones a lazo abierto. El monitoreo se realizaba a partir de muestras manuales y análisis fuera de línea. Tareas tales como el cambio de una etapa a otra se realizaban casi de manera artesanal más que basadas en el estado real del proceso.

En este contexto, tomando como caso de estudio particular a la producción de bioplásticos, los objetivos principales de la presente tesis son:

- Desarrollar algoritmos de estimación para las tasas específicas de reacción principales en bioprocesos de producción con alta densidad celular, que sirvan tanto para el monitoreo del proceso como para la implementación de lazos de control avanzados. Los algoritmos además deben tener en cuenta las incertidumbres y restricciones típicas del tipo de proceso.

- Desarrollar algoritmos de control para la optimización en tiempo real de procesos de alta densidad celular, maximizando su productividad. Los algoritmos deben ser robustos frente a las fuertes incertidumbres del proceso y los modelos.

\subsection{Problemas abordados}

La modelización de los procesos juega un rol fundamental en su monitoreo y control. Típicamente se emplean modelos de balance de masa obtenidos bajo la hipótesis de que el microorganismo sigue una determinada ruta metabólica. Luego, se diseñan algoritmos de control basados en estos modelos matemáticos macroscópicos relativamente simples (aunque no lineales) y de bajo orden. En los procesos reales, sin embargo, los microorganismos pueden seguir distintas rutas metabólicas. Esto puede ocurrir de manera voluntaria o forzada (mediante el perfil de alimentación) o involuntaria (condiciones atmosféricas, oxigenación, evolución de concentraciones de sustratos) $[2,11,12]$. Por otra parte, existe un vacío en la inclusión de factores físicos como las densidades de medios y volúmenes de productos no disueltos, que cobra relevancia en procesos de alta densidad celular.

El desarrollo e implementación de controladores versátiles y robustos requiere de la realimentación de variables para las cuales, en la mayoría de los casos, no se dispone del sensor adecuado o simplemente no existe forma de medirlas. Surge entonces la necesidad de diseñar algoritmos de estimación u observadores que permitan estimar las variables necesarias para el monitoreo y control sobre la base de modelos existentes y las medidas disponibles de otras variables.

En lo que concierne al control de los procesos biotecnológicos, el diseño no sólo se ve afectado por la falta de sensores, sino también por restricciones en los actuadores, dinámicas no lineales variantes en el tiempo, comportamientos híbridos e incertidumbre paramétrica. En 
muchos casos el objetivo de control está especificado en la maximización de una tasa de crecimiento o producción, cuyo valor es desconocido a priori. Una técnica cuya utilización está volviendo a ganar interés es la de seguimiento de máximos o extremum-seeking. Esta consiste en diseñar controladores que a partir de observaciones de la respuesta del sistema a distintos estímulos buscan hallar puntos de operación que maximicen (o minimicen) una variable. Es de interés el desarrollo de este tipo de controles para su aplicación en la producción de bioplásticos, biogases y otros procesos similares donde los puntos de operación óptimos no son conocidos con exactitud debido a la incertidumbre existente respecto a la flora del proceso y la impureza de los sustratos.

\subsection{Organización de la tesis}

La tesis está dividida en siete capítulos. El Capítulo 1 corresponde a esta introducción. El Capítulo 2 ofrece una introducción a los bioprocesos. Se exponen conceptos fundamentales de la temática y se clasifican y describen los modelos. Los capítulos 3 al 6 constituyen el trabajo original de la tesis.

En el Capítulo 3 se presenta el proceso de producción de bioplásticos y se detallan sus modelos. Luego, se proponen nuevos modelos para describir los cambios de volumen en procesos de alta densidad celular alimentados con medios concentrados.

En los capítulos 4 y 5 se exponen los aportes de la tesis respecto a la estimación de tasas de reacción en procesos de producción de bioplásticos. En el Capítulo 4 se describe el estado del arte en materia de estimación de concentraciones y tasas de crecimiento en bioprocesos. Luego se propone un esquema de observadores para la estimación de la tasa de crecimiento en el proceso de producción de bioplásticos. En el Capítulo 5 se propone un observador para la estimación de la tasa de producción de bioplásticos en el proceso estudiado, basado en el modelo de volumen propuesto en el Capítulo 3.

En el Capítulo 6 se plantea el problema de maximización de tasas de reacción en bioprocesos con cinética desconocida y se propone una nueva estrategia de control con tal fin utilizando estimaciones del gradiente del mapa cinético. Además, se proveen demostraciones de estabilidad del control propuesto y resultados de simulación, incluyendo su aplicación al proceso de producción de bioplásticos.

Finalmente, en el Capítulo 7 se resumen las principales conclusiones extraídas durante el trabajo de tesis y se plantean posibles líneas de investigación a futuro.

\subsection{Aportes originales de la tesis}

Los principales aportes realizados en esta tesis son

1. Nuevos modelos para las variaciones del volumen en procesos de producción de bioplás- 
ticos y procesos de alta densidad celular en general. Estos tienen en cuenta la contracción de volúmenes al mezclar medios de distintas densidades, consumo de sustratos y la acumulación de productos intracelulares.

2. Un esquema de observadores para la estimación de la tasa específica de crecimiento en el proceso de producción de bioplásticos, utilizando mediciones de densidad óptica e información obtenida del lazo de control de $\mathrm{pH}$. Además, se provee un análisis original de los errores de estimación producidos por las distintas incertidumbres que pueden aparecer en los procesos estudiados. El esquema propuesto es una solución para el monitoreo del proceso en un caso real, y es aplicable en otros procesos de alta densidad celular con instrumentación estándar, como la disponible en muchos laboratorios e industrias. El observador es validado mediante simulación y experimentalmente.

3. Un observador para la estimación de la tasa específica de producción de bioplásticos, basada en la medición de los cambios de volumen del proceso causados por la acumulación del producto. Se propone un algoritmo no lineal para cancelar las no linealidades específicas de la etapa del proceso. El observador se presenta en dos versiones, una por medición de la concentración celular y la otra por medición del volumen del proceso. El mismo es implementable en otros bioprocesos en que la dinámica del volumen sea afín a una tasa de producción. Se proveen pruebas de estabilidad y se analiza la tasa de decaimiento del error con respecto a las ganancias del algoritmo, lo que constituye una herramienta para la sintonización. El observador es validado mediante simulación y con datos experimentales.

4. Una nueva estrategia de control para seguimiento de extremos, con el fin de maximizar las tasas de crecimiento y producción en procesos con cinéticas no monótonas y modelos desconocidos. La estrategia se basa en un controlador y un estimador de gradiente, ambos utilizando técnicas de modos deslizantes de segundo orden. Se proveen por primera vez demostraciones de estabilidad del controlador y criterios para la sintonización de las ganancias. La estrategia se valida mediante simulación en una serie de escenarios distintos, incluyendo la maximización de la tasa de crecimiento y de la tasa de producción del proceso de producción de bioplásticos.

\subsubsection{Lista de publicaciones}

\section{Artículos en revistas}

- Martín Jamilis, Fabricio Garelli, Md. Salatul Islam Mozumder, Castañeda Teresita y Hernán De Battista. Modeling and estimation of production rate for the production phase of non-growth-associated high cell density processes. Bioprocess and Biosystems Engineering, 38(10):1903-1914, 2015. doi: 10.1007/s00449-015-1430-7

- Martín Jamilis, Fabricio Garelli, Md. Salatul Islam Mozumder, Eveline Volcke y Hernán 
De Battista. Specific growth rate observer for the growing phase of a polyhydroxybutyrate production process. Bioprocess and Biosystems Engineering, 38(3):557-567, 2014. doi: 10.1007/s00449-014-1295-1

\section{Artículos en proceso de revisión}

- Martín Jamilis, Fabricio Garelli, y Hernán De Battista. Growth rate maximization in fedbatch processes using high order sliding controllers and observers based on cell density measurement. Journal of Process Control.

\section{Artículos en congresos internacionales (con referato de trabajo completo)}

- Martín Jamilis, Fabricio Garelli y Hernán De Battista. Smooth extremum-seeking control for fed-batch processes. 11th IFAC Symposium on Dynamics y Control of Process Systems, including Biosystems (DYCOPS-CAB 2016). Seleccionado para su presentación oral. En prensa en IFAC-PapersOnLine, ISSN: 2405-8963.

\section{Artículos en congresos nacionales (con referato de trabajo completo)}

- Martín Jamilis, Fabricio Garelli y Hernán De Battista. Production rate estimation in processes with high cell concentration. 2015 XVI Workshop on Information Processing and Control (RPIC 2015). doi: 10.1109/RPIC.2015.7497108

- Martín Jamilis, Fabricio Garelli, Hernán De Battista, Md. Salatul Islam Mozumder, Eveline Volcke, Lindsey Garcia Gonzalez. Observador de tasa de crecimiento en producción de bioplásticos. XV Reunión de Trabajo en Procesamiento de la Información y Control (RPIC 2013), 615-620. 


\section{|| Capítulo 2 \\ Introducción a los bioprocesos}

El hombre hace uso de microorganismos desde antes de descubrir su existencia, ya en la antigüedad se producía pan o bebidas fermentadas como la cerveza, vinagre y vino. Durante el siglo XX se comienzan a producir nuevos productos como glicerol, ácido láctico, acetona, butanol y etanol. Sin embargo, por conveniencia económica, la producción a niveles industriales de estos productos se derivó por otras vías. No es hasta el descubrimiento de la penicilina en 1928 por Alexander Fleming y su producción en masa durante la segunda guerra mundial que la biotecnología cobra impulso por el desarrollo de técnicas y procedimientos para la producción de grandes volúmenes y la aparición de nuevos productos como antibióticos, enzimas y proteínas. Un segundo impulso es recibido en la década del 80 con el desarrollo de la ingeniería genética, surgiendo microorganismos genéticamente modificados capaces de producir sustancias como insulina, hormonas de crecimiento y otras relacionadas a la salud [13].

En este capítulo se da una introducción general a los bioprocesos. En la primera parte se definen conceptos importantes, características principales, tipos de procesos y reactores. En la segunda parte se tratan los modelos de bioprocesos. Se hace una revisión de las clasificaciones, de sus fundamentos (estequiometría y cinética) y de los modelos para biorreactores de tanque agitado.

\subsection{Definiciones y conceptos generales}

\subsubsection{Bioprocesos}

Un bioproceso se puede definir como un proceso químico que involucra agentes biológicos para la generación de productos de interés, biomasa (masa celular) o servicios. Los agentes biológicos pueden ser microorganismos como levaduras y bacterias, células animales, células vegetales o enzimas [13]. Los productos obtenibles son muy variados, en el rubro de la salud se producen vacunas, antibióticos como la penicilina y ácido clavulánico [14], vitaminas y hormonas como la insulina. El campo de los alimentos es el más antiguo, se producen alimentos fermentados como quesos, cervezas, vinos, yoghurt, o también aminoácidos [15], 
saborizantes y levaduras de panificación. Se pueden producir también productos industriales como etanol, acetonas, ácidos cítrico y láctico $[16,17]$ y biopolímeros [18]. Como servicios se destacan el tratamiento de efluentes, la biorremediación de suelos y la producción de biogases con fines energéticos.

Tanto la proliferación y mantenimiento celular como la generación de productos se realiza sobre la base de varios sustratos, es decir, de materias primas y nutrientes esenciales a partir de los cuales se produce la biorreacción. Éstos se pueden clasificar según las concentraciones necesarias en el medio de cultivo, su naturaleza y función [13]:

- Fuente de carbono y energía (FCE): es la que suministra el carbono y la energía necesarios para el crecimiento y para llevar a cabo los procesos metabólicos internos. El carbono constituye el $50 \%$ del peso seco de un microorganismo estándar [13]. FCEs típicas son azúcares fermentables como la glucosa, fructosa, sacarosa, etc. O alcoholes como el glicerol y sorbitol [19].

- Fuente de nitrógeno (FN): el nitrógeno constituye aproximadamente un $12 \%$ del peso seco del microorganismo estándar [13]. La FN es el compuesto que provee de nitrógeno requerido para la síntesis de proteínas, ácidos nucleicos y componentes de la pared celular. En general se utilizan en forma de compuestos inorgánicos como amoníaco, amonio y dinitrógeno, o compuestos orgánicos como aminoácidos, urea y peptonas [19].

- Macroelementos: son aquellos nutrientes que se adicionan en concentraciones del orden de los gramos por litro. Los principales macronutrientes son fósforo, azufre, calcio, magnesio, potasio y sodio. Los mismos se proporcionan en forma de sales [13].

- Microelementos: aquellos nutrientes necesarios en concentraciones pequeñas, del orden de miligramos por litro o menos. Por ejemplo, minerales como el cinc, hierro y manganeso, o bien, compuestos orgánicos como aminoácidos y vitaminas [13].

- Oxígeno: Este nutriente es esencial para microorganismos aeróbicos y opcional para microorganismos facultativos ${ }^{1}$, en general compone un $20 \%$ del peso seco [20]. El microorganismo lo asimila disuelto en la fase líquida, por lo que es necesario favorecer el intercambio del mismo entre el medio del cultivo y la atmósfera.

Recientemente ha crecido el interés por la generación de productos industriales obtenidos a partir de usar residuos industriales o agrícolas como FCE. Por ejemplo: bagazo y glicerol provenientes de la producción de bioetanol, suero de leche y otros productos lácteos, vinazas y almidón (proveniente de residuos de cosechas), entre otros. Se pueden obtener productos de alto valor agregado como hidrógeno [21, 22], ácidos orgánicos [23], lípidos para producción de biocombustibles [24], butanol [25] y ácido láctico [26]. De particular interés en esta tesis es la producción de bioplásticos, específicamente el polyhydroxybutyrato (PHB) [27, 28] de la familia de los polyhydroxyalkanoatos (PHA) [28].

\footnotetext{
${ }^{1}$ Que puede crecer tanto en aerobiosis como anaerobiosis.
} 
La mayoría de los nutrientes se encuentran en exceso en el medio de cultivo, siempre y cuando el exceso no tenga un efecto inhibitorio sobre la reacción. Aquel sustrato que se encuentra en una concentración tal que restringe el crecimiento de los microorganismos se llama sustrato limitante. En general el sustrato limitante puede ser la FCE o la FN dependiendo del caso. En procesos aeróbicos el oxígeno siempre es limitante ya que se puede agotar fácilmente por su rápida dinámica y escasas cantidades en las que se encuentra disuelto. Por ende, en esos casos siempre es necesario un control que lo mantenga por encima de los valores críticos.

Además de la presencia y concentraciones de los distintos nutrientes en el medio de cultivo, otros factores externos afectan el crecimiento y la velocidad de las biorreacciones en general. La temperatura es uno de los factores físicos más importantes, ya que los microorganismos son muy sensibles a la variación térmica. Es de vital importancia la existencia de controles a lazo cerrado que garanticen condiciones de temperatura cercanas a la óptima. Para organismos mesófilos ésta se encuentra entre 15 y $35^{\circ} \mathrm{C}$, para organismos termófilos será por encima de los $45^{\circ} \mathrm{C}$, para psicrófilos entre 12 y $15^{\circ} \mathrm{C}$ y para psicrótrofos menos de $7^{\circ} \mathrm{C}$. Desde el punto de vista químico un factor importante es el $\mathrm{pH}$, ya que la acidez del medio define si es apto para el crecimiento de determinados organismos. Por lo tanto, su control también es necesario en la mayoría de los bioprocesos. En general, se requiere operar con $\mathrm{pH}$ cercano a 7, aunque existen microorganismos extremófilos capaces de crecer en medios muy ácidos o muy alcalinos.

Por su complejidad los bioprocesos pueden ser clasificados de diversas maneras, a continuación se detallan algunas de las clasificaciones más importantes.

\section{Procesos aeróbicos y anaeróbicos}

Los procesos aeróbicos son aquellos en los que se suministra oxígeno al cultivo, por ser éste esencial para el crecimiento del microorganismo utilizado. Procesos anaeróbicos son aquellos que se realizan en ausencia de oxígeno en el medio, ya que éste no es requerido por el microorganismo (o les es tóxico) o su ausencia activa una ruta metabólica deseada. Por ejemplo, la levadura de panificación Saccharomyces cerevisiae crece cuando hay oxígeno disuelto en el medio de cultivo, mientras que cuando éste se agota produce etanol. A aquellos microorganismos capaces de desarrollarse tanto en presencia como ausencia de oxígeno se los llama facultativos.

\section{Culturas puras y mixtas}

Los procesos con culturas puras son aquellos en los que se utiliza una única cepa microbiana, es decir, una única especie de microorganismo. Estos procesos requieren de condiciones de esterilidad estrictas de los reactores y medio de cultivo para asegurar la única presencia del microorganismo en cuestión. Los procesos con culturas mixtas son aquellos en los que intervienen distintas cepas o tipos de microorganismos. Puede ser en un medio estéril con un número de cepas perfectamente identificadas, o en medios no estériles con una gran diversidad de 
microorganismos (bacterias en general). Por ejemplo, los procesos con barros activados para producción de biogases o tratamientos de aguas [29].

\section{Bioprocesos sumergidos y de estado sólido}

Se llaman procesos sumergidos a aquellos en que el medio de cultivo es líquido, con un contenido de agua de más del $95 \%$. En este tipo de procesos se dispone de un dispositivo o mecanismo que provee un mezclado eficaz del medio, obteniéndose una composición de medio y reacciones homogéneas. Usualmente se utiliza para todo tipo de productos industriales. Procesos de estado sólido son aquellos en que los sustratos utilizados son sólidos con niveles de humedad muy bajos, de entre el $40 \%$ y el $80 \%$. Se suelen utilizar para la fermentación de productos agrícolas o alimentos (arroz, trigo, soja, etc.). Los procesos de estado sólido tienen como ventaja su bajo volumen, menor riesgo de contaminación (la baja humedad no es favorable para bacterias), la facilidad de separación posterior del producto y eficiencia energética. La desventaja es la heterogeneidad del medio debido a la falta de mezclado, que resulta en problemas de control de $\mathrm{pH}$, temperatura y oxígeno disuelto [30].

\section{Bioprocesos de alta y baja densidad celular}

Se llaman procesos de alta densidad celular a aquellos en que la concentración de microorganismos supera los 50 a 100 gramos por litro. Los bioprocesos de baja densidad celular son aquellos en que no se superan esas concentraciones, siendo los más comunes en el ámbito de la investigación. Las condiciones de alta densidad celular sirven para incrementar la productividad volumétrica, es decir, para obtener la mayor cantidad de biomasa o producto en un determinado volumen y tiempo [10,31]. Las elevadas concentraciones de biomasa que se pretenden alcanzar se corresponden con una gran cantidad de sustrato total a consumir a lo largo del proceso. Esa cantidad de sustrato no se puede agregar al medio toda junta al inicio del mismo, tanto por problemas de solubilidad, inhibición del crecimiento, volatilidad de los sustratos, activación de rutas metabólicas indeseadas y elevada demanda de oxígeno [10]. En consecuencia los sustratos se deben alimentar gradualmente de manera controlada [32]. En particular es necesario regular las concentraciones de oxígeno disuelto, FCE y FN ya que son las que más influyen en las tasas de crecimiento y producción. Las concentraciones de los sustratos de alimentación suelen ser altas para evitar diluir demasiado la biomasa y otros nutrientes que no son alimentados externamente (que se encuentran en exceso en el medio desde el principio del proceso). Ejemplos de procesos de alta densidad están dados en $[33,12]$ para la producción de bioplásticos, o en [7, 34, 8] para la producción de lípidos. En ambos casos los productos son intracelulares y los procesos constan de dos etapas, una de crecimiento donde se acumulan microorganismos, y otra de producción donde se almacena el producto en la gran población de microorganismos.

Los procesos de baja densidad celular son muy comunes en investigación debido a la 
facilidad de operación y menores requerimientos nutricionales. En general se utilizan para modelizado de microorganismos, determinación de medios de cultivo óptimos, desarrollo de procesos, etc. La desventaja de estos procesos es la baja productividad, y los grandes volúmenes de medio a procesar tras la fermentación.

\subsubsection{Biorreactores}

Un biorreactor es un recipiente o dispositivo en donde un bioproceso se lleva a cabo. El diseño de un biorreactor no es trivial, ya que el mismo debe ser capaz de mantener condiciones aptas para el desarrollo de microorganismos, por ejemplo el $\mathrm{pH}$, temperatura y concentraciones de sustratos. A la vez debe proveer un transporte rápido y eficaz de sustratos y productos entre fases y a los microorganismos, y composición y condiciones homogéneas. Dentro del biorreactor se pueden diferenciar distintas fases [2]:

Líquida: Es mayormente agua que contiene disueltos todos los compuestos necesarios para el crecimiento celular o generación de productos, fuente de carbono, fuente de nitrógeno, fósforo, oxígeno y vitaminas. También puede contener productos extracelulares disueltos como etanol o penicilina.

Gaseosa: Está compuesta por los gases en la parte superior del reactor y los gases en las burbujas que atraviesan la fase líquida. Los gases más relevantes son el oxígeno y dióxido de carbono, el primero funciona como sustrato y es de vital importancia en muchos procesos, el segundo se encuentra presente en aire de entrada y además suele ser un producto de la reacción.

Sólida: Está compuesta por elementos inmiscibles en el medio líquido. Pueden ser fracciones de los sustratos, células inmovilizadas en soportes sólidos (pegadas sobre su superficie o dentro de ellos), o aglomeraciones de células. La presencia de partículas sólidas afecta el mezclado del medio y el transporte de sustratos en el medio.

Biótica: Está formada por todas las células presentes en el medio de cultivo, que no se hayan disueltas en el mismo. Normalmente el tamaño de una célula es del orden del $\mu \mathrm{m}$ y su densidad es similar a la del agua, por lo que su volumen se desprecia. Sin embargo, en presencia de densidades celulares elevadas acumulando producto intracelular puede llegar a ser necesario tener en cuenta su volumen. Este tema se desarrolla en la Sección 3.3.2.

En el campo de los cultivos sumergidos existen distintos tipos de biorreactores [2], a continuación se listan algunos de ellos.

\section{Reactor de tanque agitado (STR)}

Un reactor de tanque agitado consta básicamente de un recipiente (tanque) de vidrio o acero inoxidable y un dispositivo de agitación para proveer el mezclado del medio y distribución del aire que se suministra desde el fondo del mismo. A su vez dispone de conductos 
de entrada para el ingreso de medio de cultivo fresco, y de salida para toma de muestras o evacuación de efluentes. Este tipo de reactores pueden tener volúmenes útiles del orden del litro a escala de laboratorio, a $10 \mathrm{~m}^{3}$ a nivel industrial. La Figura 2.1a muestra un esquema de un STR típico. Éste admite varios modos de operación según los caudales de entrada y salida:

- Batch: cuando los caudales de entrada y salida de sustratos son nulos.

- Fed-batch: cuando existe un caudal de entrada de sustrato pero no de salida. En este modo el volumen del medio se incrementa a lo largo del proceso.

- Continuo: cuando los caudales de entrada y salida de sustrato son iguales y distintos de cero.

Este tipo de reactor es el utilizado en la presente tesis. En la Sección 2.5 se explican los modos de operación en profundidad junto con los modelos dinámicos asociados.

\section{Reactor de columna de burbujas y reactor airlift}

Cuando se necesita operar con volúmenes mayores a los de un STR, hasta $500 \mathrm{~m}^{3}$, la energía para agitación y mezclado puede provenir de la expansión del aire comprimido que se inyecta en el biorreactor. Para ello es conveniente que el reactor sea una columna con una relación de 10:1 entre la altura y el diámetro. Sin embargo, en la columna de burbujas la velocidad del líquido es lenta y el patrón de mezclado indefinido, lo que resulta en un mezclado poco eficaz. Los reactores airlift mejoran el mezclado al incorporar un tubo interior por donde circulan los gases inyectados. Se forma entonces un circuito para el líquido, ascendente por la región de circulación de gas y descendente por la región sin gases. Un esquema del mismo se muestra en la Figura 2.1b. El reactor airlift dispone de un buen mezclado con poco requerimiento energético, la desventaja es que la ausencia de gases en el exterior del tubo interno puede resultar en limitaciones de oxígeno disuelto en esa zona.

\section{Reactores de membrana}

En este tipo de reactores el oxígeno se suministra a través de una membrana tubular porosa (del orden del $\mu \mathrm{m}$ ). Se utilizan para el cultivo de células animales donde las fuerzas de corte deben ser pequeñas para evitar daños en las mismas, ya que no tienen pared celular. De esta manera se eliminan casi completamente las burbujas (y las fuerzas). La transferencia de oxígeno es baja, pero esto no es inconveniente en células animales cuyo crecimiento es lento y el requerimiento de oxígeno es bajo.

\section{Cultivos con retención celular}

En los cultivos continuos típicos parte de la biomasa producida se pierde por el caudal de salida del biorreactor. Esto deriva en una baja productividad específica (productividad por 
microorganismo). Existen procesos en los cuales es de interés mantener al agente biológico (células o enzimas) dentro del biorreactor mediante algún mecanismo de retención o de filtrado. Por ejemplo, si se desea transformar un sustrato en otro compuesto, o para generar un producto no ligado al crecimiento. Una manera de lograrlo es filtrando o centrifugando las células del caudal de salida y reingresándolas al biorreactor. Otras maneras consisten en inmovilizar las células en soportes sólidos (frecuentemente esferas de polímeros insolubles) o inclusión en membranas semipermeables [35, 2, 19]. En la Figura 2.1c se muestra un esquema de un biorreactor de lecho fluidizado, donde las células inmovilizadas se mantienen en suspensión mediante una corriente de sustrato.

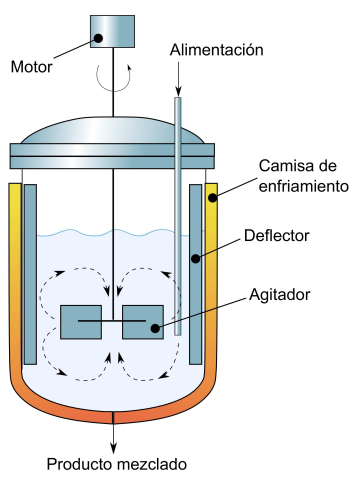

(a) Esquema de un reactor de tanque agitado. Por Daniele $\mathrm{Pu}$ gliesi (Own work) [GFDL or CC BYSA 3.0], via WikimediaCommons.

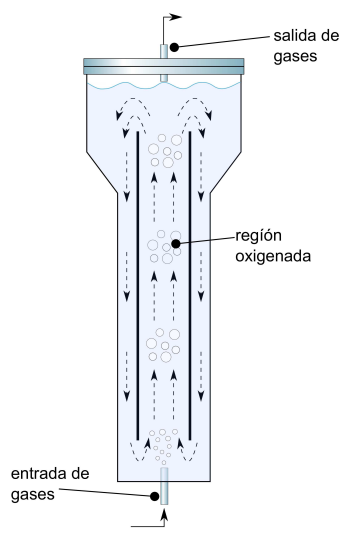

(b) Esquema de un reactor airlift.

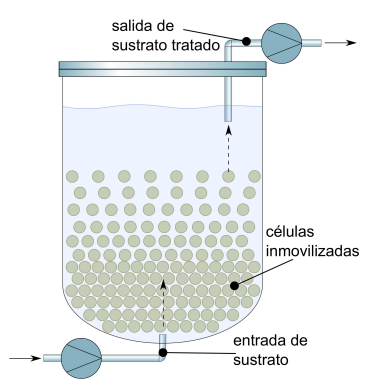

(c) Esquema de un lecho fluidizado.

Figura 2.1: Esquemas de distintos tipos de biorreactores.

\subsection{Instrumentación disponible para biorreactores}

En cualquier bioproceso existe una gran cantidad de variables y parámetros de naturaleza física, química y biológica. No se puede decir lo mismo de la disponibilidad de sensores, sobre todo para la medición de variables biológicas, que en general son escasos. Básicamente, se puede distinguir entre dos tipos de mediciones dependiendo de la forma en que se manejan las muestras:

- En línea: medidas en las que la muestra no se separa del proceso, o bien, si se separa es devuelta inmediatamente después de la medida. Típicamente los sensores se encuentran insertos en el biorreactor o existe un flujo de circulación hacia el sensor y de vuelta al biorreactor. Este tipo de medidas admite una tasa de muestreo alta con respecto a la dinámica de un bioproceso, del orden de minutos o segundos.

- Fuera de línea: medidas en las que se aísla una muestra del proceso para ser analizada externamente mediante un equipo, sensor o técnica. Este tipo de mediciones no admite 
tasas de muestreo rápidas porque en general la extracción y análisis se realizan manualmente, siendo los períodos del orden de las horas. Existen sistemas automáticos para este tipo de medidas, en general muy costosos y poco disponibles incluso en investigación. Además, se debe tener en cuenta que cada vez que se extrae una muestra el volumen del proceso disminuye, por lo que las tasas de muestreo altas aún no serían convenientes.

El control y monitoreo de bioprocesos se realiza preferentemente por medio de mediciones en línea. Los sensores estándar en cualquier planta experimental son para medir temperatura y $\mathrm{pH}$, ya que los lazos de control de estas variables suelen ser imprescindibles. Usualmente la temperatura se mide por medio de termocuplas, termistores o detectores de temperatura resistivos (RTD). Los sensores de $\mathrm{pH}$ más comunes son electroquímicos y constan de un electrodo especial de vidrio que por la interacción con los iones de hidrógeno produce un potencial proporcional al pH de la solución. Dicho potencial se compara con el de un electrodo de referencia sumergido en una solución de $\mathrm{pH}$ neutro. Por principios similares a los de medición de $\mathrm{pH}$ existen sensores para medir la concentración de dióxido de carbono disuelto en la fase líquida (presión parcial de $\mathrm{CO}_{2}$ ).

Los sensores de concentración de oxígeno disuelto en la fase líquida (presión parcial de oxígeno disuelto) se pueden encontrar frecuentemente en muchas instalaciones. En general estos sensores son electroquímicos, constando de electrodos de Clark separados por una mebrana permeable que producen una corriente proporcional a la presión de oxígeno disuelto [36]. Existen también sensores ópticos que miden fluorescencia o luminiscencia causada por la reacción entre el oxígeno y un gel [36, 37].

Ocasionalmente se disponen de dispositivos analizadores de gases para medir sus concentraciones en los conductos de entrada y salida del biorreactor. Lo usual es que estos equipos midan concentraciones de oxígeno y dióxido de carbono [38]. Sin embargo existen versiones con la capacidad de medir otros gases como metano y óxido nitroso. Estos equipos suelen ser muy costosos y pocas veces están disponibles en un laboratorio estándar. La medida de oxígeno puede realizarse mediante celdas electrolíticas mientras que la de dióxido de carbono se determina por su absorción en el espectro infrarrojo. Además se necesita regular o compensar la temperatura, humedad y presión a la que se realiza la medida.

La medición en línea de biomasa puede obtenerse mediante sensores de densidad óptica. Éstos tienen un elemento emisor de luz visible o infrarroja y un elemento receptor de luz, en general se usan leds y fotodiodos. La atenuación en la intensidad de luz recibida se relaciona con la cantidad de microorganismos por medio de la ley de Beer-Lambert [39]. Este método funciona bien a concentraciones bajas y medias pero no altas, ya que a medida que la concentración es mayor la luz transmitida es cada vez menor y el sensor termina por saturar. Alternativamente existen versiones que miden la intensidad de luz reflejada, de mejor desempeño a altas concentraciones. Existen también sensores para medir la capacitancia del medio (espectroscopía dieléctrica). Dado que, en un determinado rango de frecuencias, las 
células se comportan como pequeños capacitores, se puede hallar una correlación lineal entre la capacidad del medio y la concentración de microorganismos [40, 41, 42]. A diferencia de las medidas ópticas, este tipo de sensores sólo mide células vivas, ya que las células muertas rompen su membrana celular y no presentan capacidad. Además, la medida no se ve afectada por la burbujas de aire como en los sensores ópticos. La desventaja de este método es que pierde exactitud a concentraciones muy bajas. Se ha mostrado que cuando los microorganismos almacenan un producto intracelular como lípidos o polihidroxibutirato los sensores de capacitancia pueden discriminar al producto del resto de la célula (biomasa residual) [43, 44], midiéndose solamente la biomasa residual.

Existen dispositivos para la medición de algunos sustratos y productos extracelulares específicos, por ejemplo para glucosa y lactato [45] o etanol [46]. En general, se trata de biosensores donde una enzima reacciona con el sustrato a medir, liberando iones o consumiendo oxígeno como parte de la reacción. Luego, mediante un transductor (como los usados en la medición de $\mathrm{pH}$ o de oxígeno) se miden los iones liberados u oxígeno consumido. Estos sensores, al ser tan específicos, son de gran utilidad en investigación y desarrollo de productos de alta pureza como vacunas u hormonas. Sin embargo, su aplicación es limitada en procesos de interés para la industria en los que los sustratos usados son impuros y provienen de residuos agroindustriales.

\subsection{Control de bioprocesos}

En algunos procesos es de interés la regulación de tasas de reacción o concentraciones ante perturbaciones y no linealidades típicas de los bioprocesos. En general, cuando se regula la concentración de un sustrato, el objetivo real es la regulación de una tasa de reacción asociada a esa concentración de sustrato, o bien, evitar la activación de una ruta metabólica indeseada. En este último caso el objetivo es, indirectamente, regular la tasa de producción de un metabolito indeseado en cero.

Existen también objetivos de seguimiento, por ejemplo, de perfiles óptimos para las concentraciones [47]. En algunos casos estos perfiles se corresponden con tasas de reacción constantes u óptimas. Por ejemplo, en un proceso del tipo batch alimentado la tasa de crecimiento óptima se corresponde con un aumento exponencial en la biomasa total.

Es usual encontrar procesos donde la regulación de concentraciones se realiza a lazo abierto. Algunas de las estrategias para lograr esto son:

- Chemostat: Un chemostat es el modo de operación a lazo abierto más común para cultivos continuos. El medio del reactor contiene todos los nutrientes en exceso excepto por uno, el sustrato limitante. Luego, se alimenta el sustrato limitante con un caudal de alimentación constante de manera tal que la dilución sea menor que la máxima tasa de reacción. Se puede alcanzar (asintóticamente) un estado estacionario cuando la tasa de crecimiento de los microorganismos se iguala a la tasa de dilución. Este tipo 
de operación se puede volver inestable cuando los microorganismos tienen cinéticas no monótonas o cuando la dilución supera la tasa de reacción máxima [48, 49].

- Alimentación exponencial: En procesos batch alimentado donde los microorganismos crecen con una tasa específica constante $\left(\mu_{r e f}\right)$ la biomasa total aumenta exponencialmente:

$$
x v=x_{0} v_{0} e^{\mu_{r e f} t}
$$

Entonces, se alimenta el sustrato exponencialmente para cubrir el requerimiento de la biomasa

$$
F_{s}=\lambda x v
$$

donde $\lambda$ es una constante que depende de $\mu_{\text {ref }}[32,50]$. Existen versiones de lazo cerrado de la alimentación exponencial, por ejemplo, haciendo que $\lambda$ sea una función de la tasa específica de crecimiento verdadera [51, 52].

Desde luego, existen también estrategias de lazo cerrado basadas en la utilización de distintos sensores, algunas de ellas son:

- Realimentación de pH (pH-stat): Este modo de operación es utilizado en procesos continuos y batch alimentado. El consumo del sustrato como producto de la actividad metabólica produce variaciones en el $\mathrm{pH}$. Entonces, utilizando al $\mathrm{pH}$ como variable de realimentación, se alimenta el medio de manera de estabilizar el $\mathrm{pH}$ en un dado valor $[48,32,53]$. En algunos procesos, la regulación del $\mathrm{pH}$ puede implicar la regulación de otra variable como el nitrógeno o se puede utilizar para inferir las cantidades de sustrato consumidas [33]. Si bien esta técnica ha sido muy utilizada se debe mencionar que la respuesta del pH usualmente es lenta con lo que la regulación puede ser deficiente.

- Realimentación de oxígeno disuelto (do-stat): Este modo de operación se basa en la utilización de sensores de oxígeno disuelto para definir la alimentación de sustrato en procesos aeróbicos. Inicialmente, se busca mantener el oxígeno disuelto en un valor apenas encima del crítico ya que en ese punto se obtiene la máxima tasa de crecimiento (o producción) [32, 53].

- Realimentación directa de sustratos y metabolitos (auxostat): En caso de disponer de un sensor que mida la concentración de sustratos o de metabolitos se puede controlar directamente la concentración de los mismos. En general, se llama auxostat a las estrategias donde se regula la misma variable que es medida actuando sobre el caudal de entrada. La Figura 2.2 muestra un esquema del tipo de control. Por ejemplo, si se dispone de un sensor de glucosa la misma puede regularse directamente utilizando un controlador PID (nutristat). O bien, si se puede medir la turbidez del medio se puede regular la concentración de microorganismos (turbidostat) [54].

- Control con sensores virtuales (software sensors): La teoría de control ofrece herramientas para el diseño de observadores de estados que permiten estimar variables no me- 


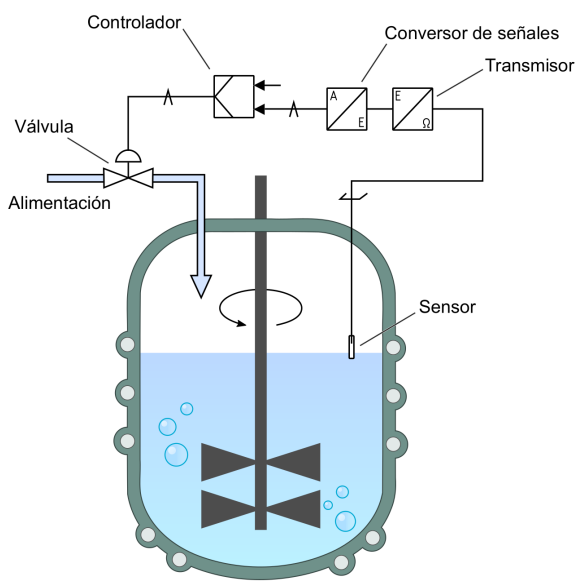

Figura 2.2: Esquema de un auxostat. Por GYassineMrabetTalk (Own work) [CC BY-SA 3.0) or GFDL ], via WikimediaCommons.

didas [55, 56]. Esas estimaciones se pueden utilizar para el diseño de leyes de control robustas, linealizar por realimentación [57], hacer controles adaptivos [11] o para seguimiento de máximos [58]. Además se abre la posibilidad de regular directamente las tasas de reacción [47], en lugar de hacerlo indirectamente a través de la regulación de un sustrato.

\subsection{Modelos de bioprocesos}

Un modelo es una representación de un fenómeno natural, físico o químico, que describe algunos aspectos del mismo con un dado grado de profundidad, siendo entonces una imagen incompleta. Se podría decir que un modelo es una fotografía o incluso una caricatura del fenómeno observado, dependiendo del grado de profundidad. Por supuesto existen distintas maneras de modelizar un sistema, por ejemplo una descripción verbal o lógica como si se inocula Saccharomyces cerevisiae en un medio rico en glucosa las levaduras se multiplicarán y producirán dióxido de carbono. Sin embargo, el mayor grado de abstracción que puede dar un modelo está dado por modelos matemáticos cuya descripción se realiza en forma de ecuaciones diferenciales ordinarias (ODEs) y ecuaciones diferenciales en derivadas parciales (PDEs) donde se relacionan entradas, salidas, estados y parámetros del sistema. Por lo general, en el estudio macroscópico de bioprocesos las entradas son los caudales o flujos de sustancias entrando a un reactor y los estados son aquellas variables que representan la acumulación de materia o energía, por ejemplo las concentraciones, las masas o la temperatura. Las salidas dependen de la aplicación puntual y de los sensores disponibles, en general son algunas de las concentraciones del proceso. Los parámetros serán generalmente las constantes del modelo, como rendimientos o concentraciones en los caudales de alimentación. En muchos casos algunas variables como la temperatura y el $\mathrm{pH}$ se pueden considerar como parámetros si existe un control de lazo cerrado adecuado que las mantenga en un valor constante. 
El modelo de un proceso es una herramienta fundamental tanto para el análisis y comprensión del mismo como para predecir su evolución en el tiempo o el valor de estados no medibles. En el marco de esta tesis los modelos de los bioprocesos son utilizados como herramienta con los siguiente objetivos:

- Monitoreo del estado fisiológico de los microorganismos, esto es, estimación de tasas de reacción.

- Diseño de controles a lazo cerrado de bioprocesos tipo fed-batch.

- Simulación de los procesos para la validación de algoritmos de estimación y control.

Si bien la mayoría de los modelos para procesos biológicos provienen de observaciones experimentales, existen muchas maneras de modelizar dependiendo de la aplicación y objetivo. A continuación, se describen los distintos tipos de modelos que se suelen utilizar para bioprocesos. En la Sección 2.5 se describen el biorreactor de tanque agitado, los balances utilizados para describir las concentraciones y los modos de operación. En la Sección 2.6 se describen modelos para biorreacciones, la estequiometría y la cinética del crecimiento microbiano.

\subsubsection{Clasificación de modelos para bioprocesos}

\section{Modelos mecanísticos y de caja negra}

La clasificación de modelo más inmediata se puede dar según si el modelo se obtuvo de manera teórica o empírica [59]. Cuando las expresiones del modelo se han derivado de la descripción de sus partes (o mecanismos) por medio de leyes físicas y químicas se dice que el modelo es mecanístico o teórico. Ejemplos simples serían el cálculo de la corriente en un circuito eléctrico basado en las leyes de Kirchoff, o de la determinación de la velocidad de una manzana en caída libre según las leyes cinemáticas. Cuando, en cambio, el modelo es una descripción de la relación entre la entrada y la salida del proceso basada en la observación del mismo, se dice que el modelo es empírico o de caja negra. Ejemplos simples de este tipo de modelos son las leyes sobre las que se basan modelos mecanísticos, como la ley de ohm o la ley de atracción de masas en los ejemplos anteriores, cuya formulación es originalmente empírica.

En lo que respecta a la modelización de bioprocesos, a pesar del estado de avance actual por ejemplo en materia de análisis de flujos metabólicos, es muy difícil disponer de un modelo puramente mecanístico. Más bien, se plantean modelos mixtos en los que se complementan planteos mecanísticos con empíricos. Es el caso al estudiar macroscópicamente un biorreactor, el enfoque mecanístico surge de los balances de masa y energía, pero los modelos sólo se completan al agregar los términos cinéticos obtenidos empíricamente. 


\section{Modelos no estructurados y estructurados}

En un modelo no estructurado se considera que las reacciones biológicas dependen solamente de variables macroscópicas como las concentraciones del medio líquido del biorreactor, la temperatura o el $\mathrm{pH}$. Bajo esta óptica la única variable de estado biológica es la concentración celular, y se consideran en el modelo sólo aquellas variables que tienen una gran influencia o sensibilidad en el modelo [2]. En general, los rendimientos celulares se consideran constantes a lo largo de un proceso. Sin embargo, es posible considerar variaciones en los mismos, por ejemplo cuando el consumo de sustrato para mantenimiento celular no es despreciable. Un ejemplo simple surge al considerar el crecimiento e incorporación de sustrato de una cultura homogénea y dependiendo de un único sustrato limitante. Su modelo es ${ }^{2}$ :

$$
\begin{aligned}
\dot{x} & =\mu x \\
\dot{s} & =-\frac{\mu x}{y_{x s}}
\end{aligned}
$$

siendo $x$ la concentración celular, $s$ la del sustrato, $y_{x s}$ el rendimiento que indica qué tanta masa celular se obtiene del sustrato, y $\mu$ la tasa específica de crecimiento. Esta última es en general una función no lineal del sustrato, se obtiene empíricamente y se conoce como modelo cinético. Por ejemplo, el conocido modelo de Monod:

$$
\mu=\mu_{\max } \frac{s}{k_{s}+s}
$$

Por otra parte, los modelos estructurados consideran que la célula está constituida por varios grupos funcionales y compuestos intracelulares, como también por los flujos de sustancias e información entre ellos [2]. El modelo entonces es capaz de describir una cadena metabólica completa, o su versión reducida. Por lo tanto, da información del estado fisiológico del microorganismo, su composición y adaptación al medio. El agregado de balances intracelulares lleva a que los modelos sean más complejos y de mayor dimensión que los no estructurados. El análisis de flujos metabólicos es un claro ejemplo de aplicación de modelos estructurados de gran dimensión [60]. Por otra parte, los modelos de compartimento son un ejemplo de menor dimensión.

\section{Modelos segregados}

Tanto los modelos estructurados como los no estructurados consideran que la población de microorganismos es homogénea y constituida por una única especie. A este tipo de modelos se los llama no segregados ya que tienen como característica que no consideran culturas mixtas, diferencias morfológicas entre microorganismos, gradientes espaciales de crecimiento y alteraciones del metabolismo o de la respuesta fisiológica.

\footnotetext{
${ }^{2}$ Este modelo se presenta aquí a modo de ejemplo y se explica en detalle en la Sección 2.6.
} 


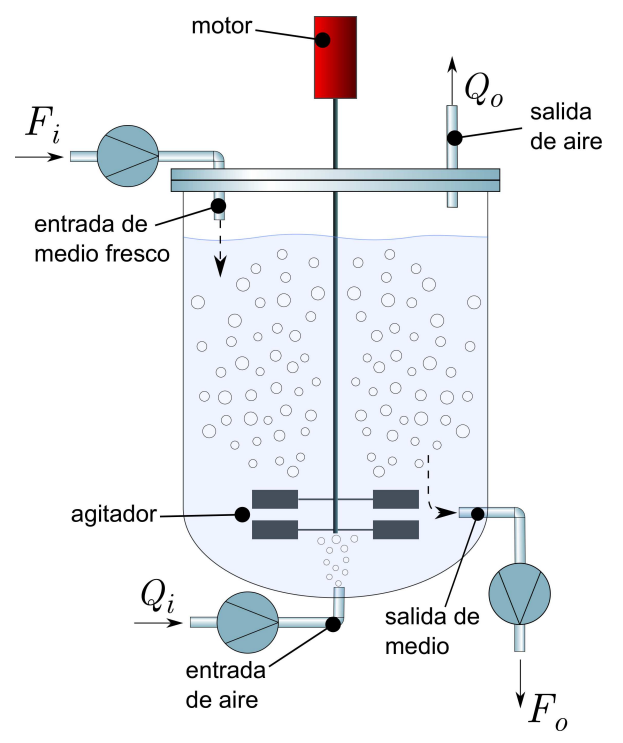

Figura 2.3: Esquema de un reactor de tanque agitado

En contraste, un modelo segregado considera muchos tipos de células, donde cada una de ellas puede estar descripta por un modelo no estructurado o incluso estructurado. Se puede considerar tanto un número finito de clases de células como una variación continua descripta en ese caso por una PDE. En caso de tener un número finito de clases se llaman modelos segregados simples. Por ejemplo, en procesos de producción de biogas y tratamiento de aguas se consideran distintas especies pertenecientes a la flora bacteriana [29].

\subsection{Reactor de tanque agitado y sus modelos}

Un reactor de tanque agitado o STR, por sus siglas en inglés (Stirred Tank Ractor), se puede describir como un tanque con múltiples conductos de entrada y salida por los que se puede ingresar tanto medio de cultivo como gases. Dispone de un dispositivo de agitación que permite obtener un mezclado perfecto en el interior del mismo. Se puede en consecuencia asumir que la composición del medio dentro del biorreactor es homogénea. En la Figura 2.3 muestra un esquema de un STR, donde se pueden observar tanto los conductos de entrada y salida, como el agitador que provee el mezclado. Por los conductos de entrada se puede ingresar medio de cultivo, solución ácida/base para control de $\mathrm{pH}$, anti-espumante, aire u oxígeno puro. Incluso se pueden suministrar gases carbónicos y nitrogenados como sustratos para el crecimiento $[5,61]$. En la presente tesis nos enfocaremos solamente en el medio de cultivo ingresado, que tendrá concentraciones de fuente de carbono y de nitrógeno $s_{f}$ y $n_{f}$ respectivamente. El caudal de entrada $F_{i}$ será único si ambos sustratos están disueltos en el mismo medio, o habrá dos caudales $F_{s}$ y $F_{n}$ si cada sustrato se alimenta de manera independiente. Por otra parte, también puede existir un caudal de salida $F_{o}$ impulsado por una bomba independiente, o bien, por rebalse.

En la Sección 2.1.2 se explicaron las distintas fases que existen dentro de un biorreactor. 
En cada una de ellas se pueden plantear balances de masa para derivar un modelo dinámico que describa las concentraciones de cada componente del medio (fuente de carbono, fuente de nitrógeno, biomasa, etc.). Sea $C$ la masa de una dada sustancia, $V$ el volumen de la fase y $c=C / V$ la concentración de la sustancia, las variaciones de $C$ en una determinada fase estarán dadas por la masa de la misma ingresada por los conductos de alimentación, la masa extraída por el conducto de salida, la masa convertida de una fase a otra (intercambio) y la generada o consumida como consecuencia de la reacción:

$$
\dot{C}=F_{i} c_{f}-F_{o} c \pm r_{c} V \pm \text { intercambio, }
$$

donde $c_{f}$ es la concentración de la sustancia en el medio de entrada y $r_{c}$ la velocidad volumétrica de consumo o producción de la sustancia en $[\mathrm{g} /(\mathrm{lh})]$ o $[\mathrm{c}-\mathrm{mol} /(\mathrm{lh})]$. Por otra parte, es muy útil plantear los modelos en términos de las concentraciones definidas como la masa por unidad de volumen de una determinada sustancia $c=C / V$, teniendo en cuenta que $\dot{C}=\dot{c} V+c \dot{V}$, se puede obtener el siguiente modelo:

$$
\dot{c}=-c \frac{\dot{V}}{V}+\frac{F_{i}}{V} c_{f}-\frac{F_{o}}{V} c \pm r_{c} \pm \frac{\text { intercambio }}{V} .
$$

Lo usual es que en cultivos de baja densidad celular y de medio se asuma que la variación de volumen de la fase líquida sea la diferencia entre los caudales de entrada y de salida, $\dot{V}=F_{i}-F_{o}$, quedando entonces el modelo de concentraciones

$$
\dot{c}=\frac{F_{i}}{V}\left(c_{f}-c\right) \pm r_{c} \pm \frac{\text { intercambio }}{V} .
$$

Por ejemplo, aplicando el modelo anterior a un proceso que involucra la concentración celular $x$, una fuente de carbono $s$, fuente de nitrógeno $n$ y producto $p$ queda

$$
\left\{\begin{array}{l}
\dot{x}=r_{x}-\frac{F_{i}}{V} x \\
\dot{s}=-r_{s}+\frac{F_{i}}{V}\left(s_{f}-s\right) \\
\dot{n}=-r_{n}+\frac{F_{i}}{V}\left(n_{f}-n\right) \\
\dot{p}=r_{p}-\frac{F_{i}}{V} p
\end{array}\right.
$$

Las $r_{i}$ son las tasas o velocidades volumétricas de producción o consumo de la sustancia $i$. Como $s$ y $n$ son sustratos que se están consumiendo $\left(-r_{s}\right)<0$ y $\left(-r_{n}\right)<0$, en cambio la de la biomasa $r_{x}>0$ siempre y cuando el mantenimiento celular no sea importante. El signo de la tasa volumétrica de producto depende mucho del proceso, ya que además de producirlo el microorganismo podría utilizarlo como sustrato.

Existen varios modos de operación para el STR dependiendo de cómo son los caudales de 
entrada y salida $[62,63,2]$, los mismos se encuentran esquematizados en la Figura 2.4 y se describen a continuación.

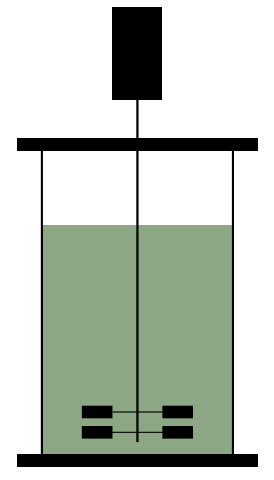

Batch

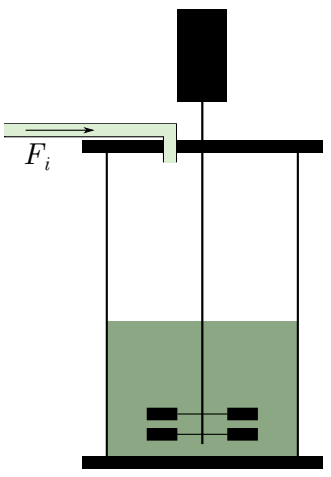

Fed-Batch

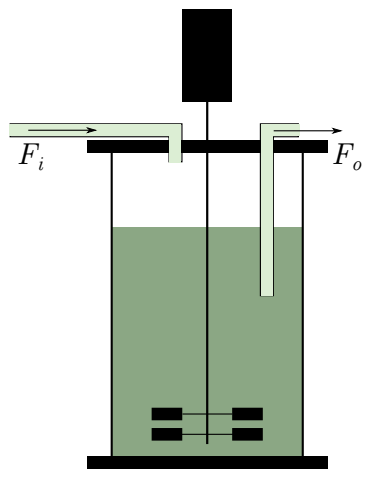

Continuo

Figura 2.4: Esquema de modos de operación de un reactor de tanque agitado.

\section{Cultivos por lotes o batch}

En los cultivos batch o por lotes no existen caudales de entrada ni de de salida $\left(F_{i}=F_{o}=\right.$ 0 ), por lo tanto los sustratos y nutrientes usados únicamente son los que se agregan al principio del proceso. El volumen es constante $(\dot{V}=0)$ y además no hay ningún control sobre el crecimiento más allá del provisto por los controles de temperatura y $\mathrm{pH}$. La mayor fortaleza de este modo de operación es su fácil implementación, operación y mínimo requerimiento de equipamiento. Además, es mucho más fácil mantener las condiciones de esterilidad debido a que el reactor se mantiene cerrado durante todo el cultivo. En procesos donde el sustrato no tiene un efecto inhibitorio sobre el crecimiento, se termina operando la mayor parte del proceso con una tasa de crecimiento máxima a la que se denomina fase exponencial. Esto constituye una ventaja si el objetivo final es obtener una productividad de biomasa alta $^{3}$. Sin embargo, si se desea obtener un metabolito que se manifiesta a velocidades específicas de crecimiento bajas, este modo de operación resulta contraproducente. Por otra parte, en procesos donde el exceso de sustrato inicial inhibe el crecimiento se termina operando a tasas de reacción muy bajas. Los excesos en la concentración de sustrato inicial pueden traer problemas también al elevarse la presión osmótica y en consecuencia deshidratando las células. En concreto, las limitaciones en las concentraciones iniciales de sustrato se traducen en productividades generalmente bajas. Se le puede agregar a esto que el crecimiento descontrolado puede resultar en acumulación de productos inhibidores y limitación de oxígeno por la elevada demanda.

\footnotetext{
${ }^{3}$ Productividad $=X\left(t_{\text {final }}\right)-X\left(t_{\text {inicial }}\right) / t_{\text {final }}$
} 
En este caso el modelo del ejemplo (2.4) se reduce a

$$
\left\{\begin{array}{l}
\dot{x}=r_{x} \\
\dot{s}=-r_{s} \\
\dot{n}=-r_{n} \\
\dot{p}=r_{p} .
\end{array}\right.
$$

Se puede notar que el modelo en términos de masas se obtiene simplemente al multiplicar a ambos lados de las ecuaciones por $V$, que en este caso es constante.

\section{Cultivos semi-continuos o fed-batch}

En los cultivos fed-batch, batch alimentado o semi-continuo existe un caudal de entrada por el que se suministra medio de cultivo al reactor $\left(F_{i} \neq 0, F_{o}=0\right)$, pudiéndose entonces suministrar los sustratos de manera gradual y controlada. Esto permite controlar la cinética de crecimiento o producción del proceso, pudiéndose operar en principio a cualquier tasa de reacción que se desee. En procesos con inhibición por sustrato permite operar a bajas concentraciones, próximas a la óptima, obteniéndose tasas de reacción más elevadas que en el modo batch. La adición de medio conlleva un incremento constante del volumen, lo que permite incrementar los volúmenes de producción finales y mejorar la productividad respecto al batch. Sin embargo, también aumenta la complejidad en la operación del mismo; el proceso se vuelve inestable y la estabilización es en torno a una trayectoria más que a un punto de operación ${ }^{4}$. La estrategia de alimentación no es trivial, caudales muy altos pueden terminar lavando al biorreactor, haciendo que $s \rightarrow s_{f}$ y $x \rightarrow 0$. La esterilización en este modo de operación es un poco más compleja debido a que el biorreactor no está completamente cerrado y crecen los riesgos de contaminación. Por último se debe tener en cuenta que cuando la masa celular generada dentro del biorreactor es grande el mantenimiento celular empieza a cobrar importancia.

En este caso el modelo del ejemplo (2.4) pasa a ser

$$
\left\{\begin{aligned}
\dot{x} & =r_{x}-D x \\
\dot{s} & =-r_{s}+D\left(s_{f}-s\right) \\
\dot{n} & =-r_{n}+D\left(n_{f}-n\right) \\
\dot{p} & =r_{p}-D p
\end{aligned}\right.
$$

donde

$$
\left\{\begin{array}{l}
\dot{V}=F_{i} \\
D=\frac{F_{i}}{V} .
\end{array}\right.
$$

${ }^{4}$ Razón por la cual es muy atractivo desde el punto de vista del control automático. 
La dilución $D$ es una medida de la tasa a la que se diluye el contenido del biorreactor. Se puede ver que si $D>r_{x} / x$ la concentración celular tiende a decrecer, ya que crece más lento que lo que se la diluye. Al factor $r_{x} / x$ se lo llama tasa o velocidad específica de crecimiento, designado por la letra $\mu$, y representa la velocidad de crecimiento por célula con unidades en $[1 / \mathrm{h}]$.

\section{Cultivos continuos}

En un cultivo continuo existe un caudal de salida igual al de entrada $\left(F_{i}=F_{o} \neq 0\right)$, generalmente obtenido por rebalse. Consecuentemente, el volumen del biorreactor permanece constante. Así como el fed-batch, el modo continuo permite control en el crecimiento y producción del proceso, con la diferencia que si no se usan diluciones muy altas el proceso es estable a lazo abierto, siendo posible alcanzar puntos de operación estacionarios. Los procesos continuos son en general de gran duración, lo que sumado a la adición de un conducto de salida aumenta en gran manera el riesgo de contaminación. En aplicaciones industriales se prefiere para procesos que no requieran de condiciones estériles, como el tratamiento de aguas. En condiciones de laboratorio es muy útil para realizar estudios del metabolismo y fisiológicos, ya que con una dilución constante se alcanza una tasa específica de crecimiento constante. Como ventaja adicional se puede mencionar que el aprovechamiento del tiempo es mejor con un cultivo continuo por la ya mencionada duración del mismo. En este aspecto los procesos batch y fed-batch están muy por detrás, ya que los cultivos tienen una duración menor y el tiempo de parada para limpiar, esterilizar e iniciar otra cultivo es significativo. Sin embargo, se debe tener en cuenta que parte del medio y de la biomasa se pierde por el caudal de salida. Por lo tanto, la eficiencia es menor que la de un cultivo fed-batch.

En este caso el modelo del ejemplo (2.4) pasa a ser

$$
\left\{\begin{array}{l}
\dot{x}=r_{x}-D x \\
\dot{s}=-r_{s}+D\left(s_{f}-s\right) \\
\dot{n}=-r_{n}+D\left(n_{f}-n\right) \\
\dot{p}=r_{p}-D p
\end{array}\right.
$$

donde

$$
\left\{\begin{array}{l}
\dot{V}=F_{i}-F_{o}=0 \\
D=\frac{F_{i}}{V} .
\end{array}\right.
$$

Se puede notar que la diferencia entre los modelos para procesos fed-batch y continuos radica en la dinámica del volumen, como se ve en (2.7) y (2.9).

Hasta aquí se ha explicado cómo evolucionan las concentraciones dentro de un biorreactor en relación a flujos de entrada y salida, cambios de fase y consumo o producción de sustancias. Este último término tiene que ver con la bioconversión llevada a cabo y se explica en la 
siguiente sección.

\subsection{Modelos de biorreacciones}

En esta sección se explica cómo analizar un bioproceso como una serie de reacciones químicas elementales, los balances estequiométricos que surgen de ellas y los modelos cinéticos comúnmente hallados en la literatura.

\subsubsection{Procesos biológicos como reacciones químicas}

En un nivel macroscópico es posible representar al proceso biológico como una o más reacciones químicas donde una serie de $n$ sustratos hacen de reactivos para obtener biomasa y otros $m$ productos, es decir los reactantes. Por ejemplo

$$
S_{1}+S_{2}+\cdots+S_{n} \longrightarrow X+P_{1}+\cdots+P_{m}
$$

donde las $S_{i}$ denotan las cantidades de sustrato, las $P_{i}$ de los productos y $X$ de la biomasa generada. Dependiendo de la segregación del modelo, $X$ puede representar a la fase biótica en su totalidad o parcialmente, es decir, en algunos casos $X$ representa a la biomasa total y en otros sólo una parcialidad de la misma. Por ejemplo, si se acumulan productos intracelulares, $X$ podría representar a la célula como estructura y el producto se representaría de manera separada por una $P_{i}$. En ese caso, $X$ se suele llamar biomasa residual ya que sería descartada para quedarse sólo con el producto. En general, el término $X$ está presente en reacciones que implican crecimiento y producción de metabolitos asociados al crecimiento, como dióxido de carbono o etanol. Sin embargo, en reacciones donde se sintetizan productos independientemente del crecimiento (no asociados al crecimiento) el término puede no estar.

Una mejor manera de describir las reacciones es agregando coeficientes estequiométricos que indiquen la cantidad de cada sustrato necesaria para obtener una unidad de biomasa $X$, y la cantidad de producto asociado que se genera. $\mathrm{O}$ bien, que indique la cantidad de sustrato necesaria para generar un producto no asociado al crecimiento. De manera general, tomando un caso con dos reacciones

$$
\begin{aligned}
& k_{11} S_{1}+k_{12} S_{2}+\cdots+k_{1 n} S_{n} \stackrel{r_{1}}{\longrightarrow} X+k_{1(n+1)} P_{1}+k_{1(n+2)} P_{2}+\cdots+k_{1 m} P_{m} \\
& k_{21} S_{1}+k_{22} S_{2}+\cdots+k_{2 n} S_{n} \stackrel{r_{2}}{\longrightarrow} P+k_{2(n+1)} P_{1}+k_{2(n+2)} P_{2}+\cdots+k_{2 m} P_{m},
\end{aligned}
$$

donde cada $r_{i}$ es la velocidad volumétrica que domina a cada reacción y $k_{i j}$ son los coeficientes estequiométricos, que deben cumplir $k_{i j} \geq 0$. Cada reacción independiente tendrá una tasa asociada. Además, los productos de una reacción pueden ser sustratos en otra. En la primera reacción, $r_{1}$ indica la velocidad a la que se genera la biomasa $X$. En la segunda, $r_{2}$ indica la velocidad a la que se produce el producto no asociado a crecimiento $P$. Por tanto, la veloci- 
dad a la que se consume un sustrato o se genera un producto asociado será proporcional a las velocidades de producción de $X$ y de $P$. Por ejemplo, la velocidad de consumo de $S_{1}$ es $r_{s 1}=k_{11} r_{1}$. Lo mismo sucede con la segunda reacción, donde por ejemplo la velocidad de generación del producto asociado $P_{m}$ es $r_{p m}=k_{2 m} r_{2}$. Esto se puede escribir matricialmente como

$$
\phi=\mathbf{K r}
$$

donde $\boldsymbol{\phi}$ es una matriz que contiene a todas las tasas del proceso, $\mathbf{K}$ es una matriz de rendimientos y $\mathbf{r}$ es un vector con las tasas de las reacciones principales. Por ejemplo

$$
\begin{aligned}
& \boldsymbol{\phi}^{T}=\left[\begin{array}{lllllllll}
r_{1} & r_{2} & r_{s 1} & r_{s 2} & \cdots & r_{s n} & r_{p 1} & \cdots & r_{p m}
\end{array}\right] \\
& \mathbf{K}^{T}=\left[\begin{array}{llllll}
1 & 0 & k_{11} & k_{12} & \cdots & k_{1 m} \\
0 & 1 & k_{21} & k_{22} & \cdots & k_{2 m}
\end{array}\right] \\
& \mathbf{r}^{T}=\left[\begin{array}{ll}
r_{1} & r_{2}
\end{array}\right]
\end{aligned}
$$

\subsubsection{Estequiometría del crecimiento microbiano}

\section{Carbono mol y fórmula mínima de la biomasa}

Se define como 1 c-mol (carbono mol) de un compuesto orgánico a la cantidad del compuesto que contiene 1 átomo gramo de carbono. Por su parte, 1 átomo gramo de carbono es el peso de $1 \mathrm{~mol}$ de carbono (6022e23 átomos de carbono), correspondiente a 12g. Por ejemplo, 1 mol de glucosa $\mathrm{C}_{6} \mathrm{H}_{12} \mathrm{O}_{6}$ equivale a 6 c-moles de la misma, o bien, 1 c-mol de glucosa tiene una fórmula mínima $\mathrm{CH}_{2} \mathrm{O}$. De esta manera se pueden expresar los compuestos mediante una fórmula mínima en c-mol que resulta muy útil en los balances estequiométricos. Así, se pueden referir todas las cantidades necesarias en la reacción a una unidad de fuente de carbono. Sin embargo, no se debe entender a la fórmula mínima como una descripción de la estructura molecular, sino de su peso y cantidades relativas. La Tabla 2.1 lista varios compuestos orgánicos, su fórmula mínima y la masa en gramos de 1 c-mol de la misma.

Se ha encontrado que la composición elemental de un importante número de microorganismos, cultivados bajo diferentes condiciones, no varía sustancialmente de uno a otro [13]. Se puede definir entonces un microorganismo promedio de composición estándar cuya composición molecular es $\mathrm{C}=46,5 \% ; \mathrm{H}=6,94 \% ; \mathrm{O}=31,0 \%$ y $\mathrm{N}=10,85 \%$, donde aproximadamente el $5 \%$ restante son sales. A partir de esto se puede definir una fórmula mínima para el microorganismo promedio como $\mathrm{CH}_{1.79} \mathrm{O}_{0.5} \mathrm{~N}_{0.2}$, esto es, $1 \mathrm{c}$-mol de biomasa estándar

$$
1 \mathrm{c}-\mathrm{mol} \text { de biomasa }=\frac{12+1,79+16 \cdot 0,5+14 \cdot 0,2}{0,95}=25,8 \mathrm{~g}
$$




\begin{tabular}{lllr}
\hline Compuesto & Fórmula molecular & c-mol & $\begin{array}{r}\text { Peso de } \\
\text { 1 c-mol }\end{array}$ \\
\hline ácido oxálico & $\mathrm{C}_{2} \mathrm{H}_{2} \mathrm{O}_{4}$ & $\mathrm{CHO}_{2}$ & $45 \mathrm{~g}$ \\
ácido fórmico & $\mathrm{CH}_{2} \mathrm{O}_{2}$ & $\mathrm{CH}_{2} \mathrm{O}_{2}$ & $46 \mathrm{~g}$ \\
ácido acético & $\mathrm{C}_{2} \mathrm{H}_{4} \mathrm{O}_{2}$ & $\mathrm{CH}_{2} \mathrm{O}$ & $30 \mathrm{~g}$ \\
glucosa & $\mathrm{C}_{6} \mathrm{H}_{12} \mathrm{O}_{6}$ & $\mathrm{CH}_{2} \mathrm{O}$ & $30 \mathrm{~g}$ \\
glicerol & $\mathrm{C}_{3} \mathrm{H}_{8} \mathrm{O}_{3}$ & $\mathrm{CH}_{2.66} \mathrm{O}$ & $30.66 \mathrm{~g}$ \\
etanol & $\mathrm{C}_{2} \mathrm{H}_{6} \mathrm{O}$ & $\mathrm{CH}_{3} \mathrm{O}_{0.5}$ & $23 \mathrm{~g}$ \\
metanol & $\mathrm{CH}_{4} \mathrm{O}$ & $\mathrm{CH}_{4} \mathrm{O}$ & $32 \mathrm{~g}$ \\
metano & $\mathrm{CH}_{4}$ & $\mathrm{CH}_{4}$ & $16 \mathrm{~g}$ \\
isoleucina & $\mathrm{C}_{6} \mathrm{H}_{13} \mathrm{O}_{2} \mathrm{~N}$ & $\mathrm{CH}_{2.16} \mathrm{O}_{0.33} \mathrm{~N}_{0.17}$ & $21,82 \mathrm{~g}$ \\
alanina & $\mathrm{C}_{3} \mathrm{H}_{7} \mathrm{O}_{2} \mathrm{~N}$ & $\mathrm{CH}_{2.33} \mathrm{O}_{0.33} \mathrm{~N}_{0.17}$ & $21,99 \mathrm{~g}$ \\
\hline
\end{tabular}

Tabla 2.1: Valores en gramos de 1 c-mol de distintas fuentes de carbono

\section{Balances estequiométricos}

En base a la definición de c-mol, se puede representar a la biorracción mediante una reacción química, donde intervienen como sustratos una fuente de carbono y energía (FCE), una fuente de nitrógeno (FN) y oxígeno (en reacciones aeróbicas), y a su vez son productos la biomasa, metabolitos secundarios, dióxido de carbono, agua, protones y energía (calor). Otros microelementos como sales y vitaminas, aunque esenciales, no se consideran en el balance.

Por ejemplo, la reacción

$$
\underbrace{\mathrm{CH}_{2} \mathrm{O}}_{F C E}+\underbrace{\mathrm{aNH}_{4}^{+}}_{F N}+\mathrm{bO}_{2} \longrightarrow \underbrace{\mathrm{cCH}_{1.8} \mathrm{O}_{0.5} \mathrm{~N}_{0.2}}_{\text {biomasa }}+\underbrace{\mathrm{dCH}_{3} \mathrm{O}_{0.5}}_{\text {producto }}+\mathrm{eCO}_{2}+\mathrm{gH}^{+}+\mathrm{wH}_{2} \mathrm{O}+\text { calor }
$$

describe a un microorganismo estándar creciendo en glucosa y amonio, y dando como subproductos etanol y dióxido de carbono. Todos los compuestos figuran con su fórmula mínima, siendo los coeficientes $c, d, e, g \mathrm{y} w$ las cantidades de c-moles de cada sustancia obtenibles a partir de 1 c-mol de fuente de carbono, y $a$ y $b$ las cantidades de moles de fuente de nitrógeno y oxígeno necesarias para obtenerlas. Dichos coeficientes se conocen como rendimientos, la nomenclatura más aceptada para cada uno es $Y_{i / j} \circ Y_{i j}$ donde $i$ corresponde a un producto y $j$ a un sustrato. En particular, $c=Y_{x s}, d=Y_{p s}$ y $e=Y_{c o_{2} s}$. Los coeficientes $a$ y $b$ indican las cantidades necesarias de FN y oxígeno para obtener $c$ c-mol de biomasa a partir de $1 \mathrm{c}$ mol de glucosa. De manera similar se pueden obtener rendimientos que indiquen la cantidad de producto o biomasa obtenible a partir de dichas fuentes. Éstos se pueden obtener como $Y_{x n}=\frac{c}{a}, Y_{x o}=\frac{b}{a}$. Así calculados estos rendimientos tienen unidades en [c-mol/c-mol] (o de [c-mol/mol] para $Y_{x n}$ y $Y_{x o}$ ), para transformarlos a gramos basta con multiplicar y dividir por las masas de $1 \mathrm{c}$-mol de producto y $1 \mathrm{c}$-mol de sustrato:

$$
y_{i j}=Y_{i j} \cdot \frac{\text { masa de } 1 \mathrm{c}-\mathrm{mol} \text { de } i}{\text { masa de } 1 \mathrm{c}-\mathrm{mol} \mathrm{de} j}
$$




\begin{tabular}{ll}
\hline Reacción de oxidación & $\gamma$ \\
\hline $\mathrm{C}+\mathrm{O}_{2} \longrightarrow \mathrm{CO}_{2}$ & 4 \\
$\mathrm{CH}_{4}+2 \mathrm{O}_{2} \longrightarrow \mathrm{CO}_{2}+2 \mathrm{H}_{2} \mathrm{O}$ & 8 \\
$\mathrm{CO}+0.5 \mathrm{O}_{2} \longrightarrow \mathrm{CO}_{2}$ & 2 \\
$\mathrm{CH}_{2} \mathrm{O}+\mathrm{O}_{2} \longrightarrow \mathrm{CO}_{2}+\mathrm{H}_{2} \mathrm{O}$ & 4 \\
$\mathrm{CH}_{3} \mathrm{O}_{0.5}+1.5 \mathrm{O}_{2} \longrightarrow \mathrm{CO}_{2}+1.5 \mathrm{H}_{2} \mathrm{O}$ & 6 \\
$\mathrm{CH}_{2.5} \mathrm{ON}_{0.5}+0.75 \mathrm{O}_{2} \longrightarrow \mathrm{CO}_{2}+0.5 \mathrm{H}_{2} \mathrm{O}+0.5 \mathrm{NH}_{3}$ & 3 \\
$\mathrm{CH}_{1.8} \mathrm{O}_{0.5} \mathrm{~N}_{0.2}+1.05 \mathrm{O}_{2} \longrightarrow \mathrm{CO}_{2}+0.6 \mathrm{H}_{2} \mathrm{O}+0.2 \mathrm{NH}_{3}$ & 4.2 \\
\hline
\end{tabular}

Tabla 2.2: Grados de reducción de compuestos orgánicos al oxidarse.

siendo $y_{i j}$ un rendimiento expresado en $\left[\mathrm{gg}^{-1}\right]$.

Observación 1: Algunos de los rendimientos se pueden medir al comparar las cantidades iniciales y finales de cada sustrato y producto en un cultivo batch:

$$
y_{x s}=\frac{\Delta x}{\Delta s} \quad y_{x n}=\frac{\Delta x}{\Delta n} \quad y_{p s}=\frac{\Delta p}{\Delta s} \quad y_{p n}=\frac{\Delta p}{\Delta n}
$$

Los rendimientos de la reacción (2.13) deben ser tales que las cantidades de cada compuesto de un lado y otro de la ecuación sean los mismos. Son de particular interés el balance de carbono y el balance de grado de reducción.

\section{Balance de carbono}

El balance de carbono indica que la cantidad de c-moles de carbono a un lado y otro de la reacción debe ser el mismo, que se verifica si

$$
Y_{x s}+Y_{p s}+Y_{c o_{2} s}=1
$$

O bien, expresado en gramos

$$
y_{x s}+y_{p s}+y_{\mathrm{co}_{2} s}=12 \mathrm{~g} \text {. }
$$

\section{Balance de grado de reducción}

Al oxidar un compuesto el grado de reducción es el número de electrones disponibles para transferir al oxígeno por c-mol del compuesto. Para calcularlo basta con sumar el número de electrones que cada elemento de la molécula puede ceder, es decir, $\mathrm{C}=4, \mathrm{H}=1, \mathrm{O}=-2$ (porque los recibe) y $\mathrm{N}=-3$. En la Tabla 2.2 se muestran las reacciones de oxidación para algunos compuestos y sus correspondientes grados de reducción $\gamma$. 
Algunos compuesto como el $\mathrm{CO}_{2}, \mathrm{H}_{2} \mathrm{O}$ y $\mathrm{NH}_{3}$ tienen $\gamma=0$. De manera general si el compuesto tiene una fórmula mínima $\mathrm{CH}_{\mathrm{a}} \mathrm{O}_{\mathrm{b}} \mathrm{N}_{\mathrm{c}}$, y la reacción de oxidación es

$$
\mathrm{CH}_{\mathrm{a}} \mathrm{O}_{\mathrm{b}} \mathrm{N}_{\mathrm{c}}+\mathrm{nO}_{2} \longrightarrow \mathrm{dCO}_{2}+\mathrm{eH}_{2} \mathrm{O}+\mathrm{fNH}_{3}
$$

el grado de reducción será

$$
\gamma=4+a-2 b-3 c
$$

El balance de grados de reducción implica que el número de electrones disponibles a un lado y otro de una reacción (como (2.13)) deben ser iguales, entonces

$$
\gamma_{s}-4 b=y_{x s} \gamma_{x}+y_{p s} \gamma_{p}
$$

o bien

$$
\frac{y_{x s} \gamma_{x}+y_{p s} \gamma_{p}+4 b}{\gamma_{s}}=1
$$

Se debe tener en cuenta que (2.19) se obtiene al considerar al $\mathrm{NH}_{3}$ como producto de la oxidación, en caso de obtenerse $\mathrm{N}_{2} \mathrm{u}$ otro compuesto se deberá cambiar el balance de manera acorde.

\subsubsection{Cinética del crecimiento microbiano}

La reacción (2.13) también puede expresar las velocidades de consumo y producción

$$
\begin{aligned}
\mathrm{r}_{\mathrm{s}} \mathrm{CH}_{2} \mathrm{O}+\mathrm{r}_{\mathrm{n}} \mathrm{NH}_{4}^{+}+\mathrm{r}_{\mathrm{o} 2} \mathrm{O}_{2} \longrightarrow & \\
& \mathrm{r}_{\mathrm{x}} \mathrm{CH}_{1.8} \mathrm{O}_{0.5} \mathrm{~N}_{0.2}+\mathrm{r}_{\mathrm{p}} \mathrm{CH}_{3} \mathrm{O}_{0.5}+\mathrm{r}_{\mathrm{co} 2} \mathrm{CO}_{2}+\mathrm{r}_{\mathrm{w}} \mathrm{H}_{2} \mathrm{O}+\mathrm{r}_{\mathrm{h}} \mathrm{H}^{+}+\mathrm{r}_{\mathrm{q}} \text { calor }
\end{aligned}
$$

donde se puede ver que las tasas volumétricas están relacionadas entre sí a través de los rendimientos como se expresaba en (2.11c). O sea, teniendo un modelo de $r_{x}$ es posible obtener el resto de las velocidades.

Los modelos cinéticos para tasas volumétricas son en esencia empíricos y es uno de los puntos de más incertidumbre del proceso. Estos modelos deben respetar algunas restricciones físicas para ser válidos [62]:

1. Todas las concentraciones deben ser positivas.

2. Las concentraciones deben permanecer acotadas si la masa entrando al reactor también lo está.

3. La tasa tiene que ser nula si está ausente uno de los reactivos esenciales para la reacción.

Sea $\xi$ el vector de estados que contiene a las concentraciones del proceso y $\xi_{\max }$ y $\xi_{\min }$ 
sus cotas máximas y mínimas respectivamente, las primeras dos condiciones se cumplen si

$$
\begin{aligned}
& \xi_{i}=\xi_{\text {min }} \Rightarrow \dot{\xi} \geq 0 \\
& \xi_{i}=\xi_{\text {max }} \Rightarrow \dot{\xi} \leq 0 .
\end{aligned}
$$

Por otra parte, si los estados $\xi_{1}$ a $\xi_{j}$ son esenciales para la reacción, la tercera condición se cumple si el modelo es factorizable en esos estados:

$$
r_{i}(\xi)=\prod_{n=1}^{j} \xi_{n} v(\xi),
$$

donde $v(\xi)$ es una dada función de los estados (esenciales y no esenciales). Como la biomasa es siempre esencial en la reacción lo más aceptado es definir

$$
r_{i}(\xi)=q_{i}(\xi) x
$$

donde a las $q_{i}$ se las llama velocidades específicas, y son tasas de reacción por célula en [1/h]. Para la velocidad específica de crecimiento $\left(q_{x}\right)$ se utiliza la letra $\mu$, luego el resto de las tasas específicas son proporcionales a ella como en $(2.11 c)$ :

$$
\mathbf{q}=\mathbf{K} \mu
$$

donde $\mathbf{q}$ es un vector que contiene a todas las tasas específicas del proceso, $\mathbf{K}$ es la matriz de rendimientos y $\boldsymbol{\mu}$ es un vector con las tasas de las reacciones principales. Por ejemplo, teniendo crecimiento y producción de un metabolito no ligado al crecimiento, tendremos dos tasas específicas independientes $\mu$ y $q_{p}$, luego las matrices se plantean como

$$
\begin{aligned}
& \mathbf{q}^{T}=\left[\begin{array}{lllllllll}
\mu & q_{p} & q_{s 1} & q_{s 2} & \cdots & q_{s n} & q_{p 1} & \cdots & q_{p m}
\end{array}\right] \\
& \mathbf{K}^{T}=\left[\begin{array}{llllll}
1 & 0 & k_{11} & k_{12} & \cdots & k_{1 m} \\
0 & 1 & k_{21} & k_{22} & \cdots & k_{2 m}
\end{array}\right] \\
& \boldsymbol{\mu}^{T}=\left[\begin{array}{ll}
\mu & q_{p}
\end{array}\right] \text {. }
\end{aligned}
$$

Observación 2: Se puede notar que dividiendo a (2.11c) por $x$ se obtiene (2.25c). En relación a la estequiometría del crecimiento, se puede notar que los rendimientos $k$ son simplemente las inversas de los rendimientos y. Esto se ilustra con un ejemplo: supóngase que se tiene la siguiente reacción donde $S$ es la FCE, $N$ la FN, se produce como metabolito secundario dióxido de carbono, pero además hay producción de un metabolito $P$ no ligado al crecimiento celular:

$$
\begin{aligned}
& k_{11} S+k_{12} N \stackrel{r_{x}}{\longrightarrow} X+k_{13} \mathrm{CO}_{2} \\
& k_{21} S+k_{22} N \stackrel{r_{p}}{\longrightarrow} P+k_{23} \mathrm{CO}_{2},
\end{aligned}
$$




\begin{tabular}{lc|lc}
\hline & \multicolumn{2}{c}{ Sin inhibición } & \multicolumn{2}{c}{ Con inhibición } \\
\hline Nombre & Modelo normalizado $\left(\mu / \mu_{\text {max }}\right)$ & Nombre & Modelo normalizado $\left(\mu / \mu_{\max }\right)$ \\
\hline Monod & $\frac{s}{k_{s}+s}$ & Haldane & $\frac{s}{k_{s}+s+\frac{s^{2}}{k_{i}}}$ \\
Blackman & $\min \left(1, k_{s} S\right)$ & Levenspiel, Luong & $\left(1-\frac{c_{i}}{k_{i}}\right)^{N}$ \\
Teissier & $1-e^{-k_{s} s}$ & Teissier & $e^{\frac{c_{i}}{k_{i}}}-e^{-k_{s} s}$ \\
& $\frac{s^{N}}{k_{s}^{N}+s^{N}}$ & Ierusalimsky & $\frac{k_{i}}{k_{i}+c_{i}}$ \\
\hline
\end{tabular}

Tabla 2.3: Modelos cinéticos

luego es claro que

$$
\begin{array}{lll}
k_{11}=y_{x s}^{-1} & k_{12}=y_{x n}^{-1} & k_{13}=y_{c 0_{2} s}^{-1} \\
k_{21}=y_{p s}^{-1} & k_{22}=y_{p n}^{-1} & k_{23}=y_{c o_{2} p}^{-1}
\end{array}
$$

Volviendo a los modelos cinéticos, la Tabla 2.3 detalla algunos de los más comunes encontrados en la bibliografía [2, 64]. Los modelos aparecen normalizados respecto al parámetro $\mu_{\max }$.

Los modelos de la columna izquierda de la tabla son modelos sin inhibición, se considera un único sustrato que domina la reacción y la expresión describe una función monótonamente creciente (modelos monótonos). Entre ellos el modelo de Monod es uno de los más utilizados, tiene una expresión similar a la ley de Michaelis-Menten que describe la cinética de enzimas. Sin embargo, a diferencia del de Michaelis-Menten, el modelo de Monod es un modelo netamente empírico. El modelo de Mosser es una generalización del modelo de Monod y suele ser utilizado cuando se usan sustratos gaseosos. En los modelos sin inhibición la tasa de crecimiento o producción está limitada por la tasa a la que el microorganismo incorpora el sustrato. En las cinéticas con inhibición se contempla el efecto negativo que puede tener un exceso de sustrato en el crecimiento, como en el modelo de Haldane, o bien la presencia de un inhibidor de concentración $c_{i}$. Este tipo de cinéticas están descriptas por funciones no monótonas y existirán concentraciones óptimas a las que se expresa la máxima tasa de reacción.

La Figura 2.5 muestra ejemplos de las cinéticas de Monod, Haldane y Teissier (cuando la inhibe el mismo sustrato) para un único sustrato $s$. Se puede notar que para el modelo de Monod la máxima tasa de reacción se alcanza para valores moderadamente grandes de $s$ teniendo en cuenta que la constante de saturación en general es $k_{s} \ll 1 \mathrm{~g} / 1$. En particular cuando $s=k_{s}$ se obtiene una tasa igual a la mitad de la máxima. No es extraño entonces 


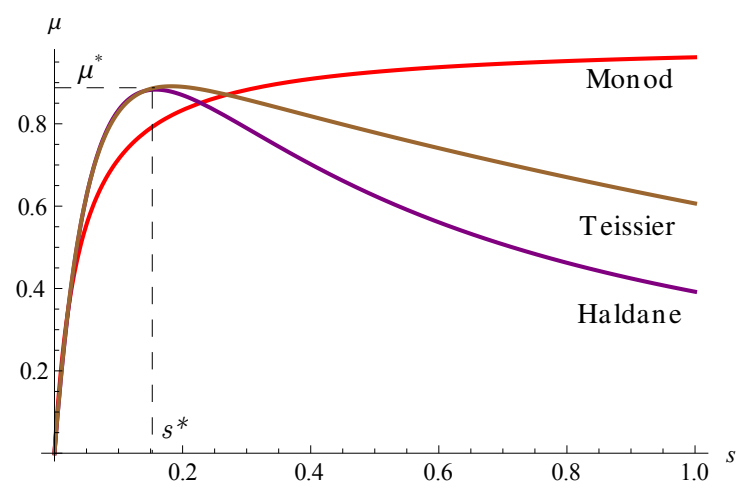

Figura 2.5: Ejemplos de cinéticas de Monod, Haldane y Teissier con inhibición

que en un cultivo batch se opere a la máxima velocidad hasta que prácticamente se agota el sustrato. El modelo de Haldane en cambio, muestra una tasa máxima cuando la concentración de sustrato es $s^{*}=\sqrt{k_{s} k_{i}}$ y la tasa máxima (normalizada) es $s^{*} /\left(2 k_{s}+s^{*}\right)$.

Usualmente, en estos modelos se tiene en cuenta el efecto de un único sustrato sobre la reacción. Esto se debe a que el resto de los sustratos se encuentran en abundancia en el medio de cultivo, siendo $s$ el único sustrato limitante. Sin embargo, se puede contabilizar el efecto de varios sustratos o inhibidores sobre la reacción. La combinación de cinéticas se puede hacer de varias maneras [2]:

- Interactiva: La tasa total es el producto de las tasas parciales

$$
\mu\left(s_{1}, s_{2}, s_{3}, \ldots, s_{n}\right)=\mu_{\max } \prod_{i=1}^{n} \mu_{i}\left(s_{i}\right),
$$

donde $\mu_{i}\left(s_{i}\right)$ son tasas normalizadas y $\mu_{\max }$ es la tasa máxima.

- No-Interactiva: La tasa más lenta domina por sobre las otras tasas

$$
\mu\left(s_{1}, s_{2}, s_{3}, \ldots, s_{n}\right)=\min \left(\mu_{i}\left(s_{i}\right)\right)
$$

En este caso las $\mu_{i}$ no están normalizadas y cada una tiene su propia $\mu_{i \max }$

- Aditiva: La tasa total es la suma de las tasas parciales

$$
\mu\left(s_{1}, s_{2}, s_{3}, \ldots, s_{n}\right)=\sum_{i=1}^{n} \mu_{i}\left(s_{i}\right) .
$$

Nuevamente las $\mu_{i}$ no están normalizadas. 


\subsubsection{Modelo final para biorreactores de tanque agitado}

Combinando los modelos estequiométricos y cinéticos, se puede obtener el modelo final para un reactor de tanque agitado. Por simplicidad el modelo final se expresa matricialmente utilizando los elementos expuestos en las secciones anteriores

$$
\dot{\xi}=K r(\xi)+D\left(\xi_{f}-\xi\right)-Q
$$

o de manera alternativa

$$
\dot{\xi}=K \mu(\xi) x+D\left(\xi_{f}-\xi\right)-Q,
$$

donde $\xi$ es el vector de estados cuyos elementos son las concentraciones, $K$ es la matriz de rendimientos definida en (2.25c), $r(\xi)$ es el vector de velocidades volumétricas definido en (2.11c), $\boldsymbol{\mu}$ es el vector de velocidades específicas definido en (2.25c), $\xi_{f}$ es el vector con las concentraciones de entrada de los estados (carbono, nitrógeno, etc.) y $Q$ es un vector que contiene los flujos de fase líquida a gaseosa (oxígeno, dióxido de carbono, hidrógeno, etc.). Si el proceso tiene $m$ estados y $p$ reacciones entonces $\xi, \xi_{f}$ y $Q \in \mathbb{R}^{m}, r(\xi) \in \mathbb{R}^{p}$ y $K \in \mathbb{R}^{m \times p}$.

A continuación se dan algunos ejemplos ilustrativos.

Ejemplo 1: crecimiento y producción asociada al crecimiento

En este caso tenemos una FCE representada por $S$, una FN representada por $N$ y como productos tenemos a la biomasa $X$ y un metabolito secundario $P$ asociado al crecimiento, por ejemplo $\mathrm{CO}_{2}$. La reacción simplificada sería

$$
S+N \stackrel{\mu}{\longrightarrow} X+P
$$

El modelo para un biorreactor fed-batch al que se le suministran FCE y FN mediante la misma bomba es

$$
\left\{\begin{array}{l}
\dot{x}=\mu x-D x \\
\dot{s}=-\frac{\mu x}{y_{x s}}+D\left(s_{f}-s\right) \\
\dot{n}=-\frac{\mu x}{y_{x n}}+D\left(n_{f}-n\right) \\
\dot{p}=\frac{\mu x}{y_{x p}}-D p .
\end{array}\right.
$$

El modelo de volumen se omite, ya que es igual que en (2.6). Aquí se puede observar que $r_{s}=\frac{\mu x}{y_{x s}}$ y $r_{n}=\frac{\mu x}{y_{x n}}$. 


\section{Ejemplo 2: crecimiento y producción no asociada al crecimiento}

Este caso es similar al anterior con la diferencia que el producto no está ligado al crecimiento y presenta una cinética independiente:

$$
\begin{aligned}
& S+N \stackrel{\mu}{\longrightarrow} X \\
& S+N \stackrel{q_{p}}{\longrightarrow} P .
\end{aligned}
$$

El modelo para un fed-batch como el del ejemplo anterior es

$$
\left\{\begin{array}{l}
\dot{x}=\mu x-D x \\
\dot{p}=q_{p} x-D p \\
\dot{s}=-\frac{\mu x}{y_{x s}}+\frac{q_{p} x}{y_{p s}}+D\left(s_{f}-s\right) \\
\dot{n}=-\frac{\mu x}{y_{x n}}+\frac{q_{p} x}{y_{p n}}+D\left(n_{f}-n\right)
\end{array}\right.
$$

El modelo de volumen se omite, es igual que en (2.6). Si analizamos las velocidades volumétricas para los sustratos en este ejemplo son $r_{s}=\left(\frac{\mu}{y_{x s}}+\frac{q_{p}}{y_{p s}}\right) x$ y $r_{n}=\left(\frac{\mu}{y_{x n}}+\frac{q_{p}}{y_{p n}}\right) x$. 


\section{|| Capítulo 3 \\ Modelizado de bioprocesos de alta densi- dad celular y de producción de bioplásticos}

En este capítulo se trata el modelizado de procesos de alta densidad celular. Se presenta como caso de estudio de la tesis al proceso de producción de bioplásticos mediante Cupriavidus necator y se describen sus modelos. Finalmente, se proponen nuevos modelos para la descripción de los volúmenes de fase líquida y biótica del biorreactor en procesos de alta densidad celular, parte de los cuales han sido publicados en [65]: Martín Jamilis, Fabricio Garelli, Md. Salatul Islam Mozumder, Castañeda Teresita y Hernán De Battista. Modeling and estimation of production rate for the production phase of non-growth-associated high cell density processes. Bioprocess and Biosystems Engineering, 38(10):1903-1914, 2015.

\subsection{Producción de bioplásticos}

Los materiales plásticos son actualmente una parte indispensable en nuestra vida y son utilizados en las más diversas áreas de aplicación. La producción de polímeros está basada mayormente en combustibles fósiles por procesos petroquímicos. Tanto los procesos de fabricación en sí como el hecho de ser materiales no-biodegradables traen aparejados un fuerte impacto ambiental. El creciente interés público en el medio ambiente, el cambio climático y el agotamiento de los recursos fósiles han incentivado la investigación en materiales alternativos a los derivados del petróleo. En cambio se busca obtener polímeros a partir de recursos renovables y que además sean fácilmente biodegradables [66].

Como alternativa a los plásticos convencionales surgen los bioplásticos. En general, son polímeros biobasados, biodegradables, o ambos. Esto quiere decir que han sido obtenidos a partir de recursos biológicos renovables, pudiendo ser biodegradables o no. O bien, que aún siendo derivados de recursos fósiles son biodegradables. Aunque los niveles de producción de bioplásticos no son aún comparables a los tradicionales derivados del petróleo, en este momento el mercado de bioplásticos crece un $30 \%$ anual [18]. Entre los polímeros biodegradables y obtenidos biológicamente se puede nombrar al almidón, celulosa, lignina, quitosano, 


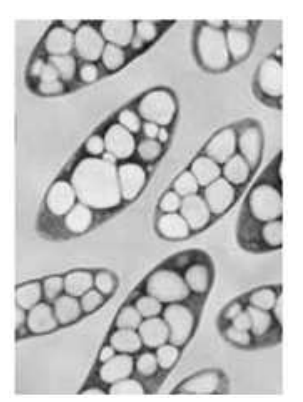

Figura 3.1: Fotografía de bacterias acumulando PHA. Por Njacquel (Own work) [CC BY-SA 3.0], via WikimediaCommons.

ácido poliláctico (PLA) y los polyhydroxyalkanoatos (PHAs) [18, 4].

El polihidroxibutirato (PHB) es un polímero de la familia de los PHAs, que puede ser sintetizado por fermentación bacteriana a partir de diversas fuentes de carbono y que es totalmente biodegradable tanto en condiciones aeróbicas como anaeróbicas. Un microorganismo modelo para la producción de PHB es Cupriavidus necator, antes conocido como Ralstonia eutropha, Wautersia eutropha y Alcaligenes eutropha. Esta bacteria es capaz de almacenar PHB intracelularmente en el citoplasma como un medio para asimilar y guardar fuente de carbono. En la Figura 3.1 se muestra una foto de las bacterias almacenando el polímero. El PHB tiene propiedades termoplásticas similares al polietileno y el polipropileno [66, 67]. Se han reportado aplicaciones prácticas como film de embalaje en bolsas, recipiente y recubrimiento de papel . También para elementos descartables como cubiertos, vasos, y recipientes de cosméticos y shampoo. Hay aplicaciones médicas para encapsulación de drogas y como soporte para crecimiento de tejidos $[68,69,70,71,72]$.

Al igual que otros bioplásticos, su comercialización se ve afectada por el elevado costo de producción en comparación con los plásticos derivados del petróleo [4]. Se ha reportado que el $50 \%$ del costo de producción está dado por la materia prima, de la cual el $80 \%$ es la fuente de carbono [66]. Por esta razón, la investigación se centra en el mejoramiento genético de los microorganismos para aumentar la productividad y en buscar fuentes de carbono baratas que permitan reducir los costos, por ejemplo, residuos de la producción agrícola o industrial.

La producción de PHB mediante culturas puras se puede realizar en un bioproceso de dos fases: crecimiento celular y producción del biopolímero. La fase de crecimiento consiste en mantener las concentraciones de sustrato en valores que favorecen el crecimiento celular. Debido a que la presencia de fuente de nitrógeno inhibe fuertemente la producción de PHB [73], en esta etapa la generación de producto es muy baja. La etapa de producción sigue a la de crecimiento y se caracteriza por las condiciones desfavorables para el crecimiento, es decir, se realiza privando a la bacteria de sustratos esenciales como nitrógeno, fosfato u oxígeno $[73,74,75]$. De esta manera, el crecimiento celular se detiene y se favorece la síntesis de PHB (no asociada al crecimiento), como mecanismo para continuar asimilando la FCE. En la presente tesis se muestran resultados para el proceso en el que se priva al microorganismo de nitrógeno [33]. Las fases de este proceso se esquematizan en la Figura 3.2. 


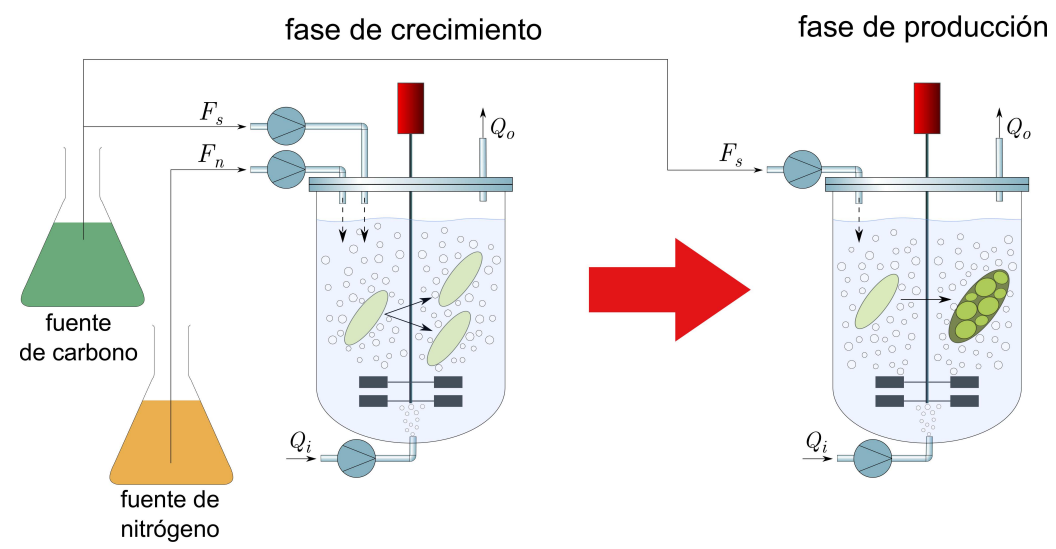

Figura 3.2: Esquema de fases del proceso de producción de PHB.

Como alternativa, se puede producir PHB a partir de culturas mixtas de manera asociada al crecimiento (en una única etapa). Este método permite reducir costos tanto en equipamiento como en energía al no requerir esterilización $[76,77,6]$. A pesar de estas ventajas, los rendimientos y productividades volumétricas son más bajas que las obtenidas con culturas puras y se producen otros metabolitos y polímeros extracelulares. Además, es necesaria una etapa de selección de microorganismos capaces de producir PHB, mediante ciclos de abundancia y escasez de sustratos [77, 78].

\subsection{Modelo para la producción de PHB}

En esta sección se detalla el modelo para un proceso de producción de PHB mediante cultura pura de Cupriavidus necator. El modelo original fue recientemente propuesto en [12, 79]. Se considera un STR al cual se suministra la FCE y la FN de manera independiente, dando lugar a los caudales $F_{s}$ y $F_{n}$ para cada una de ellas (ver Figura 3.2).

Este proceso de producción está marcado por dos reacciones bien distintas. Primero, el crecimiento sobre una fuente orgánica de carbono, que podría ser glucosa o glicerol. De manera general, se puede describir la fuente como $\mathrm{C}_{\mathrm{w}} \mathrm{H}_{\mathrm{x}} \mathrm{O}_{\mathrm{y}}$. Luego, la reacción para el crecimiento es

$$
\mathrm{C}_{\mathrm{w}} \mathrm{H}_{\mathrm{x}} \mathrm{O}_{\mathrm{y}}+\mathrm{bO}_{2}+\mathrm{cNH}_{4}^{+} \longrightarrow \mathrm{Y}_{\mathrm{xs}} \mathrm{CH}_{1.74} \mathrm{O}_{0.46} \mathrm{~N}_{0.19}+\mathrm{Y}_{\mathrm{co} 2 \mathrm{~s}} \mathrm{CO}_{2}+\mathrm{Y}_{\mathrm{ws}} \mathrm{H}_{2} \mathrm{O}+\mathrm{Y}_{\mathrm{hs}} \mathrm{H}^{+}
$$

donde $\mathrm{CH}_{1.74} \mathrm{O}_{0.46} \mathrm{~N}_{0.19}$ es la fórmula mínima de C. necator y

$$
\begin{aligned}
b & =4 w-\frac{y}{2}+\frac{x}{4}-1,91 Y_{x s} \\
c & =0,19 Y_{x s} \\
Y_{c 0_{2} s} & =w-Y_{x s} \\
Y_{w s} & =\frac{x-1,17 Y_{x s}}{2} \\
Y_{h s} & =0,19 Y_{x s} .
\end{aligned}
$$


son los coeficientes estequiométricos.

Durante la etapa de crecimiento se consume $\mathrm{O}_{2} \mathrm{y} \mathrm{NH}_{4}^{+}$como FN, como producto asociado se genera $\mathrm{CO}_{2}$. Además, $C$. necator puede crecer consumiendo el PHB producido, que también es un compuesto orgánico $\left(\mathrm{C}_{4} \mathrm{H}_{6} \mathrm{O}_{2}\right)$. La segunda reacción es propiamente la producción del PHB

$$
\mathrm{C}_{\mathrm{w}} \mathrm{H}_{\mathrm{x}} \mathrm{O}_{\mathrm{y}}+\mathrm{bO}_{2} \longrightarrow \mathrm{Y}_{\mathrm{ps}} \mathrm{C}_{4} \mathrm{H}_{6} \mathrm{O}_{2}+\mathrm{Y}_{\mathrm{co} 2 \mathrm{~s}} \mathrm{CO}_{2}+\mathrm{Y}_{\mathrm{ws}} \mathrm{H}_{2} \mathrm{O}
$$

donde $\mathrm{C}_{4} \mathrm{H}_{6} \mathrm{O}_{2}$ es la composición del monómero de PHB y

$$
\begin{aligned}
& b=w-\frac{y}{2}+\frac{x}{4}-4,5 Y_{p s} \\
& Y_{c o_{2} s}=w-4 Y_{p s} \\
& Y_{w s}=\frac{x}{2}-3 Y_{p s} \\
& Y_{h s}=0,19 Y_{p s} .
\end{aligned}
$$

Es interesante notar que la producción del biopolímero no requiere de FN. De hecho, la presencia del mismo inhibe la producción casi por completo.

El modelo macroscópico en término de las masas es

$$
\begin{aligned}
& \dot{X}=\left(\mu_{x s}+\mu_{x p}\right) X \\
& \dot{S}=-\left(\frac{\mu_{x s}}{y_{x s}}+\frac{q_{p}}{y_{p s}}\right) X+F_{s} s_{f} \\
& \dot{N}=-\frac{\mu_{x s}+\mu_{x p}}{y_{x n}} X+F_{n} n_{f} \\
& \dot{P}=\left(q_{p}-\frac{\mu_{x p}}{y_{x p}}\right) X
\end{aligned}
$$

donde $X$ es la biomasa residual, $P$ es el PHB, $S$ es la fuente de carbono y $N$ es la fuente de nitrógeno $\left(\mathrm{NH}_{4}^{+}\right)$. Las tasas específicas son $\mu_{x s}$ de crecimiento a partir de la FCE suministrada, $q_{p}$ de producción de PHB y además una segunda tasa de crecimiento $\mu_{x p}$ cuando se utiliza al PHB producido como FCE. La tasa de crecimiento total es por lo tanto $\mu=\mu_{x s}+\mu_{x p}$. El resto de los parámetros se detallan en la Tabla 3.1.

El modelo en términos de las concentraciones se obtiene de la misma manera que (2.3)

$$
\begin{aligned}
& \dot{x}=\left(\mu_{x s}+\mu_{x p}-D\right) x \\
& \dot{s}=-\left(\frac{\mu_{x s}}{y_{x s}}+\frac{q_{p}}{y_{p s}}\right) x-D s+\frac{F_{s}}{V} s_{f} \\
& \dot{n}=-\frac{\mu_{x s}+\mu_{x p}}{y_{x n}} x-D n+\frac{F_{n}}{V} n_{f} \\
& \dot{p}=\left(q_{p}-\frac{\mu_{x p}}{y_{x p}}\right) x-D p
\end{aligned}
$$




\begin{tabular}{llc}
\hline Nombre & Descripción & Unidades \\
\hline$X$ & Masa de biomasa residual & {$[\mathrm{g}]$} \\
$S$ & Masa de fuente de carbono & {$[\mathrm{g}]$} \\
$N$ & Masa de fuente de nitrógeno & {$[\mathrm{g}]$} \\
$P$ & Masa de PHB & {$[\mathrm{g}]$} \\
$x$ & Concentración de biomasa residual & {$[\mathrm{g} / 1]$} \\
$s$ & Concentración de fuente de carbono & {$[\mathrm{g} / 1]$} \\
$n$ & Concentración de fuente de nitrógeno & {$[\mathrm{g} / 1]$} \\
$p$ & Concentración de PHB & {$[\mathrm{g} / 1]$} \\
$F_{s}$ & Caudal de fuente de carbono & {$[1 / \mathrm{h}]$} \\
$F_{n}$ & Caudal de fuente de nitrógeno & {$[\mathrm{l} / \mathrm{h}]$} \\
$s_{f}$ & Concentración de fuente de carbono de alimentación & {$[\mathrm{g} / 1]$} \\
$n_{f}$ & Concentración de fuente de nitrógeno de alimentación & {$[\mathrm{g} / 1]$} \\
$\mu_{x s}$ & Velocidad específica de crecimiento consumiendo a $s$ & {$\left[\mathrm{~h}^{-1}\right]$} \\
$\mu_{x p}$ & Velocidad específica de crecimiento consumiendo a $p$ & {$\left[\mathrm{~h}^{-1}\right]$} \\
$q_{p}$ & Velocidad específica de producción de PHB & {$\left[\mathrm{h}^{-1}\right]$} \\
$V$ & Volumen de la fase líquida en el biorreactor & {$[1]$} \\
\hline
\end{tabular}

Tabla 3.1: Parámetros del modelo del proceso de producción de PHB.

donde la dilución está formalmente definida como

$$
D=\frac{\dot{V}}{V}
$$

El cálculo de $\dot{V}$ y $D$ da lugar a varios modelos cuya validez depende de las condiciones del proceso. Esta cuestión se aborda en la Sección 3.3.2.

Es muy conveniente definir como variable adicional al contenido intracelular o fracción de $\mathrm{PHB}^{1}$

$$
\begin{aligned}
& f_{p}=\frac{p}{x}=\frac{P}{X} \\
& \dot{f}_{p}=\left(q_{p}-\frac{\mu_{x p}}{y_{x p}}\right)-\left(\mu_{x s}+\mu_{x p}\right) f_{p} .
\end{aligned}
$$

Las velocidades específicas fueron originalmente propuestas en [79, 12] basándose en diversos trabajos previos [80, 81, 82, 83, 84], los modelos son una combinación del tipo

\footnotetext{
${ }^{1}$ Alternativamente se puede definir como $\frac{P}{P+X}$. Aquí, por conveniencia, se adopta la definición enunciada.
} 


\begin{tabular}{clrr}
\hline Nombre & Descripción & Valor & Unidades \\
\hline$y_{x s}$ & Rendimiento de FCE a biomasa & 0.48 & {$[\mathrm{~g} / \mathrm{g}]$} \\
$y_{x p}$ & Rendimiento de PHB a biomasa & 0.88 & {$[\mathrm{~g} / \mathrm{g}]$} \\
$y_{p s}$ & Rendimiento de FCE a PHB & 0.3 & {$[\mathrm{~g} / \mathrm{g}]$} \\
$y_{x n}$ & Rendimiento de FN a biomasa & 8.9 & {$[\mathrm{~g} / \mathrm{g}]$} \\
$\mu_{x s}^{\max }$ & Tasa de crecimiento máxima consumiendo FCE & 0.46 & {$\left[\mathrm{~h}^{-1}\right]$} \\
$\mu_{x p}^{\max }$ & Tasa de crecimiento máxima consumiendo PHB & 0.126 & {$\left[\mathrm{~h}^{-1}\right]$} \\
$q_{p}^{\text {max }}$ & Tasa de producción de PHB máxima & 0.126 & {$\left[\mathrm{~h}^{-1}\right]$} \\
$k_{s}$ & Constante de saturación de la FCE & 1.2 & {$[\mathrm{~g} / 1]$} \\
$k_{i s}$ & Constante de inhibición de la FCE & 16.728 & {$[\mathrm{~g} / 1]$} \\
$k_{n}$ & Constante de saturación de la FN & 0.254 & {$[\mathrm{~g} / 1]$} \\
$k_{i n}$ & Constante de inhibición de la FN & 1.5 & {$[\mathrm{~g} / 1]$} \\
$k_{p s}$ & Constante de saturación de la FCE (en producción) & 4.1 & {$[\mathrm{~g} / 1]$} \\
$k_{p i s}$ & Constante de inhibición de la FCE (en producción) & 80 & {$[\mathrm{~g} / 1]$} \\
$k_{p h b}$ & Constante de inhibición del PHB & 0.148 & {$[\mathrm{~g} / 1]$} \\
$k_{p i n}$ & Constante de inhibición de la FN (en producción) & 0.262 & {$[\mathrm{~g} / 1]$} \\
$\alpha$ & Parámetro cinético & 5.85 & \\
$\beta$ & Parámetro cinético & 3.85 & \\
$f_{p}^{\max }$ & Fracción de PHB máxima & 3.3 & {$\left[\mathrm{gg} \mathrm{g}^{-1}\right]$} \\
$X_{m}$ & Concentración de biomasa máxima & 68 & {$[\mathrm{~g} / \mathrm{l}]$} \\
\hline
\end{tabular}

Tabla 3.2: Valores de los parámetros del modelo macroscópico y de los modelos cinéticos.

interactiva de factores tipo Haldane, Monod, Ierusalimsky y Luong:

$$
\begin{aligned}
\mu_{x s} & =\mu_{x s}^{\max } \cdot \frac{s}{k_{s}+s+\frac{s^{2}}{k_{i s}}} \cdot \frac{n}{k_{n}+n+\frac{n^{2}}{k_{i n}}} \cdot\left[1-\left(\frac{x}{x_{m}}\right)^{\alpha}\right] \\
\mu_{x p} & =\mu_{x p}^{\max } \cdot \frac{f_{p}}{k_{p h b}+f_{p}} \cdot \frac{n}{k_{n}+n+\frac{n^{2}}{k_{i n}} \cdot\left[1-\left(\frac{x}{x_{m}}\right)^{\alpha}\right]} \\
q_{p} & =q_{p}^{\max } \cdot \frac{s}{k_{p s}+s+\frac{s^{2}}{k_{p i s}}} \cdot\left[1-\left(\frac{f_{p}}{f_{p}^{\max }}\right)^{\beta}\right] \cdot \frac{k_{p i n}}{n+k_{p i n}} .
\end{aligned}
$$

Los valores de todos los parámetros cinéticos están listados en la Tabla 3.2.

En muchos procesos se utilizan condiciones no balanceadas de alimentación, sometiendo al microorganismo a condiciones de estrés y favoreciendo la producción de un metabolito en particular. En una primera instancia se le provee al microorganismo de todos los nutrientes y sustratos necesarios para su crecimiento, luego se le niega alguno de los nutrientes o sustratos, forzando al microorganismo a activar una ruta alternativa que le permita asimilar los nutrientes disponibles en el medio y almacenarlos de alguna forma. Estas condiciones de alimentación se pueden aplicar sobre $C$. necator para favorecer el crecimiento en una fase y la producción en otra [12,33]. En (3.10c) se puede ver que el nitrógeno tiene un fuerte efecto 
inhibitorio sobre la tasa de producción de PHB (último factor). En contraste, en (3.10a) y (3.10b) se observa que el nitrógeno es esencial para el crecimiento, ya que su ausencia anula la tasa por completo. Este tipo de condiciones de alimentación se pueden observar también en la producción de lípidos para biodiesel de segunda generación utilizando la levadura Rhodosporidium toruloides. Al igual que con C. necator, la ausencia de FN previene el crecimiento y potencia la producción de los lípidos $[7,8,34]$. Teniendo en cuenta la alimentación no balanceada, se pueden simplificar los modelos (3.5) y (3.6) para cada una de las etapas del proceso.

\subsubsection{Modelo para la etapa de crecimiento}

En la etapa de crecimiento se le provee a la bacteria tanto FCE como FN. Además, se asume que la concentración inicial de producto es nula $\left(p(0)=0\right.$ ) y que por lo tanto $q_{p}=0, \mu_{p x} \approx 0$ y $\mu \approx \mu_{x s}$. Luego el modelo (3.6) queda reducido a

$$
\begin{aligned}
& \dot{x}=\left(\mu_{x s}-D\right) x \\
& \dot{s}=-\frac{\mu_{x s}}{y_{x s}} x-D s+\frac{F_{s}}{V} s_{f} \\
& \dot{n}=-\frac{\mu_{x s}}{y_{x n}} x-D n+\frac{F_{n}}{V} n_{f} .
\end{aligned}
$$

Además, las concentraciones óptimas de FCE y FN para obtener la máxima tasa específica de crecimiento son aquellas que maximizan los factores Haldane de (3.10a), es decir, $s^{*}=$ $\sqrt{k_{s} k_{i s}}=4,48 g / l$ y $n^{*}=\sqrt{k_{n} k_{i n}}=0,62 g / l$. Luego, la tasa de crecimiento máxima a esas concentraciones es

$$
\mu^{*}=0,16\left[1-\left(\frac{x}{x_{m}}\right)^{\alpha}\right]
$$

En (3.12) se puede ver que la tasa máxima de crecimiento depende de lo concentración de biomasa residual. A bajas concentraciones de $x$ se tiene $\mu^{*} \cong 0,16$. Sin embargo, a concentraciones cercanas a $x_{m}$ el efecto inhibitorio es pronunciado y la tasa de crecimiento (y su valor máximo) terminan por anularse. La concentración de microorganismos no puede superar $x_{m}$.

Al final de la fase de crecimiento se corta el suministro de FN. Las bacterias entonces consumen la FN restante en el biorreactor hasta agotarla. Sin embargo, se debe tener cuidado de no cortar el suministro cuando la concentración de microorganismos es muy cercana a la máxima, ya que sería imposible consumir toda la FN residual. Si la concentración de nitrógeno al final de la fase de crecimiento es $n\left(t_{f}\right)$, entonces la biomasa residual debe cumplir $x\left(t_{f}\right)<$ $y_{x n} \cdot n\left(t_{f}\right)$. La correcta elección del instante de corte se puede mejorar si se dispone de un monitoreo adecuado, que provea información de la tasa de crecimiento y concentración de microorganismos. 


\subsubsection{Modelo para la etapa de producción}

En la etapa de producción se le provee a la bacteria sólo FCE, siendo la concentración de FN nula $(n=0)$. De esta manera el crecimiento no es posible y por lo tanto $\mu_{x s}=\mu_{x p}=0$ (ver (3.10a) y (3.10b)). Luego, el modelo (3.6) queda reducido a

$$
\begin{aligned}
\dot{x} & =-D x \\
\dot{s} & =-\frac{q_{p}}{y_{p s}} x-D s+\frac{F_{s}}{V} s_{f} \\
\dot{p} & =q_{p} x-D p \\
\dot{f_{p}} & =q_{p} .
\end{aligned}
$$

De (3.10c) se deduce que la concentración óptima de FCE para maximizar $q_{p}$ es $s^{*}=\sqrt{k_{p s} k_{p i s}}=$ $18,11 \mathrm{~g} / \mathrm{l}$, quedando la velocidad de producción óptima

$$
q_{p}^{*}=0,042\left[1-\left(\frac{f_{p}}{f_{p}^{\max }}\right)^{\beta}\right] .
$$

Por lo tanto, a bajos contenidos de PHB, $q_{p}^{*} \cong 0,042$. Sin embargo, contenidos intracelulares elevados, cercanos al límite $f_{p}^{\max }$ inhiben la producción anulando $q_{p}$.

Se debe notar que al no haber crecimiento, la masa total de biomasa residual permanece constante, es decir, $\dot{X}=0$. Además de (3.13a) se puede deducir que

$$
D=-\frac{\dot{x}}{x}
$$

Esto será aprovechado en esta tesis para plantear un algoritmo de estimación en el Capítulo 5.

En la Figura 3.3 se muestran las superficies generadas al evaluar $\mu_{x s}$ al principio de la etapa de crecimiento y $q_{p}$ al principio de la etapa de producción.

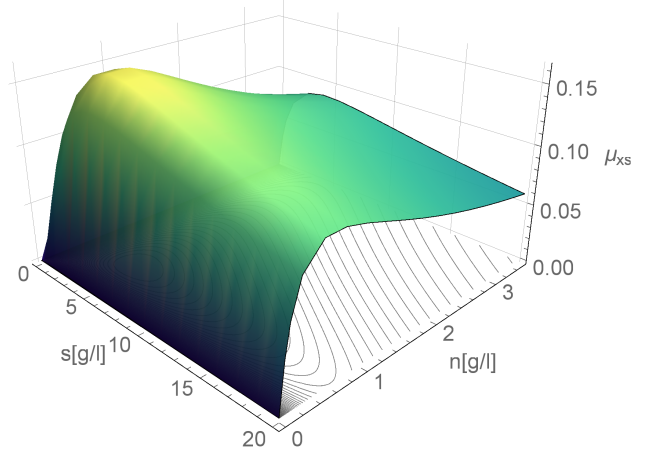

(a) Superficie de respuesta de $\mu_{x s}(x=0)$.

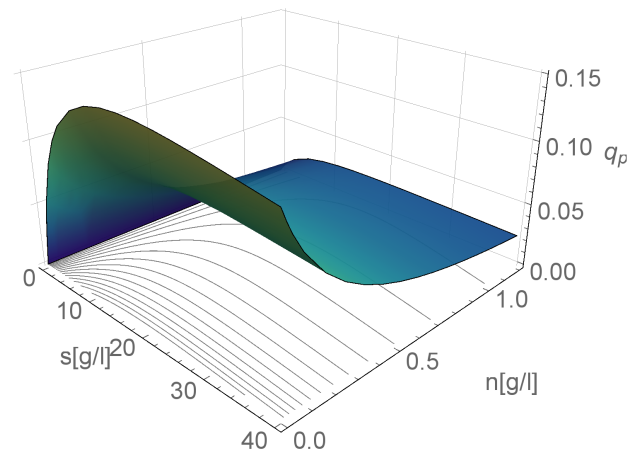

(b) Superficie de respuesta de $q_{p}\left(f_{p}=0\right)$.

Figura 3.3: Superficies de los modelos cinéticos. 


\subsection{Aportes a la modelización del volumen en alta densidad celular}

\subsubsection{Insuficiencias del modelo clásico}

Como se mencionó anteriormente, la forma más simple de modelizar los cambios en el volumen de un biorreactor es haciendo dos suposiciones:

1. El volumen de la fase biótica es despreciable frente al volumen de la fase líquida.

2. La densidad del medio de cultivo siendo alimentado al reactor es la misma que la de la fase líquida en el reactor.

Estas suposiciones son válidas siempre y cuando la concentración de biomasa total (incluyendo al producto intracelular) sea baja y el medio que se está alimentando no esté demasiado concentrado. Cualquier cultivo de baja densidad celular cumple con estas condiciones. En primer lugar, por la baja concentración de microorganismos. En segundo lugar, porque no es necesario alimentar medios de concentraciones excesivas al ser el requerimiento nutricional más bajo. En esas condiciones se considera que la variación en el volumen es la sumatoria de los caudales entrando y saliendo del biorreactor. En el caso del reactor fed-batch alimentado con caudales independientes de fuente de carbono y nitrógeno

$$
\dot{V}=F_{s}+F_{n}
$$

A pesar de que (3.16) es un modelo de volumen estándar para procesos fed-batch, siendo válido en una gran cantidad de situaciones y procesos, no es lo suficientemente preciso para describir el proceso de producción de PHB bajo estudio ni otros procesos de alta densidad celular. Para empezar, se está hablando de un proceso donde importa maximizar tanto la productividad en PHB como en biomasa residual. Esto quiere decir que se desea una gran cantidad final de producto, lo que requiere también de una gran cantidad de microorganismos produciéndolo. Se debe tener en cuenta que cada bacteria puede acumular producto hasta un cierto límite $\left(f_{p}^{\max }=3,3 \mathrm{~g} / \mathrm{g}\right)$. Por lo tanto, es necesario disponer de la mayor cantidad posible de fábricas celulares. Además, se debe tener en cuenta que el producto es intracelular. Es natural suponer que el almacenamiento de PHB tiene que resultar en un aumento en el volumen de cada célula. De hecho, se ha reportado que el incremento de volumen para $C$. necator es proporcional al producto acumulado (con proporción unitaria) [85]. Dado que el volumen de la fase biótica no es despreciable, el proceso no cumple con la primera suposición del modelo de volumen clásico.

Por otra parte, la gran cantidad de microorganismos que se pretende alcanzar conlleva un elevado consumo de sustrato ya que la velocidad volumétrica de consumo es proporcional a $x$ (ver Sección 2.6.3). Con el fin de evitar caudales de entrada que diluyan excesivamente los compuestos del medio ${ }^{2}$ y hagan aumentar demasiado el volumen líquido, es necesario utilizar

\footnotetext{
${ }^{2}$ Diluir en exceso puede convertir en sustratos limitantes a sustancias que se asumían en exceso
} 
elevadas concentraciones de sustrato de alimentación. De esta manera, para introducir una determinada masa de sustrato el caudal requerido es menor (inversamente proporcional). Por lo tanto, por su elevada concentración, el medio de cultivo de alimentación tendrá una densidad distinta a la del medio en el biorreactor, no cumpliendo la suposición de densidades de medios iguales.

Adicionalmente, se puede inferir que hay un cambio de volumen generado por la gran cantidad de FCE que es convertida a PHB. El rendimiento de conversión es lejano a la unidad y las densidades de la FCE y el PHB no necesariamente son las mismas.

\subsubsection{Modelo basado en volúmenes molares parciales}

Formalmente, para modelizar las variaciones del volumen de la fase líquida del biorreactor al alimentar con una solución concentrada hace falta una descripción físico-química de la solución y usar el concepto de volumen molar parcial [86]. El volumen molar parcial de un soluto A (el sustrato) en una solución de A y un solvente B se define como el cambio de volumen de la solución por mol de A agregado. El volumen molar parcial varía con la composición de la solución, pudiendo ir esta desde A puro hasta B puro. Formalmente la anterior definición se expresa como

$$
\bar{V}_{i}=\left.\frac{\partial V}{\partial m_{i}}\right|_{p, T, m^{\prime}}
$$

donde $m_{i}$ son los moles de la sustancia y $p, T, m^{\prime}$ significa que la presión, temperatura y cantidades de otras sustancias son constantes. Los volúmenes molares parciales usualmente se obtienen de manera experimental. Luego, cuando en una solución se agregan $d m_{A}$ moles de A y $d m_{B}$ moles de B, el volumen cambiará según

$$
d V=\bar{V}_{A} d m_{A}+\bar{V}_{B} d m_{B}
$$

o bien

$$
\dot{V}=\bar{V}_{A} \dot{m}_{A}+\bar{V}_{B} \dot{m}_{B}
$$

En caso de haber más compuestos en la solución se deben agregar más términos de la misma manera. En la producción de PHB las sustancias en la solución son la FCE, la FN y el agua, quedando entonces planteado

$$
\dot{V}=\bar{V}_{s} \dot{m}_{s}+\bar{V}_{n} \dot{m}_{n}+\bar{V}_{w} \dot{m}_{w}
$$


donde los subíndices $s, n$ y $w$ corresponden a la FCE, FN y agua respectivamente. A su vez

$$
\begin{aligned}
\dot{m}_{s} & =\frac{-r_{s} V+F_{s} s_{f}}{M_{s}} \\
\dot{m}_{n} & =\frac{-r_{n} V+F_{n} n_{f}}{M_{n}} \\
\dot{m}_{w} & =\frac{F_{s}\left(\rho_{s f}-s_{f}\right)}{M_{w}}+\frac{F_{n}\left(\rho_{n f}-n_{f}\right)}{M_{w}} .
\end{aligned}
$$

Las ecuaciones (3.21a) y (3.21b) surgen de dividir a (3.6b) y (3.6c) por sus respectivos pesos moleculares $M_{s}$ y $M_{n}$ (en $\mathrm{g} / \mathrm{mol}$ ). La obtención de (3.21c) es levemente más compleja. Los términos $F_{s} \rho_{s f}$ y $F_{n} \rho_{n f}$ corresponden a las masas de las soluciones entrando al biorreactor. Luego, se le restan los términos $F_{s} s_{f}$ y $F_{n} n_{f}$, que corresponden a las masas de FCE y FN entrando al biorreactor. El resultado es la masa de agua entrante, que luego se divide por su peso molecular.

Reemplazando (3.21) en (3.20) y agrupando términos, finalmente se obtiene la variación de volumen de la fase líquida del biorreactor

$$
\dot{V}_{l}=F_{s}\left[\frac{s_{f} \bar{V}_{s}}{M_{s}}+\frac{\left(\rho_{s f}-s_{f}\right) \bar{V}_{w}}{M_{w}}\right]+F_{n}\left[\frac{n_{f} \bar{V}_{n}}{M_{n}}+\frac{\left(\rho_{n f}-n_{f}\right) \bar{V}_{w}}{M_{w}}\right]-\left(\frac{r_{s}}{M_{s}}+\frac{r_{n}}{M_{n}}\right) V
$$

Luego, como el producto está contenido dentro de las células y éstas son inmiscibles en el medio líquido, el volumen total en el biorreactor es la suma del volumen de medio líquido y el de las células

$$
\begin{aligned}
& V=V_{l}+V_{c} \\
& \dot{V}=\dot{V}_{l}+\dot{V}_{c}
\end{aligned}
$$

donde $V$ es el volumen total, $V_{l}$ es el volumen del medio líquido y $V_{c}$ es el volumen de los microorganismos.

El cambio en el volumen de microorganismos depende a su vez del aumento en el número de células y por otra del incremento en el volumen de cada célula por acumulación de producto

$$
\dot{V}_{c}=\dot{V}_{x}+\dot{V}_{p}=\frac{\dot{X}}{\rho_{x}}+\frac{\dot{P}}{\rho_{p}}
$$

donde $V_{x}$ es el volumen de las células sin producto $\left(f_{p}=0\right), V_{p}$ es el volumen del producto, $\rho_{p}$ y $\rho_{x}$ son las densidades del producto y de las células respectivamente. Reemplazando (3.5a) y (3.5d) en (3.25) se obtiene

$$
\dot{V}_{c}=\left(\frac{r_{x}}{\rho_{x}}+\frac{r_{p}}{\rho_{p}}\right) V=\left(\frac{\left(\mu_{x s}+\mu_{x p}\right)}{\rho_{x}}+\frac{\left(q_{p}-\mu_{x p}\right)}{\rho_{p}}\right) x V
$$

A partir de (3.26) se puede deducir que el volumen de las células es significativo siempre y 


\begin{tabular}{llc}
\hline Nombre & Descripción & Unidades \\
\hline$\rho_{s f}$ & Densidad de la solución de FCE con concentración $s_{f}$ & {$[\mathrm{~g} / \mathrm{l}]$} \\
$\rho_{n f}$ & Densidad de la solución de FN con concentración $n_{f}$ & {$[\mathrm{~g} / \mathrm{l}]$} \\
$\rho_{s}$ & Densidad del medio con concentración de FCE $s$ & {$[\mathrm{~g} / \mathrm{l}]$} \\
$\rho_{p}$ & Densidad del PHB & {$[\mathrm{g} / \mathrm{l}]$} \\
$\rho_{x}$ & Densidad de las células & {$[\mathrm{g} / \mathrm{l}]$} \\
$M_{s}$ & Masa molecular de la FCE & {$[\mathrm{g} / \mathrm{mol}]$} \\
$M_{n}$ & Masa molecular de la FN & {$[\mathrm{g} / \mathrm{mol}]$} \\
$M_{w}$ & Masa molecular del agua & {$[\mathrm{g} / \mathrm{mol}]$} \\
$\bar{V}_{s}$ & Volumen molar parcial de la FCE & {$[1 / \mathrm{mol}]$} \\
$\bar{V}_{n}$ & Volumen molar parcial de la FN & {$[1 / \mathrm{mol}]$} \\
$\bar{V}_{w}$ & Volumen molar parcial del agua & {$[1 / \mathrm{mol}]$} \\
\hline
\end{tabular}

Tabla 3.3: Parámetros de los modelos de volumen para procesos de alta densidad.

cuando la densidad celular sea grande $(x)$, o bien, lo sea la masa total celular $(X=x V)$, siempre acompañado por tasas de crecimiento o producción altas.

Finalmente la dinámica del volumen se obtiene reemplazando (3.26) y (3.22) en (3.24)

$$
\begin{array}{r}
\dot{V}=F_{s}\left[\frac{s_{f} \bar{V}_{s}}{M_{s}}+\frac{\left(\rho_{s f}-s_{f}\right) \bar{V}_{w}}{M_{w}}\right]+F_{n}\left[\frac{n_{f} \bar{V}_{n}}{M_{n}}+\frac{\left(\rho_{n f}-n_{f}\right) \bar{V}_{w}}{M_{w}}\right] \\
-\left(\frac{r_{s}}{M_{s}}+\frac{r_{n}}{M_{n}}\right) V+\left(\frac{r_{x}}{\rho_{x}}+\frac{r_{p}}{\rho_{p}}\right) V
\end{array}
$$

En la Tabla 3.3 se repasan los parámetros del modelo.

El modelo de volúmenes molares parciales desarrollado contempla las características propias de un proceso de alta densidad celular. Tiene en cuenta la contracción de volumen por mezclar medios de distintas densidades, el volumen de la fase biótica y el consumo de sustrato. Sin embargo, los volúmenes molares parciales no son fáciles de conocer, su obtención es empírica y además tienen una variación no lineal con la concentración de los sustratos en el biorreactor. Por ende, aunque el modelo es formalmente correcto, es poco práctico para la implementación de algoritmos de estimación y control.

\subsubsection{Propuesta de modelo práctico para la etapa de crecimiento}

Durante la etapa de crecimiento la variación de volumen por diferencia de densidades en los medios es más notable que por el incremento en la biomasa, especialmente cuando su concentración es baja. En [12] se propone que la variación del volumen corresponde únicamente a la cantidad de agua ingresada al biorreactor, considerando que el sustrato ingresado con la solución es consumida y no aporta al volumen. Proponiendo como modelo

$$
\dot{V}=F_{s} \frac{\rho_{s f}-s_{f}}{\rho_{w}}+F_{n} \frac{\rho_{n f}-n_{f}}{\rho_{w}}
$$


donde $\rho_{s f}$ y $\rho_{n f}$ son las densidades de las soluciones de FCE y FN en los reservorios y $\rho_{w}$ es la densidad del agua. Los términos $F_{s} \rho_{s f}$ y $F_{n} \rho_{n f}$ representan masas (por unidad de tiempo) de solución alimentada (sustrato+agua), a eso se le resta $F_{s} s_{f}$ y $F_{n} n_{f}$ que son las masas por unidad de tiempo de la FCE y FN respectivamente. Al hacer la diferencia entre las masas de solución y de sustrato se obtiene la masa de agua ingresando al biorreactor. Finalmente, al dividir por su densidad se obtiene el volumen.

El modelo (3.28) es tal vez una mejor representación que la del modelo clásico dado en (3.16). Sin embargo, continúa siendo muy simplista en cuanto a que no es agua pura el medio de cultivo que se ingresa al biorreactor, ni el que se encuentra en su interior. Además, no se consideran los cambios de volumen por el sustrato consumido.

En esta tesis se propone un modelo que aproxima mejor al fenómeno real, al considerar el volumen de solución ingresada que tiene la misma concentración que el medio en el biorreactor. Tómese el caso de la fuente de carbono, que se alimenta en una solución concentrada cuya concentración es $s_{f}$. Dentro del biorreactor la FCE se encuentra diluida con una concentración $s \ll s_{f}$. Entonces, se desea calcular el volumen de solución ingresada al biorreactor que tiene la concentración de la diluida $s$. El volumen de solución diluida ingresada es virtual, no existe físicamente como tal pero nos da una mejor idea del cambio de volumen debido al caudal de entrada. La Figura 3.4 esquematiza este concepto.

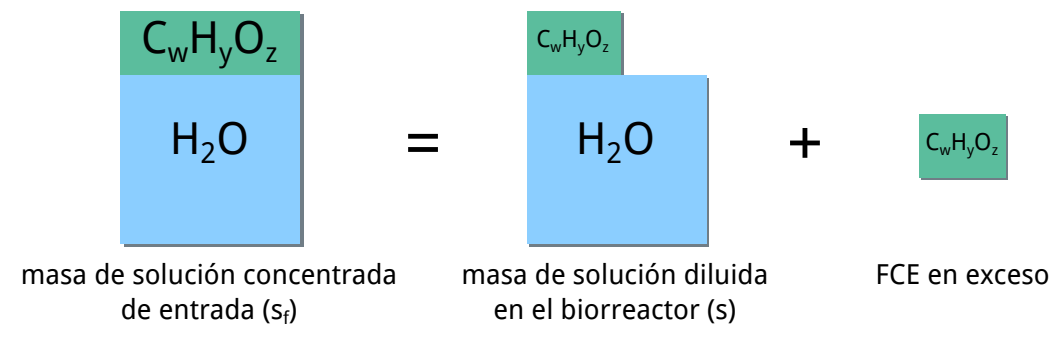

Figura 3.4: Esquema de masa equivalente de solución diluida.

El cálculo de la solución diluida de entrada (virtual) se obtiene de plantear balances de masa en el caudal de alimentación. Si llamamos $M_{s_{f}}$ a la masa de solución concentrada agregada al biorreactor con concentración $s_{f}, M_{s}$ a la masa de solución diluida (virtual) con concentración $s$ y $M_{\text {exc }}$ a la masa de FCE no diluida sobrante (excedente), luego se puede expresar

$$
M_{s_{f}}=M_{s}+M_{e x c} .
$$

Luego, (3.29) se puede expresar en términos de volúmenes, densidades y concentraciones

$$
V_{s_{f}} \rho_{s_{f}}=V_{s} \rho_{s}+\left(V_{s_{f}} s_{f}-V_{s} s\right)
$$

donde $\rho_{s_{f}}$ y $\rho_{s}$ son las densidades de las soluciones concentradas y diluidas respectivamente y $V_{s_{f}}$ y $V_{s}$ son los volúmenes de solución concentrada y diluida. A pesar de tener las mismas unidades, no se deben confundir las densidades con concentraciones. Las densidades indican el peso por unidad de volumen de una solución. En cambio, las concentraciones indican la 
cantidad de un sustrato por unidad de volumen de solución. El segundo término del lado derecho de (3.30) corresponde a la masa de sustrato sobrante $M_{\text {exc }}$, que sale de la diferencia entre las masas de sustrato en la solución concentrada y diluida.

A continuación, si deseamos conocer la variación de volumen del biorreactor debido al sustrato ingresado, de (3.30)

$$
\begin{aligned}
& V_{s}=V_{s_{f}} \frac{\rho_{s_{f}}-s_{f}}{\rho_{s}-s} \\
& \dot{V}_{s}=F_{s} \frac{\rho_{s_{f}}-s_{f}}{\rho_{s}-s},
\end{aligned}
$$

donde $F_{s}$ es el caudal de FCE de entrada al biorreactor, que tiene concentración $s_{f}$.

En el proceso bajo estudio (3.11) hay un caudal de entrada para la solución de FCE y otro para la FN, siendo $s_{f}$ y $n_{f}$ las concentraciones de las soluciones concentradas de alimentación, $\rho_{s f}$ y $\rho_{n f}$ sus densidades, $s$ y $n$ las concentraciones en la solución diluida en el biorreactor $\mathrm{y}$ $\rho_{s}=\rho_{n}$ su densidad. El modelo finalmente queda como

$$
\dot{V}=F_{s} \frac{\rho_{s f}-s_{f}}{\rho_{s}-s}+F_{n} \frac{\rho_{n f}-n_{f}}{\rho_{n}-n},
$$

o de manera simplificada

$$
\begin{aligned}
\dot{V} & =\gamma_{s} F_{s}+\gamma_{n} F_{n} \\
\gamma_{s} & =\frac{\rho_{s f}-s_{f}}{\rho_{s}-s} \\
\gamma_{n} & =\frac{\rho_{n f}-n_{f}}{\rho_{n}-n} .
\end{aligned}
$$

Este modelo mejora al propuesto en [12], ya que se hacen consideraciones realistas en cuanto a la composición de los medios. Además, la dinámica del sustrato es tenida en cuenta al incluir su concentración en el modelo. Eventualmente, si las concentraciones de sustrato son reguladas, se puede considerar a $s$ y $n$ como constantes. Notar en particular que si se considera el caso en que la concentración de sustrato en el medio del biorreactor es nula $(s=n=0 \mathrm{y}$ $\rho_{s}=\rho_{n}=\rho_{w}$ ) se obtiene (3.28). Es necesario recalcar que el volumen de solución diluida es un volumen virtual o equivalente, y no está modelizando el fenómeno físico real que sucede al mezclar ambas soluciones. Este modelo se puede mejorar si se suma el volumen de las células como en (3.23). Sin embargo, como no se conoce bien la densidad del microorganismo, se omite este término. En el diseño de observadores y controladores, el error producido se puede considerar como una perturbación. 


\subsubsection{Propuesta de modelo práctico para la etapa de producción}

Se puede obtener un modelo para el cambio de volumen en la etapa de producción a partir del modelo dinámico de la FCE (3.13b). Para ello es necesario redefinir la concentración de fuente de carbono teniendo en cuenta la alta densidad celular del proceso. Entonces, se toma el cociente entre la masa de FCE sobre el volumen de la fase líquida únicamente

$$
s=\frac{S}{V_{l}}
$$

Luego, reemplazando (3.34) en (3.5b) (considerando etapa de producción) se obtiene un modelo para la dinámica del volumen de la fase líquida.

$$
\begin{aligned}
\dot{S}=\dot{s} V_{l}+s \dot{V}_{l} & =-\frac{q_{p} X}{y_{p s}}+F_{s} s_{f} \\
\dot{V}_{l} & =-\frac{q_{p} X}{s y_{p s}}+F_{s} \frac{s_{f}}{s}-V_{l} \frac{\dot{s}}{s} .
\end{aligned}
$$

Si por la existencia de un adecuado control para regular $s$, se puede asumir que la concentración de FCE prácticamente no varía, el último término de (3.36) se puede despreciar ya que $\dot{s}=0$. Por lo tanto, la concentración de FCE es constante e igual a un valor de referencia $s=s_{r}$, reduciendo al volumen de la fase líquida (3.36) a

$$
\dot{V}_{l}=-\frac{q_{p} X}{s_{r} y_{p s}}+F_{s} \frac{s_{f}}{s_{r}} .
$$

Durante la etapa de producción se tiene una elevada concentración celular y además las células incrementan su volumen al almacenar el PHB. Por lo tanto, es necesario agregar el volumen de las células al de la fase líquida para obtener una mejor aproximación del volumen total. De (3.26) y considerando que en la etapa de producción no hay crecimiento se puede deducir que

$$
\dot{V}_{c}=\frac{r_{p}}{\rho_{p}} V=\frac{q_{p}}{\rho_{p}} x V
$$

Finalmente, el modelo de volumen del biorreactor se obtiene al sumar el volumen de las células (3.38) y el de la fase líquida (3.37)

$$
\dot{V}=F_{s} \frac{s_{f}}{s_{r}}-\frac{q_{p} X}{s_{r} y_{p s}}+\frac{q_{p} X}{\rho_{p}} .
$$

El modelo obtenido, al igual que el modelo formal (3.27), cuenta con un término que marca la contribución del caudal de la FCE de entrada, un término referido al consumo del sustrato y otro a la generación de producto. Además, se pueden definir las siguientes constan- 
tes

$$
\begin{aligned}
& \gamma=\frac{s_{f}}{s_{r}} \\
& v=-\frac{1}{s_{r} y_{p s}}+\frac{1}{\rho_{p}} .
\end{aligned}
$$

Quedando finalmente el modelo (3.39) reducido a

$$
\dot{V}=F_{s} \gamma+q_{p} v X
$$

Esta estructura de modelo es exactamente la misma que se obtiene en (3.27) al considerar las condiciones de la fase de producción $\left(F_{n}=\mu_{x s}=\mu_{x p}=n=0\right)$.

\subsubsection{Discusión}

En este capítulo se presentó al proceso de producción de PHB y su modelo. Además, se obtuvieron modelos reducidos para cada una de sus fases. Luego, se presentaron las deficiencias del modelo dinámico clásico del volumen para su utilización en el proceso de producción de PHB y procesos de alta densidad en general. A partir de ese punto se detallan los aportes de la tesis al modelizado.

Primero, en la Sección 3.3.2 se presentó un modelo formal, con bases en conceptos físicoquímicos. El modelo representa ambas fases del proceso y tiene en cuenta tanto la contracción de volumen por la utilización de medios de cultivo con distintas densidades, el consumo de sustrato para crecimiento y producción de PHB, y el volumen de la fase biótica. Sin embargo, este modelo requiere conocer los volúmenes molares parciales de varias soluciones. Estos parámetros en general no se conocen, requieren una identificación empírica y además presentan una variación no lineal con la composición de las soluciones. Esto no es conveniente tanto por la complejidad que toma el modelo como por la utilización de sustratos impuros.

Como alternativas prácticas al modelo formal, en las Secciones 3.3.3 y 3.3.4 se propusieron modelos de volumen para cada fase del proceso. El modelo para la fase de crecimiento es una mejora de otros disponibles en la literatura. Está basado en balances de masa y tiene en cuenta la composición del medio en el biorreactor y consumo de sustratos. A pesar de que no se incluyó un término que contemple el volumen de los microorganismos, éste se podría agregar si se conociera la densidad de las células. De todas maneras el error producido será apreciable solo en las horas finales de la etapa. El modelo para la fase de producción también estás basado en balances de masa. Tiene la misma estructura que el modelo formal de la Sección 3.3.2 y contempla tanto la adición de medio de cultivo denso, el consumo de sustrato para producción de PHB y el volumen propio del PHB. La validez del modelo está sujeta a la existencia de un control que regule la concentración de FCE y no permita grandes variaciones. Ambos modelos son fácilmente aplicables a otros procesos de alta densidad celular, particularmente en procesos con productos intracelulares. 
Los dos modelos propuestos son de gran utilidad en la tesis para el diseño de algoritmos de estimación. Cuanto mayor es la calidad de los modelos, mejor es la precisión de las estimaciones obtenidas. Se debe notar que es necesario conocer el volumen para calcular las diluciones. Además, el modelo para la fase de producción es la base para el estimador de tasa de producción que se propone en el Capítulo 5. Se puede notar en (3.42) que los cambios en el volumen contienen información de $q_{p}$. Además, excediendo los objetivos de la presente tesis, se pueden utilizar para mejorar el diseño de leyes de control a lazo abierto de uso común. 


\section{|| Capítulo 4 \\ Observadores para etapa de crecimiento}

En este capítulo se trata el problema de estimación de tasas de crecimiento en la etapa de crecimiento de un proceso de producción de PHB. Primero se realiza un repaso de los principales algoritmos de estimación encontrados en la literatura. A continuación se propone un esquema conmutado de observadores para la estimación de la tasa de crecimiento en el proceso de producción de PHB con las restricciones impuestas por la operación del proceso. A elevadas concentraciones celulares se obtiene una estimación de la tasa de crecimiento a partir de un observador asintótico. Además, se realiza un análisis de los errores que pueden surgir de las distintas fuentes de incertidumbre. Finalmente, se presentan resultados experimentales y de simulación.

Parte de los contenidos y resultados expuestos en este capítulo han sido publicados en [87]: Martín Jamilis, Fabricio Garelli, Md. Salatul Islam Mozumder, Eveline Volcke y Hernán De Battista. Specific growth rate observer for the growing phase of a polyhydroxybutyrate production process. Bioprocess and Biosystems Engineering, 38(3):557-567, 2014.

\subsection{Introducción}

Además de la incertidumbre en los modelos, otra seria restricción al monitoreo y control de bioprocesos es la escasez de sensores adecuados para la medición en línea de variables importantes del proceso. Para peor, en muchos casos en que los sensores existen, éstos tienen un elevado costo y están orientados a determinadas aplicaciones específicas. Por ejemplo, existen sensores capaces de determinar concentración de glucosa en el medio, pero que no permiten medir la concentración de una FCE distinta. Esta escasez de sensores genera la necesidad de diseñar sensores virtuales que provean estimaciones de variables no medibles.

En primer lugar resulta interesante estimar algunas de sus concentraciones. Esto permite saber su evolución, conocer puntos de operación y establecer el final o inicio de distintas fases. Por otra parte, también es de interés el conocimiento de las tasas de reacción, tanto para la optimización y control del proceso, como para la determinación del estado metabólico. Surge entonces la necesidad de diseñar algoritmos de estimación, adecuados a las características de 
los procesos, que permitan estimar variables no medibles a partir de las medidas disponibles. Estos algoritmos son comúnmente llamados sensores de software en el área de procesos y pueden ser obtenidos mediante diferentes técnicas. En la presente tesis nos hemos centrado en el enfoque determinístico aplicando herramientas del control automático, siendo los algoritmos esencialmente observadores de estados no lineales. Existen otros enfoques que aquí no se tratan desde un punto de vista estocástico y también de redes neuronales.

Un observador de estado es un algoritmo que permite estimar variables de estado no medidas en un sistema dinámico a partir de mediciones de otras variables, de las entradas del proceso y de un modelo (determinístico) que las relacione. En la Figura 4.1 se muestra un esquema donde se puede observar la estructura clásica de un observador. En sí, un observador consta de un modelo dinámico que funciona como una copia del proceso real al cual se le alimentan las mismas entradas que al proceso. Posteriormente, por integración se obtienen los estados del modelo. Idealmente, con un modelo perfecto e iguales condiciones iniciales, las salidas y estados del observador deberían ser iguales a las del proceso. Como en realidad los modelos son imperfectos y no se conocen exactamente las condiciones iniciales de todos los estados, la estimación basada únicamente en el modelo estaría afectada por errores y podría fácilmente divergir del valor verdadero de la variable estimada. A este tipo de estimaciones se las llama de lazo abierto. Con el fin de asegurar convergencia de las estimaciones a los valores verdaderos, se aplica un término de corrección al realimentar el error de estimación (residuo) de los estados medibles o salidas [88, 89, 90].

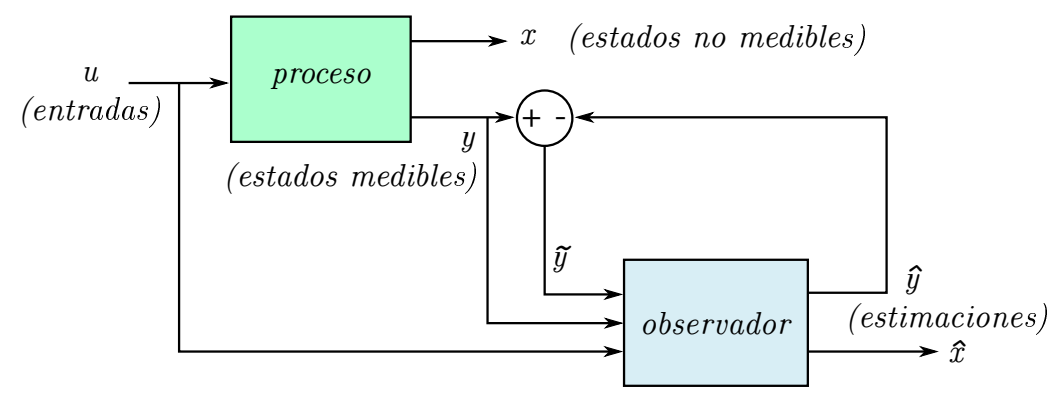

Figura 4.1: Esquema de un observador de estados: $u$ entradas del proceso, $y$ estados medibles o salidas, $x$ estados no medibles, $\hat{y}$ estimación de estados medibles, $\hat{x}$ estimación de estados no medibles, $\tilde{y}$ error de estimación en estados medibles.

Por su parte, los observadores de estado para bioprocesos deben ser robustos frente a las incertidumbre de los modelos, particularmente la presente en los parámetros de los modelos cinéticos. En este aspecto se pueden tomar dos caminos. El primero consiste en estimar los parámetros inciertos junto a los estados del proceso. Para ello se agranda el vector de estados incluyendo los parámetros inciertos (sin dinámica) de manera que estos sean afines en el modelo. Luego, se diseña un observador capaz de estimar tanto los estados como los parámetros, lo que es de utilidad si se requiere identificar los modelos cinéticos o para la implementación de controles adaptivos [90]. Sin embargo, se debe tener en cuenta que este enfoque puede derivar en diseños muy complejos en su análisis teórico y de difícil sintonización en la práctica [91]. Alternativamente, se puede considerar directamente a las tasas de reacción (específica 
o volumétricas) como estados adicionales a estimar sin tener en cuenta sus modelos cinéticos ni sus parámetros. Este enfoque permite ganar robustez en las estimaciones, a la vez que se simplifica la sintonización e implementación [11].

El objetivo principal abordado en este capítulo es la estimación de la velocidad específica de crecimiento de $C$. necator en la etapa de crecimiento del proceso de producción de PHB utilizando el equipamiento disponible en un laboratorio estándar, tomando como referencia la planta experimental del Flemish Institute for Technological Rsesearch VITO (Bélgica) en la que se realizaron los ensayos. En la Sección 4.2 se hace un repaso de los principales algoritmos de estimación que se pueden encontrar en la bibliografía, la mayoría de ellos basados en los trabajos de G. Bastin y D.Dochain. Además se introducen los observadores por modos deslizantes con aplicación a bioprocesos, línea con la cual el grupo de trabajo más ha contribuido. En la Sección 4.3 se desarrolla el aporte de la tesis a la estimación de tasas de crecimiento en el proceso de aplicación de PHB con las restricciones propias de un laboratorio estándar tomadas de un caso real. Finalmente, en la Sección 4.4 se realiza la validación de los algoritmos propuestos mediante simulación bajo condiciones realistas (Sección 4.4.1) y de manera experimental(Sección 4.4.2).

\subsection{Estado del arte}

Como se explicó en la Sección 2.6.4, los modelos de balance de masa se pueden expresar de forma vectorial como

$$
\dot{\xi}=K r(\xi)+D\left(\xi_{f}-\xi\right)-Q
$$

donde $\xi$ es el vector de estados cuyos elementos son las concentraciones, $K$ es la matriz de rendimientos definida en (2.25c), $r(\xi)$ es el vector de velocidades volumétricas, $\xi_{f}$ es el vector con las concentraciones de entrada de los estados (carbono, nitrógeno, etc.) y $Q$ es un vector que contiene los flujos de fase líquida a gaseosa (oxígeno, dióxido de carbono, hidrógeno, etc.). Si el proceso tiene $m$ estados y $p$ reacciones entonces $\xi, \xi_{f}$ y $Q \in \mathbb{R}^{m}, r(\xi) \in \mathbb{R}^{p}$ y $K \in \mathbb{R}^{m \times p}$. A su vez $\xi$ se puede separar entre estado medibles y no medibles $\xi_{1}$ y $\xi_{2}$ respectivamente. Si de los $m$ estados, $n$ de ellos son medibles $(n<m)$ entonces se puede definir a $\xi_{1}=L \xi$ donde $L$ es una matriz de unos y ceros de $n \times m$ que permite seleccionar los estados medibles.

El problema de estimación en bioprocesos se puede resumir en tres casos básicos: estimación de concentraciones, estimación de parámetros y estimación de tasas de reacción. Estos problemas están relacionados entre sí y muchas veces se los afronta de manera conjunta. De todas formas en la literatura se pueden encontrar observadores desarrollados específicamente para cada caso. Por supuesto, la elección queda sujeta al proceso en cuestión, medidas disponibles, incertidumbre de los modelos y aplicación. A continuación se hace un breve repaso de los principales algoritmos que se encuentran en la literatura relacionados con el desarrollo de esta tesis. Para un panorama más completo se sugiere consultar [11, 62, 90, 92]. 


\subsubsection{Observadores exponenciales y de alta ganancia}

Un primer acercamiento a la estimación de los estados del proceso surge de extender el observador de Luenberger a bioprocesos (no lineales) [89, 93]

$$
\dot{\hat{\xi}}=K \phi(\hat{\xi})+D\left(\xi_{f}-\hat{\xi}\right)-Q+\Omega(\hat{\xi})\left(\xi_{1}-\hat{\xi}_{1}\right)
$$

donde $\hat{\xi}$ y $\hat{\xi}_{1}$ son los vectores de estados estimados y $\Omega(\hat{\xi}) \in \mathbb{R}^{m \times n}$ es una matriz de realimentación. La obtención de los estados estimados surge de integrar (4.2), pudiéndose mostrar que la dinámica del error de estimación es

$$
\dot{\tilde{\xi}}=K(\phi(\xi)-\phi(\hat{\xi}))-D \tilde{\xi}-\Omega(\hat{\xi}) L \tilde{\xi}
$$

donde los errores de estimación de los estados y de los estados medibles se definen como $\tilde{\xi}=\xi-\hat{\xi}$ y $\tilde{\xi}_{1}=\xi_{1}-\hat{\xi}_{1}$ respectivamente ${ }^{1}$. Mediante una adecuada selección de $\Omega(\hat{\xi})$ se puede moldear la dinámica del error y asegurar la convergencia de las estimaciones. De hecho, al linealizar (4.3) se obtiene

$$
\begin{gathered}
\dot{\tilde{\xi}}=[A(\hat{\xi})-\Omega(\hat{\xi}) L] \tilde{\xi} \\
\left.A(\hat{\xi}) \triangleq K \frac{\partial \phi(\xi)}{\partial \xi}\right|_{\xi=\hat{\xi}}-D I_{n} .
\end{gathered}
$$

Según se diseñe la dinámica del error linealizado con la elección de la matriz $\Omega(\hat{\xi})$ surgen el Observador de Luenberger Extendido (ELO) o el Observador de Kalman Extendido (EKO). En el caso del ELO se elije $\Omega$ para obtener un error linealizado acotado por una exponencial, en el caso del EKO se busca minimizar el error (linealizado) cuadrático medio [11, 90, 91]. Este tipo de observadores se pueden realizar si el sistema (4.1) es exponencialmente observable. Una condición necesaria para la observabilidad exponencial (local) es que la matriz de observabilidad

$$
\mathscr{O}=\left[\begin{array}{lllll}
L & L A(\xi) & L A(\xi)^{2} & \cdots & L A(\xi)^{m-1}
\end{array}\right]
$$

sea de rango completo. Donde $A(\xi)$ proviene del modelo linealizado, como se define en (4.4b) [11]. El problema de este algoritmo de estimación es que requiere conocimiento de los modelos cinéticos, ya que $\phi(\hat{\xi})$ está incluido en el diseño. Aún conociendo la estructura completa del modelo cinético, el observador obtenido no es muy robusto debido a la elevada incertidumbre de los parámetros.

Por otra parte, se pueden plantear algoritmos similares a (4.2) para la estimación de las tasas de reacción. Para ello, se debe conocer el vector de estados $\xi$ completo, por medición o estimación a través de otro observador. Suponiendo que se puede separar el vector de tasas

\footnotetext{
${ }^{1}$ A lo largo de la tesis se conserva la notación $(\hat{\bullet})$ para estimaciones y $(\tilde{\bullet})$ para errores de estimación
} 
de reacción en una parte conocida y otra, quedando el modelo del proceso

$$
\dot{\xi}=K H(\xi) \rho(\xi)+D\left(\xi_{f}-\hat{\xi}\right)-Q
$$

donde $\phi(\xi)=H(\xi) \rho(\xi)$, siendo $H(\xi)$ la parte conocida del vector de tasas (o del modelo cinético) y $\rho(\xi)$ la parte desconocida o incierta. Luego, los elementos de $\rho(\xi)$ pasan a ser estados del sistema que el observador debe estimar, asumiendo que los mismos no tienen dinámica, quedando el observador de la forma

$$
\begin{aligned}
& \dot{\hat{\xi}}=K H(\xi) \hat{\rho}(t)+D\left(\xi_{f}-\xi\right)-Q-\Omega(\xi-\hat{\xi}) \\
& \dot{\hat{\rho}}=[K H(\xi)]^{T} \Gamma(\xi-\hat{\xi}) .
\end{aligned}
$$

Los mismos criterios que en el ELO y en el EKO se pueden aplicar al observador (4.7) para dar forma a la dinámica del error. Si $\Omega$ y $\Gamma$ son matrices diagonales, las velocidades de convergencia serán mayores cuanto más grandes los elementos de la diagonal, de aquí la denominación de observador de alta ganancia. Sin embargo, se debe tener en cuenta que al aumentar el ancho de banda del observador se lo hace más sensible al ruido de medición, de donde surgen enfoques como el del EKO que busca una relación de compromiso.

Es interesante notar que mediante la adecuada elección de $H(\xi)$ y $\rho(\xi)$ se pueden estimar velocidades específicas y volumétricas sin necesidad de presuponer ningún modelo cinético en particular. Por ejemplo, para la estimación de la tasa específica en un proceso como el descripto por (2.32) se toma $H(\xi)=x[1-1-1-1]^{T}$ y $\rho(\xi)=\mu$, o bien, para la estimación de tasas volumétricas se puede tomar directamente $H(\xi)=\left[1-1 / y_{x s}-1 / y_{x n}-1 / y_{x p}\right]$ y $\rho(\xi)=r_{x}$. Sin embargo, no siempre es necesario conocer todas las concentraciones de un proceso $(x, s, n$ y $p$ ) para estimar las tasas. En el ejemplo anterior, bastaría con medir solamente la biomasa para estimar la tasa de crecimiento:

$$
\begin{aligned}
& \dot{\hat{x}}=\hat{\mu} x-D x-\Omega(x-\hat{x}) \\
& \dot{\hat{\mu}}=x \Gamma(x-\hat{x})
\end{aligned}
$$

donde $\xi=x, \rho=\mu$ y $H(\xi)=x$. En cambio, si se midiera únicamente la concentración de sustrato $s$, no sería posible estimar $\mu$, pero si $r_{x}=\mu x$ :

$$
\begin{aligned}
\dot{\hat{s}} & =-\frac{\hat{r}_{x}}{y_{x s}}+D\left(s_{f}-s\right)-\Omega(s-\hat{s}) \\
\dot{\hat{r}}_{x} & =-\frac{1}{y_{x s}} \Gamma(s-\hat{s})
\end{aligned}
$$

donde $\xi=s, \rho=r_{x}=\mu x$ y $H(\xi)=-\frac{1}{y_{x s}}$.

Ejemplos de este tipo de observadores se pueden ver también en [55, 94, 95, 96]. 


\subsubsection{Observadores asintóticos}

Los observadores asintóticos se usan para estimar los estados del proceso en el caso que el modelo no sea exponencialmente observable y no se pueda implementar un observador exponencial como los de la sección anterior. Una ventaja importante de los observadores asintóticos es que la estimación es independiente del modelo cinético, con lo cual se reduce el impacto de las incertidumbres.

Se puede utilizar un observador asintótico bajo las siguientes condiciones:

- Se conocen todos los rendimientos (matriz K)

- $n \geq \operatorname{rango}(K)$, siendo $n$ el número de estado medibles,

Primero se debe encontrar una partición del espacio de estados $\left(\xi_{a}, \xi_{b}\right)$, donde $\xi_{a} \in \mathbb{R}^{a} \mathrm{y}$ $\xi_{b} \in \mathbb{R}^{m-a}$, tal que

$$
\begin{aligned}
& Z=A_{0} \xi_{a}+\xi_{b} \\
& \dot{Z}=-D Z+A_{0}\left(F_{a}-Q_{a}\right)+\left(F_{b}-Q_{b}\right)
\end{aligned}
$$

donde $A_{0} \in \mathbb{R}^{(m-a) \times a}$ y $F_{a}, Q_{a}, F_{b}$ y $Q_{b}$ son las submatrices obtenidas de $F$ y $Q$ al separar el espacio de estados, con $F_{a}$ y $Q_{a} \in \mathbb{R}^{a}$, y $F_{b}$ y $Q_{b} \in \mathbb{R}^{m-a}$ Lo más destacable es que el sistema transformado (4.10b) es independiente de las tasas de reacción, por lo que se lo puede usar como base para construir un observador de estados robusto a la incertidumbre en las cinéticas.

A continuación, se debe hallar la manera de expresar a $Z$ como una combinación lineal de los estados medibles y no medibles $\xi_{1}$ y $\xi_{2}$, es decir, hallar $A_{1}$ y $A_{2}$ tales que

$$
Z=A_{1} \xi_{1}+A_{2} \xi_{2}
$$

$\operatorname{con} A_{1} \in \mathbb{R}^{(m-a) \times n}$ y $A_{2} \in \mathbb{R}^{(m-a) \times(m-n)}$.

Si es posible hallar la partición (4.10), la combinación lineal (4.11) y además existe la pseudo-inversa izquierda de $A_{2}$ entonces se puede plantear un observador asintótico de la forma

$$
\begin{aligned}
\dot{\hat{Z}} & =-D \hat{Z}+A_{0}\left(F_{a}-Q_{a}\right)+\left(F_{b}-Q_{b}\right) \\
\hat{\xi}_{2} & =A_{2}^{+}\left(\hat{Z}-A_{1} \xi_{1}\right)
\end{aligned}
$$

donde $\hat{Z}$ y $\hat{\xi}_{2}$ son las estimaciones de $Z$ y $\xi_{2}$ respectivamente y $A_{2}^{+}$es la pseudo-inversa izquierda de $A_{2}$.

Definiendo los errores de estimación como $\tilde{Z}=Z-\hat{Z}$ y $\tilde{\xi}_{2}=\xi_{2}-\hat{\xi}_{2}$, se puede obtener su 
dinámica

$$
\begin{aligned}
\dot{\tilde{Z}} & =-D \tilde{Z} \\
\tilde{\xi}_{2} & =A_{2}^{+} \tilde{Z}
\end{aligned}
$$

de donde se puede deducir, al derivar (4.13b), que la dinámica del error de estimación (de los estados no medibles) es

$$
\dot{\tilde{\xi}}_{2}=-D \tilde{\xi}_{2}
$$

Sabiendo que $D \geq 0$, de (4.14) se puede deducir que la estimación converge al valor verdadero siempre y cuando la dilución no sea nula por períodos muy largos de tiempo. Esto se cumple si existen constantes positivas $\delta$ y $\varepsilon$ tales que [11]

$$
\int_{t}^{t+\delta} D(\tau) d \tau \geq \varepsilon>0 .
$$

La propiedad (4.15) se conoce como persistencia de excitación. Se debe notar también que diluciones bajas conllevan tiempos de convergencia muy altos, lo que debe ser tenido en cuenta al momento de seleccionar la concentración de sustrato de alimentación. En efecto, cuanto más alta es esta concentración, más baja es la dilución resultante.

Existen muchos ejemplos de aplicación de observadores asintóticos en la literatura. Algunos ejemplos son $[11,90,91,62,97,98,99,100]$.

\subsubsection{Observadores por modos deslizantes}

Como alternativa a los observadores exponenciales se pueden diseñar observadores para las tasas de reacción basados en algoritmos por modos deslizantes (MD). En este tipo de algoritmo se utiliza una acción discontinua para lograr que las trayectorias del sistema alcancen una variedad del espacio de estados y permanezcan en ella el tiempo subsiguiente. La variedad a alcanzar se llama superficie de deslizamiento y es una función de los estados medibles y parámetros conocidos del sistema. Cuando se aplica a la estimación de variables la superficie debe ser tal que asegure la convergencia del error de estimación a cero con una determinada dinámica. En general, primero se define una función o coordenada de deslizamiento como función de los estados medibles del sistema $\sigma(\xi)$, usualmente una combinación lineal de los mismos, luego la superficie de deslizamiento se define como $\sigma=0$ [101]. Además, son condiciones necesarias para el régimen en modos deslizantes que localmente en torno a la superficie se cumplan las condiciones de invarianza

$$
\begin{aligned}
& \sigma=0 \\
& \dot{\sigma}=0 .
\end{aligned}
$$

Caso contrario, las trayectorias podrían estar cruzando la superficie sin permanecer en ella. 
Una de las principales ventajas de los algoritmos por modos deslizantes es que se puede obtener convergencia de las estimaciones (convergencia a la superficie) en tiempo finito, en lugar de asintótica o exponencialmente como en los observadores continuos. Además, al mantener al sistema en la superficie de deslizamiento se asegura un error de estimación nulo aún cuando la variable a estimar varía, es decir, no se agrega dinámica al sistema a diferencia de los observadores exponenciales extendidos para estimación de tasas. Por otra parte se puede lograr una mejor robustez que en los ya mencionados observadores continuos en lo que respecta al rechazo a ruido y perturbaciones.

El orden de los algoritmos por MD viene dado por el orden de la derivada de la función de deslizamiento en la cual aparece la acción discontinua. Los algoritmos por modos deslizantes de primer orden (MDPO) fueron los primeros en surgir, en ellos la acción discontinua aparece en la primera derivada. Posteriormente surgieron los algoritmos de segundo orden (MDSO), donde la acción discontinua se sitúa en la segunda derivada de la función de deslizamiento. El más conocido de estos algoritmos es el Algoritmo Super-Twisting (STA) propuesto por [102], y que toma su nombre por la trayectoria en forma de espiral en el plano de estados. Los algoritmos de primer orden tienen el inconveniente que en muchos casos las estimaciones obtenidas son discontinuas, por ejemplo si se estiman tasas de reacción. Resulta entonces necesario un filtrado de la estimación, lo que termina por agregar dinámica a la estimación. En el caso de los algoritmos de segundo orden, las estimaciones obtenidas son continuas, ahorrándose la necesidad de filtrado y conservando la dinámica nula.

La aplicación de los MD a la estimación en bioprocesos es bastante reciente. En observadores de primer orden se puede nombrar a $[103,104]$ donde se estiman tasas volumétricas de reacción a partir de mediciones de sustrato, por otra parte en $[105,106]$ se estiman tasas específicas de crecimiento a partir de mediciones de biomasa e hidrógeno respectivamente. En tanto, en $[107,56]$ se proponen algoritmos de segundo orden que mejoran a los de primer orden en la suavidad de las estimaciones, ya que las estimaciones obtenidas son continuas y convergen en tiempo finito.

\subsubsection{Antecedentes en la producción de PHB}

La estimación de variables en el proceso de producción de PHB mediante Cupriavidus necator ha sido tratada por algunos autores. En [91] se proponen observadores adaptivos (ELO y EKO) y se usa la producción de PHB como ejemplo de aplicación, habiendo además medición de sustrato. Los diseños incluyen al modelo cinético, y se analiza el error producido tanto en la estimación del sustrato (medido) como de la biomasa (estimada). Es necesario resaltar que el mismo autor menciona que este tipo de observadores son muy difíciles de implementar y sintonizar en la práctica por su complejidad. Los datos experimentales mostrados son tomados de $[108,97]$, donde se propone un control por linealización para la regulación del nitrógeno, el cual es estimado con un observador asintótico a partir de la medición de biomasa. Además se estima la tasa de crecimiento con un observador exponencial a partir de las estimaciones de 
nitrógeno. En [109] se verifica experimentalmente un observador asintótico para la estimación de biomasa, PHB y nitrógeno basado en medición de oxígeno disuelto y gases de salida. El mismo ejemplo es presentado en [11]. Por otra parte, en [95] se propone un observador de alta ganancia adaptivo para estimar concentraciones a partir de la medición de glucosa en línea. En este caso es en una cultura mixta de Lactobacillius delbrueckii y C. necator, donde uno convierte glucosa en lactato y el otro consume lactato para producir PHB. Sobre el mismo proceso se trabaja en [110] estimando las tasas de consumo de lactato y glucosa mediante observadores exponenciales y la medición de sus concentraciones. En [111] se utiliza un EKO para la estimación de varias concentraciones basándose en la medición de gases de salida, oxígeno disuelto y concentración celular, sobre un proceso de producción de PHB mediante Methylobacterium rhodesianum.

\subsection{Observador de tasa de crecimiento}

En esta sección se proponen observadores para la estimación de la tasa específica de crecimiento en el proceso de producción de PHB. Como se explicó en la Sección 3.2.1, la producción de PHB se ve casi completamente inhibida en presencia de FN, quedando el modelo del proceso como se describe en (3.11) y que aquí se repite por comodidad:

$$
\begin{aligned}
\dot{x} & =(\mu-D) x \\
\dot{s} & =-\frac{\mu}{y_{x s}} x-D s+\frac{F_{s}}{V} s_{f} \\
\dot{n} & =-\frac{\mu}{y_{x n}} x-D n+\frac{F_{n}}{V} n_{f} \\
D & =\frac{\dot{V}}{V}=\frac{\gamma_{s} F_{s}+\gamma_{n} F_{n}}{V} .
\end{aligned}
$$

Notar que la dilución $D$ se obtiene por medio del modelo propuesto en (3.33). Obsérvese que, para simplificar la notación, se renombró a la tasa de crecimiento como $\mu=\mu_{x s}$. Además se definen las siguientes variables

$$
\begin{aligned}
D_{s} & =\frac{F_{s}}{V} \\
D_{n} & =\frac{F_{n}}{V} .
\end{aligned}
$$

Se requiere entonces estimar la tasa específica de crecimiento tanto para el monitoreo como para el control del proceso. El diseño del observador depende en gran medida de las medidas y sensores disponibles.

El caso de estudio surge de una colaboración con el Grupo de Control de Biosistemas de la Universidad de Gante y con el Flemish Institute for Technological Research (VITO), Bélgica. Los ensayos experimentales se llevaron a cabo en VITO por lo que en el primer escenario a considerar se plantea un observador para ser utilizado con el equipamiento disponible en el 
laboratorio, el cual es representativo de los elementos disponibles en cualquier laboratorio estándar, en particular en la Argentina.

El equipamiento incluye un biorreactor de tanque agitado de 3 litros de volumen útil (Applikon Biotechnology, the Netherlands) que dispone de un sistema de adquisición y control (EZ-control, Applikon Biotechnology, the Netherlands). El mismo equipo se completa con bombas para suministro de FCE, soluciones ácida y base, suministro de aire y oxígeno puro. La FN es el mismo hidróxido de amonio $\mathrm{NH}_{4} \mathrm{OH}$ utilizado como solución base para neutralizar el pH. El mismo software se utiliza para regular la concentración de oxígeno disuelto en un $55 \%$ de la de saturación en aire y la temperatura en unos $30^{\circ} \mathrm{C}$.

Las variables medidas en línea son el pH (AppliSens, The Netherlands, Z001023551), temperatura, oxígeno disuelto y densidad óptica (Optek-Danulat GmbH, Germany, ASD19-N-EB01). La medida de biomasa entregada por el sensor de $\mathrm{OD}^{2}$ es solamente válida durante las primeras horas del cultivo, ya que cuando la densidad celular toma valores elevados el método de medida pierde sensibilidad y satura. El límite está dado para una absorbancia de 0.6 aproximadamente ${ }^{3}$. En cuanto a las entradas del biorreactor, todos los caudales de entrada líquidos y gaseosos son conocidos y registrados, así como la velocidad de agitación. Sin embargo, no se dispone de medida de los caudales y composición de los gases de salida. El período de muestreo del equipo es de 1 minuto (mínimo período permitido por el software BioExpert).

La regulación de las concentraciones de FCE y FN se logra mediante dos controles distintos. La FCE se regula mediante un control de lazo abierto del tipo alimentación exponencial. En cambio, la regulación de FN se logra mediante un lazo cerrado indirecto del tipo pH-auxostat [112, 33], descripto a continuación.

\section{pH-auxostat}

Como consecuencia del crecimiento, se liberan iones de hidrógeno al medio líquido que aumentan su acidez (ver (3.1)). Se adiciona entonces solución base de hidróxido de amonio $\left(20 \% \mathrm{NH}_{4} \mathrm{OH}\right)$ para compensar los cambios en el $\mathrm{pH}$ y regularlo en un valor de 6,8 [33]. Cada protón libre se puede enlazar con un ion oxidrilo, liberando un ion amonio $\mathrm{NH}_{4}^{+}$que sirve de FN para el microorganismo. De (3.1) se puede ver que por cada mol de $\mathrm{NH}_{4}^{+}$consumido se libera la misma cantidad de moles de $\mathrm{H}^{+}$. Por tanto, al adicionar una dada cantidad de moles de $\mathrm{NH}_{4} \mathrm{OH}$ para compensar el $\mathrm{pH}$, indirectamente se estará compensando la FN consumida. En síntesis, el control de $\mathrm{pH}$ alimenta la FN de manera proporcional a su consumo y, por tanto, proporcional al crecimiento

La correlación entre la cantidad de nitrógeno alimentado para compensar $\mathrm{pH}$ y el requerido en sentido estequiométrico para obtener la cantidad final de células se ha verificado

\footnotetext{
${ }^{2}$ Densidad óptica por sus siglas en inglés (Optical density). DO en general se utiliza para el oxígeno disuelto (Dissolved oxygen).

${ }^{3}$ La absorbancia es una magnitud adimensional y por lo tanto no lleva unidades. Algunos autores, en un abuso de notación, usan unidades de absorbancia AU.
} 
experimentalmente. Sin embargo, la relación no es unitaria debido a que parte de la FN adicionada se pierde en forma gaseosa. Por ello se introduce un rendimiento $\eta$ en (4.17c) que tiene en cuenta esas pérdidas [33]:

$$
\dot{n}=-\frac{\mu}{y_{x n}} x-D n+\eta \frac{F_{n}}{V} n_{f} .
$$

El rendimiento $\eta$ se determina experimentalmente, siendo en promedio 0,75 para las condiciones del laboratorio.

A partir del control de pH se define una ley de alimentación de FCE con el fin de regularla a un valor constante. Dado que el caudal de FN cubre el requerimiento estequiométrico para un crecimiento exponencial, la FCE se debe alimentar a un ritmo proporcional

$$
F_{s}=\eta \frac{n_{f} F_{n}}{y_{n s}} \frac{1}{s_{f}}
$$

donde $y_{n s}=0,19 Y_{x s} M_{n} / M_{s}$ es el rendimiento entre nitrógeno y carbono dado por (3.2b), siendo $M_{n}$ y $M_{s}$ las masas moleculares de 1 C-mol de FN y de FCE respectivamente.

\subsubsection{Observador de tasa específica de crecimiento}

En esta sección se explica el esquema combinado de observadores propuesto. Aprovechando la disponibilidad de la medida en línea de biomasa durante las primeras horas del cultivo, primero se utiliza un observador de convergencia rápida, que puede ser tanto un exponencial o de modos deslizantes. Luego, cuando la medida de biomasa alcanza el valor de saturación y ya no es confiable, se conmuta a un observador asintótico cuya condición inicial está dada por la última estimación hecha por el observador de las primeras horas. El observador exponencial usa infromación provista por el pH-auxostat.

\subsubsection{Observador asintótico propuesto}

Como se explicó anteriormente, en el caso bajo estudio la medida de OD no está disponible durante todo el proceso debido a que el sensor de OD pierde sensibilidad y satura a altas concentraciones celulares. Al perderse la medida de biomasa se puede aprovechar la información brindada por el pH-auxostat sobre la concentración de nitrógeno por medio de un observador asintótico.

Normalmente los observadores asintóticos se utilizan para la estimación de concentraciones del proceso, ya que se basan en la utilización de balances de masa y no involucran a las tasas específicas del proceso. En esta tesis se propone como aplicación original su utilización para estimar la tasa específica de crecimiento $\mu$. Además, como novedad, se estudian los errores en la estimación de la tasa surgidos de diversas incertidumbres.

La formulación del observador requiere tres pasos: 
- Transformación del sistema de manera que no dependa de la tasa de crecimiento, se define entonces una variable auxiliar $z$.

- Estimación de z a partir de un observador asintótico y la información disponible del proceso.

- A partir de la estimación de $z$ se calcula la tasa de crecimiento $\mu$.

Sabiendo que la concentración de nitrógeno es prácticamente constante debido al control de $\mathrm{pH}$, conviene plantear la variable auxiliar como

$$
z=\frac{x}{y_{x n}}+n
$$

que representa la suma del nitrógeno en el medio más el que se utilizó para producir biomasa (en concentraciones). Aquí se puede ver también que $z \geq 0$. La dinámica de la nueva variable se obtiene al derivar (4.21) y reemplazar (4.17a) y (4.17c)

$$
\begin{aligned}
& \dot{z}=\frac{\dot{x}}{y_{x n}}+\dot{n} \\
& \dot{z}=-D z+D_{n} n_{f} \eta .
\end{aligned}
$$

Luego, a partir de (4.22b) se puede plantear un observador asintótico para estimar z

$$
\dot{\hat{z}}=-D \hat{z}+D_{n} n_{f} \eta
$$

donde $\hat{z}$ es la estimación de $z$. Se puede ver que en estado estacionario tanto $z$ como $\hat{z}$ tienden al mismo valor:

$$
\lim _{t \rightarrow \infty} z=\lim _{t \rightarrow \infty} \hat{z}=\frac{D_{n}}{D} n_{f} \eta .
$$

Si se define al error de estimación como $\tilde{z}=z-\hat{z}$ se puede mostrar que la dinámica del error está dada por

$$
\dot{\tilde{z}}=-D \tilde{z}
$$

La ecuación (4.25) tiene un único autovalor $\lambda=-D$ y su solución es una exponencial con constante de tiempo $D^{-1}$. Como $D>0$ en procesos fed-batch con alimentación exponencial, se puede deducir entonces que el error es estable y converge a cero exponencialmente.

De la estimación $\hat{z}$ se puede obtener una estimación de la concentración de biomasa residual aplicando la transformación inversa de (4.21)

$$
\hat{x}=(\hat{z}-n) y_{x n} .
$$

Esta estimación se puede usar para monitoreo aunque se debe tener en cuenta que es muy sensible a errores en el rendimiento $y_{x n}$ o a cambios no previstos en la concentración de nitrógeno. Del control de $\mathrm{pH}$ se espera que $n=n(0) \forall t$. El siguiente paso es obtener una 
estimación de $\mu$ a partir de $\hat{z}$. A partir de (4.19) se puede observar que

$$
\mu x=\left(-D x+D_{n} n_{f} \eta-\dot{x}\right) \cdot y_{x n},
$$

por tanto, $\mu$ se puede calcular de (4.27) y (4.21) como

$$
\mu=\frac{D_{n} n_{f} \eta-D n-\dot{n}}{z-n} .
$$

A partir de (4.28) se puede plantear la estimación de $\mu$

$$
\hat{\mu}=\frac{D_{n} n_{f} \eta-D n}{\hat{z}-n} .
$$

Finalmente, el error de estimación de la tasa de crecimiento definido como $\tilde{\mu}=\mu-\hat{\mu}$ es

$$
\tilde{\mu}=\frac{D_{n} n_{f} \eta-D n-\dot{n}}{z-n}-\frac{D_{n} n_{f} \eta-D n}{\hat{z}-n} .
$$

Anteriormente en (4.24) se muestra que tanto $z$ como $\hat{z}$ tienden al mismo valor en estado estacionario, por lo tanto se puede concluir que $\tilde{\mu}$ tiende a un valor en estado estacionario obtenible al evaluar (4.30) cuando $\tilde{z}=0$

$$
\lim _{t \rightarrow \infty} \tilde{\mu}=-\frac{\dot{n}}{z-n}=-\frac{\dot{n}}{x / y_{x n}}
$$

Como se explicó anteriormente, el lazo de control de $\mathrm{pH}$ a su vez regula la concentración de nitrógeno. Por lo tanto, $\dot{n}=0$ y el error de estimación $\tilde{\mu}$ tiende a cero.

Para completar el análisis del desempeño del observador, se analiza el efecto de incertidumbres en los parámetros del modelo y errores en las mediciones. Primero se analiza el efecto de incertidumbre en $y_{x n}$ y $\eta$, luego se analiza el efecto de no conocer bien la concentración de nitrógeno. Del análisis de los errores de estimación (4.25) y (4.30) se puede observar que el valor de $y_{x n}$ no afecta a los errores de estimación $\tilde{z} y \tilde{\mu}$, afectando sí a la estimación de la biomasa $\hat{x}$. Se plantea entonces un escenario pesimista considerando un $y_{x n}$ variable. Al incluir los parámetros inciertos, las ecuaciones (4.22b), (4.23) y (4.25) pasan a ser

$$
\begin{aligned}
& \dot{z}=-D z+D_{n} n_{f} \eta-\dot{y}_{x n} \frac{x}{y_{x n}^{2}} \\
& \dot{\tilde{z}}=-D \hat{z}+D_{n} n_{f} \hat{\eta} \\
& \dot{\tilde{z}}=-D \tilde{z}+D_{n} n_{f} \tilde{\eta}-\dot{y}_{x n} \frac{x}{y_{x n}^{2}}
\end{aligned}
$$

donde $\hat{\eta}$ es el valor (erróneo) de $\eta$ utilizado y $\tilde{\eta}$ el error. En (4.32c) se puede ver que, siempre y cuando la perturbación dada por $D_{n} n_{f} \tilde{\eta}-\dot{y}_{x n} \frac{x}{y_{x n}^{2}}$ sea acotada, el error es estable y 
convergente a un valor distinto de cero

$$
\lim _{t \rightarrow \infty} \tilde{z}=\frac{D_{n} n_{f}}{D} \tilde{\eta}-\dot{y}_{x n} \frac{x}{y_{x n}^{2} D} .
$$

Se puede notar también que conocer erróneamente el valor de $n$ no implica errores en la estimación de $z$, ya que $z$ tiene en cuenta toda la FN que alguna vez hubo en el biorreactor, haya sido convertida o no a biomasa.

$\mathrm{Al}$ incluir el efecto de incertidumbre en la estimación de la tasa de crecimiento se llega a que (4.29) se reescribe como

$$
\hat{\mu}=\frac{D_{n} n_{f} \hat{\eta}-D \hat{n}}{\hat{z}-\hat{n}}
$$

donde $\hat{n}$ es el valor erróneo de $n$ considerado, es decir, $\hat{n}=n-\tilde{n}$. Luego, el error de estimación de la tasa de crecimiento es

$$
\tilde{\mu}=\frac{D_{n} n_{f} \eta-D n-\dot{n}}{z-n}-\frac{D_{n} n_{f} \hat{\eta}-D \hat{n}}{\hat{z}-\hat{n}} .
$$

Algunos factores de (4.35) se pueden desarrollar:

$$
\begin{aligned}
\frac{1}{z-n}=\frac{1-\frac{n}{z}+\frac{n}{z}}{z-n}= & \frac{1-\frac{n}{z}}{z-n}+\frac{\frac{n}{z}}{z-n} \\
& =\frac{1}{z}+\frac{1}{z} \frac{n}{z-n} .
\end{aligned}
$$

Lo mismo se puede hacer con

$$
\frac{1}{\hat{z}-\hat{n}}=\frac{1}{\hat{z}}+\frac{1}{\hat{z}} \frac{\hat{n}}{\hat{z}-\hat{n}}
$$

Luego al reemplazar en (4.35)

$$
\tilde{\mu}=D_{n} n_{f}\left(\frac{\eta}{z}-\frac{\hat{\eta}}{\hat{z}}\right)+\frac{D_{n} n_{f} \frac{\eta}{z} n-D n-\dot{n}}{z-n}-\frac{D_{n} n_{f} \frac{\hat{\eta}}{\hat{z}} \hat{n}-D \hat{n}}{\hat{z}-\hat{n}} .
$$

Teniendo en cuenta (4.32a) y (4.32b) se pueden calcular los puntos de equilibrio para $\frac{\eta}{z}$ $\mathrm{y} \frac{\hat{\eta}}{\hat{z}}$

$$
\begin{aligned}
\lim _{t \rightarrow \infty} \frac{\eta}{z} & =\frac{D}{D_{n} n_{f}}\left(\frac{1}{1-\chi}\right) \\
\lim _{t \rightarrow \infty} \frac{\hat{\eta}}{\hat{z}} & =\frac{D}{D_{n} n_{f}} \\
\chi & =\frac{\dot{y}_{x n} x}{y_{x n}^{2} \eta D_{n} n_{f}} .
\end{aligned}
$$

Por lo tanto, a partir de (4.38) se puede obtener el error de estimación de la tasa de creci- 
miento en estado estacionario

$$
\lim _{t \rightarrow \infty} \tilde{\mu}=\frac{D \chi}{1-\chi}\left(1+\frac{n}{z-n}\right)-\frac{\dot{n}}{z-n} .
$$

En (4.40) se puede ver que el efecto de los parámetros inciertos $\eta$ y $y_{x n}$ desaparece en estado estacionario (se atenúa con el tiempo). Lo mismo sucede con los errores en $n$. De hecho, son las derivadas $\dot{y}_{x n} \mathrm{y} \dot{n}$ las fuentes de error que prevalecen en el tiempo, y cuando éstas son nulas $\tilde{\mu}$ tiende a cero sin importar los valores de $\hat{\eta}$ y $\hat{y}_{x n}$. Esto evidencia la gran robustez del observador propuesto, ya que no es esperable observar alteraciones rápidas en los rendimientos. Por otra parte, al existir un lazo de control regulando la concentración de nitrógeno, pueden existir variaciones en la misma pero no es esperable que éstas sean rápidas, es decir $\dot{n}$ debería ser pequeño en comparación con el valor que toma $z$, que aumenta a lo largo del tiempo. Finalmente, cabe destacar que como la producción de PHB no requiere de nitrógeno, en el caso que existiese una pequeña producción asociada al crecimiento la estimación no se vería afectada.

\subsubsection{Primeras horas: Observador exponencial}

Durante las primeras horas del cultivo la concentración de biomasa es baja, el sensor de OD da una medida confiable. Por eso, se puede proponer un observador exponencial para obtener una rápida convergencia al valor verdadero de $\mu$ antes de conmutar al observador asintótico. La conmutación se realiza en el instante de tiempo en el que la concentración de biomasa llega a un valor de saturación de la medida $\left(x_{\text {sat }}\right)$, siendo su medición imposible para valor mayores. Como se mencionó anteriormente, la velocidad de convergencia de los observadores exponenciales se puede sintonizar mediante el ajuste de las ganancias en su diseño. Por otra parte, la estimación de la tasa obtenida converge exponencialmente a un entorno del valor verdadero, siendo nulo el error únicamente cuando ésta permanece constante en el tiempo.

El observador utilizado es

$$
\begin{aligned}
& \dot{\hat{x}}=\left(\hat{\mu}_{x}-D\right) x-\gamma_{1}(x-\hat{x}) x \\
& \dot{\hat{\mu}}=\gamma_{2}(x-\hat{x}) x
\end{aligned}
$$

donde $\hat{x}$ y $\hat{\mu}$ son la concentración de biomasa residual y tasa específica de crecimiento estimadas, respectivamente y las ganancias de diseño del observador son $\gamma_{1}$ y $\gamma_{2}$, que se deben elegir de manera de asegurar estabilidad y rápida convergencia. El análisis de estabilidad del observador se hace a partir de los errores de estimación, definidos como $\tilde{x}=x-\hat{x}$ y $\tilde{\mu}=\mu-\hat{\mu}$. $\mathrm{Al}$ derivar los errores se obtiene

$$
\left[\begin{array}{c}
\dot{\tilde{x}} \\
\dot{\tilde{\mu}}
\end{array}\right]=\left[\begin{array}{cc}
\gamma_{1} x & x \\
-\gamma_{2} x & 0
\end{array}\right]\left[\begin{array}{l}
\tilde{x} \\
\tilde{\mu}
\end{array}\right]+\left[\begin{array}{l}
0 \\
1
\end{array}\right] \dot{\mu} .
$$


El sistema (4.42) tiene dos autovalores $\lambda_{1}$ y $\lambda_{2}$ que cumplen que

$$
\begin{aligned}
& \lambda_{1}+\lambda_{2}=\gamma_{1} x \\
& \lambda_{1} \lambda_{2}=\gamma_{2} x^{2} .
\end{aligned}
$$

Como $x>0 \forall t$, surge como condición necesaria y suficiente para la estabilidad del error (para que $\lambda_{1}<0$ y $\lambda_{2}<0$ ) que $\gamma_{1}<0$ y $\gamma_{2}>0$. Para obtener una tasa de convergencia alta se deben elegir autovalores rápidos y consecuentemente ganancias grandes. Sin embargo, existe una relación de compromiso entre velocidad de convergencia y rechazo a ruido que limita la magnitud de los autovalores. Además hay que tener en cuenta que el observador incrementa su velocidad a medida que aumenta $x$ como se puede ver a partir de (4.43a) y (4.43b). Para las simulaciones y pruebas experimentales mostradas en este capítulo se escogieron autovalores $\lambda_{1}=\lambda_{2}=-x$, para los cuales las ganancias se sintonizan en $\gamma_{1}=-2$ y $\gamma_{2}=1$.

Alternativamente se puede proponer un observador exponencial cuyos autovalores no dependan de la concentración de biomasa, con el fin de obtener una velocidad de convergencia (y ancho de banda) constante. Para ello basta con elegir las ganancias de (4.41) en $\gamma_{1}=\gamma_{1}^{\prime} / x$ y $\gamma_{2}=\gamma_{2}^{\prime} / x^{2}$. Luego, el observador es

$$
\begin{aligned}
& \dot{\hat{x}}=\left(\hat{\mu}_{x}-D\right) x-\gamma_{1}^{\prime}(x-\hat{x}) \\
& \dot{\hat{\mu}}=\gamma_{2}^{\prime}(x-\hat{x}) / x .
\end{aligned}
$$

La dinámica del error en este caso es

$$
\left[\begin{array}{c}
\dot{\tilde{x}} \\
\dot{\tilde{\mu}}
\end{array}\right]=\left[\begin{array}{cc}
\gamma_{1}^{\prime} x & x \\
-\gamma_{2}^{\prime} / x & 0
\end{array}\right]\left[\begin{array}{l}
\tilde{x} \\
\tilde{\mu}
\end{array}\right]+\left[\begin{array}{l}
0 \\
1
\end{array}\right] \dot{\mu} .
$$

Y los autovalores son

$$
\begin{gathered}
\lambda_{1}+\lambda_{2}=\gamma_{1}^{\prime} \\
\lambda_{1} \lambda_{2}=\gamma_{2}^{\prime} .
\end{gathered}
$$

\subsection{Resultados}

En esta sección se muestran resultados de simulación y resultados experimentales para el observador exponencial y el observador asintótico propuesto. Las simulaciones apuntan a mostrar el desempeño de los observadores en situaciones realistas y a analizar el efecto de la incertidumbre paramétrica en la estimación de $\mu$. Los resultados experimentales permiten validar el observador en el proceso real.

Para replicar lo más fielmente posible las condiciones en el biorreactor, las simulaciones se llevan a cabo utilizando las mismas leyes de control para los caudales de FCE y FN y las mismas 


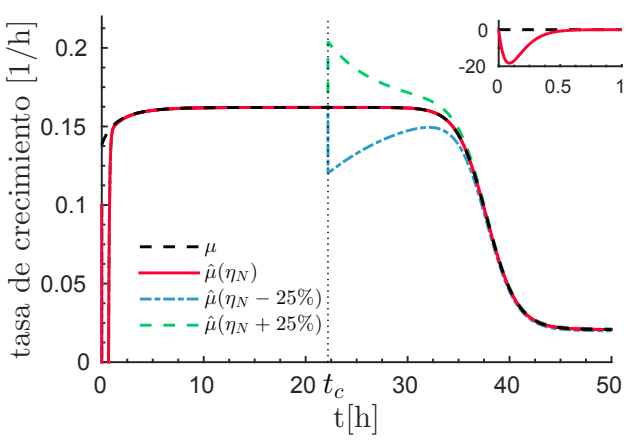

(a) Tasa específica de crecimiento.

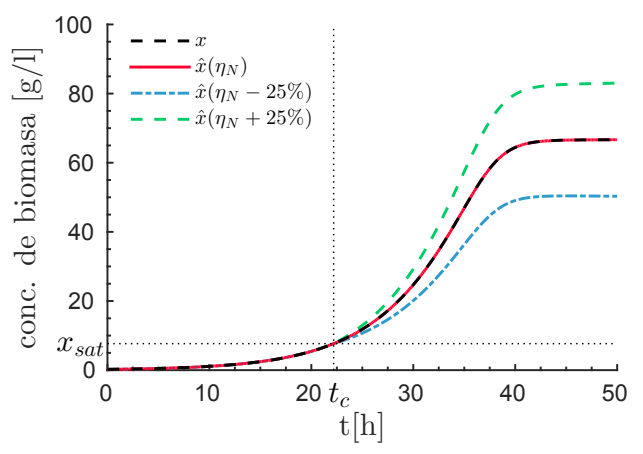

(b) Concentración de biomasa residual.

Figura 4.2: Resultados de simulación considerando incertidumbre en el rendimiento de nitrógeno alimentado $\eta$. Valor verdadero (trazo negro), estimación (línea continua roja), estimación con $\eta=$ $75 \% \eta_{N}$ (trazos y puntos azul) y estimación on $\eta=125 \% \eta_{N}$ (trazos verdes).

concentraciones de entrada $\left(s_{f}\right.$ y $\left.n_{f}\right)$. Los modelos cinéticos utilizados para la simulación son los expuestos en (4.17), (4.19) y (3.10). Los parámetros de los modelos son los detallados en la Tabla 3.2 y Tabla 3.1 .

\subsubsection{Resultados de simulaciones}

Tanto $s$ como $n$ se regulan en valores de $12 \mathrm{~g} / \mathrm{l}$ y $0,7 \mathrm{~g} / \mathrm{l}$, respectivamente, al igual que en [33]. La conmutación del observador exponencial al asintótico se hace cuando la concentración de biomasa llega a 7,67g/l correspondiente a una absorbancia $O D=0,6$.

La Figura 4.2 muestra los resultados de simulación para el caso en que se considera una incertidumbre de $\pm 25 \%$ en el rendimiento de alimentación de nitrógeno $\eta$, cuyo valor nominal es $\eta_{N}=0,75$. Es decir, se simulan casos donde el observador utiliza valores de $\eta=\eta_{N}$, $\eta=0,75 \eta_{N}$ y $\eta=1,25 \eta_{N}$. La Figura 4.2a muestra la tasa específica de crecimiento y su estimación, la Figura 4.2a muestra la concentración de biomasa residual y su concentración. En ambas figuras las curvas a trazos negros corresponden a los valores verdaderos, las curvas continuas rojas a las estimaciones utilizando $\eta_{N}$, las curvas a trazos y puntos azules y a trazos verdes corresponden a las estimaciones con incertidumbre de $+25 \%$ y $-25 \%$ de $\eta_{N}$ respectivamente $^{4}$. Los valores verdaderos son los obtenidos de la simulación del modelo del proceso. La conmutación entre los observadores se da en el instante $t_{c}$, que es cuando la medición alcanza el valor de saturación del sensor de OD $x_{\text {sat }}$. La estimación de la biomasa luego de la conmutación en el instante $t_{c}$ es la que se obtiene del observador asintótico (4.26).

Se puede ver que tan pronto como se inicia el proceso, el observador exponencial converge rápidamente al valor verdadero de $\mu$, a pesar del gran pico inverso inicial que se detalla en la ampliación de la Figura 4.2a gráfico superior. Por otra parte, se puede ver que la incertidumbre en $\eta$ no afecta a las estimaciones obtenidas a partir del observador exponencial. Cuando se conmuta al observador asintótico en el instante $t_{c}$ se pueden ver dos situaciones

\footnotetext{
${ }^{4}$ Para los casos siguiente esta información se detalla únicamente en las leyendas y capturas de cada gráfico
} 


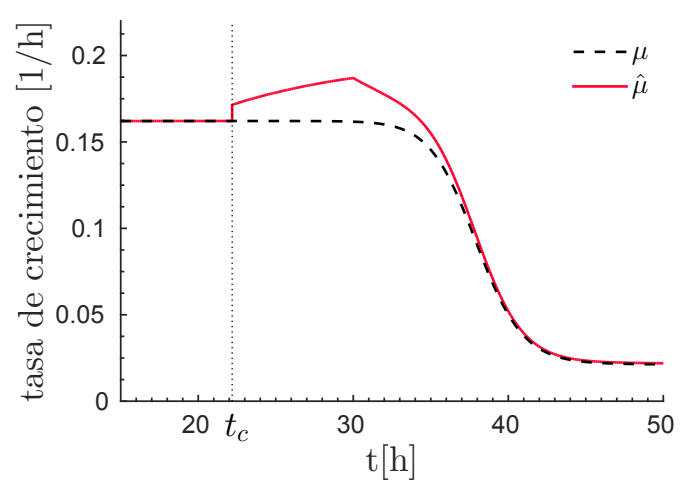

(a) Tasa específica de crecimiento (trazos negros) y estimación (continua roja).

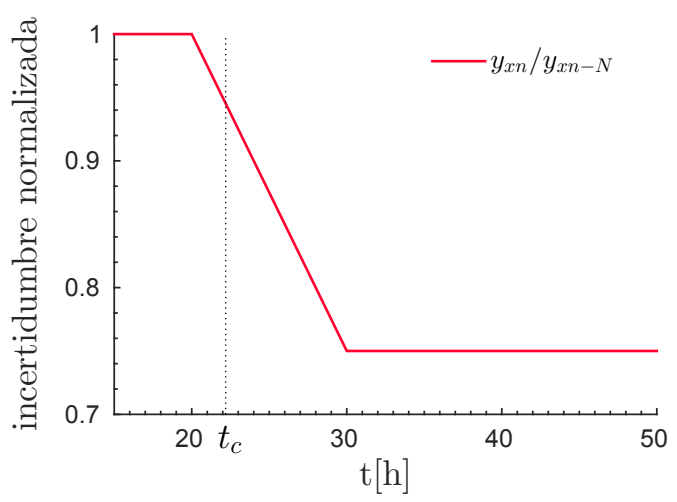

(c) Incertidumbre normalizada, variación de $y_{x n}$ respecto del valor nominal $y_{x n-N}$

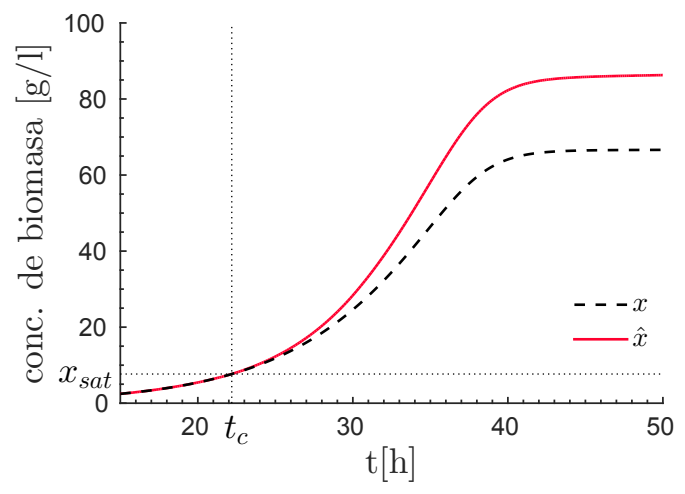

(b) Concentración de biomasa (trazos negros) y estimación (continua roja).

Figura 4.3: Resultados de simulación para el caso en que el rendimiento $y_{x n}$ presenta variación temporal.

diferentes: en el caso sin error en $\eta$, la estimación permanece de manera inalterada sobre el valor verdadero tanto para la tasa de crecimiento como para la concentración de biomasa. En cambio, en los casos con incertidumbre en $\eta$ aparecen diferencias en $\mu$ en el instante de conmutación, que están dominados mayormente por el primer término de (4.38). Sin embargo, las estimaciones convergen asintóticamente al valor verdadero como se predijo. La tasa de convergencia está determinada por la tasa de dilución que no es muy alta debido a las elevadas concentraciones de FCE y FN utilizadas para alimentar el proceso. Por otra parte se puede ver que las estimaciones de la concentración de biomasa cuando hay incertidumbre convergen a un valor erróneo con la misma tasa que la estimación de la tasa de crecimiento, sin embargo este error no se ve reflejado en $\hat{\mu}$.

La Figura 4.3 muestra los resultados de simulación para el caso en que el rendimiento de nitrógeno a biomasa varía en el tiempo, es decir, $\dot{y}_{x n} \neq 0$. Inicialmente el rendimiento tiene un valor constante igual al nominal $y_{x n-N}$. A las 20 horas empieza a decrecer linealmente hasta las 30 horas del proceso, llegando a un valor igual al $75 \%$ del nominal. A partir de ese instante nuevamente permanece constante. Se puede ver la curva en la Figura 4.3c. El valor de la pendiente del cambio en el rendimiento usada en la simulación se hizo elevada a propósito 


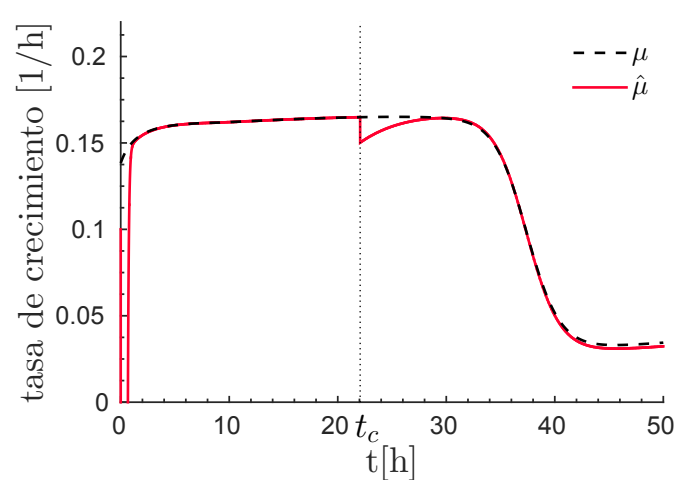

(a) Tasa específica de crecimiento (trazos negros) y estimación (continua roja).

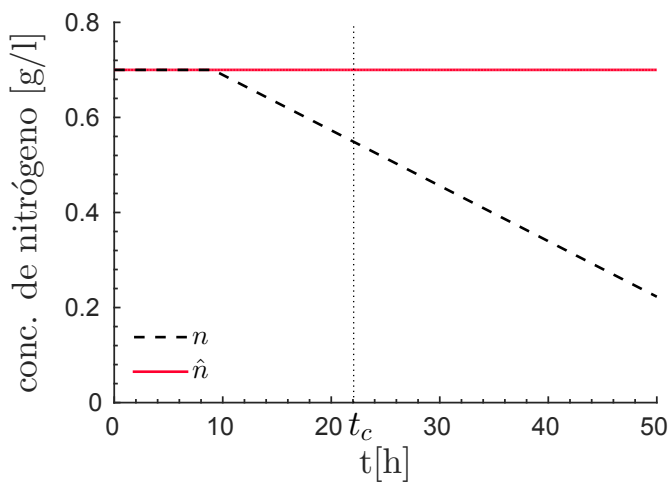

(c) Concentración de nitrógeno (trazos negros) y estimación (continua roja).

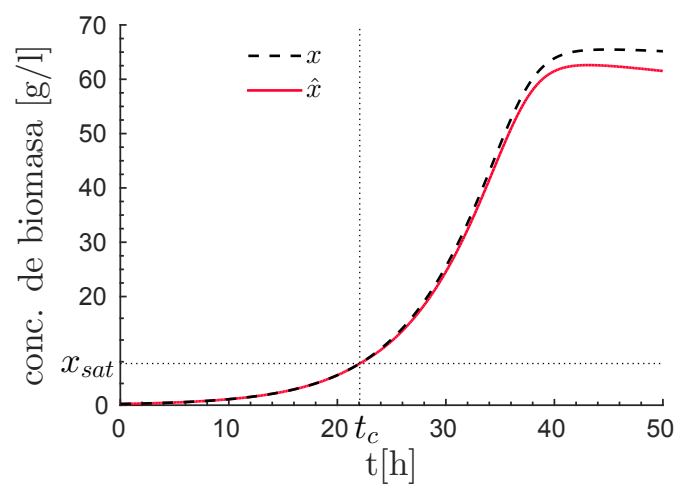

(b) Concentración de biomasa (trazos negros) y estimación (continua roja).

Figura 4.4: Resultados de simulación para el caso en que la concentración de nitrógeno varía.

para hacer más evidentes los errores producidos en la estimación de la tasa de crecimiento. Sin embargo, se debe tener en cuenta que esto representa un escenario muy pesimista, ya que no es esperable en la práctica ver grandes variaciones en los rendimientos.

Si bien no se muestra el transitorio inicial, en la Figura 4.3a se puede observar que la estimación de la tasa de crecimiento obtenida con el observador exponencial se ve inalterada al variar el $y_{x n}$ (entre las 20 y 22 horas). Luego, al conmutar al observador asintótico aparece un error en la estimación y la misma empieza a converger a un valor distinto al verdadero, como se describe en (4.38). Sin embargo, al dejar de variar el rendimiento a las 30 horas la estimación vuelve a converger (asintóticamente) al valor verdadero de $\mu$, aún cuando se tiene un valor erróneo del rendimiento. Este es un punto interesante del observador ya que es esperable tener incertidumbre en los rendimientos. En efecto, la estimación de $\mu$ no se va a ver alterada por rendimientos constantes. En la Figura 4.3b se muestra la estimación de biomasa residual. En este caso, no sólo la derivada del rendimiento afecta la estimación como se puede deducir de (4.32c), sino también el error constante en el rendimiento, ya que al recuperar $x$ de $z$ como en (4.26) es necesario afectar por el valor (erróneo) del rendimiento.

La Figura 4.4 muestra los resultados de simulación para el caso en que el nitrógeno varía 
en lugar de permanecer en un valor constante como se asume en el diseño del observador. Para esto, se simula una concentración de nitrógeno decreciente como las que se ven en [33]. La Figura 4.4a muestra la tasa específica de crecimiento y su estimación, la Figura 4.4b muestra la concentración de biomasa residual y su estimación, y la Figura 4.4c muestra la concentración de nitrógeno y el valor estimado que se supone a partir del lazo cerrado de $\mathrm{pH}$.

Se puede observar que mientras opera el observador exponencial la variación en el nitrógeno no afecta a las estimaciones (entre las 10 y 22 horas). Luego, al conmutar al observador asintótico aparece un error en la estimación de $\mu$ como se observa en Figura 4.4a, sin embargo, a pesar del decrecimiento del nitrógeno, la estimación converge a un entorno muy pequeño del valor verdadero de $\mu$. El error de estado estacionario viene dado por (4.40) con $\gamma=0$, es decir,

$$
\lim _{t \rightarrow \infty} \tilde{\mu}=-\frac{\dot{n}}{z-n}=-\frac{\dot{n} y_{x n}}{x} .
$$

Como se puede ver, este error es muy chico siempre que la variación del nitrógeno sea lenta, y el nitrógeno utilizado para formar la biomasa sea grande $\left(x / y_{x n}\right)$. En el caso de la estimación de biomasa el error también es pequeño a pesar de depender directamente del error en la concentración de nitrógeno $\left(\tilde{x}=(\tilde{z}-\tilde{n}) y_{x n}\right)$. La razón de esto es que por un lado $\tilde{z}=0$ ya que es independiente de la estimación de nitrógeno (ver (4.32c)), y por otra parte la magnitud de $\tilde{n} \cdot y_{x n}$ es pequeña comparada con la concentración celular que se alcanza al final de la etapa de crecimiento.

\subsubsection{Resultados experimentales}

En esta sección se muestra la validación experimental del observador propuesto. Se utiliza como entrada del observador a la dilución $D$, las entradas de fuente de carbono $F_{s}$, fuente de nitrógeno $F_{n}$ y la medida en línea de densidad óptica hasta que ésta deja de ser confiable (entre las 15 y las 20 horas aproximadamente). La conmutación entre observadores se realiza cuando la concentración de biomasa alcanza los 7,67g/l (absorbancia de 0.6) en el tiempo $t_{c} \cong 19 h$.

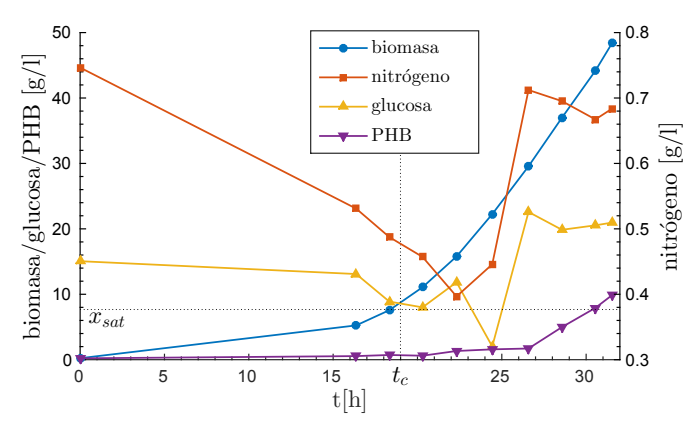

(a) Experimento A.

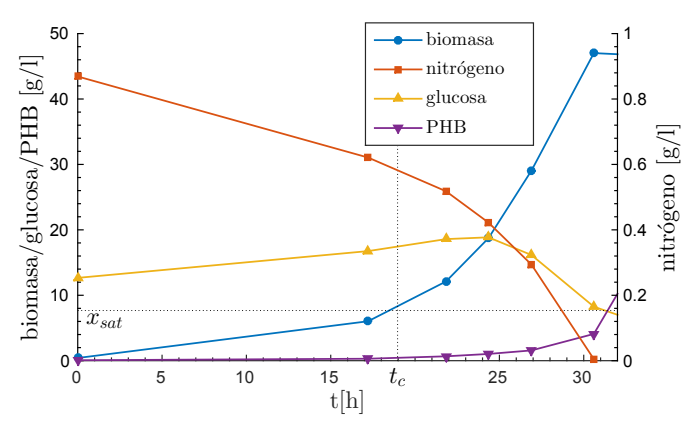

(b) Experimento B.

Figura 4.5: Resultados experimentales: Concentraciones de metabolitos y sustratos principales en dos experimentos distintos. 


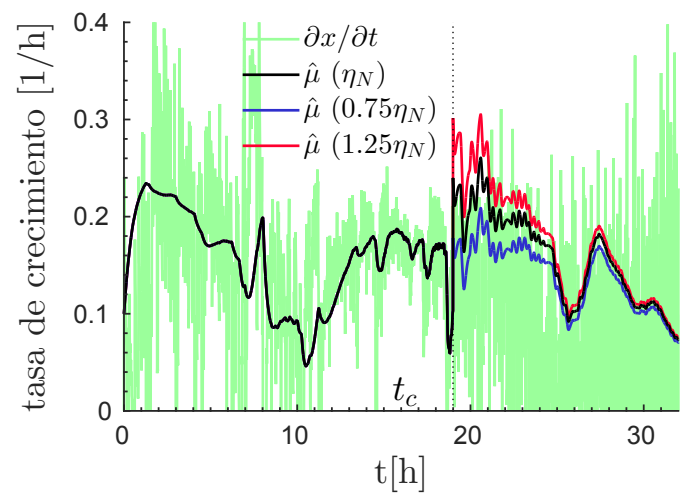

(a) Experimento A: Estimaciones de la tasa específica de crecimiento (curvas roja, negra y azul) y referencia obtenida de la diferenciación de la medición en línea de biomasa (verde).

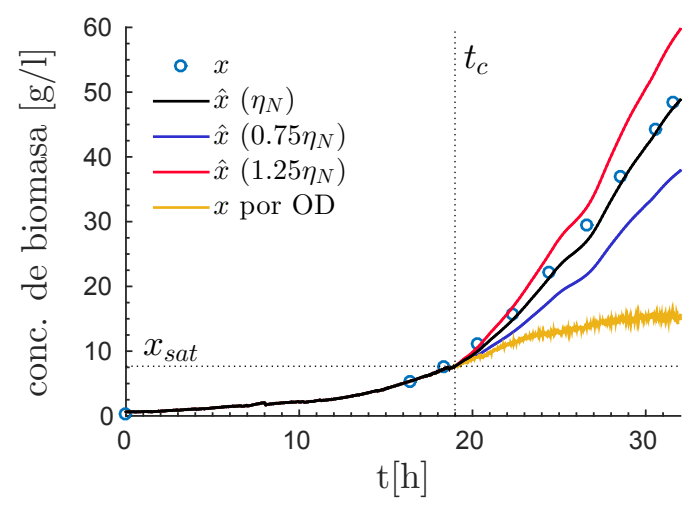

(c) Experimento A: Medidas de concentración de biomasa fuera de línea (círculos azules), en línea (curva amarilla) y estimaciones (curvas roja, negra y azul).

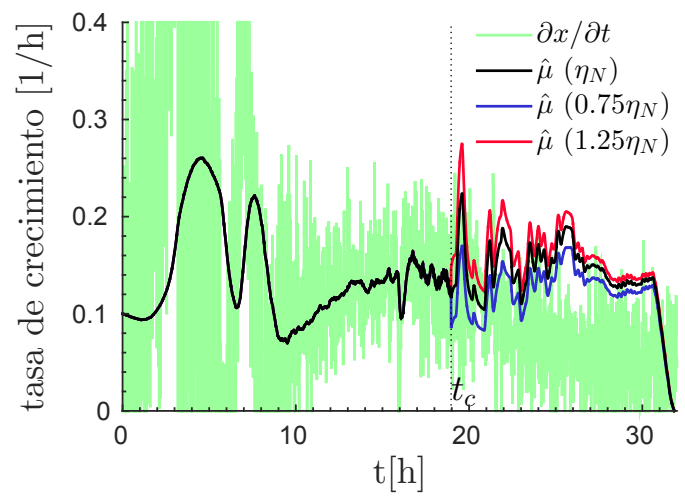

(b) Experimento B: Estimaciones de la tasa específica de crecimiento (curvas roja, negra y azul) y referencia obtenida de la diferenciación de la medición en línea de biomasa (verde).

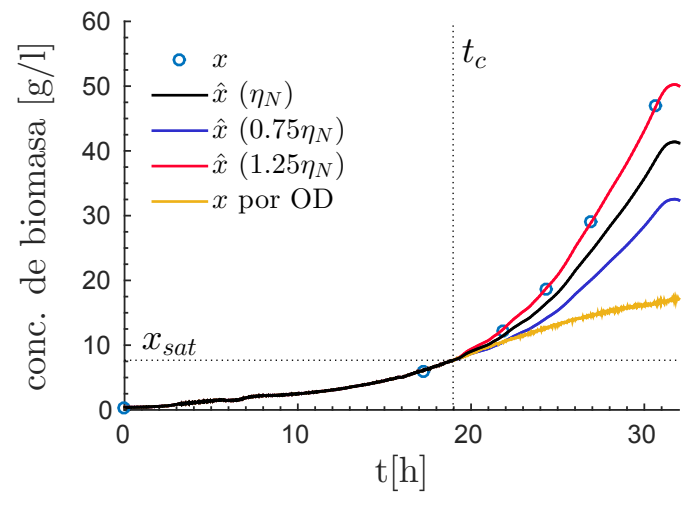

(d) Experimento B: Medidas de concentración de biomasa fuera de línea (círculos azules), en línea (curva amarilla) y estimaciones (curvas roja, negra y azul).

Figura 4.6: Resultados experimentales para el observador propuesto con diferentes valores de $\eta$.

El equipo de laboratorio es sólo capaz de manejar las bombas a una velocidad constante, por lo que los distintos valores de caudal se obtienen variando su ciclo de trabajo. De esta manera, los sustratos se alimentan al biorreactor en forma de pulsos, con varios minutos de diferencia entre dosis. Esto es particularmente así con la fuente de carbono que se debe alimentar con un caudal muy bajo debido a la alta concentración en la que se encuentra en el reservorio. Teniendo en cuenta que ésta es una limitación innecesaria del equipo utilizado, se utilizó un filtro FIR para distribuir cada pulso de sustrato en el tiempo y obtener estimaciones más suaves. Las entradas filtradas son las que se obtendrían usando otras bombas, de mayor precisión.

Las Figuras 4.5a y 4.5b muestran las medidas fuera de línea de las concentraciones de biomasa, glucosa, nitrógeno y PHB para cada uno de los experimentos. La Figura 4.6 muestra las estimaciones realizadas por el observador para dos experimentos distintos (experimento A y experimento B, respectivamente). Las Figuras 4.6a y 4.6b muestran las estimaciones de la 


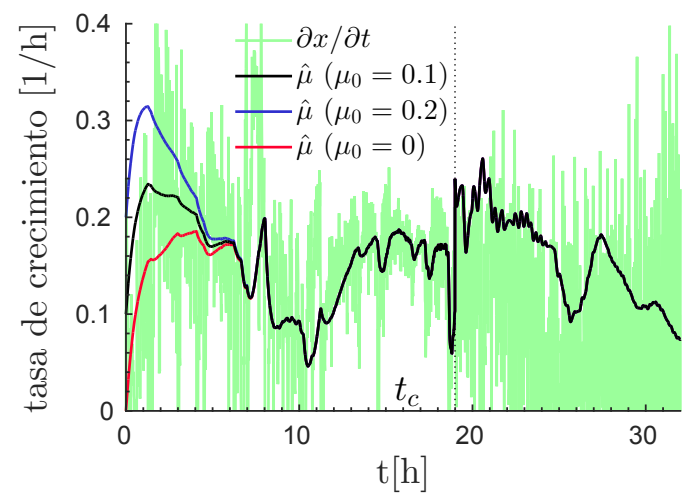

(a) Experimento A: Estimaciones de la tasa específica de crecimiento (curvas roja, negra y azul) y referencia obtenida de la diferenciación de la medición en línea de biomasa (verde).

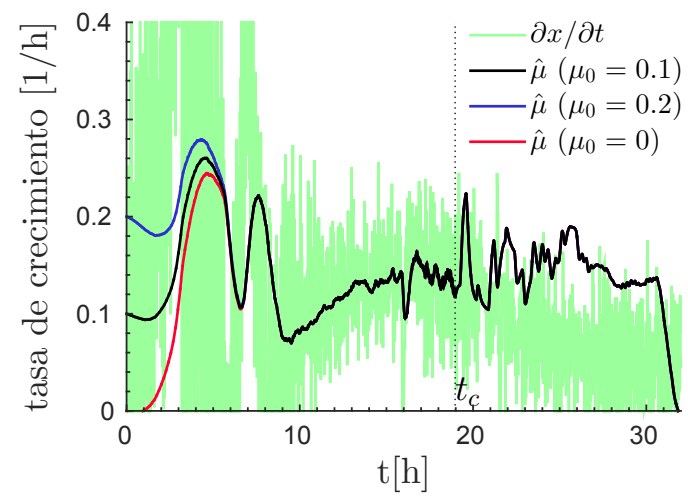

(b) Experimento B: Estimaciones de la tasa específica de crecimiento (curvas roja, negra y azul) y referencia obtenida de la diferenciación de la medición en línea de biomasa (verde).

Figura 4.7: Resultados experimentales para el observador propuesto con diferentes condiciones iniciales en el observador exponencial.

tasa de crecimiento para cada experimento, considerando varios valores para el rendimiento de alimentación de nitrógeno, de manera de hacer más explícita la convergencia de la estimación. Al igual que en las simulaciones se consideran los casos con $\eta_{N}, 0,75 \eta_{N}$ y $1,25 \eta_{N}$. Además, se incluye como referencia la tasa específica de crecimiento (ruidosa) que se obtiene de despejar $\mu$ en (4.17a) y derivar numéricamente la medición de $\mathrm{OD}$, es decir, $\hat{\mu}=\frac{\Delta x}{\Delta t} \frac{1}{x}+D$. Se debe tener en cuenta que además de ser extremadamente ruidosa, esta referencia es válida sólo durante las primeras horas del cultivo ya que luego el sensor de OD satura, lo cual explica la discrepancia entre las estimaciones realizadas y la referencia pasado el punto de conmutación. Las Figuras 4.6c y 4.6d muestran las estimaciones de la concentración de biomasa, su medida en línea obtenida por OD y sus medidas off-line como referencias.

Se puede ver en las Figuras 4.6a y 4.6b que, como se esperaba del análisis teórico, las estimaciones obtenidas por medio del observador exponencial hasta $t_{c}$ no se ven afectadas por la incertidumbre en el rendimiento $\eta$. En instante de conmutación $t_{c}$ aparecen errores en la estimación de $\mu$ atribuibles principalmente a los errores en $\eta$ y a la variación del nitrógeno que puede apreciarse en las Figuras 4.5a y 4.5b. De todas maneras, a medida que pasa el tiempo todas las estimaciones de $\mu$ convergen al mismo valor y los errores se atenúan según se describe en (4.40).

Finalmente, para destacar el aporte del observador exponencial, en las Figuras 4.7a y 4.7b se muestran las estimaciones obtenidas al variar la condición inicial de la estimación de la tasa de crecimiento para los mismos experimentos A y B. En ellas se puede observar cómo todas las estimaciones convergen a un mismo valor en aproximadamente 7 horas, siendo ya la magnitud del error chica un par de horas antes. 


\subsection{Resumen del capítulo}

En este capítulo se trató el problema de estimación de la tasa específica de crecimiento en el proceso de producción de PHB. Durante las primeras horas de la fase de crecimiento se utiliza un observador exponencial basado en la medición de la concentración celular. Luego, cuando el sensor de DO satura por la alta densidad celular, se pasa al observador asintótico propuesto. Éste toma la información proveniente del lazo de control de pH que además regula la concentración de nitrógeno. Se hizo un análisis de los errores de estimación debidos a incertidumbres en parámetros del modelo. Las simulaciones y pruebas experimentales permitieron validar lo desarrollado de manera teórica. 


\section{|| Capítulo 5 \\ Observadores para etapa de producción}

En este capítulo se trata el problema de estimación de tasas específicas de producción durante la fase de producción de PHB. Se proponen dos versiones de un observador por modos deslizantes de orden superior que obtiene información de la tasa específica de producción a partir de los cambios de volumen del proceso. La primera versión corresponde al caso en el que se dispone de medidas de biomasa residual, la segunda para cuando se dispone de medidas del volumen. El observador propuesto utiliza una función de conmutación no lineal para asegurar la convergencia global a pesar de la no linealidad del proceso y de la dinámica del volumen. Se demuestra la estabilidad del observador. Además, se analiza la tasa decaimiento de los errores en función de las ganancias del observador, proveyéndose una herramienta para su sintonización. Finalmente, se presentan resultados experimentales y de simulación que permiten validar el algoritmo propuesto. Los resultados obtenidos son extensibles a procesos de alta densidad celular en general.

Parte de los contenidos y resultados expuestos en este capítulo han sido publicados en [65]: Martín Jamilis, Fabricio Garelli, Md. Salatul Islam Mozumder, Castañeda Teresita y Hernán De Battista. Modeling and estimation of production rate for the production phase of non-growthassociated high cell density processes. Bioprocess and Biosystems Engineering, 38(10): 1903 1914, 2015.

\subsection{Introducción}

En el Capítulo 3 se introdujeron problemas asociados a procesos de alta densidad celular que dificultan la aplicación de soluciones desarrolladas para el monitoreo y control de procesos estándar. Los principales obstáculos se pueden resumir como:

- Dificultad en la medición de concentraciones por métodos ópticos debido a la gran opacidad del medio, en particular la medida de densidad óptica para determinación de la concentración de biomasa.

- Volumen de la fase biótica no despreciable frente al de la fase líquida, en particular si 
los productos generados son intracelulares, debido a la gran concentración de microorganismos y la acumulación de grandes volúmenes de producto

- Efecto de contracción del volumen de la fase líquida al alimentar medios muy concentrados, cuya densidad es mucho mayor que la densidad del medio.

Existen muchos ejemplos de este tipo de procesos [10], en general asociados a tratamientos de residuos y obtención de productos con valor a partir de éstos. La producción de PHB por C. necator es uno de estos procesos [33, 12, 69], aunque también se destaca la producción de lípidos por Rhodosporidium toruloides para la industria del biodiesel [7, 34, 8]. Por lo tanto, resulta interesante tanto para la producción de PHB, como para otros procesos de alta densidad celular el desarrollo de nuevos algoritmos de estimación adecuados a sus no linealidades y restricciones.

En el Capítulo 4 se estudió el problema de estimación de la tasa de crecimiento en la correspondiente etapa de crecimiento. En este capítulo el objetivo es estimar la tasa de producción de PHB en la etapa de producción del proceso, teniendo en cuenta las particularidades de dicha etapa. En particular, la alta concentración celular, el crecimiento nulo y las variaciones no lineales de volumen. Con este fin sería ideal disponer de un sensor capaz de medir la concentración de PHB para evitar afectar las estimaciones por las incertidumbres en los rendimientos. Sin embargo, hay poca evidencia de que se pueda medir el PHB (intracelular) de manera confiable y accesible económicamente. En $[44,42]$ se habla de la posibilidad de detectar lípidos acumulados intracelularmente por Arxula adeninivorans utilizando espectroscopía dieléctrica. Sin embargo, los resultados presentados sugieren todo lo contrario. Ya que, una vez que finaliza el crecimiento y empieza la acumulación, la capacitancia medida permanece casi constante (al menos a las frecuencias en las que se mide el crecimiento). Esto indicaría que mediante sensores capacitivos es posible medir la concentración de microorganismos independientemente del producto acumulado, como indica [43] que sucede en cultivos de Ralstonia eutropha para producción de PHB.

Surge entonces la posibilidad de estimar la tasa de producción a partir de mediciones de la concentración de biomasa residual. Para ello se debe establecer un modelo del proceso donde la tasa de producción $q_{p}$ sea observable cuando $x$ es la salida. La obtención de ese modelo se basa en los resultados obtenidos en la Sección 3.3 y se desarrolla en la Sección 5.2. Del mismo modelo se ve también que la estimación de la tasa de producción puede ser obtenida a partir de la medición del volumen total en el biorreactor, lo que es muy conveniente a nivel industrial. Alternativamente, la estimación podría obtenerse a partir de la medición de gases $\left(\mathrm{O}_{2} \mathrm{O} \mathrm{CO}_{2}\right)$ o a partir de la medición de la concentración de sustratos. En este caso particular la medición de sustrato no es la mejor opción, en primer lugar por el anteriormente mencionado costo y especificidad de la medida. En segundo lugar, porque en general los sustratos utilizados en este tipo de procesos son residuos, por lo tanto son impuros y probablemente poco caracterizados. Por otra parte, la medición de gases siempre es una buena opción. Sin embargo, se debe tener en cuenta su elevado costo, menor accesibilidad incluso a nivel de laboratorio y menor 
portabilidad que un sensor de biomasa.

Como se explica en el Capítulo 3, la obtención del volumen como la simple integración de los caudales no es completamente válida en condiciones de alta densidad celular, pudiendo incluso generar errores en la estimación de otras variables. Ya en [113] se considera de manera separada el volumen de las células y el de la fase líquida para la obtención del volumen total del proceso y definición de concentraciones. Un concepto similar se sugiere en [114, 115]. En [116] se obtienen estimaciones de la concentración de biomasa a partir de análisis de gases y considerando su efecto en el volumen total, la densidad del medio se asume uniforme. Entonces, para el desarrollo del observador, se utiliza el modelo de volumen (3.42) propuesto en la Sección 3.3.4.

El resto de este capítulo se organiza de la siguiente manera: primero, en la Sección 5.2 se adecúa el modelo de concentraciones y de volumen para el planteo del observador. Luego, en la Sección 5.3 se propone el observador para tasa de producción, se analiza su estabilidad y la tasa de decaimiento de los errores. A continuación, en la Sección 5.4.1 se muestran resultados de simulación para el observador en distintas situaciones. Finalmente, en la Sección 5.4.2 se muestran resultados experimentales para el observador.

\subsection{Reducción del modelo para la etapa de producción}

Como la masa de biomasa residual $X$ es constante y conocida durante la etapa de producción, se puede redefinir el volumen en términos de la concentración de biomasa, o bien, la biomasa en función del volumen, dependiendo de cuál de las dos variables se mide en línea. Esto permite reducir el número de estados del modelo y simplificar la formulación del observador de tasa de producción. En (3.13) se establecía la dinámica de las concentraciones del proceso en la etapa de producción

$$
\begin{aligned}
\dot{x} & =-D x \\
\dot{p} & =q_{p} x-D p \\
\dot{f}_{p} & =q_{p},
\end{aligned}
$$

donde las concentraciones de biomasa residual y PHB se definen en función de sus masas y el volumen total del biorreactor (fase líquida + fase biótica)

$$
\begin{aligned}
& x=\frac{X}{V} \\
& p=\frac{P}{V} .
\end{aligned}
$$

Además, se adopta la definición general de la dilución presentada en el Capítulo 3

$$
D=\frac{\dot{V}}{V}
$$


en lugar del cociente entre el flujo de entrada y el volumen. Por otra parte, de manera similar a lo propuesto en [113], se puede redefinir la concentración de sustrato teniendo en cuenta que, a diferencia de la biomasa y producto, se halla disuelto en la fase líquida

$$
\begin{aligned}
& s=\frac{S}{V_{l}} \\
& \dot{s}=-\frac{q_{p} X}{y_{p s} V_{l}}-\frac{\dot{V}_{l}}{V_{l}} s+\frac{F_{s}}{V_{l}} s_{f}
\end{aligned}
$$

siendo $V_{l}$ el volumen de fase líquida

$$
\dot{V}_{l}=-\frac{q_{p} X}{s_{r} y_{p s}}+F_{s} \frac{s_{f}}{s_{r}}
$$

presentado en (3.37). Finalmente, el modelo de volumen se presentó en (3.42) como

$$
\dot{V}=F_{s} \gamma+q_{p} v X
$$

Considerando el caso en el que se dispone de un sensor capaz de medir la concentración de biomasa se puede obtener un modelo reducido orientado al diseño de observadores como

$$
\begin{aligned}
V & =\frac{X}{x} \\
D & =\frac{F_{s} \gamma x}{X}+q_{p} x v \\
\dot{x} & =-\left(\frac{F_{s} \gamma}{X}+q_{p} v\right) x^{2} .
\end{aligned}
$$

En cambio, en el caso en el que se dispone de una medición de volumen

$$
\begin{aligned}
x & =\frac{X}{V} \\
\dot{V} & =F_{s} \gamma+q_{p} v X .
\end{aligned}
$$

\subsection{Observador de tasa específica de producción}

\subsubsection{Conceptos preliminares}

El observador de tasa específica de producción propuesto es una reformulación del algoritmo super-twisting [102] que tiene en cuenta las no linealidades específicas del proceso bajo estudio. El observador se presenta en dos formas distintas según se mida la biomasa residual o el volumen del proceso.

El observador que se propone no requiere del modelo cinético de $q_{p}$. Sin embargo, se requiere como condición necesaria para la convergencia que la primer derivada respecto del tiempo de la tasa de producción sea acotada: $\left|\dot{q}_{p}\right|<\bar{\varrho}$. Es decir, que se tenga una cota de qué 
tan rápido varía $q_{p}$.

\subsubsection{Observador con medición de biomasa residual}

En primer lugar plantearemos el observador en el escenario en el cual se dispone de medición en línea de biomasa residual independientemente del producto acumulado, véase por ejemplo $[43,44]$.

Primero, se reescribe (5.8c) como

$$
\dot{x}=\left(-v q_{p}+f(x, t)\right) x^{2}
$$

donde $f(x, t)=-\frac{F_{s} \gamma}{X}$ es una función del caudal de entrada. Luego, el observador propuesto es

$$
\left\{\begin{array}{l}
\dot{\hat{x}}=\left(-v \hat{q}_{p}+f(x, t)-(\bar{\varrho} v) 2 \beta|\sigma|^{\frac{1}{2}} \operatorname{sign}(\sigma)\right) \hat{x}^{2} \\
\dot{\hat{q}}_{p}=\bar{\varrho} \alpha \operatorname{sign}(\sigma) \\
\sigma=(\bar{\varrho} v)^{-1}\left(x^{-1}-\hat{x}^{-1}\right)
\end{array}\right.
$$

donde $\hat{x}$ y $\hat{q}_{p}$ son la biomasa residual y tasa de producción estimadas, $\alpha$ y $\beta$ son ganancias de diseño, $\bar{\varrho}$ es la cota para la derivada de la tasa de producción y $\sigma$ es la función de deslizamiento. Usualmente, la función de deslizamiento se define como el error de estimación en la variable medida, que sería $x-\hat{x}$. Sin embargo, aquí se propone una función distinta que permite tener en cuenta las no linealidades específicas de este proceso a la vez que se puede asegurar la convergencia global del estimador. Nótese además, que la ganancia $\alpha$ del observador debe ser $\alpha>1$ para que la estimación sea más rápida que la variable verdadera. Con esto se evita agregar dinámica a la estimación y tener un seguimiento sin errores.

\subsubsection{Análisis de estabilidad del observador}

La prueba de estabilidad para este observador se realiza en dos pasos. Primero se define una inclusión diferencial lineal politópica (PLDI) que incluya todas las trayectorias del error posibles del estimador propuesto. Segundo, se muestra la estabilidad de la PLDI según Lyapunov para un par de ganancias $\alpha$ y $\beta$.

Los errores de estimación se definen como $\tilde{x}=x-\hat{x}$ y $\tilde{q}_{p}=q_{p}-\hat{q}_{p}$. Luego, derivando y reemplazando en (5.8c) y (5.11), se obtienen las ecuaciones del error.

$$
\begin{aligned}
\dot{\tilde{x}} & =-v\left(q_{p} x^{2}-\hat{q}_{p} \hat{x}^{2}\right)-f(x, t)\left(x^{2}-\hat{x}^{2}\right)+\left(\bar{\varrho} v \hat{x}^{2}\right) 2 \beta|\sigma|^{\frac{1}{2}} \operatorname{sign}(\sigma) \\
\dot{\tilde{q}}_{p} & =\dot{q}_{p}-\bar{\varrho} \alpha \operatorname{sign}(\sigma)
\end{aligned}
$$


Lema 1. Si se aplica el cambio de coordenadas

$$
\xi \triangleq\left[\begin{array}{c}
\bar{\varrho}|\sigma|^{\frac{1}{2}} \operatorname{sign}(\sigma) \\
\tilde{q}_{p}
\end{array}\right]
$$

$a(5.12 \mathrm{a})$ y (5.12b), se puede deducir que

$$
\dot{\xi}=\frac{\bar{\varrho}}{\left|\xi_{1}\right|} A(t) \xi \quad A(t) \in \mathscr{A}
$$

donde $\mathscr{A}$ es una PLDI definida como

$$
\begin{aligned}
\mathscr{A} & =\operatorname{conv}\left(A_{1}, A_{2}\right) \\
A_{1} & =\left[\begin{array}{cc}
-\beta & 1 / 2 \\
-\alpha+1 & 0
\end{array}\right] \\
A_{2} & =\left[\begin{array}{cc}
-\beta & 1 / 2 \\
-\alpha-1 & 0
\end{array}\right]
\end{aligned}
$$

Demostración. Para empezar, se deriva $\xi_{1}$ en (5.13):

$$
\dot{\xi}_{1}=\bar{\varrho}\left(\frac{1}{2}|\sigma|^{-\frac{1}{2}} \operatorname{sign}(\sigma) \dot{\sigma} \operatorname{sign}(\sigma)+0\right)=\frac{\bar{\varrho}}{2|\sigma|^{\frac{1}{2}}} \dot{\sigma} .
$$

A continuación, se calcula $\dot{\sigma}$ en (5.11) y se lo reemplaza en (5.16):

$$
\dot{\xi}_{1}=\frac{\bar{\varrho}}{2|\sigma|^{\frac{1}{2}}}\left(\frac{\tilde{q}_{p}}{\bar{\varrho}}-2 \beta|\sigma|^{\frac{1}{2}} \operatorname{sign}(\sigma)\right)=\frac{1}{|\sigma|^{\frac{1}{2}}}\left(\frac{\tilde{q}_{p}}{2}-\beta \xi_{1}\right) .
$$

Luego, reemplazando $\left|\xi_{1}\right|=\bar{\varrho}|\sigma|^{\frac{1}{2}}$ :

$$
\dot{\xi}_{1}=\frac{\bar{\varrho}}{\left|\xi_{1}\right|}\left(\frac{\tilde{q}_{p}}{2}-\beta \xi_{1}\right)
$$

En segundo lugar, se deriva $\xi_{2}$ de (5.13):

$$
\dot{\xi}_{2}=\dot{q}_{p}-\bar{\varrho} \alpha \operatorname{sign}(\sigma)=\bar{\varrho} \operatorname{sign}(\sigma)\left(\frac{\dot{q}_{p}}{\bar{\varrho} \operatorname{sign}(\sigma)}-\alpha\right)
$$

Como $\bar{\varrho}$ es la cota superior de $\dot{q}_{p}$, el primer término dentro del paréntesis en (5.19) se puede remplazar por el parámetro $U \triangleq \frac{\dot{q}_{p}}{\bar{\varrho} \operatorname{sign}(\sigma)} \in[-1,1]$

$$
\dot{\xi}_{2}=\frac{\xi_{1}}{|\sigma|^{\frac{1}{2}}}(U-\alpha)=\frac{\bar{\varrho}}{\left|\xi_{1}\right|}(U-\alpha) \xi_{1} .
$$


Finalmente, de (5.18) y (5.20) se obtiene la inclusión diferencial

$$
\dot{\xi} \in \frac{\bar{\varrho}}{\left|\xi_{1}\right|}\left[\begin{array}{cc}
-\beta & 1 / 2 \\
U-\alpha & 0
\end{array}\right] \xi
$$

La estabilidad de una PLDI se puede demostrar en el sentido de Lyapunov. Para ello [117]:

Definición 1. Una PLDI $\left\{\dot{x}=A x, A \in \mathscr{A}, \mathscr{A}=\operatorname{conv}\left(A_{i}\right)\right\}$ se dice cuadráticamente estable si existe una función de Lyapunov cuadrática $V(x)=x^{T} P x, P \succ 0$ que decrece en todas las trayectorias no nulas, es decir, $\dot{V}(x)<0$.

Lema 2. Es condición necesaria y suficiente para que una PLDI sea cuadráticamente estable que

$$
\begin{aligned}
& P \succ 0 \\
& A_{i}^{T} P+P A_{i} \prec 0 \quad \forall i=1,2, \ldots
\end{aligned}
$$

A partir de esto, podemos definir una función de Lyapunov para el sistema (5.21) como $V(\xi)=\xi^{T} P \xi$. Luego, al derivarla se obtiene

$$
\dot{V}(\xi)=\frac{\bar{\varrho}}{\left|\xi_{1}\right|} \xi^{T}\left(A(t)^{T} P+P A(t)\right) \xi
$$

Notando que $\frac{\bar{\rho}}{\left|\xi_{1}\right|}$ es siempre positiva, se puede ver que $\dot{V}(\xi)<0$ siempre y cuando se cumpla el Lema 2.

La demostración de estabilidad queda sujeta entonces a encontrar una matriz $P$ que cumpla con (5.22). A veces encontrar esa matriz de manera analítica no es trivial, por lo que se propone como alternativa la resolución del problema numéricamente. Para ello, se traduce el problema de estabilidad en un problema generalizado de autovalores (GEVP) [117], reescribiendo las matrices $A_{1}$ y $A_{2}$ como:

$$
\begin{gathered}
A_{1}=\beta A_{0}+A_{1}^{\prime} \\
A_{2}=\beta A_{0}+A_{2}^{\prime} \\
A_{0}=\left[\begin{array}{cc}
-1 & 0 \\
0 & 0
\end{array}\right] \quad A_{1}^{\prime}=\left[\begin{array}{cc}
0 & 1 / 2 \\
(1-\alpha) & 0
\end{array}\right] \quad A_{2}^{\prime}=\left[\begin{array}{cc}
0 & 1 / 2 \\
(-1-\alpha) & 0
\end{array}\right] .
\end{gathered}
$$

Luego, tomando distintos valores de $\alpha>1$ se resuelve un problema de optimización donde el objetivo es hallar el mínimo valor de la ganancia $\beta$ para el cual el problema de optimización tiene solución. Es decir, se busca el $\beta$ mínimo que asegure estabilidad cuadrática:

$$
\left\{\begin{array}{l}
P \succ 0 \\
\left(A_{1}^{\prime T} P+P A_{1}^{\prime}\right)+\beta\left(A_{0}^{T} P+P A_{0}\right) \prec 0 \\
\left(A_{2}^{\prime T} P+P A_{2}^{\prime}\right)+\beta\left(A_{0}^{T} P+P A_{0}\right) \prec 0
\end{array}\right.
$$




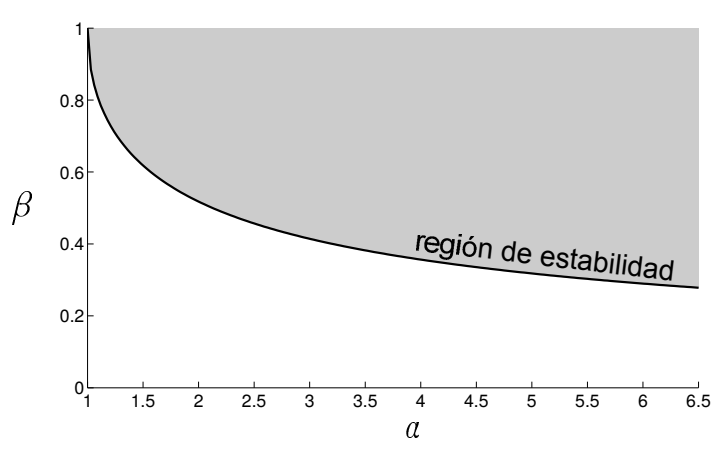

Figura 5.1: Pares de $\alpha$ y $\beta$ para los cuales se asegura estabilidad del observador.

El problema (5.27) es cuasi-convexo y se puede resolver por bisección en $\beta$ y comprobando la factibilidad del problema en cada paso de iteración. Los cálculos numéricos para resolver el GEVP se realizaron utilizando YALMIP [118]. En la Figura 5.1 se grafican los pares $(\alpha, \beta)$ para los cuales se puede garantizar la estabilidad cuadrática de (5.21).

Observación 3: Si la concentración de fuente de carbono no está siendo regulada correctamente y varía a lo largo del proceso, aparecerán errores en la estimación de la tasa de producción. Considerando esa situación, se puede replantear el error de estimación de la concentración de biomasa como

$$
\dot{\tilde{x}}=\frac{q_{p} x^{2}}{y_{p s} s}-\frac{\hat{q}_{p} \hat{x}^{2}}{y_{p s} s_{r}}-\left(\frac{x^{2}}{s}-\frac{\hat{x}^{2}}{s_{r}}\right) \frac{F_{s} s_{f}}{X}+\frac{V_{m} \dot{s} x^{2}}{X s}+\left(\bar{\varrho} v \hat{x}^{2}\right) 2 \beta|\sigma|^{\frac{1}{2}} \operatorname{sign}(\sigma) .
$$

Una vez que la estimaciones convergen $x=\hat{x}$ y $\dot{\tilde{x}}=0$. Por lo tanto, se puede mostrar que:

$$
\hat{q}_{p}=q_{p} \frac{s_{r}}{s}+\left(1-\frac{s_{r}}{s}\right) \frac{F_{s} s_{f} y_{p s}}{X}+\dot{s} \frac{V_{m} y_{p s}}{X} \frac{s_{r}}{s}
$$

donde se puede ver que la magnitud del error de estimación de la tasa de producción depende mayormente de la desviación en la concentración de sustrato respecto del valor deseado $\left(\frac{s r}{s}\right)$ y en qué tan rápido es ese desvío.

\subsubsection{Cotas para la convergencia}

Se puede obtener una condición de estabilidad más fuerte si se analiza la tasa de decaimiento de la PLDI (5.21), que se define como el $\delta$ más grande tal que

$$
\lim _{t \rightarrow \infty} e^{\delta t}\|\xi(t)\|=0
$$

para todas las trayectorias de $\xi(t)$.

Teorema 5.1. Dada una inclusión diferencial lineal (LDI) $\dot{x}=A(t) x$ y dada una función de Lyapunov cuadrática $V(x)=x^{T} P x$. Si $\dot{V}(x) \leq-2 \delta V(x)$ para todas las trayectorias, entonces 


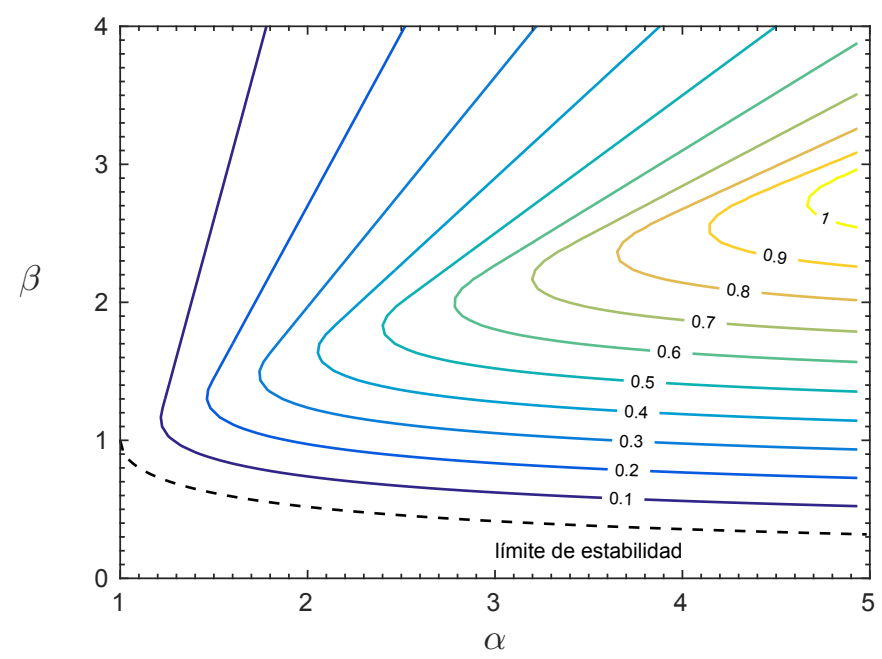

Figura 5.2: Tasa de decaimiento para distintos pares $\alpha$ y $\beta$

$V(x(t)) \leq V(x(0)) e^{-2 \delta t}$, tal que $\|x(t)\| \leq e^{-\delta t} \kappa(P)^{1 / 2}\|x(0)\|$ para todas las trayectorias, siendo $\kappa(P)$ el número de condición de $P$, y por lo tanto la tasa de decaimiento de la LDI es al menos $\delta[117$, págs. 66,31$]$.

En el caso de una PLDI, la condición $\dot{V}(x) \leq-2 \delta V(x)$ es equivalente a la desigualdad matricial (LMI)

$$
A_{i}^{T} P+P A_{i}+2 \delta P \leq 0 \quad \forall i=1,2, \ldots
$$

El objetivo entonces es encontrar el valor de $\delta$ más pequeño para el cual la LMI (5.31) tiene solución:

$$
\left\{\begin{array}{l}
P \succ 0, \alpha>0, \beta>0 \\
\operatorname{mín} \delta \\
A_{1}^{T} P+P A_{1}+2 \delta P \prec 0 \\
A_{2}^{T} P+P A_{2}+2 \delta P \prec 0
\end{array}\right.
$$

El problema (5.32) es cuasi-convexo y se puede resolver definiendo una grilla de pares $\alpha$ y $\beta$. Para cada uno de ellos se aplica bisección sobre $\delta$ y se comprueba la factibilidad del problema en cada iteración. Los cálculos se realizaron con el software YALMIP [118]. La Figura 5.2 muestra curvas de nivel para la tasa de decaimiento en función de los pares $(\alpha, \beta)$. Además se muestra el límite de estabilidad cuadrática obtenido en Sección 5.3.3 con una curva a trazos.

La Figura 5.2 es una herramienta útil para la sintonización del observador. Dada una cota para la tasa de decaimiento, se pueden elegir las ganancias $\alpha$ y $\beta$ más pequeñas que permitan satisfacerla.

\subsubsection{Observador con medición de volumen}

Cómo alternativa al observador (5.11), se propone un observador de $q_{p}$ basado en la medida del volumen del biorreactor. Este observador se torna más interesante a nivel industrial, 


\begin{tabular}{clr}
\hline Nombre & Descripción & Valor \\
\hline$V(0)$ & Volumen inicial & 0.8971 \\
$x(0)$ & Concentración de biomasa inicial & $47 \mathrm{~g} / 1$ \\
$F_{s}$ & Caudal de fuente de carbono & $18.6 \mathrm{l} / \mathrm{h}$ \\
$s_{f}$ & Concentración de fuente de carbono en el reservorio & $650 \mathrm{mg} / 1$ \\
$s_{r}$ & Concentración de fuente de carbono regulada & $12 \mathrm{~g} / 1$ \\
$\rho_{p}$ & Densidad del PHB & $1250 \mathrm{~g} / 1$ \\
$\bar{\varrho}$ & Cota de $\left|\dot{q}_{p}\right|$ & 0.026 \\
$v$ & Parámetro del modelo de volumen & $-277 \mathrm{ml} / \mathrm{g}$ \\
$\gamma$ & Parámetro del modelo de volumen & 54.167 \\
$\alpha$ & Ganancia del observador propuesto & 5.5 \\
$\beta$ & Ganancia del observador propuesto & 2.5 \\
\hline
\end{tabular}

Tabla 5.1: Valores de parámetros del observador y modelos utilizados en las simulaciones y validación experimental

dada la variedad de sensores existentes para plantas de gran escala (capacitivos, por conductividad, de radar, infrarrojos, por láser, mecánicos).

Con este fin, a partir de (5.9b) se puede proponer el observador:

$$
\left\{\begin{array}{l}
\dot{\hat{V}}=F_{s} \gamma-\hat{q}_{p} v X-(\bar{\varrho} v X) 2 \beta|\sigma|^{\frac{1}{2}} \operatorname{sign}(\sigma) \\
\dot{\hat{\mu}}_{p s}=\bar{\varrho} \alpha \operatorname{sign}(\sigma) \\
\sigma=(\bar{\varrho} v X)^{-1}(V-\hat{V})
\end{array}\right.
$$

donde $\hat{V}$ y $\hat{q}_{p}$ son el volumen y la tasa de producción estimadas respectivamente, $\alpha$ y $\beta$ son las ganancias de diseño, $\bar{\varrho}$ es la cota para la derivada de la tasa de producción y $\sigma$ es la función de deslizamiento. Nótese que en (5.33) la función de conmutación planteada es lineal, a diferencia de (5.11).

El análisis de estabilidad es similar al del observador con medición de biomasa, por lo cual no se detalla. Simplemente, se aclara que en el cambio de coordenadas (5.13) se debe utilizar la nueva variable de conmutación definida en (5.33c).

\subsection{Resultados de la aplicación del observador a la producción de PHB}

En esta sección se muestran los resultados obtenidos al aplicar el observador diseñado (5.11) en la etapa de producción del proceso de producción de PHB. En la Sección 5.4.1 se muestran resultados de simulación, mientras que en la Sección 5.4.2 se muestran resultados experimentales. Al igual que en el Capítulo 4 se utilizan los modelos cinéticos presentados en (3.10) para simular el proceso y para obtener una cota de la derivada de $q_{p}$, pero se recalca que éstos no son utilizados en las estimaciones. En la Tabla 5.1 se listan los valores de las ganancias del observador, parámetros del modelo y otras constantes del proceso. 


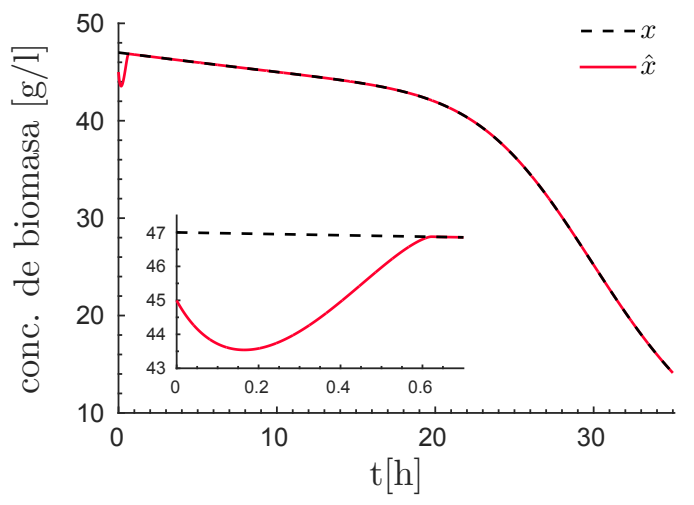

(a) Concentración de biomasa y estimación.

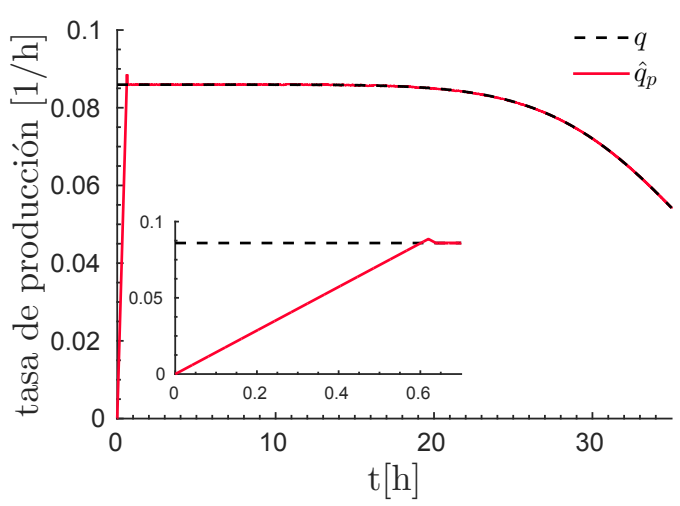

(c) Tasa específica de producción y estimación.

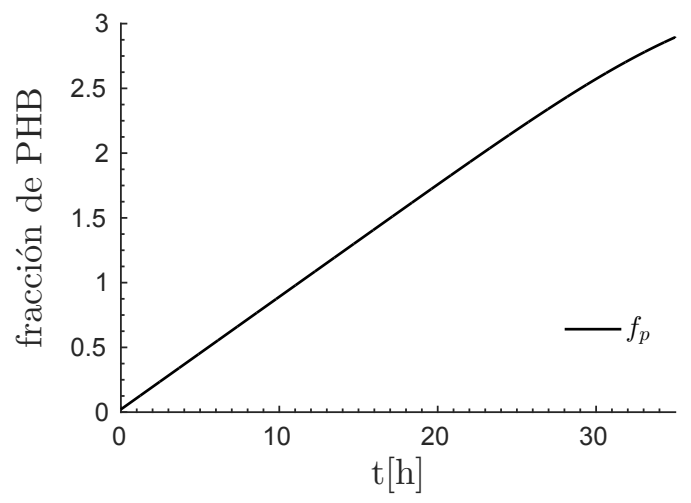

(b) Contenido intracelular de PHB.

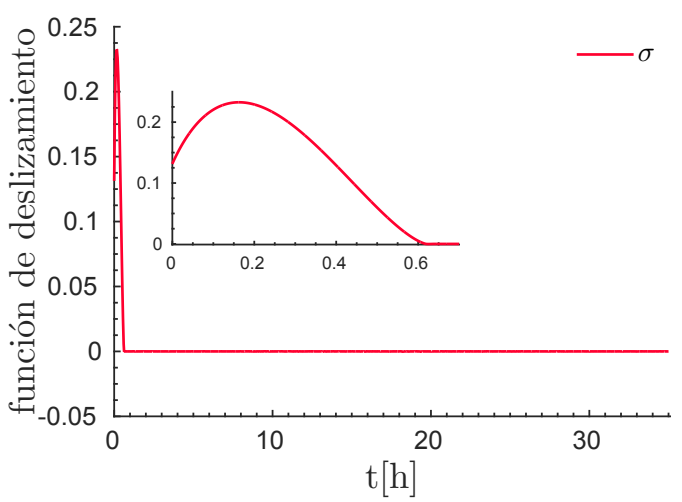

(d) Función de deslizamiento.

Figura 5.3: Resultados de simulación: sistema sin perturbar y respuesta a condiciones iniciales.

Tanto para las simulaciones como para la validación experimental se utiliza el observador (5.11) basado en medición de biomasa residual. Resultados similares se obtienen al usar el observador (5.33) basado en medición de volumen.

\subsubsection{Resultados de simulación}

En esta sección se muestran resultados de simulación para el observador propuesto (5.11). Se simulan diferentes condiciones del proceso para ilustrar las propiedades del observador, las cuales se grafican en las Figuras 5.3 a 5.6. A excepción de la Figura 5.4, los valores verdaderos de $x$ y $q_{p}$ se muestran en líneas negras a trazos y los valores estimados $\hat{x}$ y $\hat{q}_{p}$ en líneas continuas rojas. En todos los casos la fuente de carbono se regula en $12 \mathrm{~g} / \mathrm{l}$ a excepción de la Figura 5.5 donde se muestra un caso donde la concentración varía.

El primer caso de simulación se ilustra en la Figura 5.3. Muestra la respuesta del observador sin perturbaciones, con el proceso operando en condiciones normales. Además se muestra el detalle de las primeras horas con el transitorio inicial. Las condiciones iniciales usadas son $\hat{x}(0)=45 g / l, x(0)=47 g / l, \hat{q}_{p}(0)=0 h^{-1}, q_{p}(0)=0,086 h^{-1}$. Lo primero que se puede notar en las Figuras 5.3a y 5.3c es que tanto la estimación de la concentración de biomasa como la 


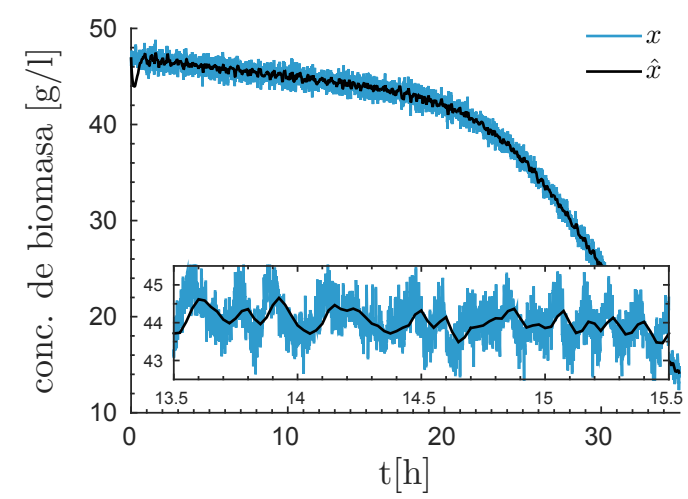

(a) Concentración de biomasa y estimación.

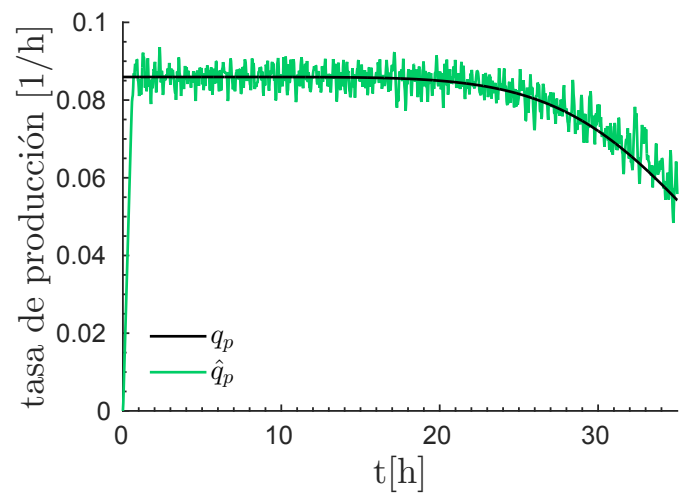

(b) Tasa específica de producción y estimación.

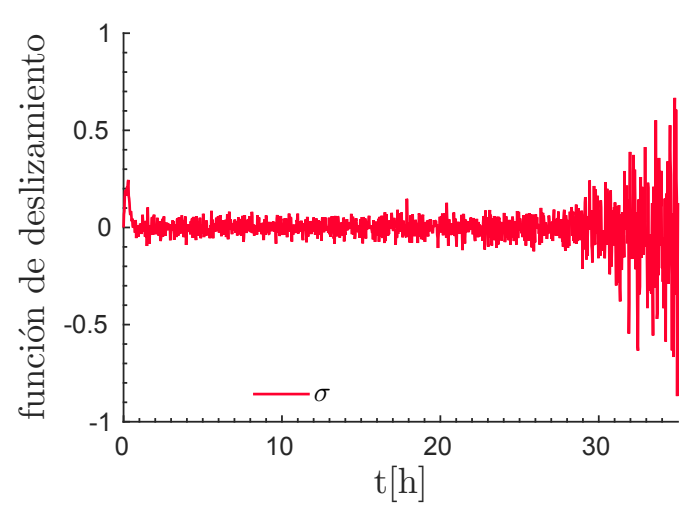

(c) Función de deslizamiento.

Figura 5.4: Resultados de simulación: efecto del ruido de medición.

de la tasa de producción convergen rápidamente a los valores verdaderos y en tiempo finito (en aproximadamente 0.65 horas). Por otra parte, como el observador no agrega dinámica adicional al sistema, el observador presenta un seguimiento perfecto aún cuando la tasa empieza a caer hacia el final de la etapa debido al efecto auto-inhibitorio del PHB. En la Figura 5.3d se muestra la función de deslizamiento y se puede ver que una vez que ésta alcanza la superficie $(\sigma=0)$ nunca más se aparta de ella, verificando las propiedades de seguimiento ya mencionadas.

La Figura 5.4 muestra la respuesta del observador cuando la medida de concentración de biomasa está afectada por ruido de baja frecuencia. Para simular se le sumó a la señal de biomasa ruido blanco filtrado entre $2 h^{-1}$ y $10 h^{-1}$ (alrededor de 0,55 a $2,7 \times 10^{-3} \mathrm{~Hz}$ ), que resulta en variaciones de unos pocos ciclos por hora. Las condiciones iniciales usadas son $\hat{x}(0)=47 g / l, x(0)=47 g / l, \hat{q}_{p}(0)=0 h^{-1}, q_{p}(0)=0,086 h^{-1}$. En la Figura 5.4a se muestra la medida ruidosa de la biomasa en azul y la estimación en negro, además se muestra una ampliación donde se aprecian mejor las variaciones del ruido y la estimación. En la Figura 5.4b se muestra la estimación de la tasa de producción en verde y el valor verdadero en negro y en la Figura 5.4c se muestra la función de deslizamiento. Se puede observar que el ruido de la medición aparece inevitablemente en la estimación de la tasa de producción por su baja 
frecuencia, sin embargo, la misma continua siguiendo correctamente al valor verdadero. El rechazo a ruido del observador está ligado a la sintonización de las ganancias $\alpha$ y $\beta$ que fijan la velocidad de respuesta del observador. En este caso se eligieron de manera tal que la estimación de biomasa $\hat{x}$ no siga las variaciones producidas por el ruido que son más rápidas que las esperables para la dinámica del microorganismo. Si se necesita una estimación más suave se pueden reducir más las ganancias perdiendo velocidad de convergencia, manteniendo siempre un $\alpha>1$ para evitar adicionar dinámica a la estimación. Otras soluciones son filtrar la estimación o la medida de biomasa, o usar una función signo con zona muerta en (5.11). Ambas alternativas ganan en rechazo a ruido pero se pierde velocidad de seguimiento. Se puede notar en la Figura 5.4c la presencia de ruido debido a que la estimación de biomasa es intencionalmente más lenta que la biomasa medida. Por otra parte, el incremento del ruido en $\sigma$ hacia el final del proceso se debe a que la potencia del ruido añadido permanece constante mientras que las concentración de biomasa decrece, siendo entonces el ruido relativo mayor.

La Figura 5.5 muestra un caso donde la concentración de sustrato $s$ no es regulada correctamente y varía en vez de permanecer constante. Esto da lugar a variaciones en la tasa de producción y en los parámetros $\gamma$ y $v$. Las condiciones iniciales son $\hat{x}(0)=47 g / l, x(0)=47 g / l$, $\hat{q}_{p}(0)=0 h^{-1}$ y $q_{p}(0)=0,089 h^{-1}$. En la Figura 5.5a se puede ver tanto la concentración de biomasa como la de sustrato. En la Figura 5.5b se muestra la tasa de producción y su estimación. Se puede ver que, a pesar de las variaciones en $s$, el error de $\hat{q}_{p}$ no es significativo, de acuerdo a lo predicho en (5.29).

Finalmente, la Figura 5.6 muestra un caso donde el sensor de biomasa residual falla, poniendo en evidencia la potencialidad del observador para monitoreo de bioprocesos. Además, a modo de comparación se muestran las estimaciones obtenidas con un observador exponencial. Las condiciones inciales son $\hat{x}(0)=47 g / l, x(0)=47 g / l, \hat{q}_{p}(0)=0 h^{-1}, q_{p}(0)=$ $0,086 h^{-1}$. Entre las 10 y 20 horas aparece un offset constante de $10 \mathrm{~g} / \mathrm{l}$ en la medición de biomasa $x_{m}$. En la Figura 5.6a se puede ver que ambos observadores siguen a la concentración de biomasa medida con una velocidad similar, teniendo el observador exponencial un sobrepaso y un tiempo de establecimiento mayor, como se ve en la ampliación. Las estimaciones de la tasa de producción en la Figura 5.6b se ven afectadas solamente al inicio y final del evento, aunque el observador por modos deslizantes retorna más rápido al valor verdadero (ver en la ampliación). A las 30 horas del proceso aparecen una serie de picos en la medición de biomasa, similar a lo que sucedería con un falso contacto o algún otro tipo de perturbación. La oscilación que se ve es rápida y tiene una amplitud máxima de $20 \mathrm{~g} / 1$. Ambas estimaciones de biomasa rechazan aceptablemente la perturbación, siendo la respuesta del observador por modo deslizantes más amortiguada. Sin embargo, al observar las estimaciones de la tasa de producción se puede ver que el observador por modos deslizantes rechaza mucho mejor la perturbación rápida de las 30 horas. El observador exponencial presenta un pico inverso de gran amplitud y duración, notorio incluso sin ampliar la zona. Se puede entonces concluir que el observador por modos deslizantes rechaza mejor las perturbaciones de alta frecuencia a igual velocidad de respuesta que el observador exponencial. Finalmente, se puede notar que 


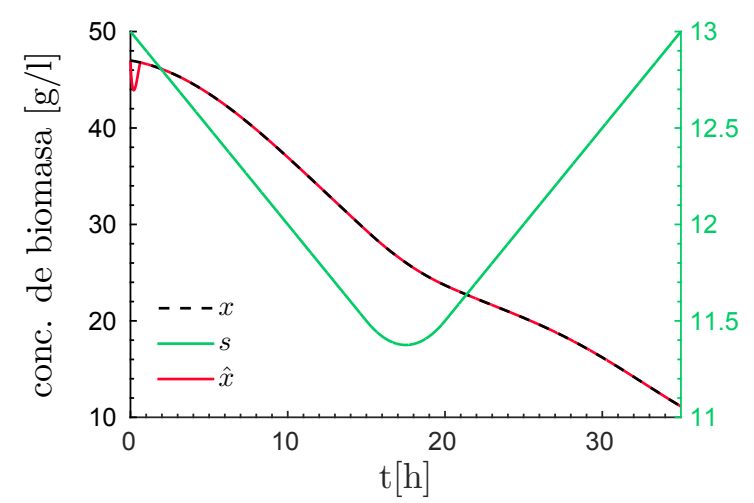

(a) Concentración de biomasa y estimación.

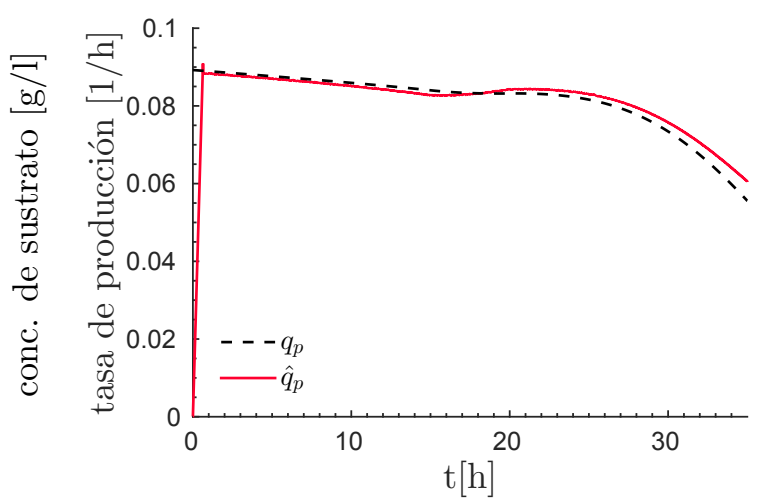

(b) Tasa específica de producción y estimación.

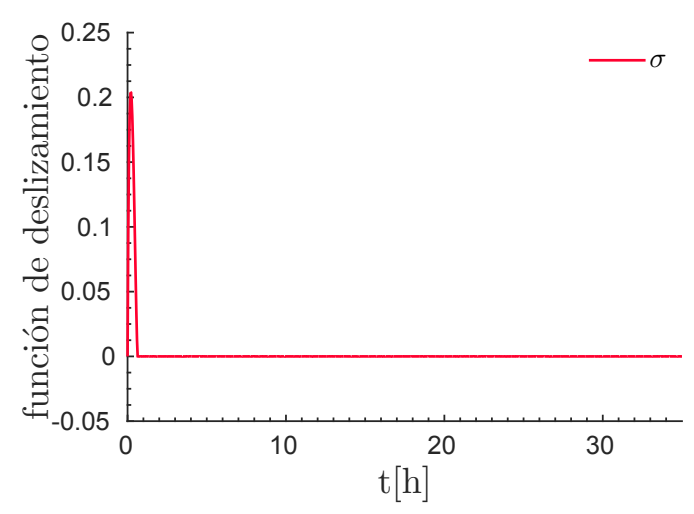

(c) Función de deslizamiento.

Figura 5.5: Resultados de simulación: respuesta del observador ante variaciones en la concentración de sustrato.

en cada uno de los instantes anteriormente analizados, la función de deslizamiento mostrada en la Figura 5.6c escapa brevemente de la superficie ( $t=10 h, t=20 h$ y $t=30 h$ ). Se puede entonces usar a $\sigma$ como una coordenada para detectar este tipo de fallos o conductas anormales del proceso.

\subsubsection{Validación experimental}

En esta sección se presentan resultados para el observador (5.11) cuando se le provee de datos obtenidos de mediciones del proceso real. Las medidas del proceso disponibles en línea son el caudal de fuente de carbono y el caudal de solución base usada para el control de pH (en base a sodio), con una tasa de muestreo de 1 minuto. La concentración de biomasa residual se mide fuera de línea tomando muestras espaciadas con un período de entre 1 y 5 horas. Como el observador requiere de una medida continua de biomasa, o al menos muestreada cada 1 minuto, se construyó una medida virtual de la biomasa interpolando las muestras obtenidas por medición fuera de línea. Luego, el algoritmo del observador se corre cada 1 segundo. Al igual que en las simulaciones, la concentración de fuente de carbono de alimentación es de 

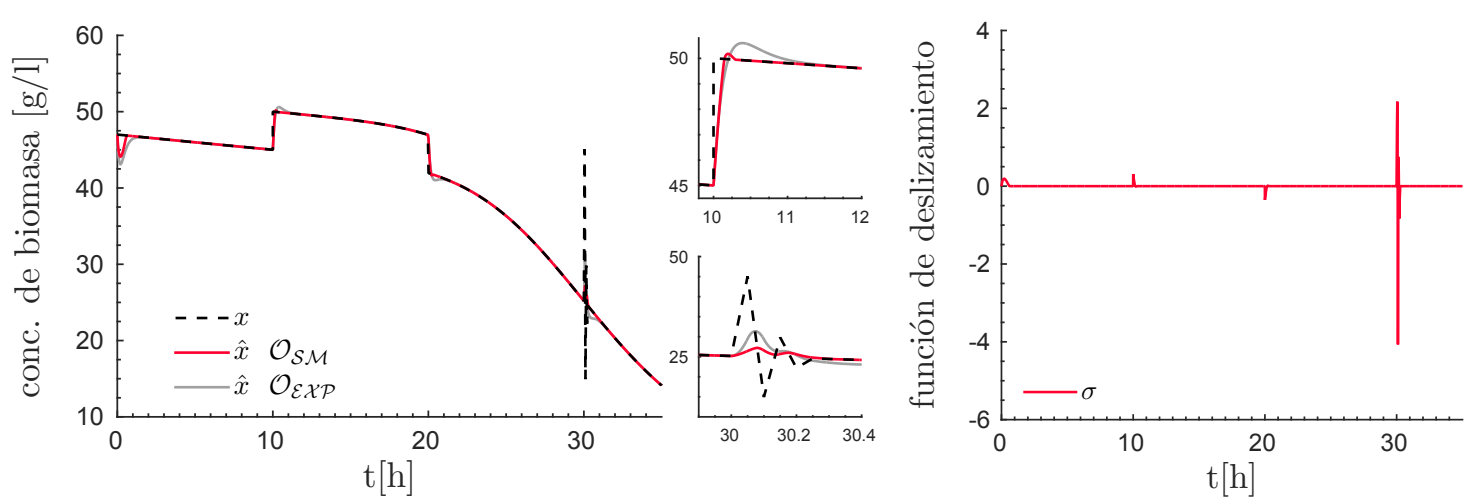

(a) Concentración de biomasa y estimaciones.
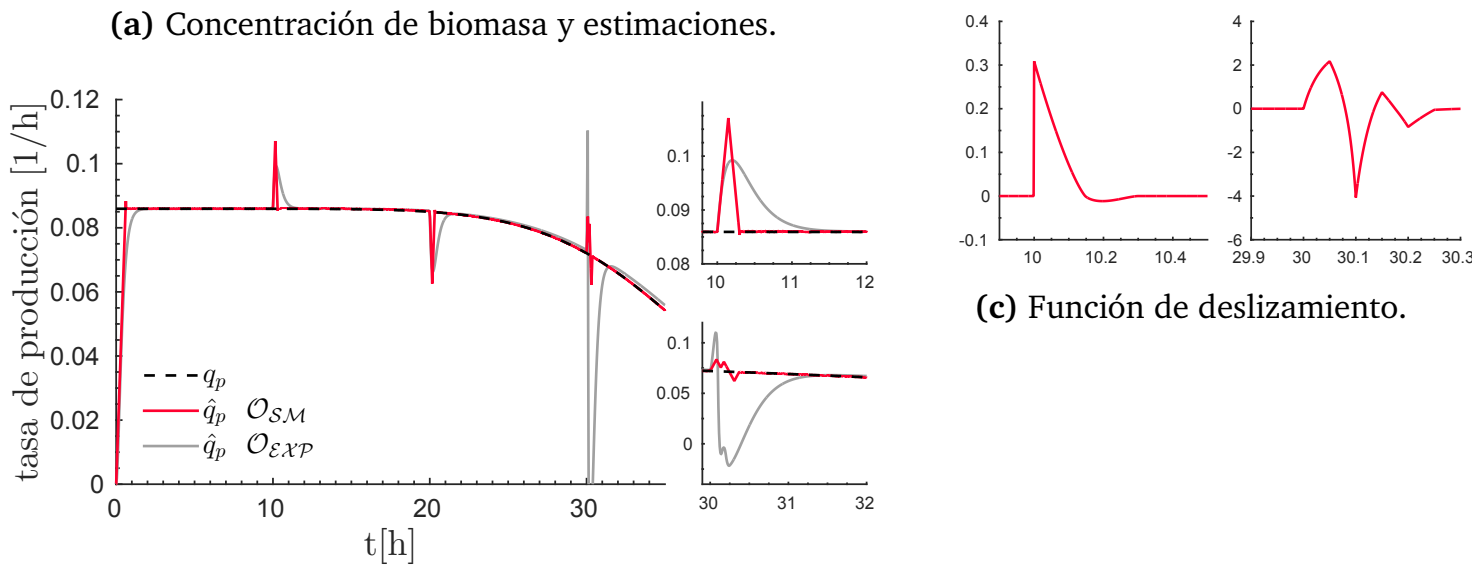

(c) Función de deslizamiento.

(b) Tasa específica de producción y estimaciones.

Figura 5.6: Resultados de simulación: respuesta del observado por modos deslizantes $\mathscr{O}_{\mathscr{S} \mathscr{M}}$ ante fallas en el sensor de biomasa y comparación con observador exponencial $\mathscr{O}_{\mathscr{E} \mathscr{X} \mathscr{P}}$.

$650 \mathrm{~g} / \mathrm{l}$, y la regulada en el biorreactor es de $12 \mathrm{~g} / \mathrm{l}$. Cada vez que se toma una muestra del biorreactor la masa total de microorganismos decrece, por lo tanto se actualiza el valor de $X$ cada vez que se toma una muestra. En las Figuras 5.7 y 5.8 se muestran los resultados obtenidos para dos experimentos distintos, a los que llamamos A y B.

La Figura 5.7 muestra las variables estimadas y la función de deslizamiento para cada uno de los experimentos. En las Figuras 5.7a y 5.7b se muestra la concentración de microorganismos medida junto a su estimación, para cada experimento. En las Figuras 5.7c y 5.7d se muestran las estimaciones de tasa de producción para cada experimento. Adicionalmente, junto a la tasa de producción estimada $q_{p}$, se muestra como referencia la tasa de producción que se debería obtener para la concentración de sustrato regulada, es decir, el valor de $q_{p}\left(s_{r}\right)$. Además, se muestra una estimación de la tasa de producción obtenida de derivar la fracción de PHB $f_{p}=\frac{p}{x}$ que, como se muestra en (5.1), $\dot{f}_{p}=q_{p} \cong \frac{\Delta p}{\Delta x}$. Se puede ver que en ambos experimentos la tasa de producción se mantiene muy próxima a la referencia $q_{p}\left(s_{r}\right)$ y a la estimación obtenida al derivar. No se debe olvidar que esta última estimación es fácilmente afectada por el ruido y los errores en la medida, tanto por la diferenciación directa como por la poca cantidad de muestras disponibles. En las Figuras 5.7e y 5.7f se muestra la función de deslizamiento. Se puede observar que se mantiene sobre la superficie todo el tiempo, salvo por 


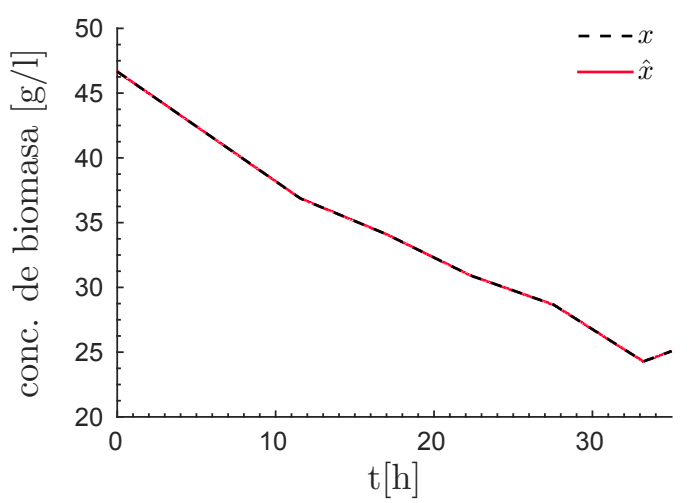

(a) Experimento A: biomasa residual.

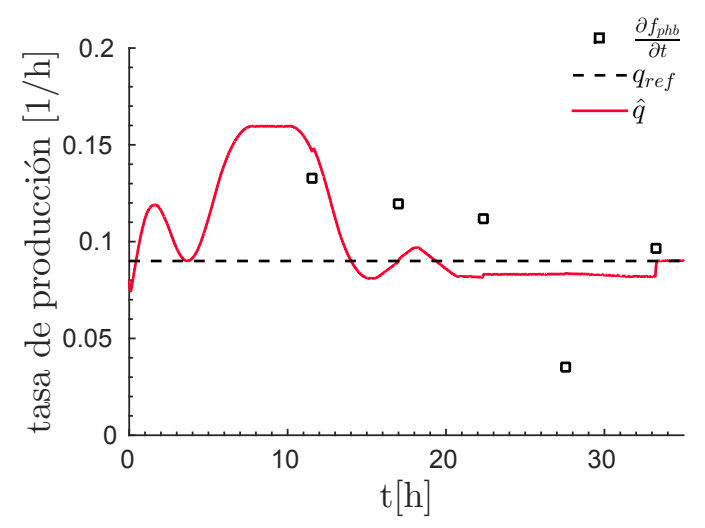

(c) Experimento A: tasa específica de producción.

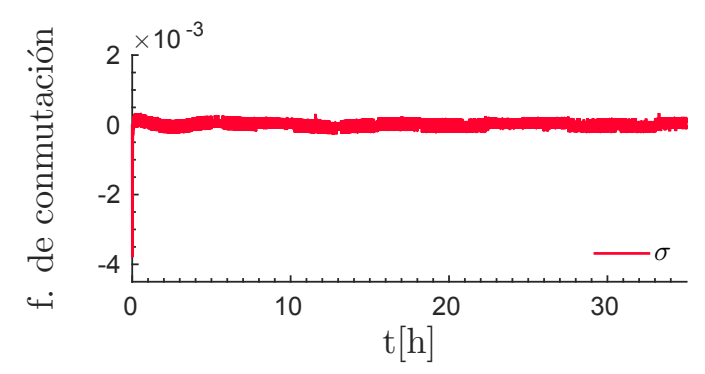

(e) Experimento A: función de conmutación.

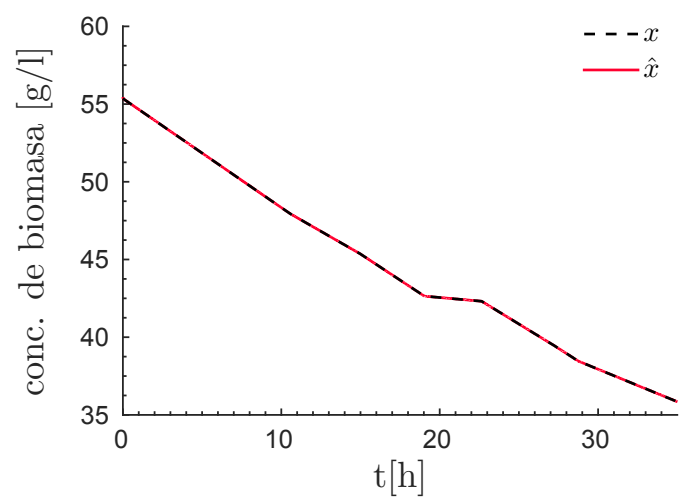

(b) Experimento B: biomasa residual.

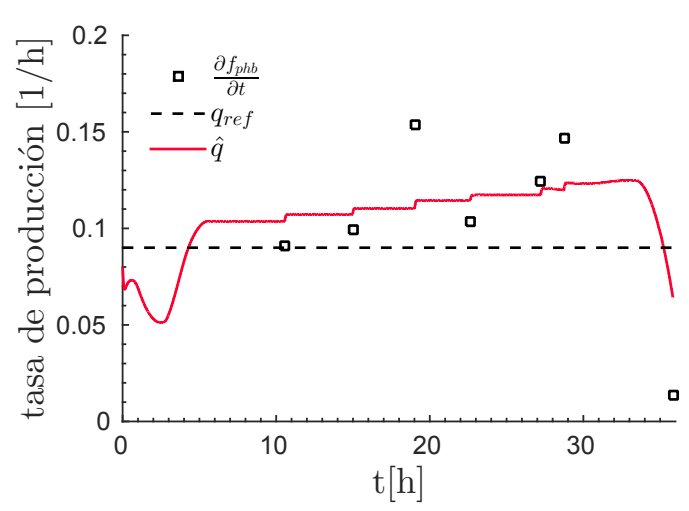

(d) Experimento B: tasa específica de producción.

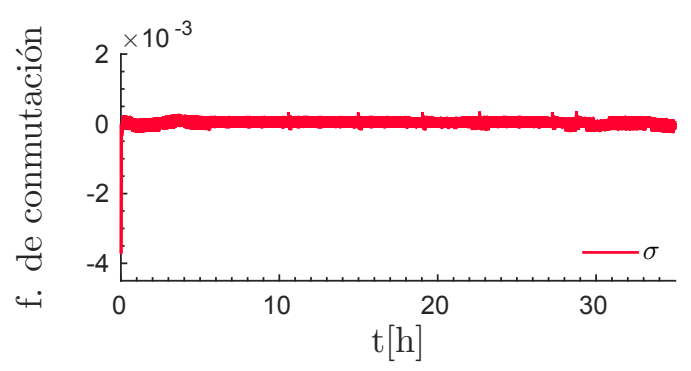

(f) Experimento B: función de conmutación.

Figura 5.7: Resultados experimentales: respuesta del observador.

un piso de ruido producto de la discretización del algoritmo. Este ruido se puede disminuir al ejecutar el algoritmo con mayor frecuencia.

Con el fin de verificar la calidad de las estimaciones de la tasa de producción se proveen estimaciones de lazo abierto del contenido intracelular de PHB y del volumen en la Figura 5.8. Las estimaciones de $f_{p}$ en las Figuras $5.8 \mathrm{a}$ y $5.8 \mathrm{~b}$ se obtiene, al integrar $\hat{q}_{p}$ a partir del instante de convergencia de la misma y se compara con la fracción calculada a partir de las muestras fuera de línea. En las Figuras 5.8c y 5.8d se muestran las estimaciones del volumen obtenidas al remplazar la tasa estimada $\hat{q}_{p}$ en (5.7), que a su vez se comparan con el volumen calculado a partir de la concentración de biomasa medida, según (5.2a). Nuevamente se puede observar 


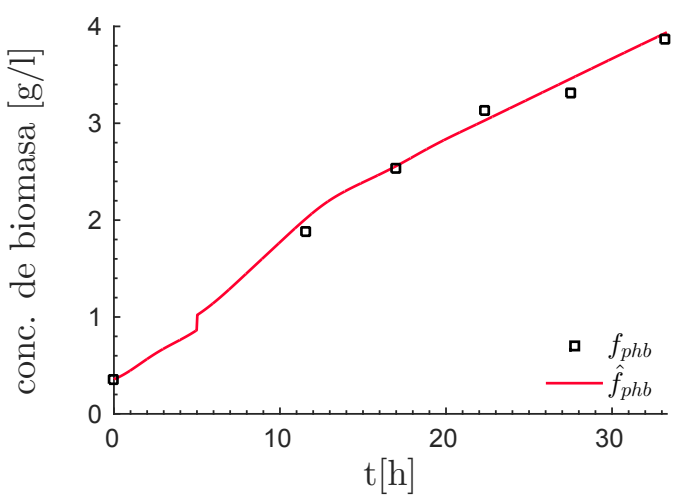

(a) Experimento A: Gráfico superior, contenido intracelular de PHB. Gráfico inferior, volumon $V(n)-\cap 71$

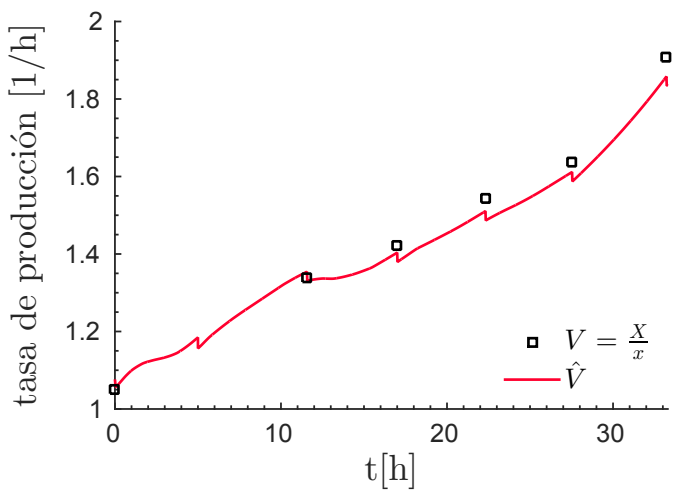

(c) Experimento A: Gráfico superior, contenido intracelular de PHB. Gráfico inferior, volumen. $V(0)=0,7 l$

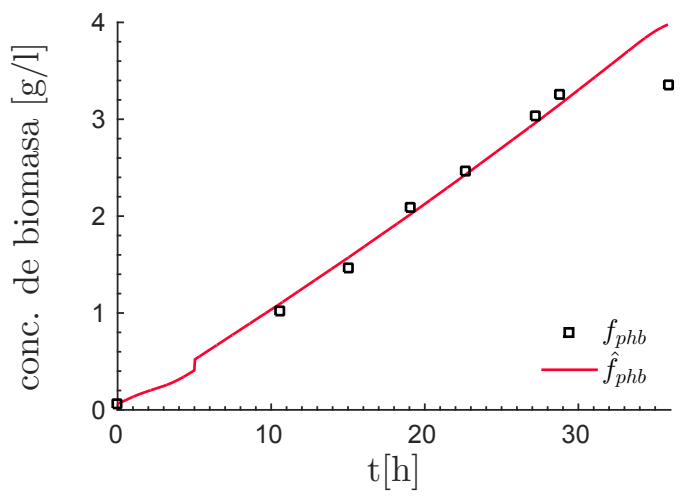

(b) xperimento B: Gráfico superior, contenido intracelular de PHB. Gráfico inferior, volumen. $\mathrm{V}(\mathrm{n})-111$

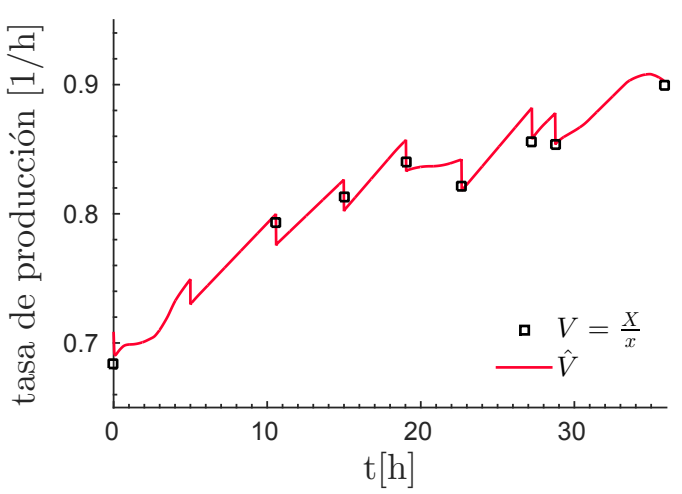

(d) Experimento B: Gráfico superior, contenido intracelular de PHB. Gráfico inferior, volumen. $V(0)=1,1 l$

Figura 5.8: Resultados experimentales: contenido intracelular de PHB y volumen.

un buen ajuste entre las estimaciones y las referencias calculadas a partir de valores verdaderos. A su vez, se verifica la validez del modelo de volumen presentado en la Sección 3.3.

\subsubsection{Discusión}

Los datos experimentales muestran que el modelo de volumen propuesto, dado por (5.7), permite realizar buenas predicciones en cuanto a su evolución temporal, como se muestra en la Figura 5.8. La mejora está dada por la adición de términos que tienen en cuenta la contracción de volúmenes al mezclar medios de distinta densidad, el consumo de sustrato y producción de PHB. Los parámetros $\gamma$ y $v$ (ver (3.40) y (3.41)) pueden presentar cierta incertidumbre asociada a las desviaciones en la concentración de sustrato respecto de la referencia. Sin embargo, siempre y cuando las desviaciones no sean excesivas ni muy rápidas, los errores en los parámetros serán pequeños al igual que el efecto sobre las estimaciones.

Con respecto al observador propuesto, las simulaciones permiten verificar la calidad de las estimaciones en diferentes escenarios. Para empezar, el observador permite seguir la tasa de producción del proceso sin incluir el modelo cinético. En todos los casos la convergencia 
es en tiempo finito, incluso en la validación experimental, a partir del momento en que $\sigma$ alcanza la superficie. Una vez que la estimación converge no se agrega dinámica ni retardos al sistema y se sigue perfectamente al valor verdadero. Las variaciones en la concentración de sustrato tienen poco efecto en las estimaciones (Figura 5.5). De hecho, la estabilidad del observador no se ve afectada, simplemente los errores convergen a un entorno alrededor de cero, cuya cota puede obtenerse de (5.29). El efecto del ruido también es bajo, en la medida que no entre dentro del ancho de banda del proceso, que por lo general es muy bajo. Se pueden introducir mejoras a la respuesta al utilizar sustitutos para la función signo, como zonas muertas, tangentes hiperbólicas, o simplemente filtrando. 


\section{|| Capítulo 6 Control para optimización en línea del proceso}

En este capítulo se trata la optimización en línea de procesos fed-batch por medio del control. Se busca optimizar la productividad a partir de operar con tasas de reacción máximas. Con este fin se propone un controlador no lineal cuyo objetivo es anular al gradiente del mapa del sustrato a tasa de reacción, que se considera desconocido. A su vez, el gradiente es estimado mediante un observador no lineal. Se analiza la estabilidad del controlador según Lyapunov en los casos con y sin perturbaciones y se derivan condiciones para su sintonización. Los algoritmos de control y estimación se prueban por simulación en una serie de escenarios diferentes. Posteriormente se presentan resultados de simulación al aplicar el controlador al proceso de producción de $\mathrm{PHB}$, para maximizar la tasa de crecimiento en la primer fase, y la de producción de $\mathrm{PHB}$ en la siguiente. El controlador propuesto logra una rápida convergencia al punto de operación óptimo. Además, la respuesta de la tasa de reacción es suave y no presenta chattering. La novedad del controlador viene también dada por su robustez a una incertidumbre estructurada.

Parte de los contenidos y resultados expuestos en este capítulo han sido publicados en [119]: Martín Jamilis, Fabricio Garelli y Hernán De Battista. Smooth extremum-seeking control for fed-batch processes. 11th IFAC Symposium on Dynamics y Control of Process Systems, including Biosystems (DYCOPS-CAB 2016).

\subsection{Introducción}

En muchos procesos químicos y bioquímicos es de interés optimizar tasas de reacción con el fin de alcanzar productividades altas o favorecer determinadas rutas metabólicas. Por ejemplo, optimizar la tasa específica de crecimiento permite maximizar la masa total de microorganismos alcanzada en un dado tiempo. Análogamente, se maximiza la masa de producto obtenida si se optimiza la tasa específica de producción. En muchos casos los microorganismos tienen cinéticas no monótonas respecto a la concentración de sustrato (como la de Haldane), 


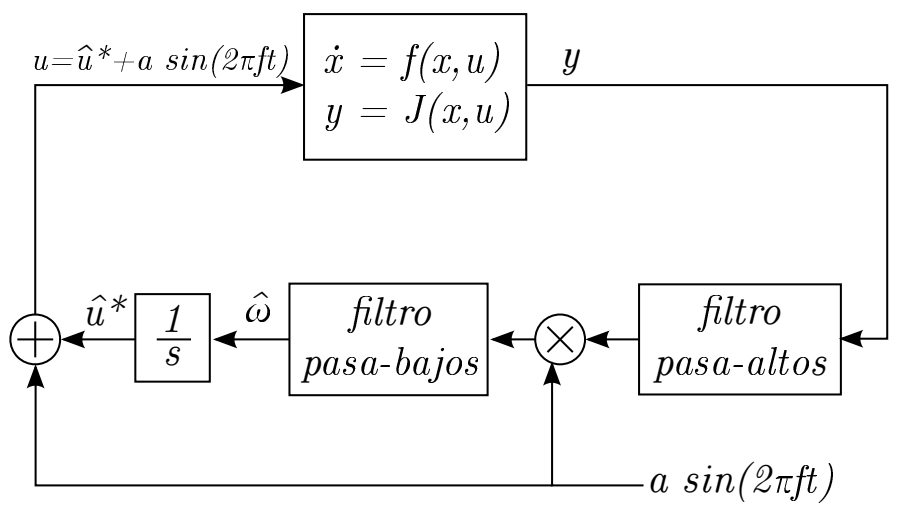

Figura 6.1: Esquema de control para seguimiento de extremos basado en perturbación. $\dot{x}=f(x, u)$ dinámica del proceso. $y=J(x, u)$ función objetivo a optimizar (medida). $\hat{u}^{*}$ estimación de acción de control óptima. $\hat{\omega}$ estimación del gradiente.

eso significa que existe una concentración óptima del sustrato para la cual la tasa específica de reacción se maximiza.

Desde el punto de vista del control automático, la optimización en línea del proceso consiste en regular la tasa específica de reacción en su valor máximo. O bien, en regular la concentración de sustrato en el valor óptimo para la cual la tasa de reacción es máxima. En la literatura hay reportados un gran número de algoritmos de lazo cerrado para la regulación de tasas o de concentraciones. Se pueden destacar entre otros, versiones de lazo cerrado de la ley de alimentación exponencial [51, 120, 121], controles linealizantes [57] y linealizantes adaptivos [11, 97, 62]. De estos últimos surgen además muchos algoritmos de estimación y monitoreo utilizados para estimar los parámetros que se adaptan en los controles. En general, la regulación de tasas específicas se realiza indirectamente a través de la regulación de la concentración de sustratos. Sin embargo, hay trabajos donde la regulación de la tasa se realiza directamente por realimentación de estimaciones de la misma, como en [122, 56], donde se utilizan conceptos de invariancia geométrica. La mayoría de los controladores antes mencionados logran los objetivos de control y son capaces de lidiar con la incertidumbre paramétrica y escasez de sensores. Sin embargo, en todos ellos es necesario conocer la referencia para la variable regulada, es decir, la concentración óptima de sustrato o la tasa de reacción máxima.

El control por seguimiento de extremos o extremum seeking control (ESC) provee herramientas útiles para la optimización en tiempo real de bioprocesos sin la necesidad de conocer exactamente la tasa máxima o concentración óptima. Básicamente, el ESC consiste en definir una acción de control que permita buscar un punto de operación del sistema donde se optimiza una dada función objetivo. Esta última podría ser una tasa específica o volumétrica de crecimiento, por ejemplo. En [58] se repasa la aplicación de ESC a bioprocesos y se destacan dos enfoques principales. El primer enfoque se basa en perturbar la entrada del sistema y observar su salida. El proceso es parcialmente una caja negra y la función objetivo no es conocida (como función de los estados) pero es medida. En general se utiliza una señal de perturbación periódica sumada a la acción de control, si la misma perturbación periódica apa- 


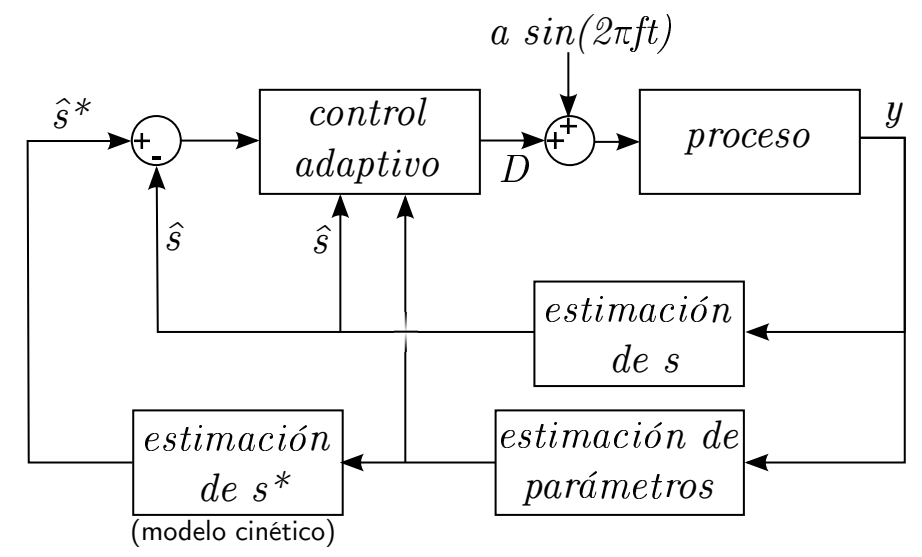

Figura 6.2: Esquema de control para seguimiento de extremos basado en modelo.

rece a la salida se puede calcular el gradiente filtrando y demodulando la misma. Luego, en base a ese gradiente se define la acción de control a través de un control integral (cuando el gradiente se anula la acción de control óptima se mantiene constante). En la Figura 6.1 se muestra un esquema de este enfoque. Esta técnica y similares se desarrollan en profundidad en [123] y su aplicación a un reactor de tanque agitado para maximizar tasas volumétricas se puede ver en [124].

El segundo enfoque es el basado en modelo. Se considera que la estructura de la función objetivo es conocida mientras que sus parámetros no. Estos últimos son estimados por medio de observadores (asintóticos o exponenciales) y la ubicación del óptimo se calcula a partir de las estimaciones. Por ejemplo, si se pretende optimizar una tasa específica de crecimiento, la estructura de la función objetivo está dada por el modelo cinético, del cual habrá que estimar sus parámetros $\left(k_{s}, k_{i}, \mu_{\max }\right.$, etc.) para recuperar la concentración de sustrato óptima. Una vez estimada la ubicación del óptimo, ésta pasa a ser la referencia de un controlador adaptivo. En la Figura 6.2 se muestra un esquema de este enfoque. Ejemplos de este enfoque son $[125,126,62,127]$.

Tanto el esquema de perturbar y observar como el basado en modelo son igualmente válidos. En el primero se requiere un conocimiento mínimo del proceso, pero se necesita una perturbación permanente que lleva a que el estado final converja a un ciclo límite alrededor del punto de operación óptimo. La ventaja del esquema basado en modelo es que se puede garantizar un cierto grado de desempeño en la respuesta transitoria. Sin embargo, se necesita asumir una estructura para la función objetivo e incluirla en el diseño. Incluso es necesario adicionar una perturbación periódica que asegura la persistencia de excitación requerida para la estimación de parámetros. Por lo que igualmente se termina convergiendo a ciclos límites.

Recientemente, han surgido enfoques alternativos mediante el uso de controles conmutados. Estos enfoques comparten con el de perturbar y observar que se considera a la función objetivo desconocida y que se puede medir o estimar. Sin embargo, difieren en que se proveen garantías para la convergencia, como en el enfoque basado en modelo. Además, en lugar de perturbar el sistema con una señal periódica para estimar el gradiente, se utiliza una acción 


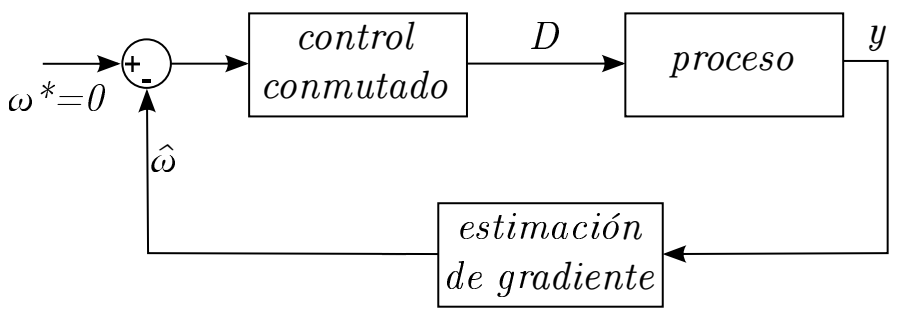

Figura 6.3: Esquema de control para seguimiento de extremos basado en perturbación.

de control conmutada. La conmutación de una acción de control a otra está dada por una variable de decisión que se puede definir de distintas maneras. Por ejemplo, una estimación de la diferencia entre la concentración de sustrato óptima y la actual (error de sustrato), o bien, una estimación del gradiente de la función objetivo. En la Figura 6.3 se muestra un esquema de este enfoque, al que llamamos enfoque del gradiente. Un ejemplo de lo antes descripto se da en [128]. Se propone un controlador pseudo-super-twisting para maximizar la tasa de producción de biogás en un proceso de barros activados. Como variable de decisión se utiliza una estimación del signo del error de sustrato. Esa estimación se obtiene a partir de una máquina de estados que analiza los cambios en sustrato y tasa de producción de un instante de muestreo al otro. Además, se utiliza la magnitud del error de sustrato en el control. Sin embargo, ésta se calcula (a lazo abierto) a partir de una función propuesta por el autor. Por el tipo de estimación usada la respuesta termina siendo muy lenta. Algo similar se propone en [129] pero utilizando un control que conmuta entre dos acciones de control proporcionales a la biomasa. En [130] se busca maximizar la tasa específica de crecimiento en un proceso fed-batch por medio de un control por modos deslizantes de primer orden (MDPO), donde la estimación del gradiente es la función de conmutación. Esta última se obtiene por medio del estimador discreto originalmente propuesto por [131] y midiendo la concentración de sustrato y la tasa de producción de gases. Si bien se cumple el objetivo de llevar a la tasa específica a un entorno del óptimo, los resultados presentados presentan mucho chattering. Éste se puede reducir disminuyendo la ganancia del control pero perdiendo rechazo a perturbaciones.

Una de las características comunes de los trabajos anteriores, es la ejecución de los algoritmos de control a frecuencias lo suficientemente bajas como para permitir variaciones apreciables en las salidas, ya que de la observación de las mismas es que se obtienen las estimaciones de los gradientes o de las variables de decisión. Esos algoritmos de estimación también son ejecutados a baja frecuencias. Si bien esto es muy conveniente en los algoritmos de control, no lo es para los de estimación, ya que introduce retardos y dinámicas adicionales en los lazos. Lo que puede incrementar el chattering y las oscilaciones más de lo necesario. Por otra parte, en todos los enfoques mencionados es común que se asuma disponible la medición del sustrato y de alguna variable asociada a la tasa a optimizar (función objetivo). Por ejemplo, que se mide la tasa de producción de un gas, proporcional a $\mu x$. Esto no siempre se puede considerar viable por las razones explicadas en la Sección 2.2 respecto a medición de sustratos. 
El objetivo de este capítulo es presentar un nuevo ESC para maximizar tasas específicas de reacción en procesos fed-batch. El esquema que se propone consta de un controlador por modos deslizantes de segundo orden, cuya función de conmutación es la estimación del gradiente de la tasa de reacción respecto de la concentración de sustrato. La estimación de este gradiente a su vez se obtiene con un observador por modos deslizantes de segundo orden. Para ello, es necesario extender el modelo dinámico del proceso y plantear el problema de estimación de gradiente como la estimación de un parámetro variante en el tiempo.

En contraste con los ESC basados en modelo, el controlador propuesto no requiere la inclusión de la estructura de la función objetivo en el diseño, que en este caso sería el modelo cinético. Sólo se requiere conocer cotas de sus derivadas parciales para el ajuste de las ganancias y asegurar la estabilidad. Tampoco se agrega la señal de perturbación periódica utilizada tanto en el enfoque de perturbar y observar como el basado en modelo. En cambio, la acción conmutada es la que permite evaluar al gradiente. Otra característica importante del control propuesto es que en el punto de operación óptimo la acción conmutada se anula. Sumado a que la acción de control producida es continua y más suave que la de un control por MDPO [130], el chattering se ve notablemente reducido. Además, la acción integral del controlador propuesto permite rechazar cualquier perturbación constante. A diferencia de [130, 128, 129], el estimador de gradiente propuesto se ejecuta en tiempo continuo en lugar de a la baja frecuencia del controlador. De esta manera se eliminan los retardos y dinámica adicional de la estimación del lazo. Otra diferencia importante con otros trabajos reportados es que el ESC propuesto está basado solamente en la medición de la concentración de células. Esto es una ventaja en muchos casos, sobre todo a nivel industrial donde una medida de concentración de sustrato no es viable económicamente, menos aún si los sustratos son residuos. Por otra parte la concentración celular es más fácil de medir, tanto a nivel industrial como de laboratorio, con sensores de densidad óptica o espectroscopía dieléctrica.

El resto del capítulo se estructura de la siguiente manera: en la Sección 6.2 se establece el marco formal del problema a resolver. En la Sección 6.3 se presenta al controlador propuesto y al observador de gradiente. En la Sección 6.4 se presentan demostraciones de estabilidad del controlador según Lyapunov tanto para el caso nominal como el perturbado. De las demostraciones de estabilidad se derivan también dominios de atracción y guías para el ajuste de las ganancias. En la Sección 6.5 se presentan resultados de simulación para un proceso estándar, con el fin de analizar las características del controlador propuesto. Finalmente, en la Sección 6.6 se presentan resultados de simulación de la aplicación del controlador propuesto al proceso de producción de PHB.

\subsection{Formulación del problema}

El desarrollo del controlador se plantea primero de manera general para la optimización de la tasa de crecimiento con respecto a un sustrato limitante por lo que el modelo del proceso 
es

$$
\begin{aligned}
\dot{x} & =(\mu-D) x \\
\dot{s} & =-\frac{\mu x}{y_{x s}}+D\left(s_{f}-s\right) \\
\dot{V} & =D V .
\end{aligned}
$$

Todas las variables y parámetros se detallan en la Tabla 6.1. Si bien en este caso se adopta como sustrato limitante a la fuente de carbono $s$, es fácilmente intercambiable por la fuente de nitrógeno $n$. Lo mismo se puede decir con respecto a la tasa de crecimiento, se puede cambiar por una tasa de producción no asociada al crecimiento sin que cambie la estructura del modelo.

Se asume también que los excesos en la concentración de sustrato tienen un efecto inhibitorio sobre la tasa específica de crecimiento (o producción), es decir, el microorganismo presenta una cinética $\mu(s)$ no monótona.

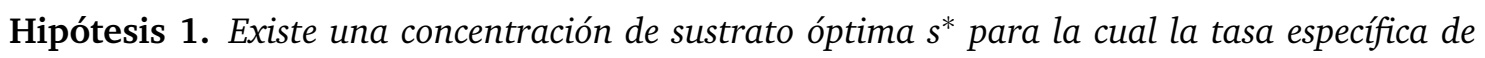
reacción es máxima, es decir,

1. $\mu\left(s^{*}\right)=\mu^{*}$.

2. $\mu(s) \leq \mu^{*} \forall s$.

Se asume también que el mapa estático $\psi: s \rightarrow \mu$ es desconocido por falta de identificación o incertidumbre, siendo entonces el punto de operación óptimo $\left(s^{*}, \mu^{*}\right)$ también desconocido.

A esta altura es conveniente definir otras variables que son utilizadas en el ESC propuesto. Habiendo asumido que la tasa de reacción depende únicamente de la concentración del sustrato $s$, se puede definir al gradiente del mapa $\psi: s \rightarrow \mu$ como

$$
\nabla \mu=\frac{\partial \mu(s)}{\partial s}=\omega(s)
$$

El gradiente es la pendiente del mapa cinético y su signo indica el sentido en la dirección de $s$ para el cual $\mu$ se incrementa. Otra variable importante a definir es el hessiano del mapa

$$
\nabla^{2} \mu=\frac{\partial^{2} \mu}{\partial s^{2}}=h(s)
$$

que en este caso resulta nuevamente escalar y describe la curvatura del mapa cinético. Si $h(s)<0$ se dice que el mapa es convexo, si $h(s)>0$ se dice que es cóncavo y si $h(s)=0$ se tiene un punto de inflexión.

A partir del gradiente y el hessiano se pueden enunciar las condiciones para la existencia de un punto de operación óptimo.

Teorema 6.1. El punto de operación $\left(s^{*}, \mu^{*}\right)$ es un extremo del mapa $\psi: s \rightarrow \mu$ si y sólo si $\omega\left(s^{*}\right)=0$. Si además $h\left(s^{*}\right)<0$ entonces el punto $\left(s^{*}, \mu^{*}\right)$ es un máximo [132]. 


\begin{tabular}{cl}
\hline Nombre & Descripción \\
\hline$x$ & concentración celular \\
$s$ & concentración de sustrato \\
$s_{f}$ & concentración de sustrato de alimentación \\
$v$ & volumen \\
$D$ & tasa de dilución \\
$y_{x s}$ & rendimiento de sustrato a biomasa \\
$\mu$ & tasa específica de crecimiento \\
$\omega(s)$ & gradiente de $\mu(s)$ con respecto a $s$ \\
$h(s)$ & hessiano de $\mu(s)$ con respecto a $s$ \\
\hline
\end{tabular}

Tabla 6.1: Variables y parámeteros

Habiendo definido al gradiente $\omega(s)$ y al hessiano $h(s)$ ( $\omega$ y $h$ de ahora en adelante), y las condiciones para que un punto de operación sea óptimo ${ }^{1}$, resulta entonces posible extender el modelo del proceso al considerar a $\omega$ y $\mu$ como parámetros variantes en el tiempo y considerar el modelo dinámico de $\mu$ y $\omega$. Por medio de la regla de la cadena:

$$
\begin{aligned}
& \dot{\mu}=\frac{\partial \mu}{\partial s} \dot{s}=\omega\left(-\frac{\mu x}{y_{x s}}+D\left(s_{f}-s\right)\right) \\
& \dot{\omega}=\frac{\partial \omega}{\partial s} \dot{s}=h\left(-\frac{\mu x}{y_{x s}}+D\left(s_{f}-s\right)\right) .
\end{aligned}
$$

Las Ecuaciones (6.4a) y (6.4b) se usan en las Secciones 6.3 y 6.4 para el diseño del estimador de gradiente y las pruebas de estabilidad del ESC.

El objetivo es el diseño de un ESC capaz de llevar a la tasa específica de reacción al punto de operación óptimo $\left(s^{*}, \mu^{*}\right)$, siendo éste desconocido. Objetivos secundarios son una rápida tasa de convergencia, una respuesta suave de la tasa de reacción (sin chattering) y además un buen rechazo a perturbaciones. Para cumplir estos objetivos se propone un controlador por modos deslizantes de segundo orden (controlador MDSO) usando como función de conmutación la estimación del gradiente. Esta última se obtiene con un observador MDSO a partir de la información disponible de la tasa de reacción y concentración de sustrato y de biomasa. En algunos de los trabajos citados previamente se considera que la concentración de sustrato se mide en línea. En otros se consideran disponibles las medidas de los gases producidos en el proceso, la que luego es relacionada de manera algebraica con la tasa de reacción. Siguiendo el desarrollo de esta tesis, se considera que la única variable medida en línea es la concentración de microorganismos, y por lo tanto la concentración de sustrato y la tasa de reacción se estiman a partir de ella. Sin embargo, el ESC propuesto es igualmente válido e implementable si se dispone de otro tipo de instrumentos como los mencionados anteriormente. De hecho, mostraría una mejor robustez de medirse el sustrato y la tasa de reacción (a través de los gases), ya que se eliminarían las perturbaciones que generan los errores de estimación de estas variables.

\footnotetext{
${ }^{1}$ En un abuso del lenguaje nos referiremos al máximo como óptimo.
} 


\subsection{Controlador para seguimiento de extremos}

El esquema del ESC propuesto se describe en la Figura 6.4. Consta del control para búsqueda de extremos, un estimador de gradiente y observadores para la tasa de reacción y el sustrato. La única variable medida en línea es la concentración de microrganismos. En esta

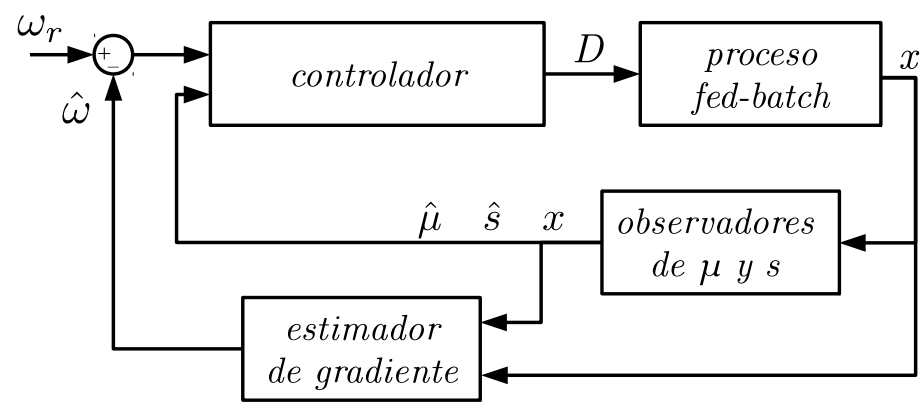

Figura 6.4: Esquema del control para seguimientos de extremos propuesto.

sección se describe cada componente del esquema de control, mientras que en la Sección 6.4 se analiza la estabilidad de todo el sistema junto con la sintonización del algoritmo.

\subsubsection{Ley de control propuesta}

El controlador propuesto busca estabilizar el gradiente en $\omega=0$. La ley de control es:

$$
\begin{aligned}
D & =\left(\frac{\hat{\mu} x}{y_{x s}}+u_{1}+u_{2}\right)\left(s_{f}-\hat{s}\right)^{-1} \\
u_{1} & =k_{1}|\hat{\omega}|^{1 / 2} \operatorname{sign}(\hat{\omega}) \\
\dot{u}_{2} & =k_{2} \operatorname{sign}(\hat{\omega})
\end{aligned}
$$

donde $k_{1}>0$ y $k_{2}>0$ son ganancias de diseño y $\hat{\mu}$ y $\hat{s}$ son las estimaciones de la tasa específica de reacción y concentración de sustrato, obtenidas a partir de los observadores descriptos en la Sección 6.3.3. El primer término de (6.5a) es una acción de control continua que cancela la dinámica natural de consumo del sustrato.

Suponiendo que todos los errores de estimación son nulos $\hat{\mu}=\mu, \hat{s}=s$ y $\hat{\omega}=\omega$. Reemplazando (6.5a) en (6.1b) se obtiene

$$
\dot{s}=u_{1}+u_{2},
$$

de donde se ve que la dinámica del sustrato es dominada por los términos de modos deslizantes.

La ley de control propuesta es robusta frente a incertidumbres en el modelo y perturba- 
ciones. Además, la acción de control es continua y más suave que los algoritmos de modos deslizantes de primer orden. Esto en conjunción con que el término (6.5b) se anula en la superficie $(\hat{\omega}=0)$, la magnitud de chattering producido es significativamente menor. Por otra parte, la inclusión del término integral permite rechazar perturbaciones acotadas en la dilución. La estabilidad del controlador y su robustez dependen de la correcta sintonización de las ganancias $k_{1} \mathrm{y} k_{2}$.

\subsubsection{Estimación de gradiente}

Como se explica en las secciones precedentes, la función de deslizamiento usada en el controlador es una estimación del gradiente del mapa $\psi: s \rightarrow \mu$. De (6.4a) se puede observar que $\omega$ puede estimarse con un observador siempre y cuando $x, \mu$ y $s, \mathrm{o}$ al menos sus estimaciones, estén disponibles para realimentar. Con el fin de obtener una convergencia rápida y en tiempo finito de las estimaciones se propone un observador de MDSO. El algoritmo supertwisting clásico [102] no se puede usar para estimar gradiente a partir de (6.4a). Esto se debe a que $\omega$ se encuentra multiplicada por $\dot{s}$, cuyo signo cambia a lo largo del proceso. Es una condición para la estabilidad del algoritmo, en este caso, que $\dot{s}$ no cambie de signo [133]. Se utiliza entonces una versión modificada del algoritmo para lidiar con esta particularidad. El observador propuesto está inspirado en [134, 135].

Para simplificar las ecuaciones del observador renombramos a $\dot{s}$ :

$$
f(\mu, x, s) \triangleq \dot{s}=-\frac{\mu(s) x}{y_{x s}}+D\left(s_{f}-s\right)
$$

Luego, las ecuaciones del observador son

$$
\begin{aligned}
\dot{\varpi} & =\hat{\omega} f(\hat{\mu}, x, \hat{s})-\kappa_{1}|f(\hat{\mu}, x, \hat{s})||\sigma|^{1 / 2} \operatorname{sign}(\sigma) \\
\dot{\hat{\omega}} & =-\kappa_{2} f(\hat{\mu}, x, \hat{s}) \operatorname{sign}(\sigma) \\
\sigma & =\hat{\mu}-\varpi
\end{aligned}
$$

donde $\varpi$ es un estimación auxiliar de la tasa de reacción, $\hat{\omega}$ es la estimación del gradiente y $\kappa_{1}$ y $\kappa_{2}$ son las ganancias de diseño. La función de deslizamiento $\sigma$ es el error entre la estimación de la tasa de reacción hecha por el observador de tasa de reacción que se presenta en la Sección 6.3.3 (aquí considerado el valor verdadero) y la hecha por el observador de gradiente. El problema de cambio de signo se maneja al agregar $f(\hat{\mu}, x, \hat{s})$ en el término integral del observador. Las pruebas de estabilidad de este observador son similares a [135].

La ventaja de este enfoque para la estimación del gradiente es que se obtiene una convergencia muy rápida y en tiempo finito, sin agregar dinámica propia del observador al lazo. Sin embargo, se debe notar que el observador es alimentado con estimaciones de $s$ y $\mu$ en lugar de sus valores verdaderos (cómo se hace en [130], por ejemplo). Esto tiene como efecto que la estimación de $\hat{\omega}$ es susceptible a errores originados en los errores de estimación de $s$ y $\mu$. 
Notar que sobre la superficie, $\varpi$ converge a $\hat{\mu}$. Si esta difiere de la tasa verdadera $\mu$ en un error, es lógico que la estimación de gradiente también. De todas formas, mediante la adecuada sintonización de los observadores de $\mu$ y $s$, se pueden mantener los errores de estimación de $\omega$ acotados.

\subsubsection{Observadores auxiliares}

Las estimaciones de la tasa de reacción y concentración de sustrato se obtienen con observadores como los descriptos en los Capítulos 4 y 5 . Por ejemplo, en el caso de la optimización de tasa de crecimiento, $\hat{\mu}$ se puede obtener con un observador exponencial

$$
\begin{aligned}
& \dot{\hat{x}}=\left(\hat{\mu}-D-\gamma_{1}(x-\hat{x})\right. \\
& \dot{\hat{\mu}}=\gamma_{2} \frac{(x-\hat{x})}{x},
\end{aligned}
$$

donde $\hat{x}$ es la estimación de la concentración de microorganismos (medida). Las ganancias $\gamma_{1}$ y $\gamma_{2}$ se ajustan para asignar los autovalores $\lambda_{1}$ y $\lambda_{2}$ de la dinámica del error

$$
\begin{aligned}
\lambda_{1}+\lambda_{2} & =\gamma_{1} \\
\lambda_{1} \lambda_{2} & =\gamma_{2} .
\end{aligned}
$$

Por otra parte, la estimación de la concentración de sustrato $s$ se puede obtener con un observador asintótico

$$
\begin{aligned}
& \dot{\hat{z}}=-D\left(\hat{z}-s_{f}\right) \\
& \hat{s}=\hat{z}-\frac{x}{y_{x s}} .
\end{aligned}
$$

u otros observadores de la literatura [105].

Observación 4: El algoritmo de control se ejecuta con una frecuencia suficientemente baja como para que la concentración de sustrato y la tasa de crecimiento muestren alguna variación antes de que se aplique la nueva acción de control. Esto es importante para que la estimación del gradiente sea más confiable. El lazo pasa a ser menos sensible al ruido, retardos propios del proceso y de los observadores que pueden producir errores en la estimación del gradiente. Por otra parte, ayuda a reducir la interacción entre el controlador y el observador por MDSO. 


\subsection{Demostración de estabilidad del controlador}

El algoritmo de control propuesto utiliza estimaciones de las variables del proceso para el cálculo de la acción de control. Esto tiene un efecto sobre la estabilidad del lazo porque los observadores (exponenciales y asintóticos) tienen su propia respuesta dinámica y están sujetos a errores provenientes de la incertidumbre en los modelos o de las mediciones. En esta sección se demuestra la estabilidad del algoritmo de control propuesto. Primero en la Sección 6.4.1, se prueba la estabilidad nominal, considerando nulos los errores de estimación y perturbaciones. En la Sección 6.4.2 se demuestra la estabilidad práctica considerando perturbaciones y errores de estimación. Además, se obtienen condiciones para la sintonización de las ganancias del controlador.

\subsubsection{Estabilidad nominal del controlador}

Supóngase que no hay errores de estimación. Reemplazando (6.5a) en (6.4b) con $\hat{\mu}=\mu$, $\hat{s}=s$ y $\hat{\omega}=\omega$ se obtiene el siguiente sistema

$$
\begin{aligned}
\dot{\omega} & =h\left(k_{1}|\omega|^{\frac{1}{2}} \operatorname{sign}(\omega)+u_{2}\right) \\
\dot{u}_{2} & =k_{2} \operatorname{sign}(\omega)
\end{aligned}
$$

donde $h$ es el hessiano (escalar) de $\mu$, como se definió en (6.3). Este sistema difiere de los usualmente analizados, por ejemplo en [133], en que todos los términos de (6.12a) están multiplicados por una variable adicional $(h)$.

Aplicando el siguiente homeomorfismo global (similar al usado en [133]):

$$
\begin{aligned}
& \xi_{1}=|\omega|^{\frac{1}{2}} \operatorname{sign}(\omega) \\
& \xi_{2}=u_{2},
\end{aligned}
$$

se obtiene un nuevo sistema:

$$
\begin{aligned}
& \dot{\xi}_{1}=\frac{1}{2\left|\xi_{1}\right|}\left(k_{1} \xi_{1}+\xi_{2}\right) h \\
& \dot{\xi}_{2}=\frac{1}{2\left|\xi_{1}\right|}\left(2 k_{2} \xi_{1}\right)
\end{aligned}
$$

cuyos punto de equilibrio es $\left(\xi_{1}, \xi_{2}\right)=(0,0)$. Éste se puede reescribir como

$$
\dot{\xi}=\frac{1}{2\left|\xi_{1}\right|} A(h) \xi
$$

donde

$$
A(h)=\left[\begin{array}{ll}
h k_{1} & h \\
2 k_{2} & 0
\end{array}\right] .
$$


La localización de los autovalores de $A$ está dada por

$$
\operatorname{eigs}\{A(h)\}=\frac{h k_{1}}{2} \pm \sqrt{\left(\frac{h k_{1}}{2}\right)^{2}+2 k_{2} h} .
$$

Además como $k_{1}>0$ y $k_{2}>0$, de la inspección de (6.17) queda claro que $\mu(s)$ tiene que ser convexa $(h<0)$ para que $(6.15)$ sea estable.

A partir de (6.15) se puede definir una función de Lyapunov cuadrática $V(\xi)=\xi^{T} P \xi>0$, donde $P$ es la matriz simétrica y definida positiva

$$
P=\frac{1}{2}\left[\begin{array}{cc}
k_{1}^{2} & k_{1} \\
k_{1} & 2
\end{array}\right] .
$$

Luego, derivando $V(\xi)$ con respecto al tiempo se obtiene

$$
\dot{V}=-\frac{1}{2\left|\xi_{1}\right|} \xi^{T} Q \xi
$$

donde

$$
\begin{aligned}
& Q(h)=-\left(A(h)^{T} P+P A(h)\right)= \\
& =\left[\begin{array}{cc}
-h k_{1}^{3}-2 k_{1} k_{2} & -h k_{1}^{2}-2 k_{2} \\
-h k_{1}^{2}-2 k_{2} & -h k_{1}
\end{array}\right]
\end{aligned}
$$

y

$$
\operatorname{det}\{Q(h)\}=-2 h k_{1}^{2} k_{2}-4 k_{2}^{2}
$$

Como antes, si $k_{1}>0$ y $k_{2}>0$, entonces es necesario que $h<0$ para que $Q>0$. Entonces, se puede obtener de (6.20) una condición suficiente para la estabilidad:

Teorema 6.2. Es condición suficiente para la estabilidad del sistema (6.12) que las ganancias $k_{1}$ y $k_{2}$ satisfagan

$$
-\frac{2 k_{2}}{k_{1}^{2}}>h
$$

Demostración. De hacer que los menores principales de (6.20) sean mayores que cero, al igual que (6.21), se obtiene la inecuación (6.22).

Esto significa que dado un par de ganancias $k_{1}$ y $k_{2}$ la estabilidad está garantizada para valores de $h$ lo suficientemente negativos. La Ecuación (6.22) da lugar a una superficie límite que definiremos como

$$
\underline{h} \triangleq-2 k_{2} / k_{1}^{2} \text {. }
$$

La misma se representa en la Figura 6.5a y algunas curvas de nivel en la Figura 6.5b. Estas cotas representan el valor de $h$ más próximo a cero admisible para asegurar estabilidad, o bien, la menor curvatura, siempre convexa, que el mapa $\psi: s \rightarrow \mu$ puede tener. De su análisis surge por ejemplo que, para valores fijos de $k_{2}$, valores decrecientes de $k_{1}$ reducen la región 


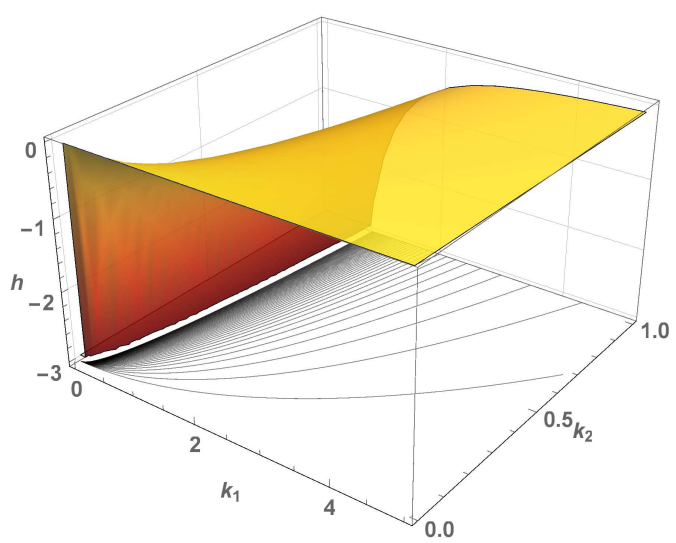

(a) Cota de estabilidad, mostrando el máximo hessiano posible para los pares de ganancias del controlador.

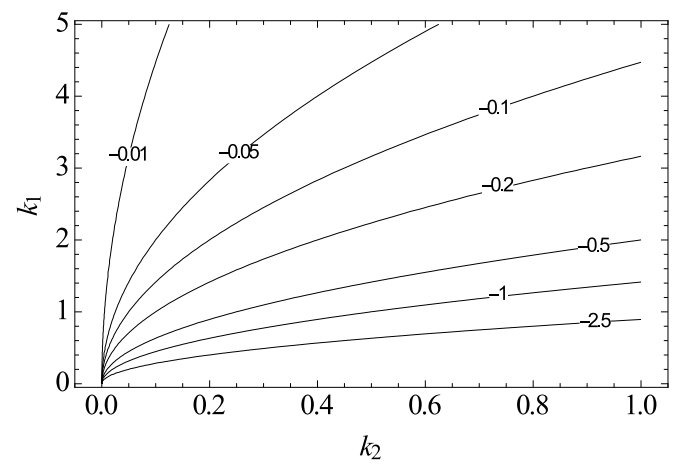

(b) Pares mínimos de ganancias que aseguran estabilidad para distintos valores del hessiano.

Figura 6.5: Cotas en el hessiano para asegurar estabilidad nominal.

de estabilidad al volverse $\underline{h}$ más negativo. También se puede notar que cuando $k_{2} \rightarrow 0$, la cota $\underline{h} \rightarrow 0$, de manera similar al control por modos deslizantes de primer orden presentado en [130]. Se puede concluir que la estabilidad nominal depende fuertemente de la relación entre $k_{1}$ y $k_{2}$.

\subsubsection{Estabilidad práctica}

El controlador propuesto depende de estimaciones hechas por observadores de estado. Si existen errores en las estimaciones, éstos aparecen como perturbaciones en (6.12a) y (6.12b). De manera general se define un nuevo sistema perturbado

$$
\begin{aligned}
\dot{\omega} & =h \dot{s}=h\left(k_{1}|\omega|^{\frac{1}{2}} \operatorname{sign}(\omega)+u_{2}+\rho_{1}\right) \\
\dot{u}_{2} & =k_{2} \operatorname{sign}(\omega)+\rho_{2}
\end{aligned}
$$

donde $\rho_{1}$ y $\rho_{2}$ son los términos de perturbación.

Asumiendo que las perturbaciones surgen exclusivamente de los errores de estimación se puede mostrar que

$$
\left|\rho_{1}\right|<\frac{x}{y_{x s}}|\tilde{\mu}|+k_{1}|\tilde{\omega}|^{\frac{1}{2}}=\delta_{1}
$$

donde $\tilde{\mu}$ y $\tilde{\omega}$ son los errores de estimación de $\mu$ y $\omega$ respectivamente. En (6.25) se ha despreciado el efecto del error de estimación en la concentración de sustrato $\tilde{s}$, porque aparece como un factor de la forma

$$
\frac{s_{f}-s}{s_{f}-\hat{s}} \cong 1,
$$

ya que en general se satisface que $s_{f} \gg s$. Además, $\tilde{s} \rightarrow 0$ por lo que el término anterior tiende a 1. 
En este contexto, la estabilidad práctica [136] puede ser obtenida en términos del siguiente teorema:

Teorema 6.3. El sistema (6.24a)-(6.24b) es prácticamente estable si las perturbaciones pueden ser acotadas según $\left|\bar{h} \rho_{1}\right| \leq \delta_{1} y\left|\rho_{2}\right| \leq \delta_{2}$, para $\delta_{1} \geq 0, \delta_{2} \geq 0$, y además

$$
\delta_{2}<\frac{\lambda_{\min }\{Q(h)\}}{4 \lambda_{\max }\{P\}} \quad \forall \delta_{1} \geq 0,
$$

donde $\lambda_{\min }\{Q(h)\}$ y $\lambda_{\max }\{P\}$ son el mínimo autovalor de $Q(h)$ y máximo autovalor de $P$, respectivamente.

Demostración. Primero, se realiza el cambio de coordenadas (6.14) sobre el sistema perturbado (6.24), lo que da lugar a

$$
\dot{\xi}=\frac{1}{2\left|\xi_{1}\right|}\left(A(h) \xi+\varrho_{1}(h)\right)+\varrho_{2}
$$

y los vectores de perturbación son

$$
\varrho_{1}(h)=\left[\begin{array}{c}
h \rho_{1} \\
0
\end{array}\right] \quad \varrho_{2}=\left[\begin{array}{c}
0 \\
\rho_{2}
\end{array}\right] .
$$

Bajo esta misma estructura se puede volver a utilizar la misma función de Lyapunov que en el caso nominal $V(\xi)=\xi^{T} P \xi$. La diferencia es que considerando perturbaciones su derivada es

$$
\dot{V}=-\frac{1}{2\left|\xi_{1}\right|}\left(\xi^{T} Q(h) \xi-\varrho_{1}(h)^{T} P \xi\right)+2 \varrho_{2}^{T} P \xi
$$

Luego, si se satisface (6.27), $\dot{V}$ se puede acotar como

$$
\begin{aligned}
\dot{V} & \leq-\epsilon \frac{\frac{1}{2} \lambda_{\min }\{Q(h)\}-2 \delta_{2} \lambda_{\max }\{P\}}{\lambda_{\max }^{\frac{1}{2}}\{P\}} V^{\frac{1}{2}}, \\
\forall\|\xi\|_{2} & >\frac{\delta_{1} \lambda_{\max }\{P\}}{2(1-\epsilon)\left(\frac{1}{2} \lambda_{\min }\{Q(h)\}-2 \delta_{2} \lambda_{\max }\{P\}\right)}, \\
0 & <\epsilon<1 .
\end{aligned}
$$

Los detalles de cómo se obtiene (6.31) de (6.30) siguen la línea de [133] pero teniendo en cuenta que aquí $Q$ no es una matriz de coeficientes constantes.

El resultado obtenido en (6.31) asegura que todas las trayectorias de (6.24) que empiezan en una región de $\mathbb{R}^{2}$ convergen a una bola alrededor del origen.

La matriz $Q(h)$ es simétrica y definida positiva, pero además depende de $h$, por lo tanto 
sus autovalores $\lambda_{Q i}$ son reales, positivos y también dependientes de $h$ :

$$
\begin{aligned}
\lambda_{Q i} & =-h \frac{k_{1}}{2}\left(1+k_{1}^{2}\right)-k_{1} k_{2} \pm\left(a h^{2}+b h+c\right)^{\frac{1}{2}} \\
a & =\frac{k_{1}^{2}}{4}\left(1+2 k_{1}^{2}+k_{1}^{4}\right) \\
b & =k_{1}^{2} k_{2}\left(3+k_{1}^{2}\right) \\
c & =k_{2}^{2}\left(4+k_{1}^{2}\right) .
\end{aligned}
$$

Por esta razón, el autovalor mínimo de $Q$ se debe hallar minimizando (6.32) con respecto a $h$ y restringido al intervalo $(\bar{h}, \underline{h})$, donde $\bar{h}<\underline{h}<0$. El parámetro $\underline{h}$ se obtiene de (6.22) y $\bar{h}$ se puede obtener a partir del modelo cinético, si es que está disponible, o una aproximación del mismo.

Existe la posibilidad de que $\lambda_{\min }\{Q(h)\}=0$, cuando $h=\underline{h}$. Por esa razón, se debe tomar un margen de estabilidad en el diseño para obtener $\lambda_{\min }\{Q(h)\}>0$ de manera estricta. Volviendo a (6.20), la condición de estabilidad se puede restablecer incluyendo el margen de estabilidad

$$
Q(h)=\left(-A^{T} P+P A\right)>2 \alpha P .
$$

Esto constituye un problema de tasa de decaimiento como el presentado en Sección 5.3.4. Si $P>0$ existe, los autovalores de $A(h)$ son eigs $\{A(h)\}<-\alpha$. Aún más, los autovalores de $Q(h)$ son eigs $\{Q(h)\}>2 \alpha \lambda_{\min }\{P\}$. De (6.20), (6.18) y (6.33) se pueden obtener nuevas condiciones para la estabilidad.

Teorema 6.4. Es condición suficiente para que

$$
\operatorname{eigs}\{Q(h)\}>2 \alpha \lambda_{\min }\{P\}
$$

que las ganancias $k_{1}$ y $k_{2}$ en (6.24) satisfagan

$$
\begin{aligned}
& h<\frac{-\alpha k_{1}-2 k_{2}}{k_{1}^{2}} \\
& h<-\frac{2 \alpha}{k_{1}} .
\end{aligned}
$$

$\forall h \in[\bar{h}, \underline{h}]$.

Demostración. De (6.33) la condición de estabilidad es equivalente a

$$
-M(h) \triangleq A(h)^{T} P+P A(h)+2 \alpha P<0 .
$$


Luego, se puede deducir que

$$
M(h)=\left[\begin{array}{cc}
-k_{1}\left(\alpha k_{1}+h k_{1}^{2}+2 k_{2}\right) & -\left(\alpha k_{1}+h k_{1}^{2}+2 k_{2}\right) \\
-\left(\alpha k_{1}+h k_{1}^{2}+2 k_{2}\right) & -\left(2 \alpha+h k_{1}\right)
\end{array}\right]>0 .
$$

Finalmente, resolviendo las desigualdades para todos los menores principales de $M$ se deducen las condiciones (6.35a) y (6.35b).

Observación 5: La región de estabilidad se define inicialmente por la relación $-2 k_{2} / k_{1}^{2}$, como se postula en (6.22), donde se establece una cota $\underline{h}$ para la curvatura de la cinética del microorganismo (el valor más pequeño de $h<0$ ). Para fortalecer la estabilidad se consideran condiciones más estrictas en (6.35a) y (6.35b). Basándose en estas condiciones se pueden establecer guías para la sintonización de las ganancias del controlador si es que se conoce un modelo cinético aproximado del microorganismo. Los pasos a seguir son:

1. Calcular la derivada segunda de $\mu(s)$ con respecto a s para obtener $h(s)$, o al menos una aproximación de ella.

2. Buscar cotas máximas y mínimas para $h(s)$. Si para algún valor de $s$ el hessiano $h(s) \geq 0$ se debe definir una concentración de sustrato límite s tal que $h(\underline{s})=\underline{h}<0$.

3. Definir un valor para $\alpha$. Éste puede surgir de evaluar los posibles autovalores de Q dados por (6.32).

4. Hallar $k_{1} y k_{2}$ tales que $\frac{-\alpha k_{1}-2 k_{2}}{k_{1}^{2}}>\underline{h} y-\frac{2 \alpha}{k_{1}}>\underline{h}$, es decir, que se cumpla (6.35) cuando $h=\underline{h}$.

5. Si las ganancias obtenidas son demasiado grandes, o bien, no existen ganancias que satisfagan las restricciones, se debe repetir el procedimiento eligiendo $\alpha$ o s más pequeños.

\subsection{Ejemplo de aplicación del controlador propuesto a un crecimiento simple}

En esta sección se muestran resultados de simulación de la aplicación del controlador propuesto para la optimización de la tasa específica de crecimiento en un proceso simple bajo diferentes escenarios y situaciones. El proceso puede ser descripto por (6.1) y su cinética depende exclusivamente de un único sustrato, siendo el modelo:

$$
\mu=\frac{\mu_{\max } s}{k_{s}+s+\frac{s^{2}}{k_{i}}}
$$

donde los valores de los parámetros son: $\mu_{\max }=0.41 \mathrm{~h}^{-1}, k_{s}=1.2 \mathrm{gl}^{-1}, k_{i}=17.43 \mathrm{gl}^{-1}$, $s_{f}=200 \mathrm{gl}^{-1}, y_{x s}=0.48 \mathrm{gg}^{-1}$. Además, el punto de operación óptimo es $s^{*} \cong 4.6 \mathrm{~g} \mathrm{~L}^{-1} \mathrm{y}$ $\mu^{*} \cong 0.27 \mathrm{~h}^{-1}$.

Las ganancias del observador de tasa de crecimiento son $\gamma_{1}=-40$ y $\gamma_{2}=400$ para asegurar una tasa de convergencia rápida y seguimiento con poco retraso, teniendo un doble 


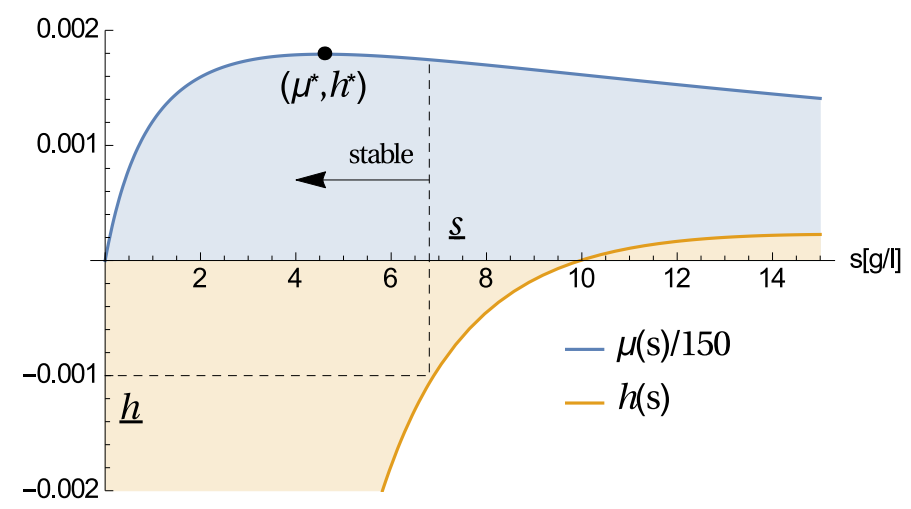

Figura 6.6: Modelo cinético de $\mu$ y hessiano usados en las simulaciones

autovalor en $\lambda=-20$. Las ganancias del estimador de gradiente son $\kappa_{1}=4,5$ y $\kappa_{2}=10$. Las ganancias del controlador son $k_{1}=20$ y $k_{2}=0,2$, que de (6.22) dan una cota máxima para el hessiano $\underline{h} \cong-0.001 \mathrm{~L}^{2} \mathrm{~h}^{-1} \mathrm{~g}^{-2}$, correspondiente a una concentración de sustrato máxima $\underline{s} \cong 7 \mathrm{gl}^{-1}$. El autovalor mínimo de $Q$ para $h<\underline{h}$ es cero cuando $h=\underline{h}$. Por eso, para que $\lambda_{\min }\{Q(h)\}>0$, se utilizan (6.35a) y (6.35b) con $\alpha=0,01$ y las ganancias previas, obteniéndose una nueva cota $\underline{h}=-0.0015 \mathrm{~L}^{2} \mathrm{~h}^{-1} \mathrm{~g}^{-2}$, reduciéndose la región de estabilidad. En la Figura 6.6 se muestra el modelo cinético (6.38) y su hessiano ${ }^{2}$. La región de estabilidad se muestra con línea a trazos.

El primer escenario de simulación se muestra en la Figura 6.7 para dos concentraciones de sustrato iniciales distintas. Las curvas azules corresponden al caso donde la concentración inicial es mayor que la óptima $\left(s(0)=8.2 \mathrm{gl}^{-1}\right)$ y las curvas en rojo corresponden al caso en que la concentración inicial es menor que la óptima $\left(s(0)=0.9 \mathrm{gl}^{-1}\right)$. Ambas condiciones iniciales son equidistantes del óptimo y en particular la concentración mayor está fuera de la región de estabilidad. Con respecto a los observadores de tasa de crecimiento y concentración de sustrato, en este escenario se inician sin errores. En la Figura 6.7a se puede ver que la tasa específica de crecimiento alcanza el valor óptimo en aproximadamente 2 horas. Lo mismo puede observarse con la concentración de sustrato en la Figura 6.7c. La Figura 6.7b muestra al gradiente $\omega$ y su estimación $\hat{\omega}$ para ambos casos, donde se puede observar una tasa de convergencia rápida de las estimaciones, en menos de una hora, y cómo el gradiente converge a cero debido a la acción de control mostrada en la Figura 6.7e. La Figura 6.7d muestra la trayectoria seguida en el plano $(s, \mu)$, donde se puede observar claramente la convergencia a la tasa óptima.

Los errores presentes en la estimación del gradiente provienen del retraso que tiene la estimación de la tasa de crecimiento con respecto al valor verdadero. Estos errores se propagan a la concentración de sustrato donde la respuesta está relativamente distorsionada luego de converger a $s^{*}$, no así con la tasa de crecimiento que prácticamente no presenta variaciones. La sintonización del observador de tasa de crecimiento se hace manteniendo una relación de compromiso entre velocidad de convergencia y rechazo a ruido (que es uno de los casos

\footnotetext{
${ }^{2} \mu(s)$ se muestra atenuado 150 veces para que su magnitud sea comparable a la de $h(s)$
} 


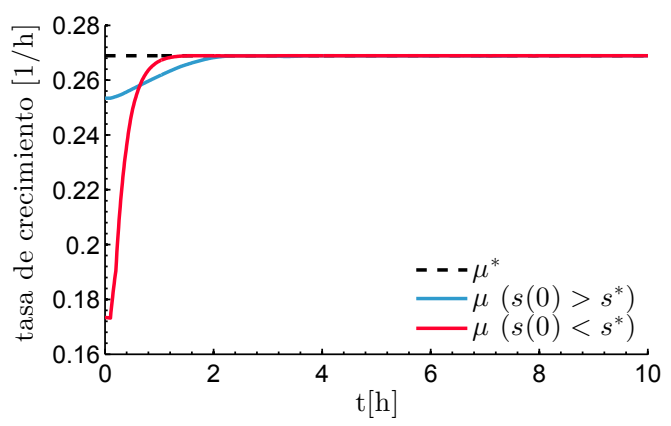

(a) Tasa específica de crecimiento.

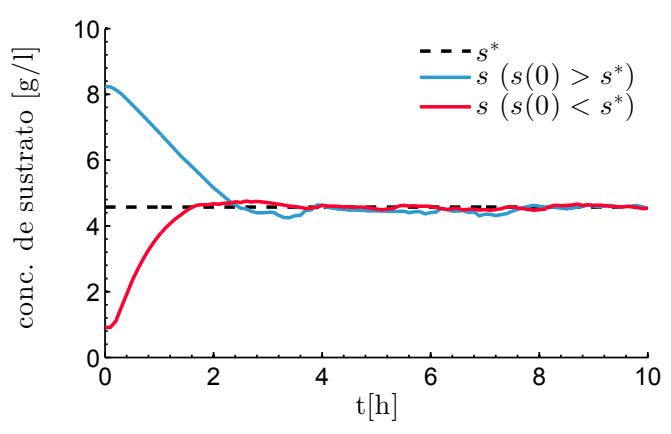

(c) Concentración de sustrato.

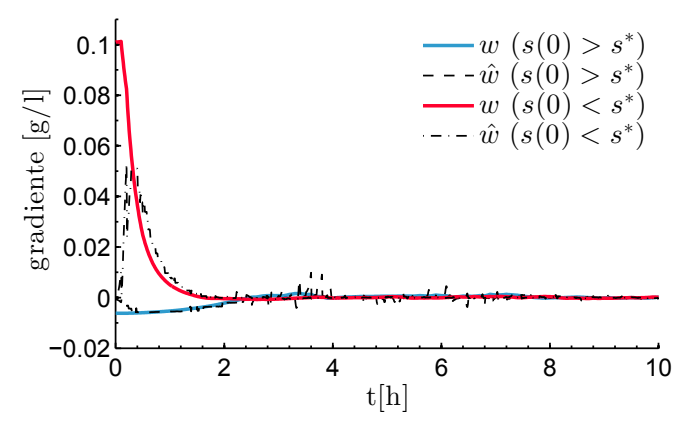

(b) Gradiente v estimación.

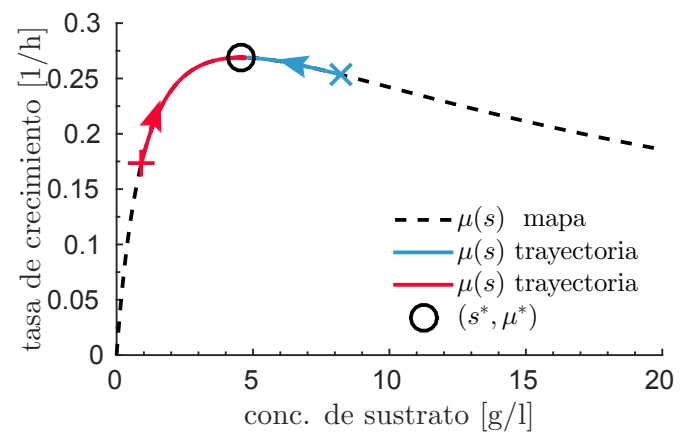

(d) Mapa de concentración de sustrato y tasa específica de crecimiento.

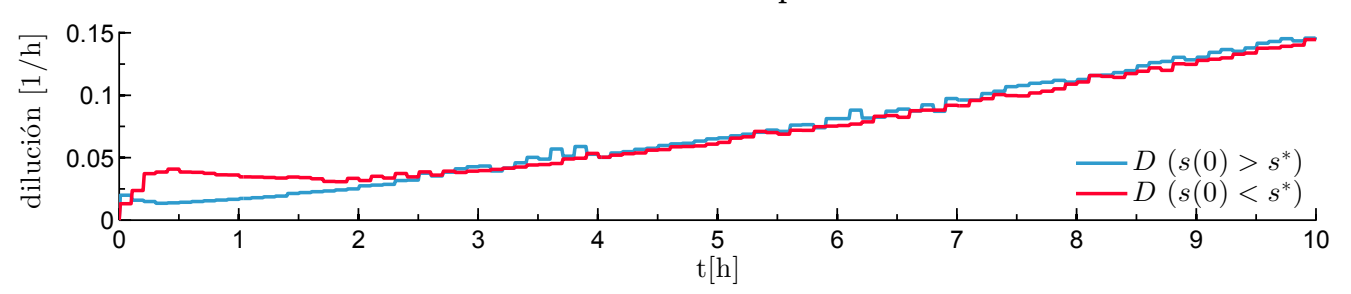

(e) Tasa de dilución.

Figura 6.7: Resultados de simulación para el controlador propuesto con diferentes condiciones iniciales del sustrato. Líneas rojas: concentración de sustrato inicial menor al valor óptimo. Líneas azules: concentración inicial de sustrato mayor a la óptima.

simulados en esta sección). Una sintonización alternativa de los observadores mejora la respuesta del gradiente estimado. La Figura 6.8 muestra la respuesta del sistema cuando los observadores tienen mayor velocidad de convergencia. Las ganancias usadas en ese caso para el observador de tasa de crecimiento son $\gamma_{1}=-80$ y $\gamma_{2}=1600$, dando polos iguales en $\lambda=-40$. Además se modificó la ganancia $k_{1}$ del controlador a $k_{1}=40$. Se puede observar cómo mejora la respuesta del sustrato en la Figura 6.8a y la estimación del gradiente en la Figura 6.8b. Sin embargo, por su velocidad, esta sintonización no tiene tan buen desempeño frente al ruido como la anterior.

La Figura 6.9 muestra el escenario en que el observador de tasa de crecimiento y el de sustrato son iniciados con errores, es decir, $\left.\hat{\mu}\right|_{t=0} \neq\left.\mu\right|_{t=0}$ y $\left.\hat{s}\right|_{t=0} \neq\left. s\right|_{t=0}$. En el caso de la tasa de crecimiento el error es del $50 \%$ y para el sustrato es del $200 \%$, como se puede observar en las Figuras 6.9a y 6.9b. La estimación de la tasa de crecimiento tiene una rápida convergencia, en concordancia con las ganancias $\gamma_{1}$ y $\gamma_{2}$ elegidas. En contraste, la estimación de la 


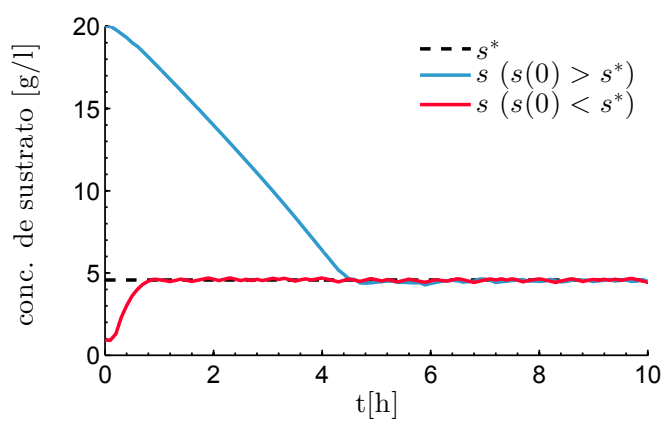

(a) Concentración de sustrato.

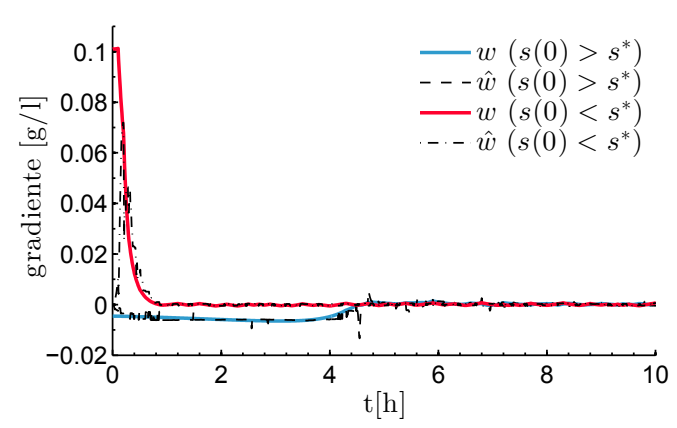

(b) Gradiente y estimación.

Figura 6.8: Resultados de simulación para el controlador propuesto, sintonización de las ganancias para mayor velocidad de convergencia.

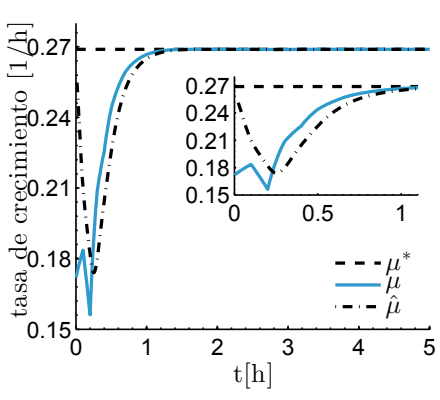

(a) Tasa especfica de creci-(b) miento y estimación.

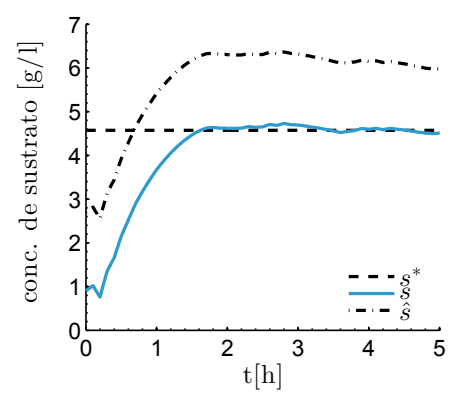

(b) Concentración de sustrato y estimación.

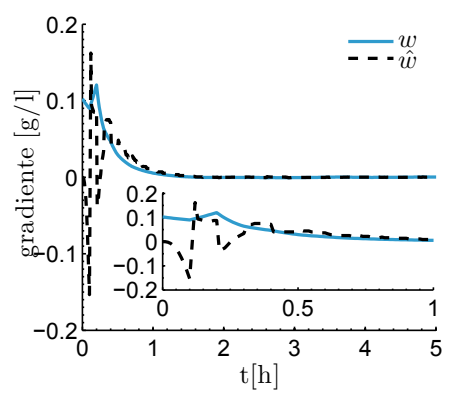

(c) Gradiente y estimación.

Figura 6.9: Resultados de simulación para el controlador propuesto cuando las condiciones iniciales de los observadores tienen errores. Líneas continuas: valores verdaderos. Líneas a trazos y puntos: valores estimados. Líneas a trazos: valores óptimos

concentración de sustrato converge muy lentamente, ya que su tasa de convergencia es igual a la dilución usada. De todas formas, el error en la estimación del sustrato no tiene un gran efecto en la estimación del gradiente, es su derivada $\dot{\hat{s}}=-\hat{\mu} x / y_{x s}+D\left(s_{f}-\hat{s}\right)$ la que tiene un mayor efecto en lugar de su valor instantáneo (ver (6.7) y (6.8a)). Como $s_{f} \gg s$ en (6.7) se puede concluir que $\dot{\hat{s}}$ no es afectada significativamente por los errores en $\hat{s}$. La Figura 6.9c muestra al gradiente y su estimación, se puede observar que a pesar del pico inverso inicial en la estimación (mayoritariamente debido al error de estimación de la tasa de crecimiento), la convergencia al valor verdadero es rápida.

El siguiente escenario consiste en modificar el mapa $\psi: s \rightarrow \mu$ por un mapa multivariable $\Upsilon: s, n \rightarrow \mu$ donde $n$ es un segundo sustrato. Como solamente se controla la concentración de $s$, la variación de $n$ resultará en una tasa de crecimiento óptima variante en el tiempo. Los resultados se muestran en la Figura 6.10. La variación de $\mu^{*}$ se produce al introducir un factor adicional en el modelo cinético, siendo entonces

$$
\mu=\frac{\mu_{\max } s}{k_{s}+s+\frac{s^{2}}{k_{i}}} \cdot \frac{n}{k_{n}+n+\frac{n^{2}}{k_{i n}}},
$$


donde $\mu_{\max }=0,745, k_{n}=5, k_{i n}=30, k_{s} \mathrm{y} k_{i}$ son los mismos del modelo anterior (6.38). Teniendo en cuenta el nuevo factor, $s^{*}$ se mantiene igual y $\mu^{*}$ varía según la concentración del sustrato $n$. Además, ambos sustratos se suministran con el mismo caudal, siendo la concentración de alimentación del segundo $n_{f}=40 \mathrm{gl}^{-1}$ que resulta en una lenta acumulación del mismo. Como se muestra en la Figura 6.10b, la estimación del gradiente se ve apreciable-

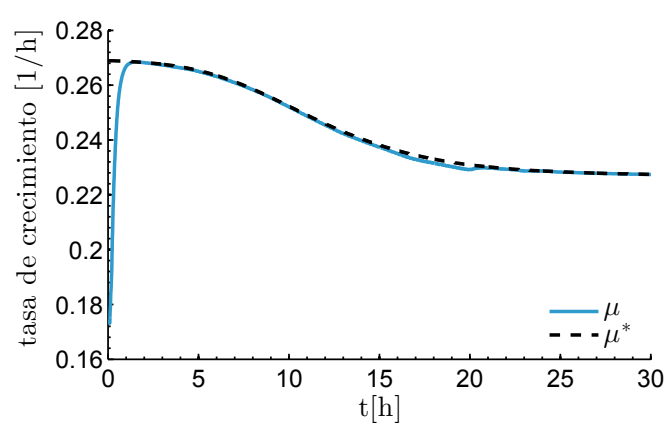

(a) Tasa específica de crecimiento.

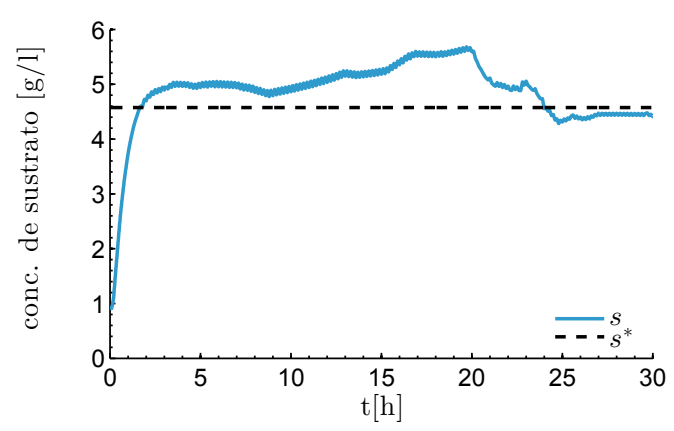

(c) Concentración de sustrato.

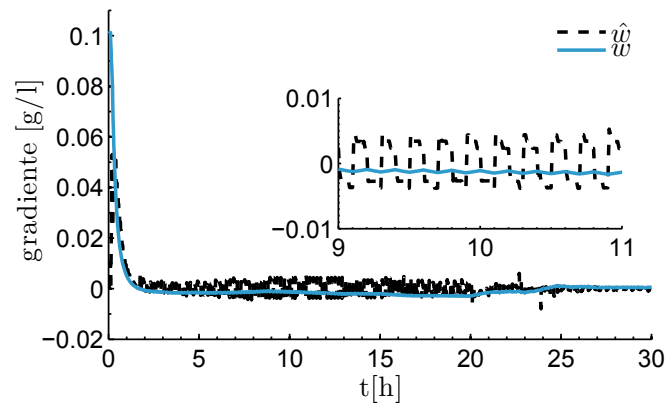

(b) Gradiente y estimación.

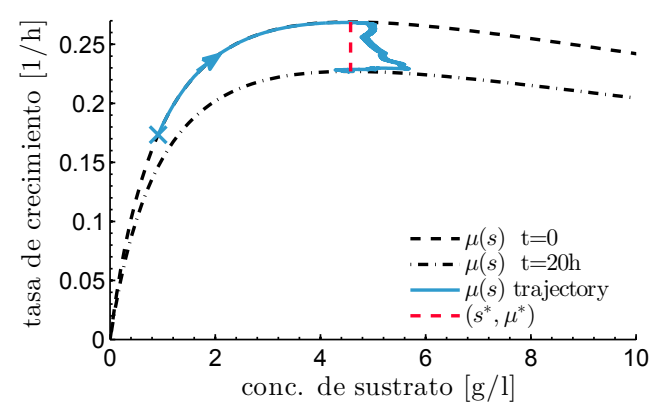

(d) Mapa de concentración de sustrato a tasa de crecimiento.

Figura 6.10: Resultados de simulación para el control de seguimiento de extremos propuesto para maximizar la tasa específica de producción de PHB. Líneas azules: valores verdaderos. Líneas a trazos: (a) y (c) valores óptimos, (b) gradiente estimado, (d) mapa inicial. Líneas a trazos y puntos: (d) mapa final.

mente afectada por las variaciones en la tasa de crecimiento óptima. Esto se debe a que estas variaciones se manifiestan como una perturbación en (6.2):

$$
\dot{\mu}=\omega \dot{s}+\frac{\partial \mu}{\partial n} \dot{n}=\omega \dot{s}+\phi
$$

donde $\phi$ es el término de perturbación que representa las variaciones en $\mu$ debido a $n$. El error de estimación de la tasa de crecimiento se puede obtener al hacer la diferencia entre (6.40) y (6.8a):

$$
\dot{\tilde{\mu}}=\dot{\sigma}=\dot{\mu}-\dot{\varpi}=\tilde{\omega} \dot{s}+\phi-\kappa_{1}|\dot{s}||\sigma|^{1 / 2} \operatorname{sign}(\sigma),
$$

luego, cuando se alcanza un equilibrio y $\dot{\sigma}=\sigma=0$ se puede deducir que

$$
\tilde{\omega}=-\frac{\phi}{\dot{s}} .
$$


Ante todo se debe recordar que la operación del controlador es en tiempo discreto, por lo que en general $\dot{s} \neq 0$ la mayor parte del tiempo como se observa en la Figura 6.10 c donde $s$ presenta un pequeño rizado. En segundo lugar se puede observar en (6.42) que la perturbación $\phi$ no debería ser grande para poder asegurar errores pequeños en la estimación del gradiente. Esto quiere decir que es necesario que la pendiente en la dirección de $n$ dada por $\frac{\partial \mu}{\partial n}$ sea pequeña, que es una suposición válida si $n$ no es el sustrato limitante. O bien, es necesario que la tasa de cambio de $n$ sea pequeña. Esto es lógico ya que la hipótesis inicial es que hay un único factor influenciando la tasa de reacción, esta hipótesis es válida siempre y cuando la variación producida por otros factores sea pequeña. Esto se ilustra entre las 10 y 20 horas donde se puede observar que la tasa de variación del óptimo es mayor (Figura 6.10a), la estimación de gradiente está más degradada (Figura 6.10b) y el sustrato está más alejado de la concentración óptima (Figura 6.10c).

La estimación de gradiente se muestra en la Figura 6.10b y se puede observar que siempre se mantiene en un entorno del valor verdadero. La ampliación muestra saltos en la estimación, correspondientes a los cambios de signo de $s$. La Figura 6.10d muestra la trayectoria seguida en el plano $(s, \mu)$, se agregan además los modelos cinéticos en el instante inicial y final del proceso (curva a trazos negros y curva a trazos y puntos negros respectivamente) así como la trayectoria óptima $\left(s^{*}, \mu^{*}\right)$ (trazos rojos). Se puede observar que si bien el sustrato se aleja levemente de la trayectoria óptima, el efecto sobre la tasa es despreciable.

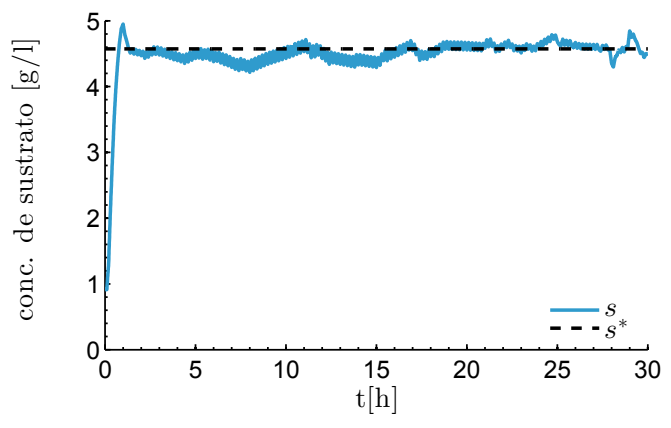

(a) Concentración de sustrato.

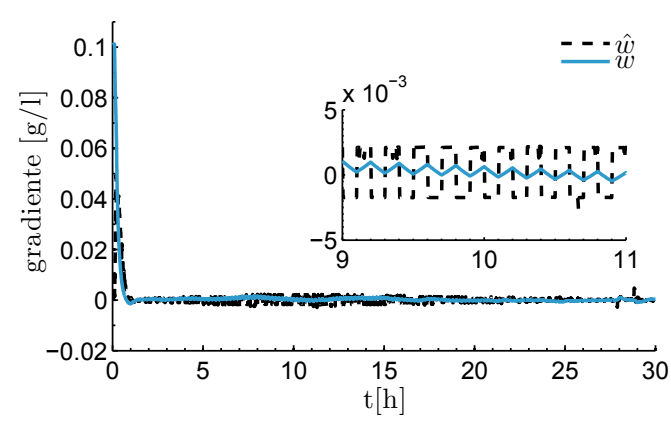

(b) Gradiente y estimación.

Figura 6.11: Resultados de simulación para el control de seguimiento de extremos propuesto para maximizar la tasa específica de producción de PHB con un $k_{1}$ mayor. Líneas azules: valores verdaderos. Líneas a trazos: (a) y (c) valores óptimos, (b) gradiente estimado, (d) mapa inicial. Líneas a trazos y puntos: (d) mapa final.

En la Figura 6.11 se muestran la respuesta del sustrato y del estimador de gradiente al incrementar la ganancia $k_{1}$ del controlador a $k_{1}=40$. Se puede observar una mejora importante en la regulación de la concentración de sustrato y una disminución en la distorsión de la estimación de gradiente.

Finalmente, en la Figura 6.12 se muestra la respuesta del sistema cuando la medición de concentración de microorganismos es afectada por ruido de baja frecuencia. Se simuló ruido blanco gaussiano con media nula y varianza $\sigma^{2}=0,1$, luego se lo filtró en la banda de 240 a $1000 \mathrm{~h}^{-1}$, o equivalentemente, 0.07 a $0.3 \mathrm{~Hz}$. La respuesta de la tasa de crecimiento y su esti- 

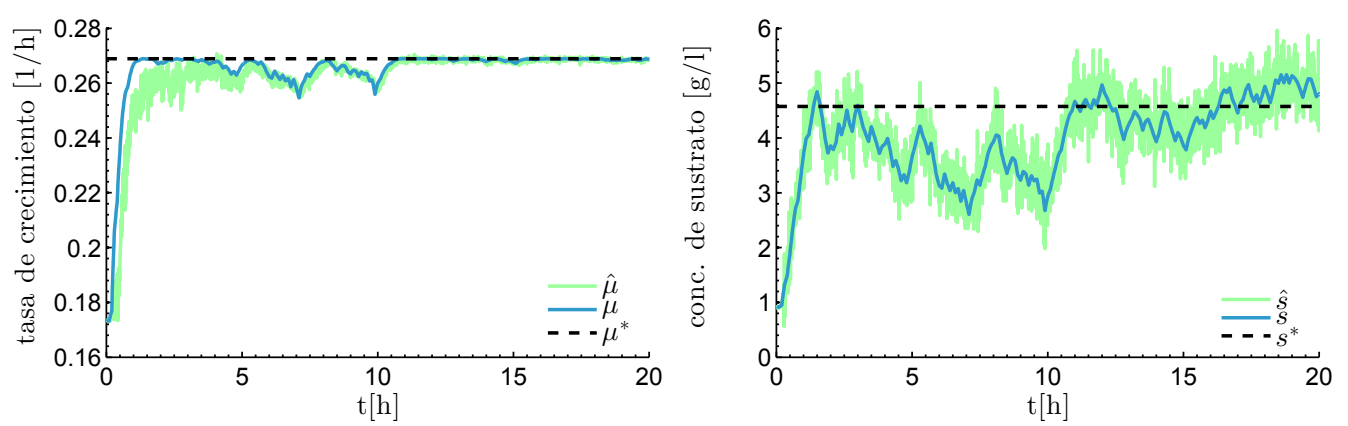

(a) Tasa especfica de crecimiento y estimación.

(b) Concentración de sustrato y estimación.

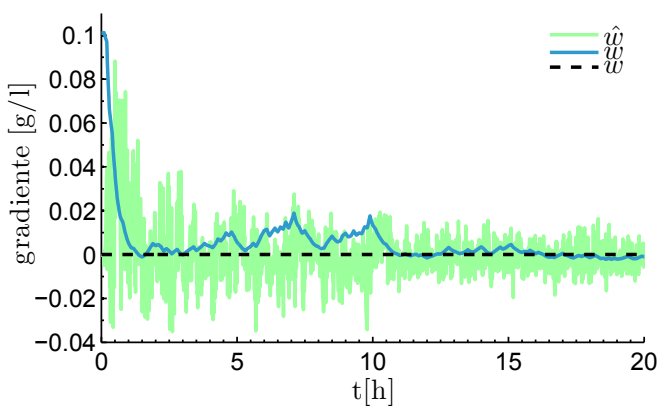

(c) Gradiente y estimación.

Figura 6.12: Resultados de simulación para el control propuesto bajo ruido de medición. Líneas azules: valores verdaderos. Líneas verdes: valores estimados. Líneas a trazos: valores óptimos.

mación se muestran en la Figura 6.12a. Se puede observar que a pesar de que el seguimiento del óptimo se ve degradado por el ruido, a medida que la concentración celular aumenta el ruido en la estimación decrece. Esto se debe, a una mejora en la relación señal a ruido de entrada con el incremento de la biomasa. La concentración de sustrato y su estimación se muestran en la Figura 6.12b. En este caso la magnitud del ruido permanece constante a lo largo del proceso por el uso del observador asintótico. La combinación del ruido en ambas estimaciones es lo que degrada la estimación de gradiente, mostrada en la Figura 6.12c, y por consecuencia el desempeño del lazo cerrado. La estimación del gradiente surge de observar los cambios en $\mu$ y $s$. Si el ruido tiene una magnitud similar a la de esos cambios el estimador no será capaz de discernirlos. En el escenario simulado, el sistema a lazo cerrado logra operar sobre el punto de operación óptimo y mantenerse sobre él. Sin embargo, en casos con condiciones de ruido aún más severas se puede mejorar la respuesta aumentando el período de muestreo del controlador, permitiendo variaciones de la concentración de sustrato más grandes que se distingan del ruido.

\subsection{Aplicación al proceso de producción de PHB}

En esta sección se muestran resultados de simulación de aplicar el controlador propuesto al proceso de producción de PHB. En la Sección 6.6.1 se muestran resultados para la optimi- 
zación de la tasa de crecimiento y en la Sección 6.6.2 para la tasa de producción.

\subsubsection{Optimización de etapa de crecimiento}

En esta sección se muestran resultados de simulación al aplicar el ESC propuesto a la etapa de crecimiento de un proceso de producción de PHB, para la maximización de la tasa específica de crecimiento.

La etapa de crecimiento del proceso de producción de PHB descripto en esta tesis se describe por el modelo (3.11):

$$
\begin{aligned}
\dot{x} & =(\mu-D) x \\
\dot{s} & =-\frac{\mu}{y_{x s}} x-D s+D_{s} s_{f} \\
\dot{n} & =-\frac{\mu}{y_{x n}} x-D n+D_{n} n_{f},
\end{aligned}
$$

donde

$$
\begin{aligned}
D_{s} & =\frac{F_{s}}{V} \\
D_{n} & =\frac{F_{s}}{V} \\
D & =\frac{\dot{V}}{V} \\
\dot{V} & =\gamma_{s} F_{s}+\gamma_{n} F_{n}
\end{aligned}
$$

y el modelo cinético de $\mu$ está dado por (3.10):

$$
\mu=\mu_{x s}=\mu_{x s}^{\max } \cdot \frac{s}{k_{s}+s+\frac{s^{2}}{k_{i s}}} \cdot \frac{n}{k_{n}+n+\frac{n^{2}}{k_{i n}}} \cdot\left[1-\left(\frac{x}{x_{m}}\right)^{\alpha}\right] .
$$

Del análisis de (6.45) se puede notar que la tasa de crecimiento es más sensible a variaciones en la concentración de FN que a la de FCE, como se observa en la Figura 3.3. Por lo tanto, el ESC propuesto se aplica sobre la concentración de nitrógeno, para el cálculo de la dilución $D_{n}$. Para ello son necesarios algunos cambios en el término de linealización del algoritmo de control:

$$
\begin{aligned}
& D_{n}=\left(\frac{\mu x}{y_{x n}}+D_{s} \hat{n}+u_{1}+u_{2}\right)\left(n_{f}-\hat{n}\right)^{-1} \\
& u_{1}=k_{1}|\hat{\omega}|^{1 / 2} \operatorname{sign}(\hat{\omega}) \\
& \dot{u}_{2}=k_{2} \operatorname{sign}(\hat{\omega}) .
\end{aligned}
$$

Por otra parte se controla la concentración de sustrato mediante un control PI. El objetivo de este control es mantener una concentración aproximadamente constante, no necesariamente 


\begin{tabular}{cc}
\hline Nombre & Valor \\
\hline$s_{f}$ & $650 \mathrm{gl}^{-1}$ \\
$n_{f}$ & $35 \mathrm{gl}^{-1}$ \\
$k_{1}$ & 0.5 \\
$k_{2}$ & 0.01 \\
$\kappa_{1}$ & 18 \\
$\kappa_{2}$ & 10 \\
$\gamma_{1}$ & -80 \\
$\gamma_{2}$ & -1600 \\
\hline
\end{tabular}

Tabla 6.2: Parámetros del controlador para la etapa de crecimiento.

la óptima, pero sí próxima a la misma. Para la implementación de ambos controladores es necesario disponer de estimaciones de $n$ y $s$, que se obtienen mediante un observador asintótico de la forma

$$
\begin{gathered}
\dot{\hat{z}}=-D \hat{z}+\left[\begin{array}{c}
D_{s} s_{f} \\
D_{n} n_{f}
\end{array}\right] \\
{\left[\begin{array}{l}
\hat{s} \\
\hat{n}
\end{array}\right]=\hat{z}-x\left[\begin{array}{c}
\frac{1}{y_{x s}} \\
\frac{1}{y_{x n}}
\end{array}\right] .}
\end{gathered}
$$

Los valores de las ganancias y de los distintos parámetros del ESC se especifican en la Tabla 6.2, los parámetros del modelo del proceso y el modelo cinético se encuentran en la Tabla 3.2.

La Figura 6.13 muestra la respuesta de las variables del sistema al utilizar el ESC propuesto. Se compara además con los valores óptimos en línea a trazos (salvo en la Figura 6.13b donde la línea a trazos es el valor verdadero del gradiente y la continua su estimación). En la Figura 6.13a se muestra la evolución temporal de la tasa específica de crecimiento que, según se observa, desde las primeras horas es capaz de seguir a la tasa óptima hasta el final del proceso. Se puede notar además la brusca caída en la tasa de crecimiento originada en la gran cantidad de microorganismos generados (último factor de (6.45)). Esto último se puede observar en la Figura 6.13e, donde se ve que la concentración celular es próxima a la máxima $\left(x_{m}=68 \mathrm{gl}^{-1}\right)$.

La Figura 6.13b muestra al gradiente (línea a trazos) y su estimación. Se puede ver que luego de un transitorio inicial la estimación converge al valor verdadero del gradiente. Luego, aproximadamente a las 7 horas, la estimación empieza a conmutar alrededor de cero. Esta oscilación es producto de los factores que afectan a $\mu$ no considerados en el diseño, como se muestra en (6.42). En este caso el factor es el de inhibición por aproximarse a la concentración celular máxima en (6.45). Sin embargo se debe notar que la estimación del gradiente se mantiene siempre alrededor de cero y el valor verdadero muy próximo a ese valor. Esto mismo se ve reflejado en la concentración de nitrógeno en la Figura 6.13c, que luego de converger al valor óptimo se mantiene en un entorno alrededor del mismo.

La Figura 6.13d muestra las tasa de dilución para la FCE y la FN. Es interesante notar 


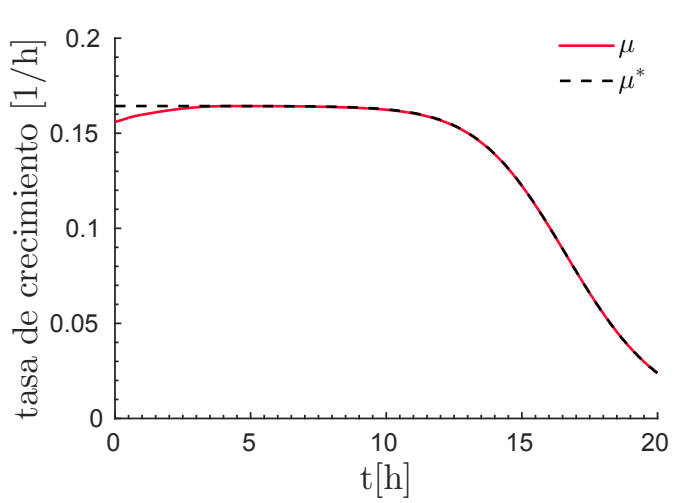

(a) Tasa específica de crecimiento.

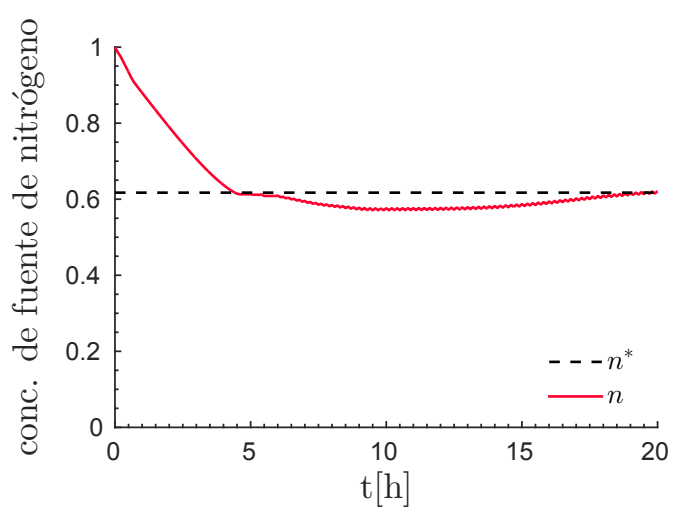

(c) Concentración de FN.

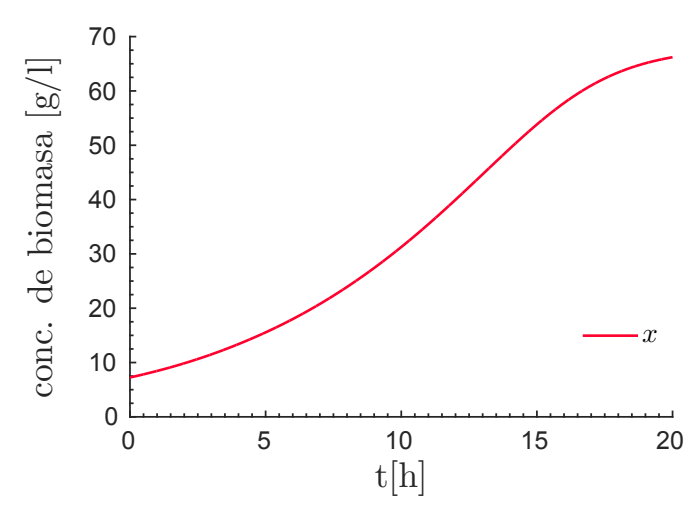

(e) Concentración celular.

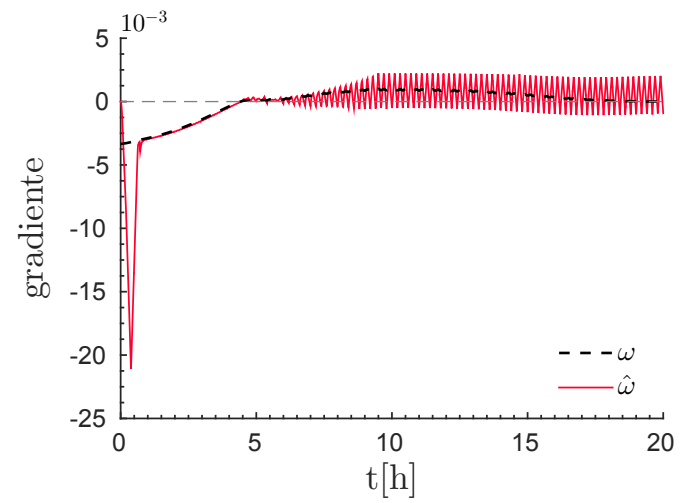

(b) Gradiente y estimación.

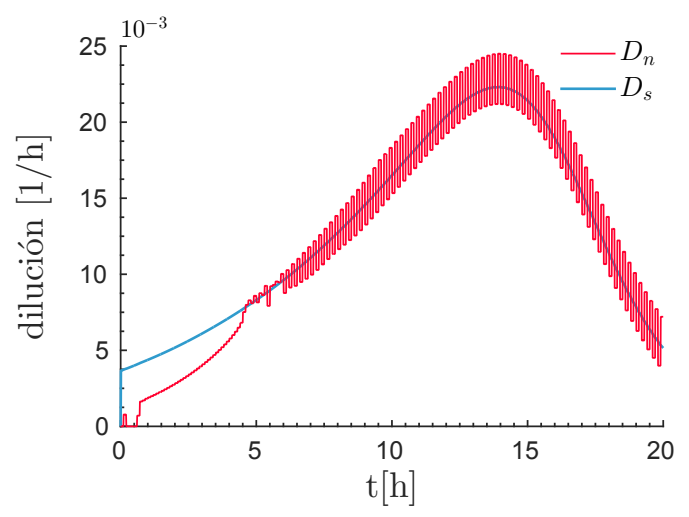

(d) Tasa de dilución y caudal.

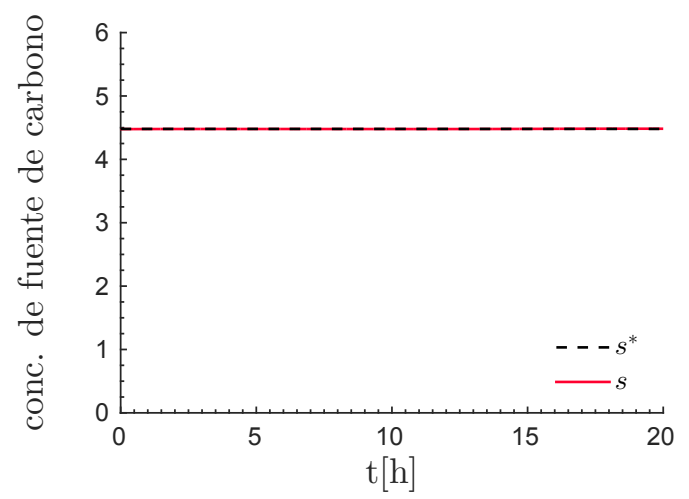

(f) Concentración de FCE.

Figura 6.13: Resultados de simulación para el control de seguimiento de extremos propuesto para la maximización de la tasa específica de crecimiento en un proceso de producción de PHB. Evolución de variables respecto al tiempo.

que luego de que ambos sustratos alcanzan los valores óptimos ambas diluciones son prácticamente iguales $\left(D_{s}\right.$ sería un promedio de $\left.D_{n}\right)$. La razón de esto es que las concentraciones de alimentación de cada sustrato se eligieron para que con un mismo volumen de cada una se puedan producir iguales cantidades finales de microorganismo por medio del balance

$$
s_{f} y_{x s}=n_{f} y_{x n}
$$


Finalmente en la Figura 6.13f se muestra la concentración de FCE, que es regulada en el valor óptimo lo suficientemente bien como para no afectar al ESC. Por supuesto, la FCE se podría regular en un valor distinto al óptimo, el resultado sería que la tasa de crecimiento seguiría a un valor sub-óptimo dado por esa concentración.

La Figura 6.14 muestra las trayectorias seguidas por el sistema, indicando las trayectorias óptimas con líneas a trazos. En la Figura 6.14a se muestra las trayectoria sobre la superficie

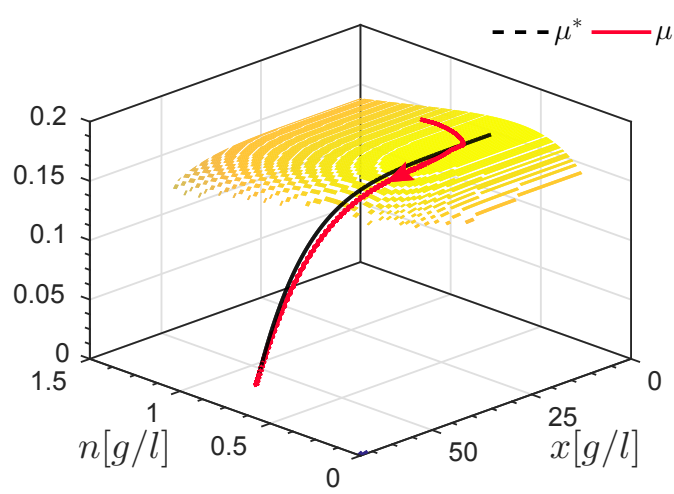

(a) Trayectoria de la tasa de producción respecto del mapa cinético.

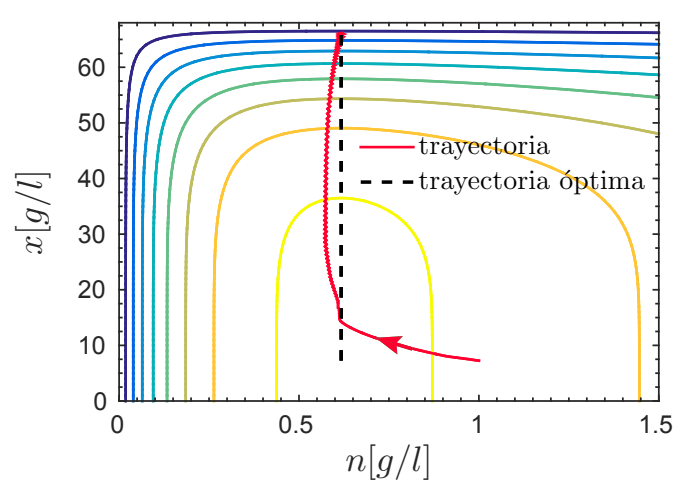

(b) Plano de concentración de sustrato vs. contenido intracelular de PHB.

Figura 6.14: Resultados de simulación para el control de seguimiento de extremos propuesto para la maximización de la tasa específica de crecimiento en un proceso de producción de PHB. Trayectorias en el plano $(n, x)$.

definida por (6.45) con $s=s^{*}$. En la Figura 6.14b se muestra la trayectoria seguida sobre el plano $(n, x)$ y las curvas de nivel de (6.45). En ambos gráficos se puede ver una convergencia hacia un entorno de la trayectoria óptima.

\subsubsection{Optimización de etapa de producción}

En esta sección se muestran resultados de simulación al aplicar el ESC propuesto a la etapa de producción de un proceso de producción de PHB, para la maximización de la tasa específica de producción.

La etapa de producción del proceso de producción de PHB descripto en esta tesis se describe por el modelo (3.13):

$$
\begin{aligned}
\dot{x} & =-D x \\
\dot{s} & =-\frac{q_{p}}{y_{p s}} x-D s+\frac{F_{s}}{V} s_{f} \\
\dot{p} & =q_{p} x-D p \\
\dot{f}_{p h b} & =q_{p},
\end{aligned}
$$




\begin{tabular}{cc}
\hline Nombre & Valor \\
\hline$s_{f}$ & $650 \mathrm{gl}^{-1}$ \\
$k_{1}$ & 130 \\
$k_{2}$ & 4 \\
$\kappa_{1}$ & 0.9 \\
$\kappa_{2}$ & 0.5 \\
$\alpha$ & 5.5 \\
$\gamma_{2}$ & 7.5 \\
\hline
\end{tabular}

Tabla 6.3: Parámetros del controlador para la etapa de producción.

donde

$$
\begin{aligned}
D & =\frac{\dot{V}}{V} \\
\dot{V} & =F_{s} \gamma+q_{p} v X
\end{aligned}
$$

y el modelo cinético de $q_{p}$ está dado en (3.10):

$$
q_{p}=q_{p}^{\max } \cdot \frac{s}{k_{p s}+s+\frac{s^{2}}{k_{p i s}}} \cdot\left[1-\left(\frac{f_{p}}{f_{p}^{\max }}\right)^{\beta}\right] \cdot \frac{k_{p i n}}{n+k_{p i n}} .
$$

El ESC en este caso se aplica sobre el caudal de alimentación de FCE. Para ello, se adapta el término de linealización de la ley de control para esta etapa:

$$
\begin{aligned}
F & =\left(\hat{q}_{p} X\left(\frac{1}{y_{p s}}+v s\right)+u_{1}+u_{2}\right)\left(s_{f}-\gamma \hat{s}\right)^{-1} \\
u_{1} & =k_{1}|\hat{\omega}|^{1 / 2} \operatorname{sign}(\hat{\omega}) \\
\dot{u}_{2} & =k_{2} \operatorname{sign}(\hat{\omega})
\end{aligned}
$$

Por otra parte, se ha utilizado el observador de tasa de producción (5.11) propuesto en el Capítulo 5. Los valores de las ganancias y de los distintos parámetros del ESC se especifican en la Tabla 6.2, los parámetros del modelo del proceso y el modelo cinético se encuentran en la Tabla 3.2.

La Figura 6.15 muestra la respuesta de las variables del sistema al utilizar el ESC propuesto sobre la tasa de producción del proceso. Se compara además con los valores óptimos en línea a trazos (salvo en la Figura 6.15b donde la línea a trazos es el valor verdadero del gradiente y la continua su estimación). En la Figura 6.15a se muestra la evolución temporal de la tasa específica de producción. Se puede ver que sigue a su valor óptimo desde las primeras horas. Casi durante todo el proceso la tasa de producción óptima decrece debido al efecto inhibitorio que el mismo PHB tiene sobre su producción, como se modeliza con el último factor de (3.10c). Esto se puede constatar en la Figura 6.15e, donde se muestra el incremento en el contenido intracelular de PHB. Se puede notar que pasadas las 25 horas el incremento es muy pequeño, 


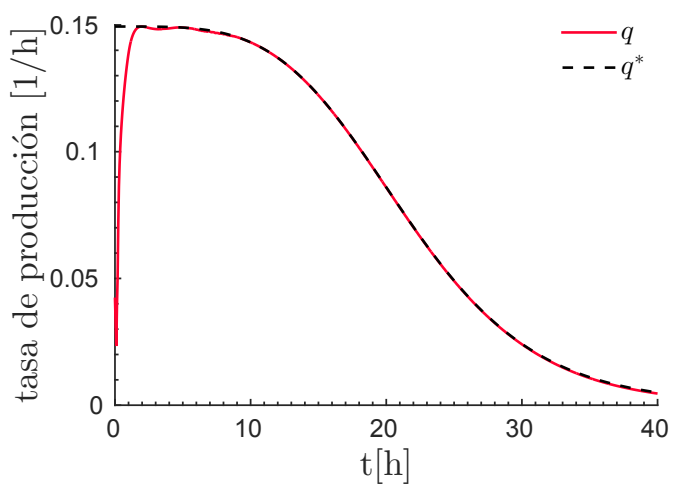

(a) Tasa específica de producción.

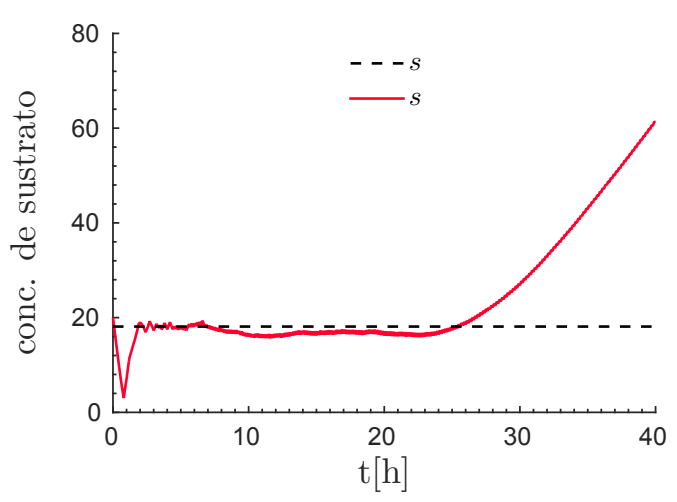

(c) Concentración de sustrato.

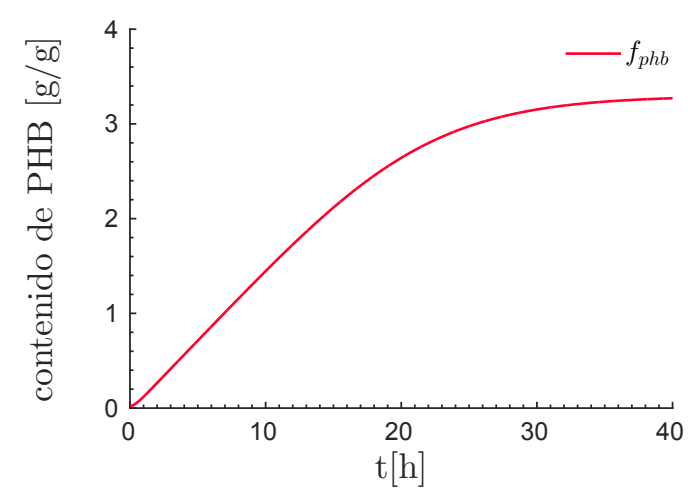

(e) Contenido intracelular de PHB.

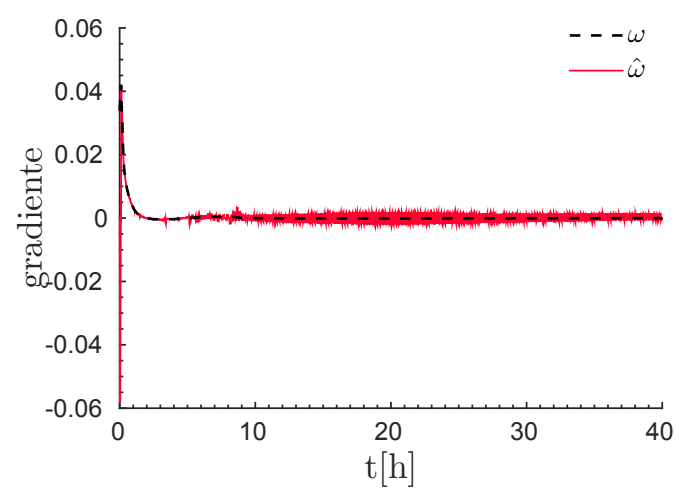

(b) Gradiente y estimación.

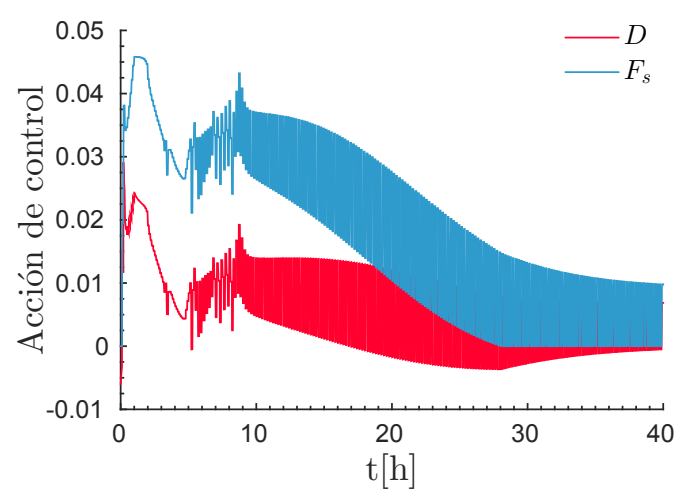

(d) Tasa de dilución y caudal.

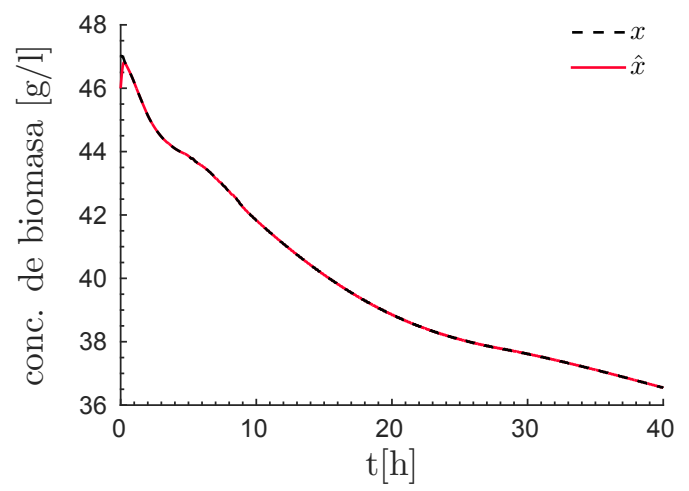

(f) Concentración celular y estimación.

Figura 6.15: Resultados de simulación para el control de seguimiento de extremos propuesto para maximizar la tasa específica de producción de PHB.

pudiéndose finalizar la etapa en ese momento.

En la Figura 6.15b se muestra al gradiente (línea a trazos) y su estimación. Se puede ver una rápida convergencia al valor verdadero y luego, aproximadamente a las 10 horas, las conmutaciones alrededor de cero causadas por la variación en la tasa debido a la acumulación de PHB. Esa conmutación va acompañada de un valor verdadero del gradiente distinto de cero, cosa que se ve reflejada en la concentración de fuente de carbono en la Figura 6.15c, que casi durante toda la etapa se mantiene cerca del valor óptimo pero no exactamente sobre él. 
La Figura 6.15d muestra el caudal y la tasa de dilución para la FCE. Estas son suaves hasta que la tasa empieza a decrecer abruptamente debido a $f_{p h b}$, produciendo algunas oscilaciones en $\hat{\omega}$ y por consecuencia en $F_{s}$. Además, cerca de las 27 horas el caudal empieza a saturar en cero, causando una acumulación de sustrato como se ve en la Figura 6.15c. El incremento en el contenido de PHB es muy pequeño a partir de ese punto, por lo que no habría problema en terminar el proceso en ese momento. Para esto, se puede usar como indicador a la tasa de producción (cuando cae por debajo de un cierto límite) o al caudal de alimentación (cuando satura).

La Figura 6.16 muestra las trayectorias seguidas por el sistema, indicando las trayectorias óptimas con líneas a trazos. En la Figura 6.16a se muestra las trayectoria sobre la superficie

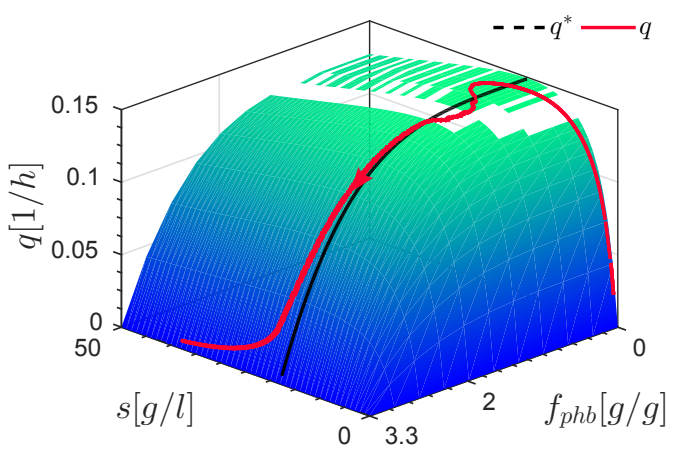

(a) Trayectoria de la tasa de producción respecto del mapa cinético.

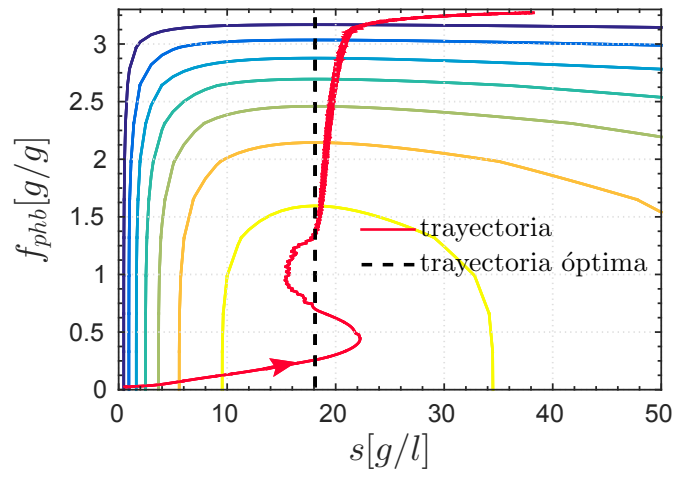

(b) Plano de concentración de sustrato vs. contenido intracelular de PHB.

Figura 6.16: Resultados de simulación para el control de seguimiento de extremos propuesto para maximizar la tasa específica de producción de PHB.

definida por (6.51). En la Figura 6.16b se muestra la trayectoria seguida sobre el plano $\left(s, f_{p h b}\right)$ y las curvas de nivel de (6.51). En ambos gráficos se puede observar la convergencia a un entorno de la trayectoria óptima.

\subsection{Discusión}

El ESC propuesto muestra cumplir con el objetivo de control a pesar de errores en las estimaciones entregadas por los observadores, condiciones de ruido o incluso si la tasa de reacción controlada es variante en el tiempo. Además, se verifican las condiciones de estabilidad presentadas en la Sección 6.4. A diferencia de otras propuestas, no se requiere adicionar una señal de perturbación a la acción de control. La perturbación necesaria para estimar el gradiente está dada por el mismo control por modos deslizantes, con la ventaja de que la amplitud de esa perturbación es más pequeña cerca del óptimo. Esto resulta en una respuesta más suave de la tasa de reacción y de las concentraciones de sustrato. Además, el término integral del control permite rechazar perturbaciones en la entrada del proceso acotadas en su amplitud y ancho de banda, sin restricciones en la cota de amplitud. Por otra parte, el estimador de gradiente propuesto muestra ser una alternativa válida a observadores discretos o máquinas 
de estado lógicas utilizadas en otras propuestas. Por ser un observador de modos deslizantes presenta características dinámicas y de robustez que le permiten obtener una buena estimación aún cuando sus entradas provienen de otros observadores. Se destaca en particular el no adicionar dinámica propia al lazo de control. Cuando el observador se utiliza en procesos con cinéticas variantes en el tiempo surgen errores que degradan el desempeño del lazo, aún así, estos errores son acotados y se pueden obtener buenos resultados como en la Sección 6.6.1. En los resultados previos se puede ver la dependencia del desempeño del controlador con el estimador de gradiente, sobre todo en la concentración de sustrato. Tanto en el caso con presencia de ruido como con punto de operación óptimo variante, la concentración de sustrato se ve afectada y sólo converge a un entorno de la óptima. Sin embargo, las variaciones producidas sobre la tasa de reacción y errores respecto de la óptima son despreciables.

En la mayor parte de los trabajos de control por seguimiento de extremos disponibles en la bibliografía se asume que la concentración de sustrato puede ser medida en línea, lo que se traduce en una mejora del rendimiento al eliminarse una estimación. De la misma manera sucede cuando se obtiene una medición indirecta de la tasa de reacción a partir de la medición de la concentración y caudal de gases, como en [130, 128]. En esta tesis no se optó por dichas opciones por razones anteriormente expuestas; los sensores de sustratos son muy específicos para cada tipo de sustrato y el costo de estos equipos y los de análisis de gases es en general muy elevado como para que estén disponibles en un laboratorio estándar o una industria. En cambio, existen muchas formas de medir la concentración de microorganismos, tanto por métodos ópticos como electromagnéticos, más accesibles en su desarrollo y versátiles en su aplicación a distintos procesos. De todas formas, si los sensores de sustrato y gases están disponibles, se puede adaptar fácilmente el ESC propuesto y obtener resultados aún mejores que los aquí presentados. 


\section{| Capítulo 7 \\ Conclusiones}

En esta tesis se ha abordado el modelado, monitoreo y control en un proceso de producción de polyhydroxybutyrato. La directiva principal ha sido el diseño de algoritmos de monitoreo y control adecuados a las particularidades de procesos de alta densidad celular como el proceso de producción de PHB. Estos deben ser de fácil implementación tanto en investigación como la industria. Además, esto se manifiesta en la elección de sensores de densidad celular y en la propuesta de modelos de volumen que tienen en cuenta factores biológicos y condiciones específicas de operación.

Como primer paso, en el Capítulo 3, se desarrollaron modelos para la dinámica del volumen en los procesos de alta densidad celular, y en particular, para la producción de PHB. Se buscó que los modelos fueran prácticos para la implementación de algoritmos de control y monitoreo, por lo que se evitó depender de parámetros difíciles de conocer, como los volúmenes molares parciales. A la vez, los modelos debían tener en cuenta características propias de los procesos de alta densidad celular, como las densidades de los medios de cultivo, elevado consumo de sustratos y volumen de la fase biótica. Los modelos obtenidos son mejores descripciones que las ya existentes en la bibliografía, y se validaron al utilizarlos para el diseño de algoritmos de estimación con resultados positivos. Particularmente, el modelo para la fase de producción de PHB es la base para el observador propuesto.

Como segundo paso, se desarrollaron observadores para la estimación de las tasas específicas de reacción para cada una de las fases del proceso (crecimiento y producción). Las estimaciones obtenidas tienen dos fines, el primero es el monitoreo del proceso. Las tasas específicas proveen información del estado metabólico y otorgan herramientas para la toma de decisiones y detección de eventos anormales. Por ejemplo, el observador diseñado para la etapa de crecimiento provee una estimación de la biomasa con la que se puede calcular el momento justo para terminar la fase. En segundo lugar, las estimaciones de las tasas específicas se utilizan para el diseño de leyes de control a lazo cerrado. Para esto fue necesario diseñar algoritmos de control robustos ante las incertidumbres del proceso.

Para la fase de crecimiento, en el Capítulo 4, se desarrolló un esquema conmutado de observadores para la estimación de la tasa de crecimiento. Esta propuesta surge como solución 
a un problema real de laboratorio, se hace uso de un sensor de densidad celular durante las primeras horas del proceso hasta que este satura y se pasa a utilizar información de la concentración de nitrógeno obtenida del lazo de control de $\mathrm{pH}$. Es una solución que se puede aplicar en otros procesos (de alta densidad celular o no) con dispositivos o controles similares. Se realizó un detallado análisis de los errores de estimación debido a incertidumbres. Luego se verificó lo desarrollado en la teoría y la robustez del esquema de observadores propuesto bajo simulación. Los efectos causados por incertidumbre en rendimientos o en la concentración de nitrógeno mostraron ser bajos para las condiciones normales del proceso. Posteriormente, se presentaron resultados experimentales, obteniéndose resultados más que satisfactorios en lo que respecta al monitoreo del proceso.

Para la fase de producción, en el Capítulo 5, se propuso un observador para estimar la tasa de producción de PHB, basado en el modelo dinámicos de volumen propuesto para dicha fase. La síntesis del observador se obtuvo por algoritmos de modos deslizantes de segundo orden y se presentaron dos versiones, una basada en la medición de densidad celular, y otra basada en medidas de volumen. Se presentaron pruebas de estabilidad para el observador y un análisis novedoso de la tasa de decaimiento de los errores, que aporta criterios para la sintonización de las ganancias. Las pruebas de simulación mostraron que el algoritmo propuesto es capaz de estimar la tasa de producción de manera rápida y precisa, siendo robusto frente al ruido o incertidumbres causadas por variaciones en la concentración del sustrato regulado. Las pruebas experimentales no solo mostraron la validez del observador, si no que también sirvieron para validar el modelo de volumen propuesto para la fase de producción.

En el Capítulo 6 se propuso un controlador para seguimiento de extremos para maximizar una tasa específica de crecimiento o la de producción cuyo modelo cinético es desconocido. El controlador propuesto se obtiene por modos deslizantes de segundo orden, cuya función de conmutación es una estimación del gradiente de la tasa específica de reacción con respecto al sustrato. Para la obtención de la estimación del gradiente se propone una extensión del modelo dinámico del proceso y un observador de modos deslizantes de segundo orden. Se dieron por primera vez pruebas analíticas de estabilidad nominal y práctica para el controlador propuesto, y se derivaron condiciones para la sintonización de las ganancias. El esquema de control y estimación se simuló bajo diferentes situaciones para su validación, incluyendo errores en las condiciones iniciales de las estimaciones, ruido de medición e incluso una función objetivo dependiente de más de un parámetro (como hipótesis la función objetivo depende solamente de la concentración de un único sustrato). En todos estos escenarios se logró alcanzar la tasa de reacción máxima en un tiempo corto verificándose las condiciones de estabilidad propuestas. Además, la respuesta de la tasa de reacción lograda es más suave que la de otras propuestas para seguimiento de extremos, como basadas en la adición de señales de perturbación [58, 125], y no presenta chattering como en las de modos deslizantes de primer orden [130].

Con respecto a la estimación de gradiente, el observador implementado se muestra como una alternativa robusta y precisa frente a otro tipo de estimadores reportados en la literatura [129, 131, 130]. El algoritmo usado tiene como ventaja el no agregado de dinámica al lazo 
y seguimiento perfecto. Cuando las entradas del estimador de gradiente provienen de otros observadores su desempeño se ve afectado, siendo las estimaciones igualmente válidas. En general, el desempeño del controlador mostró estar muy ligado a la precisión del estimador de gradiente. Tanto en el caso con mediciones ruidosas o con un óptimo variante la concentración de sustrato converge solamente a un entorno de la óptima. Sin embargo, la tasa de reacción (que es la variable de interés) prácticamente no se ve afectada. En el primer caso es mayormente debido a que las medidas y estimaciones están corrompidas por el ruido. En el caso con óptimo variante se debe a que el estimador del gradiente mal interpreta los cambios en la tasa de reacción como originados por la variación de un único sustrato. Siempre y cuando esos factores adicionales no produzcan variaciones grandes o rápidas en la tasa de reacción las perturbaciones son rechazadas en sentido práctico. Además, se debe tener en cuenta que la hipótesis de diseño era un único factor afectando la tasa de reacción, por lo que el desempeño obtenido es más que satisfactorio.

Finalmente, el control propuesto se probó sobre cada una de las fases del proceso de producción de PHB. En ambas fases se obtienen buenos resultados y se logran optimizar las tasas de crecimiento y producción. Incluso, cuando sus valores óptimos son variantes en el tiempo. Por lo tanto, queda abierta la puerta a la validación experimental de los controladores.

En el Capítulo 1 de esta tesis se mencionó que al inicio de la colaboración con la Universidad de Gante, el proceso de producción de PHB montado en el laboratorio contaba solamente con una lazo de control de $\mathrm{pH}$ y algunas alimentaciones a lazo abierto. El monitoreo se realizaba a partir de muestras manuales y análisis fuera de línea. Hoy el proceso cuenta con una monitorización más confiable, que permite conocer rápidamente su estado y aporta datos para la determinación de los tiempos de parada de cada fase. Las variables estimadas a su vez pueden ser utilizadas para mejorar las leyes de control a lazo abierto ya implementadas.

\subsection{Líneas futuras de investigación}

A partir de los resultados obtenidos se consideran los siguientes trabajos futuros:

- Validación experimental de los controles para seguimiento de máximos propuestos en el Capítulo 6. La validación no está sujeta solo al proceso de producción de PHB, sino que se puede realizar sobre otros procesos de alta densidad celular.

- En la fase de crecimiento del proceso de producción de PHB existen dos sustratos en el medio. Resulta interesante el diseño de leyes de control multivariables que maximicen la tasa de crecimiento respecto de ambos sustratos. Para ello será necesario explorar otros algoritmos para la estimación de los gradientes y para la búsqueda de máximos.

- En lo que respecta a procesos, se planea trabajar sobre procesos para tratamiento de efluentes y producción de biogases. Estos son procesos de alta densidad celular con sustratos impuros. Además, tienen el agregado de la existencia de culturas mixtas y múl- 
tiples fuentes de carbono. Se planea investigar tanto la monitorización de los procesos como su optimización en línea. 


\section{Bibliografía}

[1] MA Henson. Exploiting cellular biology to manufacture high-value products. IEEE Control Systems Magazine, 1066:54-66, 2006.

[2] Karl Schügerl and Karl-Heinz Bellgardt. Bioreaction engineering : modeling and control. Springer, Berlin New York, 2000.

[3] Food and Drug Administration. Guidance for industry: Pat. a framework for innovative pharmaceutical development, manufacturing, and quality assurance. DHHS, Rockville, MD, 2004.

[4] Suchada Chanprateep. Current trends in biodegradable polyhydroxyalkanoates. Journal of Bioscience and Bioengineering, 110(6):621 - 632, 2010.

[5] Md Salatul Islam Mozumder, Linsey Garcia-Gonzalez, Heleen De Wever, and Eveline IP Volcke. Poly (3-hydroxybutyrate) (phb) production from co 2: Model development and process optimization. Biochemical Engineering Journal, 98:107-116, 2015.

[6] Diogo Queirós, Simona Rossetti, and Luísa S. Serafim. Pha production by mixed cultures: A way to valorize wastes from pulp industry. Bioresource Technology, 157:197 205, Apr 2014.

[7] Yonghong Li, Zongbao (Kent) Zhao, and Fengwu Bai. High-density cultivation of oleaginous yeast rhodosporidium toruloides y4 in fed-batch culture. Enzyme and Microbial Technology, 41(3):312-317, August 2007.

[8] Xiaobing Yang, Guojie Jin, Zhiwei Gong, Hongwei Shen, Fengwu Bai, and Zongbao Kent Zhao. Recycling biodiesel-derived glycerol by the oleaginous yeast rhodosporidium toruloides y4 through the two-stage lipid production process. Biochemical Engineering Journal, 91:86-91, October 2014.

[9] Eleni E. Karamerou, Constantinos Theodoropoulos, and Colin Webb. Evaluating feeding strategies for microbial oil production from glycerol by rhodotorula glutinis. Engineering in Life Sciences, pages n/a-n/a, 2016.

[10] D. Riesenberg and R. Guthke. High-cell-density cultivation of microorganisms. Applied Microbiology and Biotechnology, 51(4):422-430, April 1999.

[11] G. Bastin and D. Dochain. On-line Estimation and Adaptive Control of Bioreactors. Elsevier Science, Amsterdam, 1990. 
[12] Md Salatul Islam Mozumder, Laurens Goormachtigh, Linsey Garcia-Gonzalez, Heleen De Wever, and Eveline I P Volcke. Modeling pure culture heterotrophic production of polyhydroxybutyrate (phb). Bioresource technology, 155:272-80, March 2014.

[13] Rodolfo Ertola, Osvaldo Yantorno, and Carlos Mignone. Microbiología industrial. Washington: OEA, 1994.

[14] Letícia CG Domingues, Juliana C Teodoro, Carlos O Hokka, Alberto C Badino, and Maria Lucia GC Araujo. Optimisation of the glycerol-to-ornithine molar ratio in the feed medium for the continuous production of clavulanic acid by streptomyces clavuligerus. Biochemical engineering journal, 53(1):7-11, 2010.

[15] Wolfgang Leuchtenberger, Klaus Huthmacher, and Karlheinz Drauz. Biotechnological production of amino acids and derivatives: current status and prospects. Applied Microbiology and Biotechnology, 69(1):1-8, 2005.

[16] Belén Max, José Manuel Salgado, Noelia Rodríguez, Sandra Cortés, Attilio Converti, and José Manuel Domínguez. Biotechnological production of citric acid. Brazilian Journal of Microbiology, 41(4):862-875, 2010.

[17] Camilo S López-Garzón and Adrie JJ Straathof. Recovery of carboxylic acids produced by fermentation. Biotechnology advances, 32(5):873-904, 2014.

[18] Murali M Reddy, Singaravelu Vivekanandhan, Manjusri Misra, Sujata K Bhatia, and Amar K Mohanty. Biobased plastics and bionanocomposites: Current status and future opportunities. Progress in Polymer Science, 38(10):1653-1689, 2013.

[19] María Teresita Castañeda. Obtención, caracterización y aplicación de un biocatalizador para la reducción del contenido de fenilalanina en hidrolizados proteicos. $\mathrm{PhD}$ thesis, Facultad de Ingeniería, Universidad Nacional de La Plata, 2016.

[20] Elmar Heinzle. Development of sustainable bioprocesses : modeling and assessment. John Wiley \& Sons, Chichester, England Hoboken, NJ, 2006.

[21] Ilgi Karapinar Kapdan and Fikret Kargi. Bio-hydrogen production from waste materials. Enzyme and Microbial Technology, 38(5):569-582, Mar 2006.

[22] Hai-Hsuan Cheng, Liang-Ming Whang, Man-Chien Chung, and Kun-Chi Chan. Biological hydrogen and methane production from bagasse bioethanol fermentation residues using a two-stage bioprocess. Bioresource Technology, 210:49-55, Jun 2016.

[23] Athanasios Koutinas, Maria Kanellaki, Argyro Bekatorou, Panagiotis Kandylis, Katerina Pissaridi, Agapi Dima, Konstantina Boura, Katerina Lappa, Panagiota Tsafrakidou, Panagiota-Yiolanda Stergiou, et al. Economic evaluation of technology for a new generation biofuel production using wastes. Bioresource technology, 200:178-185, 2016. 
[24] Sofia Tsakona, Argyrios G. Skiadaresis, Nikolaos Kopsahelis, Afroditi Chatzifragkou, Seraphim Papanikolaou, Ioannis K. Kookos, and Apostolis A. Koutinas. Valorisation of side streams from wheat milling and confectionery industries for consolidated production and extraction of microbial lipids. Food Chemistry, 198:85-92, May 2016.

[25] Yu-Sin Jang, Alok Malaviya, Changhee Cho, Joungmin Lee, and Sang Yup Lee. Butanol production from renewable biomass by clostridia. Bioresource Technology, 123:653663, Nov 2012.

[26] Mohamed Ali Abdel-Rahman, Yukihiro Tashiro, and Kenji Sonomoto. Recent advances in lactic acid production by microbial fermentation processes. Biotechnology Advances, 31(6):877-902, Nov 2013.

[27] Jong-il Choi and Sang Yup Lee. Process analysis and economic evaluation for poly(3hydroxybutyrate) production by fermentation. Bioprocess Engineering, 17(6):335, 1997.

[28] Everest Akaraonye, Tajalli Keshavarz, and Ipsita Roy. Production of polyhydroxyalkanoates: the future green materials of choice. Journal of Chemical Technology and Biotechnology, 85(6):732-743, 2010.

[29] Olivier Bernard, Zakaria Hadj-Sadok, Denis Dochain, Antoine Genovesi, and JeanPhilippe Steyer. Dynamical model development and parameter identification for an anaerobic wastewater treatment process. Biotechnology and Bioengineering, 75(4):424438, 2001.

[30] Michael L. Shuler and Fikret Kargi. Bioprocess engineering: basic concepts. Prentice-Hall, Englewood Cliffs, NJ, 1992.

[31] Yu-Cheng Chung, I-Lung Chien, and Der-Ming Chang. Multiple-model control strategy for a fed-batch high cell-density culture processing. Journal of Process Control, 16(1):926, Jan 2006.

[32] Tsuneo Yamanè and Shoichi Shimizu. Fed-batch techniques in microbial processes. Advances in Biochemical Engineering/Biotechnology, pages 147-194, 1984.

[33] Md Salatul Islam Mozumder, Heleen De Wever, Eveline I.P. Volcke, and Linsey GarciaGonzalez. A robust fed-batch feeding strategy independent of the carbon source for optimal polyhydroxybutyrate production. Process Biochemistry, 49(3):365-373, March 2014.

[34] Seraphim Papanikolaou and George Aggelis. Lipids of oleaginous yeasts. part ii: Technology and potential applications. European Journal of Lipid Science and Technology, 113(8):1052-1073, 2011. 
[35] Pieter J. Verbelen, David P. De Schutter, Filip Delvaux, Kevin J. Verstrepen, and Freddy R. Delvaux. Immobilized yeast cell systems for continuous fermentation applications. Biotechnol Lett, 28(19):1515-1525, Aug 2006.

[36] Sensores de oxígeno disuelto Hamilton ${ }^{\circledR}$. http://www.hamiltoncompany.com/ products/process-analytics/sensors/dissolved-oxygen.

[37] Sensores de oxígeno disuelto por fluoresencia PreSens ${ }^{\circledR}$. http://www.presens.de/ products/optical-oxygen-sensors.html.

[38] Sensores de gases Sartorius ${ }^{\circledR}$. https://www.sartorius.com/en/products/ bioprocess/process-analysers/biopat-xgas/.

[39] D. F. Swinehart. The beer-lambert law. Journal of Chemical Education, 39(7):333, 1962.

[40] H. P. Schwan and K. R. Foster. Rf-field interactions with biological systems: Electrical properties and biophysical mechanisms. Proceedings of the IEEE, 68(1):104-113, 1980.

[41] H. P. Schwan. Electrical properties of tissues and cell suspensions: mechanisms and models. In Engineering in Medicine and Biology Society, 1994. Engineering Advances: New Opportunities for Biomedical Engineers. Proceedings of the 16th Annual International Conference of the IEEE, pages A70-A71 vol.1, Nov 1994.

[42] Thomas Maskow, Anita Röllich, Ingo Fetzer, Jörg-Uwe Ackermann, and Hauke Harms. On-line monitoring of lipid storage in yeasts using impedance spectroscopy. Journal of Biotechnology, 135(1):64-70, May 2008.

[43] Lan Li, Ze-Jian Wang, Xue-Jun Chen, Ju Chu, Ying-Ping Zhuang, and Si-Liang Zhang. Optimization of polyhydroxyalkanoates fermentations with on-line capacitance measurement. Bioresource technology, 156:216-21, March 2014.

[44] Thomas Maskow, Anita Röllich, Ingo Fetzer, Jun Yao, and Hauke Harms. Observation of non-linear biomass-capacitance correlations: reasons and implications for bioprocess control. Biosensors \& bioelectronics, 24(1):123-8, September 2008.

[45] Sensores de glucosa y lactato Sartorius ${ }^{\circledR}$. https://www.sartorius.com/en/ products/bioprocess/process-analysers/biopat-trace/.

[46] S. Valentinotti, B. Srinivasan, U. Holmberg, D. Bonvin, C. Cannizzaro, M. Rhiel, and U. von Stockar. Optimal operation of fed-batch fermentations via adaptive control of overflow metabolite. Control Engineering Practice, 11(6):665-674, Jun 2003.

[47] Hernán De Battista, Jesús Picó, and Enric Picó-Marco. Nonlinear pi control of fed-batch processes for growth rate regulation. Journal of Process Control, 22(4):789-797, April 2012. 
[48] Pramod Agrawal and Henry C. Lim. Analyses of various control schemes for continuous bioreactors. Advances in Biochemical Engineering/Biotechnology, pages 61-90.

[49] A. Novick and L. Szilard. Description of the chemostat. Science, 112(2920):715-716, Dec 1950.

[50] Xin Li, Yuanjun Kang, Can Yu, Jun Dai, Zhi Wang, Zhijun Li, Juan Yao, Pei Li, Guobin Zheng, and Xiong Chen. Exponential feeding strategy of high-density cultivation of a salt-tolerant aroma-producing yeast zygosaccharomyces rouxii in stirred fermenter. Biochemical Engineering Journal, 111:18-23, Jul 2016.

[51] E. Picó-Marco, J.L. Navarro, and J.M. Bruno-Barcena. A closed loop exponential feeding law: Invariance and global stability analysis. Journal of Process Control, 16(4):395 402, 2006.

[52] Hernán De Battista, J. Picó, and E. Picó-Marco. Globally stabilizing control of fedbatch processes with haldane kinetics using growth rate estimation feedback. Journal of Process Control, 16(8):865 - 875, 2006.

[53] Jeongseok Lee, Sang Yup Lee, Sunwon Park, and Anton P.J. Middelberg. Control of fed-batch fermentations. Biotechnology Advances, 17(1):29 - 48, 1999.

[54] Chris N. Takahashi, Aaron W. Miller, Felix Ekness, Maitreya J. Dunham, and Eric Klavins. A low cost, customizable turbidostat for use in synthetic circuit characterization. ACS Synthetic Biology, 4(1):32-38, 2015.

[55] Georges Bastin and Denis Dochain. On-line estimation of microbial specific growth rates. Automatica, 22(6):705-709, 1986.

[56] Hernán De Battista, Jesús Picó, Fabricio Garelli, and José Luis Navarro. Reaction rate reconstruction from biomass concentration measurement in bioreactors using modified second-order sliding mode algorithms. Bioprocess and Biosystems Engineering, 35(9):1615-1625, 2012.

[57] Ilse Y. Smets, Georges P. Bastin, and Jan F. Van Impe. Feedback stabilization of fed-batch bioreactors: Non-monotonic growth kinetics. Biotechnology Progress, 18(5):11161125, 2002.

[58] Denis Dochain, Michel Perrier, and Martin Guay. Extremum seeking control and its application to process and reaction systems: A survey. Mathematics and Computers in Simulation, 82(3):369 - 380, 2011. 6th Vienna International Conference on Mathematical Modelling.

[59] Krist V. Gernaey, Anna Eliasson Lantz, Pär Tufvesson, John M. Woodley, and Gürkan Sin. Application of mechanistic models to fermentation and biocatalysis for next-generation processes. Trends in Biotechnology, 28(7):346-354, Jul 2010. 
[60] Agnès Provost and Georges Bastin. Dynamic metabolic modelling under the balanced growth condition. Journal of Process Control, 14(7):717-728, 2004.

[61] Linsey Garcia-Gonzalez, Md Salatul Islam Mozumder, Majorie Dubreuil, Eveline IP Volcke, and Heleen De Wever. Sustainable autotrophic production of polyhydroxybutyrate (phb) from co 2 using a two-stage cultivation system. Catalysis Today, 257:237-245, 2015.

[62] Denis Dochain, editor. Bioprocess control. ISTE Wiley, London Hoboken, NJ, 2008.

[63] John Villadsen, Jens Nielsen, and Gunnar Lidén. Bioreaction Engineering Principles. Springer Science + Business Media, 2011.

[64] A. Mulchandani and J.H.T. Luong. Microbial inhibition kinetics revisited. Enzyme and Microbial Technology, 11(2):66-73, Feb 1989.

[65] Martín Jamilis, Fabricio Garelli, Md Salatul Islam Mozumder, Teresita Castañeda, and Hernán De Battista. Modeling and estimation of production rate for the production phase of non-growth-associated high cell density processes. Bioprocess and Biosystems Engineering, 38(10):1903-1914, 2015.

[66] Li Shen, Juliane Haufe, and Martin K Patel. Product overview and market projection of emerging bio-based plastics pro-bip 2009. Report for European Polysaccharide Network of Excellence (EPNOE) and European Bioplastics, 243, 2009.

[67] Y. Doi. Microbial polyesters. VCH, 1990.

[68] DZ Bucci, LBB Tavares, and I Sell. Phb packaging for the storage of food products. Polymer testing, 24(5):564-571, 2005.

[69] C.S.K Reddy, R Ghai, Rashmi, and V.C Kalia. Polyhydroxyalkanoates: an overview. Bioresource Technology, 87(2):137 - 146, 2003.

[70] Guo-Qiang Chen and Qiong Wu. The application of polyhydroxyalkanoates as tissue engineering materials. Biomaterials, 26(33):6565-6578, Nov 2005.

[71] Tajalli Keshavarz and Ipsita Roy. Polyhydroxyalkanoates: bioplastics with a green agenda. Current Opinion in Microbiology, 13(3):321-326, Jun 2010.

[72] S. Philip, T. Keshavarz, and I. Roy. Polyhydroxyalkanoates: biodegradable polymers with a range of applications. Journal of Chemical Technology \& Biotechnology, 82(3):233-247, 2007.

[73] Beom Soo Kim, Seung Chul Lee, Sang Yup Lee, Ho Nam Chang, Yong Keun Chang, and Seong Ihl Woo. Production of poly (3-hydroxybutyric acid) by fed-batch culture of alcaligenes eutrophus with glucose concentration control. Biotechnology and Bioengineering, 43(9):892-898, 1994. 
[74] Aid Atlić, Martin Koller, Dietrich Scherzer, Christoph Kutschera, Elizabeth GrilloFernandes, Predrag Horvat, Emo Chiellini, and Gerhart Braunegg. Continuous production of poly ([r]-3-hydroxybutyrate) by cupriavidus necator in a multistage bioreactor cascade. Applied microbiology and biotechnology, 91(2):295-304, 2011.

[75] José Geraldo da Cruz Pradella, Jaciane Lutz Ienczak, Cecília Romero Delgado, and Marilda Keico Taciro. Carbon source pulsed feeding to attain high yield and high productivity in poly (3-hydroxybutyrate) (phb) production from soybean oil using cupriavidus necator. Biotechnology letters, 34(6):1003-1007, 2012.

[76] João ML Dias, Paulo C Lemos, Luísa S Serafim, Cristina Oliveira, Marta Eiroa, Maria GE Albuquerque, Ana M Ramos, Rui Oliveira, and Maria AM Reis. Recent advances in polyhydroxyalkanoate production by mixed aerobic cultures: from the substrate to the final product. Macromolecular bioscience, 6(11):885-906, 2006.

[77] João ML Dias, Adrian Oehmen, Luísa S Serafim, Paulo C Lemos, Maria AM Reis, and Rui Oliveira. Metabolic modelling of polyhydroxyalkanoate copolymers production by mixed microbial cultures. BMC systems biology, 2(1):1, 2008.

[78] Md Salatul Islam Mozumder. Optimization of a two-phase fermentation process for the production of polyhydroxybutyrate (PHB) from organic and inorganic (industrial waste) substrate. PhD thesis, Faculty of Bioscience Engineering, Ghent University, Gent, Belgium., 2015.

[79] Md. Salatul Islam Mozumder. Optimization of a two-phase fermentation process for the production of polyhydroxybutyrate (PHB) from organic and inorganic (industrial waste) substrate. PhD thesis, Ghent University, 2015.

[80] A. Mulchandani, J. H. T. Luong, and A. Leduy. Batch kinetics of microbial polysaccharide biosynthesis. Biotechnology and Bioengineering, 32(5):639-646, Aug 1988.

[81] A. Mulchandani, J.H.T. Luong, and C. Groom. Substrate inhibition kinetics for microbial growth and synthesis of poly- $\beta$-hydroxybutyric acid by alcaligenes eutrophus ATCC 17697. Applied Microbiology and Biotechnology, 30(1):11-17, 1989.

[82] J.H. Lee, H. C. Lim, and J. Hong. Application of nonsingular transformation to online optimal control of poly- $\beta$-hydroxybutyrate fermentation. Journal of Biotechnology, 55(3):135 - 150, 1997.

[83] J.M.L Dias, L.S. Serafim, P.C. Lemos, M.A.M. Reis, and R. Oliveira. Mathematical modelling of a mixed culture cultivation process for the production of polyhydroxybutyrate. Biotechnology and Bioengineering, 92(2):209-222, 2005.

[84] Ivna Vrana Špoljarić, Markan Lopar, Martin Koller, Alexander Muhr, Anna Salerno, Angelika Reiterer, Karin Malli, Hannes Angerer, Katharina Strohmeier, Sigurd Schober, 
and et al. Mathematical modeling of poly[(r)-3-hydroxyalkanoate] synthesis by cupriavidus necator DSm 545 on substrates stemming from biodiesel production. Bioresource Technology, 133:482-494, Apr 2013.

[85] C Pedrós-Alió, Jordi Mas, and Ricardo Guerrero. The influence of poly- $\beta$ hydroxybutyrate accumulation on cell volume and buoyant density in alcaligenes eutrophus. Archives of microbiology, pages 178-184, 1985.

[86] Peter Atkins and Julio de Paula. Atkins' Physical chemistry. Oxford University Press, Oxford New York, 2014.

[87] Martín Jamilis, Fabricio Garelli, Md. Salatul Islam Mozumder, Eveline Volcke, and Hernán De Battista. Specific growth rate observer for the growing phase of a polyhydroxybutyrate production process. Bioprocess and Biosystems Engineering, 38(3):557-567, Oct 2015.

[88] Karl Johan Aström and Richard M. Murray. Feedback Systems, An Introduction for Scientists and Engineers. Princenton University Press, Princenton and Oxford, 2nd edition, 2014.

[89] Chi-Tsong Chen. Linear System Theory and Design. Oxford University Press, Inc., New York, NY, USA, 2nd edition, 1995.

[90] Denis Dochain. State and parameter estimation in chemical and biochemical processes: a tutorial. Journal of Process Control, 13(8):801 - 818, 2003.

[91] D. Dochain. State observers for processes with uncertain kinetics. International Journal of Control, 76(15):1483-1492, 2003.

[92] Olivier Bernard and Jean-Luc Gouzé. Closed loop observers bundle for uncertain biotechnological models. Journal of Process Control, 14(7):765-774, Oct 2004.

[93] Hassan K Khalil and JW Grizzle. Nonlinear systems, volume 3. Prentice Hall New Jersey, 1996.

[94] Filiberto Munoz Palacios and Cherif Ben-Youssef. Biomass and phenol estimation using dissolved oxygen measurement. In null, pages 206-214. IEEE, 2006.

[95] S. Popova. On-line state and parameters estimation based measurements of the glucose in mixed culture system. Biotechnology \& Biotechnological Equipment, 20(3):208-214, 2006.

[96] D. Selisteanu, E. Petre, D. Sendrescu, M. Roman, and P. Dorin. High-gain observers for estimation of kinetics in biological sequencing batch reactors. In Automation and Logistics, 2009. ICAL 'O9. IEEE International Conference on, pages 1623-1628, 2009. 
[97] I. Cornet, D. Dochain, B. Ramsay, J. Ramsay, and M. Perrier. Application of an adaptive linearizing inferential controller to a phb process. Biotechnology \& Biotechnological Equipment, 9(1):96-102, 1995.

[98] Denis Dochain and Michel Perrier. A state observer for (bio) processes with uncertain kinetics. In Proceedings of the American Control Conference, pages 2873-2878, 2002.

[99] V Lemesle and JL Gouzé. Hybrid bounded error observers for uncertain bioreactor models. Bioprocess and Biosystems Engineering, 27(5):311-318, 2005.

[100] Emil Petre, Dan Selişteanu, and Dorin Şendrescu. Adaptive and robust-adaptive control strategies for anaerobic wastewater treatment bioprocesses. Chemical engineering journal, 217:363-378, 2013.

[101] Vadim Utkin, Jürgen Guldner, and Jingxin Shi. Sliding mode control in electromechanical systems, volume 34. CRC press, 2009.

[102] Arie Levant. Robust exact differentiation via sliding mode technique. Automatica, 34(3):379-384, 1998.

[103] J Gonzalez, G Fernandez, R Aguilar, M Barron, and J Alvarez-Ramirez. Sliding mode observer-based control for a class of bioreactors. Chemical Engineering Journal, 83(1):25-32, 2001.

[104] Ahmad Fadzli Nizam A Rahman, Sarah K Spurgeon, and Xing-Gang Yan. A sliding mode observer for estimating substrate consumption rate in a fermentation process. In Variable Structure Systems (VSS), 2010 11th International Workshop on, pages 172-177. IEEE, 2010.

[105] Jesús Picó, Hernán De Battista, and Fabricio Garelli. Smooth sliding-mode observers for specific growth rate and substrate from biomass measurement. Journal of Process Control, 19(8):1314-1323, 2009.

[106] S Nuñez, F Garelli, and H De Battista. Sliding mode observer for biomass estimation in a biohydrogen production process. International Journal of Hydrogen Energy, 37(13):10089-10094, 2012.

[107] Hernán De Battista, Jesús Picó, Fabricio Garelli, and Alejandro Vignoni. Specific growth rate estimation in (fed-)batch bioreactors using second-order sliding observers. Journal of Process Control, 21(7):1049-1055, August 2011.

[108] I. Cornet, D. Dochain, B. Ramsay, and M. Perrier. Adaptive linearizing inferential control of a phb producing process. In Control Applications, 1993., Second IEEE Conference on, pages 481-485 vol.1, 1993. 
[109] D. Dochain, E. De Buyl, and G. Bastin. Experimental validation of a methodology for on line state estimation in bioreactors. Computer Applications in Fermentation Technology: Modelling and Control of Biotechnological Processes, pages 187-194, 1989.

[110] V. Lyubenova, M. Ignatova, M. Novak, and T. Patarinska. Reaction rate estimators of fed-batch process for poly- $\beta$-hydroxybutyrate (PHB) production by mixed culture. Biotechnology \& Biotechnological Equipment, 21(1):113-116, 2007.

[111] R. Große-Uhlmann and T. Bley. A modular approach to situation identification of the dynamics of bacterial populations synthesizing poly- $\beta$-hydroxybutyrate. Bioprocess Engineering, 21(3):191-200, 1999.

[112] A. Fiecther, editor. Bioprocess parameter control. Advances in Biochemical Engineering/Biotechnology. Springer-Verlag, Berlin Heidelberg New York Tokyo, 1984.

[113] T Suzuki, H Mori, T Yamané, and S Shimizu. Automatic supplementation of minerals in fed-batch culture to high cell mass concentration. Biotechnology and bioengineering, 27:192-201, 1985.

[114] Harold G. Monbouquette. Modeling high-biomass-density cell recycle fermentors. Biotechnology and Bioengineering, 39(5):498-503, Mar 1992.

[115] Harold G. Monbouquette. Models for high cell density bioreactors must consider biomass volume fraction: Cell recycle example. Biotechnology and Bioengineering, 29(9):1075-1080, Jun 1987.

[116] Patrick Sagmeister, Patrick Wechselberger, Mohammadhadi Jazini, Andrea Meitz, Timo Langemann, and Christoph Herwig. Soft sensor assisted dynamic bioprocess control: Efficient tools for bioprocess development. Chemical Engineering Science, 96:190-198, 2013.

[117] Stephen Boyd, Laurent El Ghaoui, Eric Feron, and Venkataramanan Balakrishnan. Linear Matrix Inequalities in System and Control Theory, volume 15 of Studies in Applied Mathematics. SIAM, Philadelphia, PA, June 1994.

[118] J. Löfberg. Yalmip : A toolbox for modeling and optimization in MATLAB. In Proceedings of the CACSD Conference, Taipei, Taiwan, 2004.

[119] Martín Jamilis, Hernán De Battista, and Fabricio Garelli. Smooth extremum-seeking control for fed-batch processes. In 11th IFAC Symposium on Dynamics and Control of Process Systems, including Biosystems (DYCOPS-CAB 2016), 2016.

[120] Michal Dabros, MoiraMonika Schuler, and IanW. Marison. Simple control of specific growth rate in biotechnological fed-batch processes based on enhanced online measurements of biomass. Bioprocess and Biosystems Engineering, 33(9):1109-1118, 2010. 
[121] Richard Biener, Anne SteinkÃ $\not$ mmper, and Thomas Horn. Calorimetric control of the specific growth rate during fed-batch cultures of saccharomyces cerevisiae. Journal of Biotechnology, 160(3-4):195-201, Aug 2012.

[122] Enric Picó-Marco, Jesús Picó, and Hernán De Battista. Sliding mode scheme for adaptive specific growth rate control in biotechnological fed-batch processes. International Journal of Control, 78(2):128-141, 2005.

[123] Kartik Ariyur and Miroslav Krstic. Real time optimization by extremum seeking control. Wiley Interscience, Hoboken, NJ, 2003.

[124] Hsin-Hsiung Wang, Miroslav Krstic, and Georges Bastin. Optimizing bioreactors by extremum seeking. International Journal of Adaptive Control and Signal Processing, 13(8):651-669, 1999.

[125] Pascal Cougnon, Denis Dochain, Martin Guay, and Michel Perrier. On-line optimization of fedbatch bioreactors by adaptive extremum seeking control. Journal of Process Control, 21(10):1526 - 1532, 2011. Special Issue:Selected Papers From Two Joint \{IFAC\} Conferences: 9th International Symposium on Dynamics and Control of Process Systems and the 11th International Symposium on Computer Applications in Biotechnology, Leuven, Belgium, July 5-9, 2010.

[126] B. Daaou and D. Dochain. High order sliding mode observer based extremum seeking controller for a continuous stirred tank bioreactor. In Control, Engineering Information Technology (CEIT), 2015 3rd International Conference on, pages 1-6, 2015.

[127] N.I. Marcos, M. Guay, D. Dochain, and T. Zhang. Adaptive extremum-seeking control of a continuous stirred tank bioreactor with haldane's kinetics. Journal of Process Control, 14(3):317 - 328, 2004.

[128] Alejandro Vargas and Jaime A. Moreno. On-line maximization of biogas production in an anaerobic reactor using a pseudo-super-twisting controller. IFAC-PapersOnLine, 48(8):14 - 19, 2015. 9th \{IFAC\} Symposium on Advanced Control of Chemical Processes $\{$ ADCHEM 2015.

[129] A. Vargas, J.A. Moreno, and A. Vande Wouwer. Super-twisting estimation of a virtual output for extremum-seeking output feedback control of bioreactors. Journal of Process Control, 35:41 - 49, 2015.

[130] Gerardo Lara-Cisneros, Ricardo Femat, and Denis Dochain. An extremum seeking approach via variable-structure control for fed-batch bioreactors with uncertain growth rate. Journal of Process Control, 24(5):663 - 671, 2014.

[131] Lina Fu and Ümit Özgüner. Extremum seeking with sliding mode gradient estimation and asymptotic regulation for a class of nonlinear systems. Automatica, 47(12):2595-2603, Dec 2011. 
[132] Roger Fletcher. Practical methods of optimization. Wiley, Chichester New York, 1987.

[133] Jaime A. Moreno. Lyapunov approach for analysis and design of second order sliding mode algorithms. In Leonid Fridman, Jaime Moreno, and Rafael Iriarte, editors, Sliding Modes after the First Decade of the 21st Century, volume 412 of Lecture Notes in Control and Information Sciences, pages 113-149. Springer Berlin Heidelberg, 2012.

[134] Jesús Picó, E Picó-Marco, A Vignoni, and Hernán De Battista. Stability preserving maps for finite-time convergence: Super-twisting sliding-mode algorithm. Automatica, 49(2):534-539, 2013.

[135] Jaime Moreno and Eder Guzmán. Super-twisting observer for second-order systems with time-varying coefficient. IET Control Theory \& Applications, 9(4):553-562, 2015.

[136] Alberto Isidori. Nonlinear Control Systems II. Springer-Verlag London, 1999. 